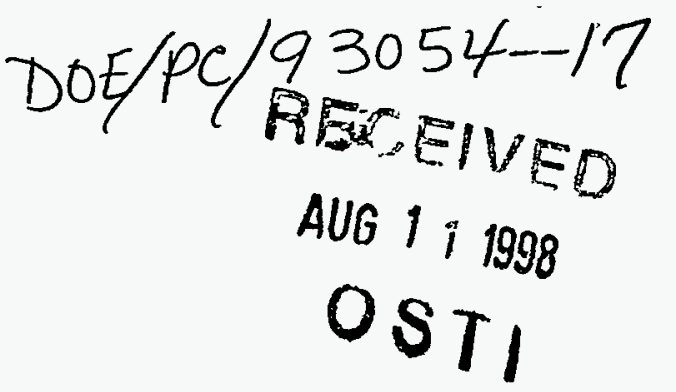

\title{
A Characterization and Evaluation of Coal Liquefaction Process Streams The Kinetics of Coal Liquefaction - Distillation Resid Conversion
}

\author{
Topical Report \\ March 1998
}

\section{By: \\ Michael T. Klein; William H. Calkins He Huang; Shojie Wang Darin Campbell}

Work Performed Under Contract No.: DE-AC22-94PC93054

For

U.S. Department of Energy

Office of Fossil Energy

Federal Energy Technology Center

P.O. Box 880

Morgantown, West Virginia 26507-0880

CONSOL Inc.

Research and Development

4000 Brownsville Road

Library, Pennsylvania 15129 


\section{Disclaimer}

This report was prepared as an account of work sponsored by an agency of the United States Government. Neither the United States Government nor any agency thereof, nor any of their employees, makes any warranty, express or implied, or assumes any legal liability or responsibility for the accuracy, completeness, or usefulness of any information, apparatus, product, or process disclosed, or represents that its use would not infringe privately owned rights. Reference herein to any specific commercial product, process, or service by trade name, trademark, manufacturer, or otherwise does not necessarily constitute or imply its endorsement, recommendation, or favoring by the United States Government or any agency thereof. The views and opinions of authors expressed herein do not necessarily state or reflec those of the United States Government or any agency thereof. 


\section{DISCLAIMER}

Portions of this document may be illegible electronic image products. Images are produced from the best available original document. 


\begin{abstract}
Under subcontract from CONSOL Inc. (DOE Contract No. DE-AC22-94PC93054), the University of Delaware studied the mechanism and kinetics of coal liquefaction resid conversion. The program at Delaware was conducted between August 15,1994, and April 30, 1997. It consisted of two primary tasks. The first task was to develop an empirical test to measure the reactivity toward hydrocracking of coal-derived distillation resids. The second task was to formulate a computer model to represent the structure of the resids and a kinetic and mechanistic model of resid reactivity based on the structural representations. An Introduction and Summary of the project authored by CONSOL and a report of the program findings authored by the University of Delaware researchers are presented here.
\end{abstract}


TABLE OF CONTENTS

Page

PROJECT ASSESSMENT

Introduction

Summary

Program Description

Reactivity Tests

Model Description

Proposed Future Work

THE KINETICS OF COAL LIQUEFACTION DISTILLATION RESID CONVERSION (University Of Delaware Final Report)

\title{
Appendix \\ LIST OF APPENDICES
}

\author{
1 User's Manual for the Structure and Reaction Models for Coal Resid \\ 2 Conversion of Resid Structure Reactivity Model Software from the IBM \\ RS-6000 to the HP-9000/735 RISC Workstation
}

Page

A1-1

A2-2 


\section{Section 1 \\ PROJECT ASSESSMENT}

\section{INTRODUCTION}

Resid hydrocracking is a key reaction of modern (i.e., distillate-producing) coal liquefaction processes. Coals are readily converted to resid and lighter products in the liquefaction process. The resid is combined with fresh coal in a ratio often greater than $1: 1$, and some vacuum gas oil and is recycled to be further converted. Understanding the chemistry of resids and resid reactivity is important to improve direct liquefaction process design and to achieve economic objectives for direct coal liquefaction. Computational models that predict resid conversion from the chemical characteristics of the resids and reaction conditions would be a cost-efficient way to explore process variables. Implementation of such models could aid in the design and operation of liquefaction facilities.

\section{SUMMARY}

\section{PROGRAM DESCRIPTION}

Under subcontract from CONSOL Inc. (U.S. DOE Contract No DE-AC22-94PC93054), the University of Delaware studied the mechanism and kinetics of coal liquefaction resid conversion. The program at Delaware was conducted between August 15, 1994, and April 30, 1997. It consisted of two primary tasks. The first task was to develop an empirical test to measure the reactivity of coal-derived distillation resids. The second task was to formulate a computer model to represent the structure of the resids and a kinetic and mechanistic model of resid reactivity based on the structural representations. The full report authored by the University of Delaware researchers is presented here. The computer model code is appended, and an electronic copy of the computer model was supplied to and is available from the U.S. DOE.

Both tasks described above were successfully accomplished. An empirical test was developed for coal liquefaction resids. The test made use of a small batch reactor system, which was constructed at the University of Delaware. The reactor system allows for short reactant heat-up times and product cool-down times, permitting the acquisition of kinetic data. To evaluate products, a method was developed to determine boiling point distribution using thermogravimetric analysis techniques. 
The reactivity test was applied to a suite of fifteen well-characterized $850^{\circ} \mathrm{F}^{+}$distillation resids. The resids were derived from the Wilsonville pilot plant and the Hydrocarbon Technology, Inc. (HTI) bench unit. Feed coals included Illinois 6 bituminous coal, Pittsburgh seam bituminous coal, and Wyodak and Anderson seam subbituminous coal. The resids were produced by distillation of process stream samples obtained from several sampling locations in the plants. Reaction conditions were chosen to produce (on average) conversions similar to those obtained on a single pass in the continuous plants from which the samples were obtained (about $30 \mathrm{wt} \%$ ). Resid conversion values were determined for each resid under this one set of conditions. To obtain kinetic data, two of the fifteen resids also were reacted at several residence times and temperatures.

Chemical characteristics supplied to Delaware by CONSOL, and the results of the reactivity tests were used to construct mathematical structural representations of the resids. The structural representations then were subjected to a set of reaction rules. The outcome of the calculations was a resid conversion value for each resid. Correlation between the model output and experimental results was good. However, the model constructed in this study is viewed as "first generation" and is now ready for further refinement and expansion.

Six publications resulted from this work. They are referenced in the following report.

\section{REACTIVITY TESTS}

The relative reactivity of the resids was determined using an empirical test developed for this purpose. A short contact time batch reactor (SCTBR) was used to react the resids and a thermogravimetric analysis (TGA) method was developed to evaluate the reaction products and allow for derivation of a conversion value. Tests were made with and without catalyst. All tests were made in tetralin. Heat-up and cool-down times of the resid/tetralin feed mixtures were ca. $0.3 \mathrm{~s}$. Agitation of the slurry was accomplished by an upflow of reacting gas $\left(\mathrm{H}_{2}\right.$ or $\left.\mathrm{N}_{2}\right)$ at $1500 \mathrm{psi}$ (cold). A homogeneous catalyst (molybdenum naphthenate) was chosen for catalytic tests after trials with heterogeneous catalyst (presulfided Shell 324 Ni/Mo on alumina) proved difficult to evaluate because the required high catalyst loadings resulted in viscous reaction mixtures and poor ash balances. Dimethyldisulfide (DMDS) was used to sulfide the Mo in situ. Tests were made under a range of solvent/resid ratios, residence times, and reaction temperatures. Conversion values were determined by separating soluble and insoluble fractions of the reaction products by filtration. The insoluble fraction was subjected to a simulated distillation 
method which uses thermogravimetric analysis techniques to determine the amount of material boiling below $454^{\circ} \mathrm{C}$. The soluble fraction was distilled to remove most of the tetralin, analyzed by gas chromatography to determine the quantity of tetralin remaining, and analyzed by TGA to determine the amount of material boiling below $454^{\circ} \mathrm{C}$. Conversion was calculated as follows:

$$
\text { Conversion }=\text { tetralin soluble fraction } \times\left(1-\frac{\text { fraction boiling above } 454^{\circ} \mathrm{C}}{\text { resid soluble fraction }}\right)
$$

where the tetralin soluble fraction was determined by ash content of the insoluble resid after hydroprocessing. Resid soluble fraction is the amount of material soluble in tetralin prior to hydroprocessing. There were large differences in conversion (as much as $15 \mathrm{wt} \%$, abs.) for the different resid samples reacted under the same conditions.

Two of the fifteen resid samples were chosen to study the kinetics of resid hydroprocessing. The two samples were chosen because they gave the highest and lowest conversions under the standard test conditions $\left(420^{\circ} \mathrm{C}, 30 \mathrm{~min}\right.$, tetralin/resid $\left.=3 / 1\right)$. Tests were made at $435^{\circ} \mathrm{C}$ to augment tests made at $420^{\circ} \mathrm{C}$. Reaction times of $5 \mathrm{~min}$ and $10 \mathrm{~min}$ were used in addition to the 30 min data already acquired. Conversion leveled off with time, consistent with the presence of a non-convertible component.

Results obtained with the SCTBR indicate that the resid must be soluble in the reaction solvent for conversion to $454^{\circ} \mathrm{C}-$ distillate to occur. The resids contain ca. 5 to $15 \mathrm{wt} \%$ (ash-free basis) tetralin insolubles. This insoluble component is, in part, responsible for the unconvertible nature of the resid and the leveling off of conversion with time. Several resids were extracted with tetralin to obtain the insoluble fraction. These fractions were hydroprocessed under the same conditions $\left(420^{\circ} \mathrm{C}, 30 \mathrm{~min}\right.$, tetralin/insolubles $\left.=3 / 1\right)$ as the resids. Less than $1 \mathrm{wt} \%$ of the insoluble fraction converted to $454^{\circ} \mathrm{C}^{-}$product.

No simple correlation of resid conversion in the SCTBR with feed characteristics, such as elemental composition, aromatic carbon content, or molecular weight, was found. In addition, resid conversion in the SCTBR did not correlate with feed coal rank, feed resid sampling location, or processing conditions that produced the feed resid. 


\section{MODEL DESCRIPTION}

Four computer programs were developed that together comprise the structure/reactivity model: a structure optimization program, a structure 'once-through' program, a reaction optimization program, and a reaction 'once-through' program.

The structure model (comprised of the structure optimization and 'once-through' programs) uses the technique of Monte Carlo construction, in which individual molecules are constructed by random sampling of probability density functions (pdfs). The pdf's represent a quantitative probability that the attribute they represent will be less than or equal to certain values. Each pdf iepresents one molecular attribute. Thirty-three attributes were incorporated in the model. Structural representations were constructed for each of the fifteen resids that were reacted experimentally. Each structure was then optimized by minimizing an objective function so that the molecular representation matched the experimental characterization data. The optimization routine required about 20 hours of processing time. However, the chemical characteristics of the computer generated structures are well matched to the experimental data.

Using the statistical representations generated from the structure model and a set of reaction rules based on known chemistry, Monte Carlo techniques were used to 'react' a set of reaction families that were used to represent the reactive moieties in the resids. A subset of five resids was used to optimize the rate constants. The output of the reaction model was a single conversion value for each resid. These conversion values were compared to the experimentally determined SCTBR values and were within two experimental standard deviations.

The model was developed on an IBM RS/6000 RISC workstation at the University of Delaware. The "User's Manual for the Structure and Reaction Models for Coal Resid" is Appendix 1 of this report. In order to use the model, CONSOL modified the software programs to run on CONSOL's HP-9000/735 workstation. The necessary changes to the software are presented in Appendix 2 of this report.

\section{PROPOSED FUTURE WORK}

The completed study included the acquisition of kinetic data for only two of the fifteen resids in the sample set. As a consequence, the reaction model was limited in determination of rate constants. It is proposed that additional data be acquired for the remaining thirteen resids. 
At the conclusion of this program, little testing of the model had been accomplished. It is recommended that the structure and reactivity models be tested to determine the sensitivity to input parameters. Additionally, it is recommended that the relationship between input parameters and product selectivity be determined. Testing of the model need not include the acquisition of more experimental hydroconversion data, although this is recommiended.

It is recommended that, in order to ensure that the model is applicable to resid samples produced in different liquefaction technologies (for example, the NEDOL process and the HTI process), data sets for resids produced in the different liquefaction technologies be acquired and the model tested to predict resid conversion.

It is recommended that the structure/reactivity model be expanded to included additional processing parameters. These include catalyst type and activity and reactor type. Additionally, economic factors could be incorporated in the reaction model. This could allow for prediction of not only product quality, but also product value.

The study of the insoluble fraction of the resids should be expanded. Methods for reaction or removal of these materials from the recycle stream should be examined.

At the conclusion of this program, a number of aspects of the resid reactivity studies and the development of the computer model have not been published. Publications dealing with the analytical methodologies employed, the hydroconversion studies, and the modeling techniques and outcome should be published in refereed journals. 


\title{
THE KINETICS OF COAL IIQUEFACTION DISTIILATION RESID CONVERSION
}

\author{
FINAI REPORT \\ Michael T. Klein \\ Principal Investigator \\ William H. Calkins \\ Co-Principal Investigator \\ He Huang
Research Associate \\ and \\ Shaojie Wang \\ visiting scientist \\ and
}

Darin Campbell

Ph.D. Candidate

Center for Catalytic science and Technology Department of Chemical Engineering University of Delaware

Newark, Delaware 19716

Date Published

August 29, 1997

Subcontract from CONSOL under DOE Contract DE-AC22-94PC93054 


\section{EXECUTIVE SUMMARY}

The objectives of this study were to understand the characteristics of coal liquefaction resids, the reactivity of these resids and the relationship between resid reactivity and resid characteristics. A suite of well-documented distillation resids obtained from two stage liquefaction tests were extensively characterized by CONSOL and various other laboratories. An empirical hydrocracking test was developed by the University of Delaware and was used to determine the relative resid reactivity of the resids in the suite. Considerable variation in the reactivity of these resids was observed, and the causes of this variability were not apparent from the coals used, the liquefaction conditions under which the resids were made or the analytical data obtained on the resids themselves.

The kinetics of hydrocracking of two of the resids having the greatest difference in reactivity, and the effect of hydrocracking variables (temperature, hydrogen pressure, catalyst concentration and resid to solvent ratio) were investigated. All these variables have a strong effect on the hydrocracking kinetics. The presence of about 10 to $15 \mathrm{wt} \%$ of an unconvertible component in the resids was indicated and isolated. This component showed a low hydrogen to carbon ratio. The source of this unconvertible material is being investigated.

The characterization data and the resid reactivities were used to formulate a structural representation (model) of direct liquefaction resids. Using this structural model, the key reactions were identified and a pathways model of resid reactivity was developed. Inconsistencies in the analytical data and choice of samples created some problems in developing these models.

\section{CONCLUSIONS}

Conclusions from Experimental studies The following conclusions can be drawn from the experimental work done under this project:

1) With the appropriate catalyst and conditions approximating coal liquefactions, high boiling coal-derived resids do break down to lower boiling products as they are recycled to the coal liquefaction process.

2) High catalyst activity appears to be necessary to convert these refractory materials to lower boiling materials.

3) Solubilization of the resid in the processing solvent is necessary for the molecular breakdown. 
4) There is considerable variation in reactivity of the resids studied even in the presence of sulfided molybdenum naphthenate catalyst. The causes of this variability may be in part due to the coal used in the production of the resid and in part due to higher aromaticity in some resids. However, these factors do not account for the large variation in resid reactivity.

5) There is a significant portion of the resids examined which are unreactive and unconvertible to low boiling material under the catalytic conditions investigated. The source of this unconvertible material is not known. It may arise from the original coal, from retrograde reactions in the liquefaction process or from retrograde reactions during the product distillation or product workup. It represents a significant amount of inert material which is being recycled to the reactor, reducing the capacity of the process, thereby increasing the operating cost and investment.

Conclusions from Modeling studies A reaction model based on the structural attributes of a coal resid has been developed for the hydroprocessing of coal resid at standard conditions. The relevant structural attributes and reaction families have been identified, and the rate constants optimized. The model runs quickly ( 1-2 CPU minutes on an RISC 6000, model 560H).

The uncorrected model predictions overestimated conversion for the light resids and for resids with high oxygen content. By correlating these predictions with the amount of oxygen present and the amount of low boiling material initially present, a model which accurately reproduces the experimental data has been developed.

For future work, it would be desirable to modify this model so that model compound data were included in the determination of rate constants. In this case, since no model compound data was available, a subset of the resids studied were used to optimize the rate constants. Since the analytical characterization of these resids had some uncertainty associated with the measurements, this uncertainty is propagated to the rate constants. This propagation was clearly seen for the oxygen content and the initial low boilers content.

Additionally, only a small amount of data was available for the optimization of rate constants. In this study, only the amount of resid which was converted to material which boils below $850^{\circ} \mathrm{F}$ was measured. Since a full molecular representation of the feed and the products is possible, however, a more detailed characterization of the products would be useful. For instance, a proton distribution or boiling point distribution of the products would increase the probability of a unique set of rate constants.

The development of a more accurate boiling point correlation for this size of molecule would also likely improve the accuracy of prediction. Unfortunately, there is a paucity of model 
compound boiling points for the types of molecules present in a coal resid. The boiling point correlation developed was generally able to model the boiling points of the model compounds accurately; however, this correlation is essentially an extrapolation for many of the species constructed in the construction program.

Another important consideration for this model is that only data at 30 minutes was used for the determination of rate constants. Therefore, the prediction of conversion at other reaction times is more uncertain. A detailed study of reactions at different times and temperatures would allow for the determination of rate constants which are more generally applicable.

\section{POSSIBLE FUTURE PROGRAM}

Some important findings in the work, suggests that a future program should be considered to complete the program and to exploit some of the findings of the project. These include:

1) Expand the kinetic studies of those resids only run under the "standard conditions". While all 15 resids were run under the "standard conditions", time and funds only permitted a more detailed investigation of two of the 15 resids originally provided. These would include resids from samples taken at other places in the wilsonville process than the composite recycle stream. Samples from other locations may give indications as to the sources of the unconvertible material in the resids. This would also allow for the optimization of Arrhenius parameters of the rate constants for the reaction model.

2) Run Hydroconversion of the coal derived resids using wilsonville recycle solvent instead of tetralin. This would involve a minor change in the equipment, since the recycle solvent is a solid which would have to be melted or dissolved in another non=H-donor solvent to be able to be fed to the unit.

3) Levise method for determining the source and amount of the "unconvertible" portion of the resid stream and consider methods of its elimination before recycle.

4) Perform more comprehensive multivariable analysis to detect relationships between resid reactivity and analytical data and process conditions.

5) Run model compound reactions for the determination or validation of rate parameters assumed in the model.

6) Perform more detailed analysis of the product for reaction model validation. 
7) Refine analytical characterization techniques.

\section{PUBLICATIONS RESULTING FROM WORK ON THIS CONTRACT}

The following publications resulted from work under Subcontract DE-AC22-94PC93054

1) Huang, H., Calkins, W.H. and M.T.Klein "The Use of a Novel Short Contact Time Batch Reactor and Thermogravimetric Analysis to Follow the Conversion of Coal-Derived Resids During Hydroprocessing" I \& E Chem Research, 33,2272-2279 (1994)

2) H.Huang, Keyu Wang, M.T.Klein and W.H.Calkins "A Novel Method for the Determination of the Boiling Range of Liquid Fuels by Thermogravimetric Analysis" ACS Fuel Chem Div. Preprints 40 (3) 485-491.

3) He Huang, Keyu Wang, Shaojie Wang, M.T. Klein and W.H.Calkins "Applications of Thermogravimetric Analysis in the Study of Fossil Fuels" ACS Fuel Chem. Div. Preprints 41 (1) 1 - 7 (1996)

4) Keyu Wang, Shaojie Wang, He Huang, M.T. Klein and W.H. CaIkins "A Novel Smoothing Routine for the Data Processing in Thermogravimetric Analysis" ACS Fuel Chemistry Div. Preprints

41 (1) $27-32$ (1996)

5) He Huang, Keyu Wang, Shaojie Wang, M.T.Klein and W.H.Calkins "Distillation of Liquid Fuels by Thermogravimetry" ACS Fuel Chem. Div. Preprints 41 (1) $87-92$ (1996)

6) S.Wang, H.Huang, K.Wang, M.T.Klein and W.H.Calkins "Kinetics of Hydroprocessing of Coal Derived Vacuum Resids" ACS Fuel Chem Div. Preprints 42 (1) 125 - 131

Other papers covering more details of the hydroconversion work should be published in a refereed journal to make the work more accessible to other researchers. A more detailed paper covering the use of SymDis TGA is also planned. Publications. of the modeling studies are being considered. 


\section{INTRODUCTION}

The Direct Coal Liquefaction Process was invented by Bergius in Germany in 1910. Since that time, a great deal of work has been done on the process in Germany, the United states and various other countries, with increasing understanding of the reactions involved and changing ideas of how the process should be carried out. The present concept for a Direct Liquefaction Process to produce liquid fuels from coal is a Closed-Coupled Integrated TwoStage Liquefaction System. A diagram of such a system as it was practiced at wilsonville, AI is shown in Figure 1. This concept includes two reaction stages with a number of possible variations. For most of the recent runs at wilsonville, it consisted of two ebulating bed catalyzed stages or a combination of a thermal (noncatalytic) and a subsequent catalyzed stage. Various temperatures in the two stages have also been experimented with. As can be seen in Figure 1 , the reaction product which is only partially converted, must be fractionated in a series of atmospheric and vacuum distillation stages and a final solvent deashing stage to separate the fuel grade product from the gases and heavy liquids and any unconverted coal and coal ash produced. Since conversion of the coal to low boiling material is not complete, considerable material consisting of a mixture of some high boiling components, some deasher effluent and some product distillate must be recycled to the process and is used as the principal solvent (marked V131B) which is fed with fresh coal to the first stage of the process. Experience has shown that recycle of some heavy product to the reaction actually results in higher conversion to fuel grade product than if the process is carried out in a single stage batch process without recycle $(1,2)$. This recycle stream therefore contains considerable high boiling material resid (b.p. $>850^{\circ} \mathrm{F}$ ) which is not suitable for processing in a conventional petroleum refinery.

The recycling of this high boiling material however, raises a number of important questions:

1. What are the optimum hydroconversion conditions for this recycle material?

2. How much of the resid is hydrocracked to useful product in the recycling process?

3. What is the effect of reaction conditions of the original liquefaction process and the coal type on the convertibility of the resid?

4, What are the resid compositional characteristics which affect resid reactivity?

It is in part to provide answers to some of these questions that this project was initiated.

Project objectives This project is part of a larger project coordinated by CONSOI Inc. aimed at reducing the cost of liquid fuels from coal by developing a comprehensive understanding of 
liquefaction process development and economics. This involves the application of advanced methods of analysis and characterization of feedstocks, reaction intermediates, and product coal liquids produced in DOE-supported Iiquefaction projects.

The University of Delaware part of the project is as follows:

1. To develop an empirical method for the evaluation of resid conversion and resid reactivity.

2. To develop simple kinetic parameters to define the resid reactivity based on hydroconversion experiments.

3. To correlate chemical and physical characteristics of resids with resid reactivity.

4. To develop a reaction model based on kinetics and structural information.

It is to document the work aimed at these objectives that this report is written.

\section{EXPERIMENTAL}

Apparatus A Laboratory scale reactor (Short Contact Time Batch Reactor SCTBR) was developed in our laboratory capable of running reactions up to $450^{\circ} \mathrm{C}$ and $2500 \mathrm{psi}$ at well defined reaction times from a few seconds to 30 minutes or longer (Figure 2). This reactor system is described in detail in two papers $(3,4)$.

In operation, both the empty $30 \mathrm{~cm}^{3}$ reactor and the preheater are immersed in a fluidized sand bath and brought up to reaction temperature. High pressure gas (hydrogen or in some cases nitrogen) provides the driving force to deliver the reaction mixture of solvent, resid and catalyst from a blow case through the preheater into the reactor at within $5-8{ }^{\circ} \mathrm{C}$ of the reaction temperature in approximately 0.3 seconds. The mixture then comes up completely to reaction temperature rapidly in the hot reactor. Hydrogen or nitrogen gas bubbled through the reaction mixture from the bottom provided the necessary agitation. Temperature control was within $\pm 2{ }^{\circ} \mathrm{C}$. Figure 3 shows a typical time temperature profile. Discharging and quenching of the reaction mixture was carried out in a similar way and similar time frame by changing the valve settings and forcing the reactor contents with high pressure gas through the precooler (immersed in a water bath) into the product receiver.

A limitation of this equipment is that in the normal experiments the product is blown out of the reactor into the receiver. This leaves some of the reaction product adhering to the walls of the reactor and particularly the preheater and precooler walls. A small amount of the reaction mixture is also left in the blow case: This precludes obtaining an accurate material balance with small samples, as normally between 80 and 90\% of the reaction product is recovered. To determine conversion, the change in ash content, which is accurately and conveniently determined by thermogravimetric analysis is measured as a tracer.

It is possible to recover essentially all of the product by 
washing the system out with a solvent, evaporating the solvent and measuring the residue. This was shown to work, but was extremely time consuming and normally no more accurate than the tracer method. Also, by this method, some of the product is exposed to a slightly different thermal history than the rest of the sample.

It is also important that a representative sample of the product be obtained for conversion determination. This was shown to be the case in resid hydroconversion by putting the reaction mixture through the reactor at room temperature and comparing the ash content of that product with the original sample. It was found that the ash component remains with the undissolved solid residue and not with the oil or liquefied components.

Materials studied Thirteen $850^{\circ} \mathrm{F}+$ distillation resids were prepared by CONSOL Inc. from liquefaction runs made at the Wilsonville, $A I$ pilot plant and two resids were made from runs from the Hydrocarbon Research Institute bench scale unit. The feed coals for these runs were Wyodak-Anderson, Illinois \#6, and Pittsburgh seam coal. Samples were taken from several points in the Wilsonville process as shown in Figure 4. The resids were produced from whole process oils by distillation in a $1^{\prime \prime} x^{\prime \prime}$ jacket-heated Vigreux column to an end point of $320^{\circ} \mathrm{C}$ pot $/ 270^{\circ} \mathrm{C}$ column/ 5 torr ( $850^{\circ} \mathrm{F}$ atm equivalent).

Proximate analysis (by TGA) and aromaticity $\left(f_{a}\right)$ of the 15 resids studied are shown in Table 1. Ultimate analyses on all 15 of the resids, and phenolic-OH concentration, average molecular weights, proton NMR data and SARA analysis on the resids are shown in Tables 2,3 and 4 .

Chemicals Used Two solvents were used, tetralin $(99 \%$ and 1methylnaphthalene $(99+$ \&) from Aldrich. Molybdenum naphthenate (6.8\% molybdenum from Shepherd Chemical company), and methyl disulfide (99\% from Aldrich) were used for the principal catalyst system. Shell $324 \mathrm{Ni} / \mathrm{Mo}$ on alumina obtained from wilsonville via CONSOL was used in some experiments. Since that catalyst had been sulfided in oil, CONSOL removed the oil by Tetrahydrofuran (THF) extraction.

Resid Conversion Reactions All hydroconversion reactions were run as mixtures of tetralin (T) (as the donor solvent) and resid (R) over a range of $T / R$ ratios, hydrogen pressure, temperatures, and catalyst concentration. In some cases, the reactions were run under nitrogen instead of hydrogen to determine the effect of hydrogen donor alone. In each reaction, 5-10 grams of resid were used together with added tetralin to make up the desired T/R ratio. The determination of conversion and subsequent analyses were based on representative aliquots.

Reaction Product Workup Procedure the reaction products were worked up by separating the solids from the liquids by filtration according to the scheme shown in Figure 5. The solid filter cake was washed with methylene chloride which went into the filtrate 
along with the product liquids. The filtrate was then distilled at low temperatures $\left(45^{\circ} \mathrm{C}\right.$ ) to remove the methylene chloride. The solid filter cake was dried in a vacuum oven at room temperature.

Analytical Methods - Conversion the conversion to tetralin soluble liquid was determined using thermogravimetric analysis (TGA) on the solid cake by an ash balance calculation. The conversion to tetralin soluble material was determined by using the formula:

$$
X(\operatorname{daf} w t \%)=1 /\left(1-A_{0}\right) \times\left(1-A_{0} / A_{s}\right) \times 100 \% \quad \text { Eq. } 1
$$

where $A_{0}$ and $A_{s}$ are the weight fractions of ash (derived from the mineral matter) in a original sample and the liquefaction residue, respectively.

The boiling range of the tetralin soluble material had to be measured to determine what portion was converted to material boiling below $454^{\circ} \mathrm{C}\left(850^{\circ} \mathrm{F}\right)$ since the original resids boiled above $454^{\circ} \mathrm{C}$. A boiling range method, SimDis TG, was developed based on thermogravimetric analysis (TGA) to accomplish this (5)). This value had to be corrected for the amount of tetralin in the liquid product. This was determined by gas chromatography using 1-methyl naphthalene as an internal standard. The tetralin removed with the methylene chloride which was distilled out in the product workup was also determined by gas chromatography.

The calculation of conversion to liquid product boiling below $454^{\circ} \mathrm{C}\left(850^{\circ} \mathrm{F}\right)$ required several steps, and a correction for the tetralin content which also boiled below $454^{\circ} \mathrm{C}$. This of course involves the accumulation of errors which appear to be about $\pm 4 \%$ or 12 \% relative (see Figure 6)

Determination of Boiling Range of the Liquid Products Since the objective of the project is in part to determine the conversion of resids boiling above $850^{\circ} \mathrm{F}$ to lower boiling material, under the hydroconversion conditions in the liquefaction process, it was necessary to develop a method for determining boiling range of the derived liquids. This had to be done on very small samples. While there is a Simulated Distillation Analysis $(7,8)$ based on gas chromatography which requires only small samples, it is limited by sample boiling range because of the stability of the column packing. Also above that temperature the materials being studied tend to crack. For those reasons, a simulated distillation analytical method, referred to above, based on thermogravimetric analysis was developed. A paper briefly describing this method is shown in Appendix I.

Resid Characterization The resids studied in this project had been characterized by CONSOI and various other research laboratories. These characterizations are the basis for developing a structural representation of the coal resids. Each of the analytical tests will be discussed briefly in the following sections. 
Elemental Analysis: Elemental analysis provides the average concentrations of the elements which comprise a feedstock. The elemental analyses of the resids studied are presented in Table 2 . Furthermore, when combined with other analytical techniques, other techniques can greatly aid in the elucidation of chemical structures present in a complex feedstock.

one of the most important pieces of information derived from the elemental analysis is the hydrogen to carbon (H/C) ratio. As with complex petroleum feedstocks, hydrogen and carbon are by far the most prevalent elements present in a coal resid. The $\mathrm{H} / \mathrm{C}$ ratio gives a good first approximation into the aromaticity of the molecules present. Generally, lower $\mathrm{H} / \mathrm{C}$ ratios indicate a higher aromaticity, whereas higher $\mathrm{H} / \mathrm{C}$ ratios indicate more saturated species.

Although the $H / C$ ratio will often yield important insight into the aromaticity of a complex feedstock, the exact aromaticity of a feedstock can not be measured in this way. For instance, 1ring aromatic compounds and 3 -ring naphthenic compounds have the same H/C ratio, so that no distinction can be made with just an elemental analysis. This means that vastly different molecules can often have equivalent $\mathrm{H} / \mathrm{C}$ ratios.

The measurement of oxygen, nitrogen, and sulfur in a coal resid is also very important. This is especially true for catalytic hydroprocessing where such atoms are removed. Although the elemental analysis does not provide the functional form of the atoms, it is usually possible to deduce the structures present from a knowledge of species present in coal and the previous processing history. For instance, organic sulfur is present in coal in both ring and alkyl structures; however, the thermal processing of the coal to the coal resid will generally consume the alkyl sulfurs, leaving sulfur present only in ring structures or as links between aromatic clusters. Oxygen will be present mainly in phenolic and furan or ether structures (8). A ratio of $2: 1$ was presumed for 5- to 6- membered ring nitrogen compounds (9).

In spite of the fact that an elemental analysis can provide many valuable constraints on a molecular representation, other tests are often needed to further eliminate possible alternate structures with similar elemental compositions. As mentioned previous, the elemental analysis can not distinguish between dissimilar species with common H/C ratios. Furthermore, an elemental analysis does not constrain the size of the molecules or distinguish between various isomers of species.

Compound Class Separation: Another powerful technique used to elucidate the structures present in the coal resids was a compound class separation. SARA (saturates, aromatics, resins, and asphaltenes) is a common solvent separation used for heavy petroleum fractions. In addition to these classes, the heptane insoluble fraction (asphaltenes) was further separated into asphaltenes (heptane insoluble, toluene soluble), preasphaltenes (toluene insoluble, tetrahydrofuran soluble), and insoluble 
organics (tetrahydrofuran insoluble). The results of the SARA analyses are presented in Table 3.

The ratios of these compound classes helped to further differentiate between molecular species. For instance, the saturates fraction which contains mainly naphthenic compounds, was separated from the aromatics fraction. This means that a distinction between 1-ring aromatic compounds and 3-ring naphthenic compounds could be made, whereas an elemental analysis could make no distinction.

Despite the additional information, more analytical characterization is necessary for constraining the molecules by size and isomers of molecules. Furthermore, although these compound classes are very useful for petroleum feedstocks, no single identifying characteristic of the aromatics, resins, asphaltenes, and preasphaltenes could be used to differentiate these molecules other than their average molecular weights. A detailed solvent separation which discriminates by functional group such as that proposed by Farcasiu may have offered more molecular insight $(10)^{-}$and is proposed for future work.

Vapor Pressure Osmometry: of the SARA-P fractions Osmometry (VPO). Knowing species allows for the fractions of the various average molecular weight further constrains requiring a molecular representation to have weight. Average molecular weights for each of the 15 resids are presented in Table 3 .

When combined with an elemental analysis and a SARA-P separation, a molecular representation can now be constrained to have a specific elemental content, a specific compound class ratio, and a specific average size.

Proton NMR: Proton nuclear magnetic resonance can be used to differentiate between various types of protons. For instance, a proton which is alpha to an aromatic ring will have a different chemical shift than a proton which is at the end of a long paraffinic sidechain. For these resids, a breakdown of the proton distribution was possible. The following classes of hydrogen were identified: aromatic, condensed aromatic, alkyl alpha, cyclic alpha, alkyl beta, cyclic beta, and gamma hydrogens. The proton distributions of each of the resids is shown in Table 4 .

This separation allows for some differentiation between molecules not possible with other techniques. For instance, a three condensed ring aromatic compound with.one sidechain of ten carbons is indistinguishable from a three condensed ring aromatic compound with ten methyl groups by elemental analyses or molecular weight determination. A detailed proton distribution, however, clearly shows differences in alkyl alpha, alkyl beta, and gamma protons between the two species.

FTIR Spectroscopy: The concentration of phenolic oxygens were 11 
measured by FTIR spectroscopy. Measuring this concentration is quite important since the amount of phenolic hydrogens with respect to the total oxygen content can vary significantly from feed to feed. Modeling this correctly is quite important since ring oxygen and ether oxygen will react quite differently. The phenolic oxygen content of all 15 resids are listed in Table 2 .

The combined analytical techniques used to characterize the coal resids in this study will allow for the definition of a molecular representation unique for each feedstock. Each feedstock has a unique elemental analysis, compound class ratio, average molecular weight, and proton distribution. Although further tests might help to further elucidate structural features of the resids, it was deemed that these tests would be sufficient given the amount of time and resources available.

Generally, the molecules of a coal resid can be thought of as aromatic clusters which are connected by short linkages le.g. sulfur bridges, oxygen bridges, methylene bridges, and biphenyl bridges) or by acid base interactions (phenolic oxygen with basic nitrogen) $(11,12,13)$. The analytical measurements which characterize these 15 resids and this basic picture for the coal resid molecule are the basis for constraining a statistical molecular representation for a coal resid. The tests used in the construction algorithm will be discussed in detail here, with emphasis on what information can be extracted from them.

\section{RESULTS AND DISCUSSION}

OBJECTIVE 1. TO DEVELOP AN EMPIRICAI METHOD FOR THE EVALUATION OF RESID CONVERSION AND RESID REACTIVITY

Preliminary Expeximents Preliminary experiments in hydroconversion of Resid A were performed in order to explore the affects of reaction variables such as temperature, tetralin to resid ratio, and time on the conversion of this resid. These experiments were done with and without catalyst and in some cases with hydrogen and in others in a nitrogen atmosphere. Resid A was produced from Wyodak-Anderson coal and was taken from the recycle solvent stream marked $V 131 \mathrm{~B}$ on Figure 4 . As such, it is representative of solvent being recycled to the process with fresh coal, and the resid produced from it represents the high boiling components of that process stream. It consists of three components: a portion of the second stage flashed bottoms product, heavy distillate, and the deashed resid from the ROSE (deashing) unit.

Some 96 runs (shown in Appendix II) were made with no catalyst, with shell $324 \mathrm{Ni} / \mathrm{Mo}$ on alumina catalyst, and with sulfided molybdenum naphthenate. The fresh alumina supported Shell catalyst was sulfided in oil at wilsonville, and the oil was removed by solvent extraction by CONSOL. The results with this catalyst turned out to be unreliable in part because of the large amount of ash contained in the catalyst, since we were using an 
ash tracer to determine conversion. CONSOL had hoped that we could use an equivalent amount of supported catalyst as resid in order to simulate the ebulating bed used at Wilsonville. However, this required the use of a very large amount of shell catalyst resulting in a huge amount of ash residue. In addition to those problems, we found that the supported catalyst changed as the hydroconversion progressed, limiting the reproducibility of the conversion determination. A further problem with use of the supported catalyst was the taking of representative samples of the reaction product. When a room temperature resid run was made with the Shell catalyst, it was apparent that we did not find the same amount of ash (by TGA) as we would expect from an unconverted sample.

Molybdenum naphthenate $16.8 \%$ molybdenum from Shepherd Chemical Co.) was the soluble catalyst was chosen for use in most of this work. The catalyst was prepared by dissolving about $0.5 \mathrm{~g}$ molybdenum naphthenate (equivalent to about 0.9 wt $\%$ Mo based on the amount of resid charged) in tetralin. The catalyst was then sulfided by reacting the solution with $1 \mathrm{~g}$ of methyl disulfide. Most of the sulfidation appeared to occur in the preheater to the reactor as the reaction mixture was added to the system. This catalyst contributed very little ash to the system, making our ash based conversion method valid.

Establishing a standard set of Hydroconversion conditions To comply with objective 1 above, a set of standard conditions for running the hydroconversion of the 15 resid samples from CONSOL Inc. had to be established. To achieve the greatest accuracy in the conversion kinetics, it was important to use as high a resid to tetralin ratio as possible. Ratios of less than $1 / 3$ however resulted in lower recoveries, and higher than $1 / 3$ would be expected to give somewhat lower precision. For that reason, a $R / T$ ratio of $1 / 3$ was selected. Experiments were run using $0.9,2.0$, 3.0 and 5.0 sulfided molybdenum naphthenate to select a catalyst level. Figure 7 shows the strong effect of that catalyst concentration on conversion. Only minor increases in conversion were observed in using $0.9 \%$ sulfided molybdenum catalyst over reactions run without catalyst. 3 wt $\%$ added sulfided molybdenum naphthenate catalyst however showed a significant increase in resid conversion. Hydrogen pressure was also shown to have a very significant effect on conversion (see figure 8). With these results, in consultation with CONSOI Inc. "standard" conditions of 30 minutes at $420{ }^{\circ} \mathrm{C}$ at 3 to 1 tetralin to resid ratio, 3 wt $\%$ sulfided molybdenum naphthenate catalyst and 1500 psig hydrogen pressure were selected as conditions giving over 30 wt $\frac{}{\circ}$ conversion for running a determination of the relative reactivity to hydroconversion of the coal derived vacuum resids.

Results and Discussion Tables 5 and 6 show the conversions to material boiling below $850^{\circ} \mathrm{C}$ for the thermal and $3 \%$ sulfided molybdenum naphthenate catalyst runs under "standard conditions". It is to be noted that significant conversion to lower boiling 
material occurs even in the absence of catalyst. However, in the presence of the molybdenum catalyst, conversion to the lower boiling material at least doubled. To attain as much as 30 to $40 \%$ conversion, requires a significant amount of catalyst. Only a portion $(76-86 \%)$ of the resid is solubilized in the hydroprocessing. A substantial amount of the resids are soluble in tetralin even at room temperature and processing at over $400^{\circ} \mathrm{C}$ increases the solubility but not completely. Table 6 shows that the presence of the catalyst in the hydroconversion process only increases the solubilization by 1 to $4 \%$. Thermogravimetric Analysis on the undissolved solids shows no material boiling below $850^{\circ} \mathrm{F}$. The hydroconversion of the resid apparently occurs only when the resid is actually dissolved in the tetralin.

As these tables show, there is considerable variation among the resids in terms of their reactivity and convertibility to lower boiling products. What is the precision of these values? As is apparent from the steps involved, there are several determinations in computing conversion where experimental error can be expected to be involved. These are summarized in Figure 6 which gives an estimation of Experimental Error. These taken together can lead to a conversion variation of $\pm 4.0 \%$ abs. This suggests that the conversion variation is real and is due to other unidentified causes. It is of interest, therefore, to determine the causes of this variation. In the thermal hydroprocessing, there appears to be a correlation with the coal type, (Figure 9) i.e. the lower rank coal used to produce the resid the higher the conversion to low boiling material on hydroprocessing in the absence of catalyst. On the other hand, if a catalyst is used, the resids from the three coals studied showed little or no difference in conversion under the conditions used. Apparently, the catalytic process overrides the thermal process or swamps it out.

Plots of the thermal and catalyzed conversions of resids vs. the aromaticity $\left(f_{a}\right)$ of the resid is shown in Figure 10. Those resids having high aromaticity (by ${ }^{13} \mathrm{C} N \mathrm{NMR}$ ) show low conversions under thermal hydroprocessing conditions while lower aromatic carbon containing resids show higher conversions in thermal hydroprocessing. No affect of resid aromaticity, however, is observable if a catalyst is used in the hydroliquefaction.

$\begin{array}{lrrrrrr}\text { OBJECTIVE } & 2 . & \text { TO } & \text { DEVELOP } & \text { SIMPIE } & \text { KINETIC } & \text { PARAMETERS } \\ \text { TO DEFINE } & \text { THE } & \text { RESID } & \text { REACTIVITY } & \text { BASED } & \text { ON }\end{array}$
HYDROCONVERSION EXPERIMENTS.

The kinetics of resid hydroconversion vs. reaction time at two temperatures for resid $\mathrm{C}$ and $\mathrm{H}$ are shown in Figures 11 and 12 . These resids were chosen as showing the highest and the lowest conversion of the resids studied under the standard conditions used. Clearly, there is at least one component of the resids which reacts rapidly and, after it is converted, the reaction becomes very slow indeed. Temperature also has a strong effect on reaction rate and conversion. 
In an effort to get some idea of the mechanisms of the hydroconversion, two kinetic assumptions were tried to explain the time vs. conversion data: a first order assumption and a second order assumption expressed in the equations shown in Figure 13. Figures 14 to 17 show the rate constants for resids $\mathrm{C}$ and $\mathrm{H}$ (representing the most and least reactive resids we had available) plotted according to the first and second order assumptions. It is obvious from these plots that neither assumption can be applied to resid hydroconversion. This is probably due to the mixture of chemical species of vastly differing reactivity in these coal derived vacuum resids.

\section{OBJECTIVE 3: TO CORREIATE CHEMICAL AND PHYSICAL CHARACTERISTICS OF RESIDS WITH RESID REACTIVITY}

Effect of Resid Composition on Resid Hydroconversion Figures 18 to 20 show plots of resid conversion vs. wt \% carbon content, hydrogen to carbon atomic ratio, and the presence of uncondensed aromatics. In none of these properties is there a clearly observable effect on the hydroconversion of resids $\mathrm{C}$ and $\mathrm{H}$ to low boiling materials.

The Presence of an Unconvertible Material in These Resids Various samples of resids were washed with tetralin to extract the soluble components and the solid residues were exhaustively extracted with tetralin at the boiling point of tetralin in a soxhlet extractor. The resulting solid residues were put through the reactor with tetralin and sulfided molybdenum naphthenate catalyst under the "standard" conditions. This material which represented some 10 - 15\% of the resid showed only about $1 \frac{\circ}{\circ}$ conversion to low boiling material. Table 7 shows the elemental analysis of the extracted and unconvertible component in the resid. These analytical data suggest that the unconvertible material is a retrograde product of some sort, either present in the original coal or arising in the liquefaction process or the ensuing distillation processes.

Summary of Hydroconversion Runs of Coal Derived Vacuum Resids Appendix II shows a lists of all hydroconversion runs made under this project.

\section{OBJECTIVE 4: TO DEVELOP STRUCTURE AND REACTION MODELS BASED ON KINETICS AND STRUCTURAL INFORMATION}

Background for structure Model Modeling the reaction of complex feedstocks such as petroleum and coal liquids is difficult due to the complexity of the mixtures. Generally on order of $10^{5}$ species will be present in such complex mixtures. Furthermore, each of these species can undergo many different reactions, with each reaction having a rate constant specific to each molecule. 
Further complicating matters is the fact that conventional analytical techniques usually will not measure the identity of the molecules directly, but only some characteristic of the molecules present.

The traditional approach for dealing with the lack of specific chemical structures is to lump molecules according to some physical characteristic such as boiling point or solubility class. Each lump is then considered to be a pseudo component in a reaction model. In addition to handling the limitations of analytical techniques, such a modeling scheme will generally limit the number of species to a small number which also allows for quick solution with Iimited computer resources.

Despite the advantages of such lumping schemes, there is a serious Iimitation to traditional lumping approaches. Often chemically dissimilar species will have some similar physical characteristics. For instance, an n-octane and ethyl benzene could be lumped in the same boiling point region. For a lumped kinetics scheme, these molecules are therefore treated chemically the same. However, the reactivity of the two molecules are quite different.

The lumping of dissimilar species leads to other drawbacks as wel1. One example is the feed specific nature of the lumps. Since each lump is defined by only a physical property, the chemical composition of a given lump will vary from feed to feed. Since the conversion of a lump is driven by the chemical structure within that lump, each lump must be feed specific to account for these differences.

Another disadvantage to such a lumping scheme is that the rate constants for such lumps will often be time dependent. Since the various chemical species which comprise a lump will react at different rates, the overall rate of conversion from one lump to another will change with time.

The limitations of lumped kinetic models motivated the development of a molecule based reaction model for the hydroprocessing of coal resid. The goal in such an approach is to determine an accurate molecular representation for the feedstock. This would allow for the construction of a reaction model which, with appropriate rate constants, predict the time dependence of the molecular composition. A practical challenge is to determine a molecular representation which balances the CPU demand, computer memory resources, and the amount of analytical characterization needed as input.

A statistical view of complicated feedstocks provides a path forward. Any molecule within a feedstock can be considered as a collection of molecular building blocks or attributes (e.g. number of aromatic rings, number of phenolic oxygens, number and length of alkyl sidechains). Neurock et al. (14) developed such a Monte Carlo construction routine for petroleum resids and asphaltenes whereby individual molecules are constructed by random sampling of probability density functions (pdf's), one for each molecular attribute. The pdf is a functions that provides the quantitative probability of finding the value or less of a given attribute. The parameters of the pdf's can be optimized so that a large 
randomly determined sample of molecules matches closely the experimentally determined properties of a feedstock.

Although a pdf representation allows for the determination of a large molecular representation of a feedstock, dealing with such a large representation is not always facile. For instance, if one were to use a deterministic reaction model where a material balance is written for each reactant and product species, the amount of memory needed to solve such a large system of equations would likely exceed most computers' limitations. On the other hand, Monte Carlo reaction schemes where one molecular reaction at a time is considered, memory limitations can be alleviated. However, when considering a large number of species, such a reaction model can be quite time consuming (a few hours of computer time for the simulation of a few minutes of reaction).

In order to balance the CPU demands and the time requirements, it is necessary to use another approach. One attractive simplification is to react the structural attributes rather than individual molecules. This simplification is based on the fact that often the detailed molecular structure of a molecule will only slightly affect the reaction of a given moiety. For instance, if a six ring aromatic molecule had two sidechains, it is likely that the rate of reaction of one sidechain is only minimally affected by the presence of the other sidechain. By considering the structural attributes separately, the number of species tracked can be reduced from several thousand to only a few hundred, greatly reducing the memory demands on the computer.

The detailed statistical representation of the coal resids studied will first be presented. This includes a description of how the various analytical techniques aided in constructing an accurate molecular representation, and how the structural attributes of the molecules have been defined. With the analytical characterization and molecular attributes defined, the pdf's can be optimized with an appropriate objective function. Finally, the predictions of the various resids will be presented with a detailed analysis.

Trauth et al. (15), used a statistical approach to represent the molecules present in a petroleum resid. A similar approach has been taken to represent a coal resid. To do this, it is first necessary to define the structural building blocks or attributes, and appropriate probability density functions which give the quantitative probability of finding a value or less of a given attribute. Conditional probability issues to insure physically realistic molecules will also be discussed.

Irreducible Structural Groups and Structural Attributes: To construct a molecular representation, it. is first necessary to identify the "building blocks" of a molecule. On the most basic level, a molecule is defined by a set of atoms which are chemically bonded together in some specific manner. In principle, a molecule can be constructed by randomly choosing atoms and connecting them. However, not all atoms can be chosen independently. For instance, if an aromatic carbon is first selected, enough other aromatic carbons must now be chosen to 
complete the aromatic structure. This group of atoms which completes the aromatic rings is now defined as an irreducible structural group.

For this model, the irreducible structural group was chosen as the basic building block. However, a quantitative way to determine the value of these units must also be chosen. For instance, if an aromatic structure is being built, the number of aromatic rings, number of naphthenic rings, and number of sidechains must be specified.

In order to account for this, the structural attribute which is related to the irreducible structural group is defined. A structural attribute is defined as an element of structure which is represented by a probability density function. This is different from the irreducible structural group by the fact that some irreducible structural groups are defined by multiple attributes. For instance, to specify a molecule both the number and length of alkyl sidechains must be specified; however, the irreducible structural group is the alkyl sidechain. Therefore, toluene would have two irreducible structural groups, an aromatic ring and an alkyl sidechain. To specify a toluene molecule, however, requires three attributes: one aromatic ring, one alkyl sidechain, and one carbon in the alkyl sidechain. Similarly, for more complex molecules, the configuration of the rings and placement of the sidechains must be specified as molecular attributes.

The attributes used to model the coal resid are listed in Table 8. The forms of the distributions used to model these attributes will be discussed in the following sections.

Probability Density Functions: As mentioned in the previous section, a molecular attribute is an element of structure which is represented by a probability density function. A discrete probability density function (pdf) is defined by equations 2 and 3:

$$
\begin{array}{ll}
0 \leq f(x) & \text { Eq. } 2 \\
\sum f(x)=1 & \text { Eq. } 3
\end{array}
$$

A continuous probability distribution function (pdf) is defined by equations 2 and 4 .

$$
\int_{-\infty}^{\infty} f(x) d x=1
$$

Eq. 4

Common discrete paf's include the discrete uniform distribution, the binomial distribution, and the Poisson distribution. Examples of continuous distributions include the normal distribution, the 
gamma distribution, and the exponential distribution. A pdf also does not need to be defined with a statistical distribution. For example, a distribution of test scores is computed simply by counting the number of each score and dividing by the population of the class.

Using Probability Density Functions to Describe Complex Mixtures: The concept of using probability density functions to describe complex mixtures is not a new one. For instance, the products of the formation and degradation of polymers have both been modeled with statistical distributions. Flory used a modified gamma distribution to fit the molecular size distribution of condensation polymers in 1936 (16). Similarly, Libanati studied the degradation of an infinite polymer (17). Results from that work indicated that the molecular weights followed a log normal distribution.

Similarly, petroleum crude can be considered to be a breakdown of the infinite polymer kerogen. Indeed, this idea has been used to model petroleum reservoirs. Whitson used a gamma distribution to fit the molar and weight distribution of the $\mathrm{C7+}$ fraction of crude oil (18). The shape of a gamma distribution is quite similar to the shape of a log normal distribution, further supporting the notion of representing crude components with pdf's. By fitting the molar distribution to a pdf, whitson was able to extend the distribution beyond experimental measurements facilitating higher accuracy in the equation of state estimates. likewise, Shibata et al. used mixed distributions to enhance phase equilibrium calculations for a petroleum reservoir (19).

In addition to previous modeling efforts, there is direct experimental confirmation that statistical distributions can be used to model petroleum. Peterson et al. used high-temperature gas chromatography to measure the weight percent distribution of carbon number up to $C_{80+}$ for 17 North sea oils (20). It was shown that an exponential distribution fit to $C_{20}$ could be used to accurately predict the quantities of heavier components. In this study, however, normal paraffin standards were used for calibration. Boduszynski has pointed out the wide divergence in boiling points with increasing carbon number for different compound classes (21). Perhaps more accurately, then, it was demonstrated that the boiling point distribution followed an exponential distribution after $\mathrm{C}_{20}$.

Trauth extended the use of paf's to model not only the molecular weights or boiling points, but to the structural attributes described in the previous section (15). Experimental proof that such an approach is valid was provided by a statistical modeling project which dealt with the thermal depolymerization of coal (22). As with the degradation of an infinite polymer, a gamma distribution accurately fit the molecular weight distribution of the products. Since products are formed primarily by bond fission reactions during pyrolysis, this result indicates that the individual structural attributes also would be well represented by gamma distributions.

Trauth demonstrated that using a gamma distribution for each 19 
of the structural attributes of a petroleum resid yielded a molecular weight distribution which was also gamma (15). By optimizing the paf parameters so that a stochastically determined molecular representation matched closely to a set of analytical characterization, it was shown that many of the key properties of the resid could be captured. Furthermore, such a representation was used to predict accurately pyrolysis results using rate constants from model compounds.

Probability Density Functional Form: As mentioned in the section defining the probability density function, there are many different functional forms. One of the key properties of the selected distribution must be that it captures the qualitative shape of that which is being modeled. Lighter fractions, which are characterized by both a minimum and a maximum boiling point generally have a boiling point distribution which is normal or skewed normal. However, investigations of both polymers and heavy components of fossil fuels indicated that functional forms like gamma distributions or exponential distributions accurately modeled such systems. This can be explained by that fact that petroleum resid is defined only by a minimum boiling point. Generally, a petroleum resids boiling point distribution is characterized by a rapid rise followed by a slow decrease which mathematically would be characterized by a gamma type distribution.

In order to capture the correct shape of the distribution for the coal resids, it was deemed that an exponential or gamma distribution would model each attribute. The gamma distribution has more flexibility than an exponential distribution, being able to approximate other distributions including the exponential distribution, the normal distribution, and the delta function. However, the cost of the added flexibility is an additional parameter which must be optimized. The extra parameter needed for a gamma distribution is very important for this study since so many structural attributes were modeled. Through initial investigations, it was found that many of the gamma distributions were in fact very similar to exponential distributions, so for these structural attributes, exponential distributions were used.

In addition to the exponential and gamma distributions which were used to model number of aromatic rings, number of naphthenic rings, number of unit sheets, and number and length of sidechains, a couple of other distributions were used to model heteroatoms and connectivity. For this work it was deemed appropriate to allow at most only one heteroatom ring per aromatic core. Furthermore, particularly for large molecules, the affect of heteroatoms on the boiling point or molecular weight is very small. As a result, these structures are modeled as on off switches. Also the position to which a moiety such as an alkyl sidechain or another unit sheet is attached can affect a molecules properties. In this model, each possible point of attachment is considered equiprobable, and the connectivity is modeled with a discrete uniform distribution.

The functional forms of the distributions used for this 20 
modeling are shown in Table 9 and their qualitative shapes can be seen in Figure 21 .

Conditional Probability: Not all combinations of the probability density functions will yield molecules which are physically reliable. For a coal resid, which is defined by a minimum boiling point of $850^{\circ} \mathrm{F}$, it is necessary to include some conditional probability to ensure that the molecules constructed are not too smal1. Furthermore, although there is no measured upper limit to the boiling range of the coal resids, extremely large molecules are not likely.

In order to account for the minimum boiling criterion, conditional probability was incorporated for each of the SARA-P Eractions. Naphthenic compounds had a minimum of three rings. However, such compounds still boil significantly below $850^{\circ} \mathrm{F}$, as do four ring naphthenic compounds. To account for this, a minimum of two alkyl sidechains were necessary for three-ring compounds and at least one alkyl sidechain was needed for four-ring naphthenic compounds. Similarly, the aromatic/resin fraction could have as few as one unit sheet. For such compounds, a minimum of four aromatic rings with one alkyl sidechain was imposed. Also a minimum of two aromatic rings was imposed on the aromatic/resin fractions, the asphaltene fractions, and the preasphaltene fractions.

The constraints imposed on these fractions do not ensure that the minimum boiling point is at least $850^{\circ} \mathrm{F}$, but they do greatly limit the number of molecules which can boil lower. Although these samples were made by distillation and collecting the material that boils above $850^{\circ} \mathrm{F}$, simulated distillation on a few of the saturates and aromatic fractions indicated that a significant portion of these fractions (-10-20\%) did boil lower than $850^{\circ} \mathrm{F}$. Furthermore, the average molecular weights for some of these fractions were quite low $(\sim 250 \mathrm{~g})$. However, saturates with this low of a molecular weight generally boil below $850^{\circ} \mathrm{F}$.

on the other end of the size spectrum, a few constraints were placed on the molecules to ensure that molecules were not too large. For all aromatic ring structures, a maximum of six aromatic rings per unit sheet was possible. Naphthenic rings could also be added to these structures, however, it will later be shown that very few naphthenic rings were present so that the possibility of building more than six rings was quite small. Naphthenic compounds were also limited to a maximum of six rings. Furthermore the number of unit sheets was Iimited according to the compound type. Although no chemical distinction could be made between the aromatic/resins fractions, the asphaltene fractions, - and the preasphaltene fractions, there was a definite size distinction between these molecules. As a result, the aromatic/resins were limited to a maximum of four unit sheets, the asphaltenes were limited to a maximum of six unit sheets, and the preasphaltenes were limited to a maximum of eight unit sheets.

Construction Algorithm: necessary to know how with a set of pdf's in hand, it is to combine them in order to obtain an 
accurate unbiased representative set of molecules.

Both the sampling order and the type of sampling are important. It is also important to be certain that an appropriate sample size is chosen.

For each molecule, the type of molecule (e.g. naphthenic, aromatic/resin, asphaltene) is first selected by randomly drawing a number and matching it to the distribution. Once the type of molecule is selected, the remainder of the molecule is specified as shown in Figure 22. The order of specification is to take advantage of the conditional probability. For instance, in order to specify the number of sidechains for a naphthenic molecule, it is first necessary to know how many rings are present. If fewer than five rings are selected, then the minimum number of sidechains will change in accordance with the conditional probability discussed in the previous section. Note that for some molecules, many attributes will be determined repeatedly. For instance, for an asphaltene molecule, after the number of unit sheets is determined, an aromatic core must be specified for each unit sheet.

These molecules are constructed by randomly sampling the pdf's. This is done by drawing a random number and matching it to the corresponding attribute value of the pdf's. Figure 23 shows the stochastic construction of a naphthenic molecule. Random sampling of these distributions is important statistically to get an unbiased sample. In order to ensure unbiased samples with a deterministic approach, it is necessary to look at all combinations. For a simple system, such as matching the expected mean of a coin flip, a deterministic approach where heads and tails are alternated will always give the expected mean. However, for the pdf's which represent the coal resids, there are millions of possible combinations. In such a complex system, a stochastic approach was able to simulate the many possibilities with some small subset.

Although a stochastic approach allows for the construction of an unbiased accurate molecular representation with many fewer iterations than a deterministic approach, an appropriate sample size must still be determined. Trauth found that for petroleum resid, a minimum of 5000 molecules must be sampled to obtain an accurate value of the analytical properties. Further increasing the sample size improves the precision of predicting these properties at the cost of extra computing time. Trauth settled on a compromise of 10,000 molecules to balance precision and time requirements. Because the coal resids are similar in complication to the petroleum resids, a sample size of 10,000 was used in the optimization of the pdf parameters.

Objective Function: The goal of using a statistical representation for a coal resid is to be able to generate a set of "computer" molecules which have properties which closely match the experimentally determined analytical properties. In order to do this some optimization technique must be chosen, as well as an objective function which must be minimized.

The optimization routine used for this work was the simulated annealing global optimization technique. A global optimization 
technique was important since the stochastic sampling of the representative pdf's led to a significant amount of noise. The simulated annealing technique essentially uses a simplex type of optimization. However, it also allows for various uphill movements which prevent the optimization from getting caught in a local minimum.

As previously stated, it is desired to optimize the pdf parameters so that the molecular representation of a complex feedstock matches closely to the experimentally determined analytical properties. Of course, there is some error associated with each of the experimentally determined properties. However, the analytical tests are well established and a good idea of the experimental standard deviations were known. The chi square statistic is a typical objective function used to optimize a representative feed to an actual feed:

$$
\begin{aligned}
& \chi^{2}=\left(\frac{M W_{\text {exp }}-H W W_{p z e d}}{0.1 * M W_{\text {exp }}}\right)^{2}+\left(\frac{H W t_{\text {exp }}-H W t_{p x e d}}{0.16}\right)^{2}+\left(\frac{C W t_{\text {exp }}-C W t_{p r e d}}{0.64}\right)^{2}+E q .5 \\
& \left(\frac{S W t_{\text {exp }}-S W t_{\text {prez }}}{0.10}\right)^{2}+\left(\frac{N W t_{\text {exp }}-N W t_{\text {pred }}}{0.11}\right)^{2}+\left(\frac{O W t_{\text {exp }}-O W t_{\text {pred }}}{1.5}\right)^{2}+ \\
& \sum_{i=1}^{n f r a c s}\left(\frac{1 \text { HNMR }_{\text {exp }}-1 \text { HNMR }_{\text {pred }}}{0.02}\right)^{2}+\sum_{i=1}^{\text {nfracs }}\left(\frac{S A R A_{\text {exp }}-S A R A_{\text {prea }}}{0.03}\right)^{2}
\end{aligned}
$$

The numerator is the square difference between the model prediction (i.e., computer molecules' properties) and the experimentally determined properties. The denominator is a weighting factor equal to the standard deviation of the experimentally determined value. This allows for tighter optimization on those properties for which there is a higher confidence in the measurement. This objective function can be modified easily for any particular analytical information on a feed. For instance, if other information such as boiling point distributions or FIMS data were available, more terms can be added onto the objective function.

The optimization technique works by selecting a set of paf parameters and building a large set of representative molecules. The properties of the molecular representation are compared to the experimentally determined properties using Eq. 5 and the paf parameters are iteratively varied until Eq. 5 is minimized.

Results and Discussion A statistical structure model has been designed for 15 coal resids which have a variety of coal origins and which have been subjected to various processing conditions. The experimentally determined analytical properties of these resids are shown in Tables 2-4. Tables 10-12 show the predicted analytical properties for a stochastic representation using the optimal paf parameters listed in Tables 13-18.

Table 2 shows that the coal resids all have unique elemental content. Hydrogen content varies from as low as 5.61 weight percent to as high as 8.55 weight percent. Similarly, the oxygen 
content and carbon content of these resids vary by as much as five weight percent. Sulfur and nitrogen content also varies greatly with differences between the maximum and minimum of approximately two weight percent sulfur and one weight percent nitrogen. These elemental compositions were obtain for the whole resid on an ash free basis.

As with the elemental composition of the feedstocks, Table 3 shows great variation in the molecular weights and the relative amounts of the SARA-P fractions. The highest average molecular weight (Resid E) was almost twice that of the lowest (Resid O). Resids $A-M$ each contain mostly aromatic/resins and asphaltenes with non-negligible saturates and preasphaltene fractions. Resids $N$ and $O$ are composed of mostly saturates and aromatics/resins with significant asphaltene and very little preasphaltene. No measurement of the molecular weight was possible for the insoluble organic matter. The content of insoluble organic matter was, however, quite significant for all feedstocks except for resids $N$ and 0 .

The proton distribution was measured for all fifteen resids as well and the results are shown in Table 4. As with the molecular weight measurement, each of these measurements was taken only on the soluble organic fraction. As with the other analytical properties, there are great differences in the proton distribution from resid to resid.

A glance at Table 10-12 show that the statistical representation was able to capture most of the analytical properties. Generally, molecular weights, hydrogen content, and condensed aromatic hydrogens were too high and carbon content and cyclic alpha content were too low. The other properties were generally quite close to the analytical data.

Figures 24-41 are the parity plots of the predicted versus the experimentally determined properties. The solid $45^{\circ}$ line is the parity line where the predicted and experimental properties coincide. The two dashed lines just above and below the parity lines are the standard errors of the measurements of the properties. Each of the fifteen resids is marked on each plot with the letter that represents the resid. Any measurement between the two confidence lines is accepted as matching the experimental data. Predictions outside of the confidence limits are considered to be statistically different from the measured property.

One of the most obvious discrepancies between the experimental data and the predicted properties was the hydrogen content. Figure 24 shows a plot of the experimental versus the predicted hydrogen weight percent. For each resid, the hydrogen is predicted to be higher than the upper confidence bound. The main reason hypothesized for this discrepancy is the fact that the elemental composition was obtained for the whole resid, whereas only the THF-soluble fractions were constructed in this model. The THF-soluble portion was chosen because no measurement of average molecular weight or proton distributions were available for the insoluble organic compounds. Also the insoluble organic compounds are considered to be unconvertible in the reaction 
model. This supposition is supported by the reactions discussed in the previous sections. As one goes from the saturates fractions to the aromatics/resins to the asphaltenes to the preasphaltenes, hydrogen content decreases. By extrapolating to the THF-insoluble fraction, it makes sense to assume the hydrogen content continues to decrease. Therefore, since a large portion of organic material (10-15\%) is insoluble and has a lower hydrogen content than the soluble fractions which are constructed, a prediction of too much hydrogen makes sense. The fact that resids $O$ and $N$ which have very little organic insolubles are predicted more closely also supports the hypothesis that not modeling the insoluble organics significantly affects the hydrogen prediction.

Analogous to the hydrogen content is the carbon content which is underpredicted for each resid as shown in Figure 25. Again, the fact that the insoluble organics which have low hydrogen and high carbon content are not modeled can be used to explain these discrepancies. Note that for the carbon, however, a few of the resids are predicted to within the confidence limits. This is because there is more uncertainty in measuring the carbon content than in measuring the hydrogen content.

Figure 26-28 show the content of heteroatoms in the resids. The content of sulfur, nitrogen and oxygen are well within the confidence limits for each resid. The sulfur and the nitrogen are well scattered about the parity line indicating true scatter. The oxygen content, however, is always slightly overpredicted, although the predictions do fall below the upper confidence limit in each case.

There are a couple of reasons for the overprediction of hydrogen and oxygen. A look at Figure 29, which shows the predicted versus the experimental phenolic oxygen content provides an explanation for some of the overpredictions. Figure 29 shows that the phenolic oxygen content is well captured by this model. Note from Table 2, however, that the total oxygen content of resids $B, C$, and $N$ are quite low. Tables 13 and 14 show the heteroatom content in ring and unit sheet links. A look at the values for fraction of aromatic cores containing oxygen rings and fraction of ether linkages shows that the values are quite negligible for these three resids. This means experimentally determined oxygen content was not high enough to account for the experimentally determined phenolic oxygen content. Since there is much more confidence (smaller error in measurement) in the phenolic oxygen content, the algorithm chose to match much more closely this measurement. A look at equation 4 shows this mathematically; the denominator for the phenolic oxygen term is much smaller than the denominator for the oxygen content. It is likely that the discrepancies in the prediction of oxygen content for resids $B, C$, and $N$ were due mainly to experimental error in the analyses. As mentioned previously, the oxygen content is determined by difference leading to a large degree of uncertainty. However, for compounds with large oxygen content, such an explanation is not likely to be valid. Even the largest phenolic oxygen content would cause at most approximately two weight percent oxygen content, so that for resids with oxygen content 
much higher than this, the phenolic oxygen can not force an overprediction.

One explanation for the overprediction of the oxygen can be obtained by first looking at the experimentally determined and predicted proton distribution in Tables 4 and 12. In particular, the predicted versus the experimentally determined amount of condensed aromatic carbons shown in Figure 36 is quite telling. Figure 36 shows that the condensed aromatic content is overpredicted for every resid, and generally above the upper confidence limit. This is because, to match the low hydrogen to carbon ratio which was determined for the whole resid, the amount of condensed aromatic compounds had to be increased. However, if a furan ring is substituted in the middle of a condensed aromatic core, the hydrogen to carbon ratio is lowered, and so is the amount of condensed aromatic protons. As with the phenolic oxygens, the limits on the hydrogen content, the carbon content, and the proton distribution are much tighter than the limits on the oxygen distribution. Since the experimental properties overpredicted the carbon content and underpredict the hydrogen content, this can partly be alleviated by increasing the amount of ring oxygen. Other heteroatom rings could also have similar effects; however, the tight confidence intervals on the sulfur and nitrogen content would for a higher objective function value.

similar to the hydrogen and carbon arguments, the overprediction of molecular weight for each of these resids can be explained by what was modeled. Figure 30 shows that the molecular weight is consistently overpredicted for each resid, although many are right at the upper confidence limit. Since only the soluble fraction is modeled, the elemental analysis forced an increase in the amount of condensed aromatics which must be constructed. However, the rest of the proton distribution must still be matched, so that other attribute values can not be decreased. The result is that the increase in aromatic rings causes a corresponding increase in the average molecular weights.

Figures 31-34 show the predicted versus the experimental SARA-P weight percent. For each of the aromatic/resin fractions, each of the asphaltene fractions, and each of the preasphaltene fractions, the predicted and experimental values match quite well. The prediction of each of these fractions falls within the confidence interval for each resid and there is no obvious trend for overprediction or underprediction. The saturates fractions for each of these resids are also fairly well predicted, although resids $N$ and $O$ fall above the upper confidence limit and the other resids appear to tend to be overpredicted.

The tendency to overpredict the saturates fraction can be explained in a couple of ways. The first explanation would be that in order to match the experimentally determined proton distribution, the saturates fraction was built too large in order to compensate for the artificially large number of condensed aromatics. The second explanation would be that the conditional probability which was designed to ensure that only a minimal number of light molecules would be built, artificially increased the size of the molecules. The boiling point correlation 
indicates that the average molecular weight of the saturates fraction of 250-300 would in fact boil below the initial boiling point for these resids. Therefore the conditional probability forces the average molecular weight, and thus the weight percent. of the saturates to be too high. This effect also contributes to the high predictions of molecular weight. Despite the tendency for overprediction of the saturates fraction, except for the lightest resids ( $N$ and $O$ ), the predictions are well within the confidence limits.

As mentioned previously, the amount of condensed aromatics is generally overpredicted, likely due to the fact that the elemental analysis and the NMR analysis were done on different fractions of the resid. Figure 35, shows that, unlike the condensed aromatic fractions, the monoaromatic is generally well captured. Only one resid (D) falls slightly outside of the confidence interval. The predictions are well scattered about the parity line, indicating that there is no bias in these predictions.

Similar to the monoaromatic protons, Figures 37,39 , and 41 show that the alkyl proton distributions are captured quite well. Figure 37 shows that the predictions of the alkyl alpha protons all fall well within the confidence limits with no obvious trends. Similarly, Figure 39 shows that the predictions for the alkyl beta protons are also quite good, with only one prediction which is slightly below the lower confidence interval. There appears to be a slight trend for underprediction of this fraction, but a few of the results are slight overpredictions. The prediction for the gamma protons is similar to the predictions for the beta protons. For the gamma protons, all of the predictions except for one (Resid C) fall within the confidence bounds. There appears to be a slight tendency for underprediction, but again, there are a few slight overpredictions.

The tendency to slightly underpredict the alkyl beta and gamma protors can be explained in a couple of ways. First, since the analytical data requires the overprediction of the condensed aromatic protons, this must be accompanied by the underprediction of some or all or the other proton types. Secondly, in order to not increase the molecular weight too much due to the elemental analysis, the increase can be alleviated somewhat by reducing the length of the sidechains.

The prediction of the cyclic alpha and cyclic beta protons are not quite as good as those of the alkyl protons. Figure 38 shows that the cyclic alpha protons are always underpredicted with about one half of the predictions falling below the lower confidence limit. At the same time, the cyclic beta protons tend to be slightly overpredicted, although only two resids exceed the upper bound. There are also several resids for which this fraction is underpredicted.

As with the alkyl beta and gamma protons, a part of the underprediction of cyclic alpha protons can be attributed to the necessary overprediction of the condensed aromatic protons. However, increasing the amount of cyclic alpha protons to match experimentally determined values can be problematic. An increase can be obtained by increasing the number of naphthenic rings. 
This would also detrimentally increase the average molecular weight and the fraction of cyclic beta protons. Perhaps the best way to increase this fraction would be to allow for greater control on the connectivity of the molecules. For instance, currently the aromatic cores of the aromatics/resins, asphaltenes, and preasphaltenes are constructed by determining the number of aromatic rings, the number of naphthenic rings, and the number and length of sidechains. The naphthenic rings are randomly substituted onto the aromatic core, and the sidechains are randomly distributed onto the peripheral aromatic and naphthenic sites. If the sidechains were preferentially distributed onto the cyclic beta or the aromatic sites, the fraction of condensed aromatic and cyclic beta protons would decrease, with a corresponding increase in the fraction of cyclic alpha protons. However, this could also potentially increase the fraction of alkyl alpha protons and decrease the fraction of alkyl beta protons, whereas these predictions are currently quite consistent with the experimentally determined data.

Summary of structure Model for the most part the predictions of the experimentally determined properties are good. The main discrepancies can generally be justified in light of what was constructed and what was measured. Furthermore, the amount of variability in some of the analytical measurements was quite significant.

One of the major sources of differences between the predicted and experimentally determined properties was the fact that the elemental analysis was performed on the whole resid. However, all of the other properties were determined for only the THF-soluble fraction and the molecules constructed were all representative of THF-soluble molecules. This could be mitigated by a couple of approaches. Perhaps the most accurate method would be to perform an elemental analysis on only the THF soluble molecules. Of course the drawback is the amount of time, effort, and capital the extra measurements would require. Another approach within the algorithm would be to increase the weighting factor (denominator) or Eq. 5. Mathematically, this translates into less strictly optimizing to the target value since there is more than just precision issues which contribute to the error. However, if this is greatly increased, this effectively just eliminates the hydrogen and carbon from the optimization as though no data were available.

Another discrepancy arose due to the large variability in the measurement of oxygen content. For three resids, the amount of oxygen measured clearly was too small in order to account for the amount of phenolic groups present. In order to improve on this it would be necessary to measure oxygen content by some other means which would reduce the variability of the data. This variability may also have some serious implications for the reaction model, where the removal of ring and ether oxygen are major pathways for conversion to lighter material.

Finally, the identification of proton types can only be made 
with great difficulty. The precision of these measurements is usually within 2\%; however, the accuracy of the measurements may be slightly worse due to overlap of peaks. The NMR spectra is divided into abutting regions, with each region associated with a proton type. However, since these peaks are adjoined, there can clearly be some overlap. If this overlap differs from resid to resid, the accuracy can also vary from resid to resid.

Despite these issues, most of the analytical properties were well represent within experimental confidence limits. Data for which there was high precision such as sulfur content, nitrogen content, and phenolic oxygens were predicted to within confidence limits for all 15 resids. Also, nearly every SARA-P weight fraction, the monoaromatic proton fraction, and the alkyl proton fractions were predicted within the confidence bounds. With a few modifications to the analytical procedures, with perhaps some modifications to the construction algorithm, many or all of the other properties should also be well predicted.

Backgrouna for Reaction Model with a statistical representation for coal resids in hand, it is cogent to consider how to model the hydroprocessing reactions accurately and efficiently. This requires an accurate reaction network to be determined and appropriate rate constants as well. The efficiency requirement means that the accuracy must also be balanced with the complexity in order to minimize CPU demand.

The traditional approach to such systems is to model using a lumped kinetics approach. However, as mentioned previously, the lack of chemically significant lumps causes models to use rate constants which are feed specific and time dependent. These problems translate into models which can not be used as predictive tools for other feedstocks and which may only be valid for a given feedstock for specific reaction times. On the other hand, lumped kinetics schemes do allow for the compact representation of complex reaction networks which are solvable quickly.

In order to address the issue of lack of chemical significance for reaction models of complex mixtures, Trauth developed a reaction model for petroleum resid using a Monte Carlo reaction scheme (23). In this model, each possible reactive bond of a molecule is assigned a pseudo-first order rate constant and the probability that any bond reacts is proportional to its rate constant. As with Monte carlo construction of a complex feedstock, a random number is drawn to select which reaction occurs. Another random number is also selected which determines the time which is required for the reaction to occur. This time step is inversely proportional to the sum of the rate constants for every possible reaction. Although the reaction model was able to accurately predict conversions and product spectra, the large number of time steps required to model the thermal reaction for even a few minutes requires hours of CPU demand.

Even though the Monte Carlo petroleum resid pyrolysis model requires a large amount of CPU time to solve, the large number of species make deterministic approaches nearly impossible due to 
memory constraints. For a deterministic model, a differential material balance is written for each reactant and product species and the concentrations can be solved for any desired reaction time using an ordinary differential equation. (ODE) solver. The advantage of a deterministic approach would be the minimal amount of CPU time required for solution. However, the large number of species (thousands of reactant and product species), makes the solution of such a problem nearly impossible due to memory requirements.

A compromise which takes advantage of the time savings offered by a deterministic approach and the ability to solve of a Monte Carlo approach was proposed by Campbell (24). This model reacted not the molecules themselves, but the structural attributes of the model. This simplification is based on the fact that often the detailed structure of a molecule will only slightly affect the reaction of one of its structural attributes. For instance, the reactivity of an alkyl sidechain attached to an anthracene core would likely not be greatly affected by the presence of other sidechains. The complexity of the feedstock is due to the large number of combinations of structural attributes. However, since only the structural attributes themselves are now considered apart from their combinations, the number of reactive species needed for a deterministic model is greatly reduced. Campbell showed that a reaction network developed for this approach was solvable quickly. (approximately one CPU minute) with predictive capabilities essentially equal to that of the Monte Carlo approach.

Similar in complexity to the pyrolysis of petroleum resid, a structural attribute reaction model has been developed for the hydroprocessing of coal resid. The following sections will discuss in detail the identification of reactive attributes for the reaction model, optimization of the rate constants for a predictive model, and model predictions of the developed model.

Reactive Attributes: The attributes which are used to construct the coal resid molecules were discussed in the section on statistical representations of complex feedstocks. The identification of reactive attributes are similar, but slightly different. In addition to account for the structural attributes which are used to construct a molecular representation, it is necessary to account for conditional probability and differences in reactivity.

As with petroleum resid, one of the important structural features which accounts for the conversion of coal resid to lighter products is the alkyl sidechain. Although the alkyl sidechains are typically much shorter for a coal. resid than for a petroleum resid, the fraction of alkyl alpha, alkyl beta, and alkyl gamma distribution indicate that there must still be a significant number of medium length alkyl sidechains. The optimal pdf parameters for the alkyl sidechain distributions determined for the 15 coal resids presented in Tables 13-16 were able to capture the alkyl proton distributions quite well. These distribution indicated that typically about $10 \%$ of the alkyl 
sidechains present were greater in length than 4 carbons with as much as $35 \%$ having greater than length 4. Alkyl sidechains of this length are still somewhat thermally reactive, and all alkyl sidechains are considered reactive under hydroprocessing conditions.

For this model the alkyl sidechains were differentiated between compound classes and alkyl sidechains beyond length 15 were not considered (although for the most part this caused very little or no adjustment to the distributions). Therefore there were four compound classes (naphthenics, aromatics/resins, asphaltenes, and preasphaltenes) which contained alkyl sidechains of up to length 15 contributing to 60 unique molecular attributes for the reaction model.

In addition to the alkyl sidechains, a small amount (10\%) of the saturates fraction was considered to be paraffinic. The paraffin distribution was considered to be the same for all resids since the total fraction of paraffins was quite small and could not be accurately differentiated between feedstocks. Additional paraffins are produced by the cleavage of alkyl sidechains from the other compound classes and from cleavage of paraffins. Although paraffins react to form lighter paraffins, though, this will have only a slight affect on the conversion since all of the paraffins boil lower than $850^{\circ} \mathrm{F}$. The incorporation of hydrogen for paraffin cracking will cause a slight increase in the conversion, however.

The initial paraffin fraction of these feeds were all between length 20 and 30 . The length of paraffins from the alkyl sidechains were from length 1 to 15 . Therefore paraffins of length 1 to 30 were considered for this model contributing for another 30 molecular attributes for the reaction model.

The most important conversion pathways for the coal resid will be the removal of heteroatoms and methylene bridges. Removal of oxygen, sulfur, and nitrogen from ring structures and the removal of oxygen and sulfur from bridge structures are key to reducing the molecular weights of the feedstocks. Methyl and biphenyl types of intersheet linkages are also allowed to react.

Heteroatom removal from ring structures is allowed to vary based on the total number of rings in the unit sheet. Larger ring structures were considered to have less access to catalytic sites so that there is a decrease in reaction rate with an increase in ring size. The compound class of the molecule is also differentiated so that it is possible to have different heteroatom removal rates between resins, asphaltenes, and preasphaltenes. since there are three different types of heteroatoms, three compound classes which contain heteroatom ring structures, and a possibility of from one to six rings per unit sheet, this contributes another 54 unique molecular attributes which must be considered in the reaction model.

As with heteroatom rings, internal naphthenic structures are also allowed to react. However, only three ring aromatic structures and higher are allowed to have internal naphthenic rings. The conversion of these is also allowed to vary according to the size of ring structure and the type of molecule. Since 
from three to six ring structures can have internal naphthenics and there are three compound classes which have internal naphthenics, an additional 12 molecular attributes are considered.

Similar to the heteroatoms in ring structures, the reaction of intersheet linkages were allowed to vary somewhat based on the size of the molecule. Again, larger structures were considered to have less access to catalytic reaction sites so that some differentiation must be made between intersheet linkages. The differences for these molecules were based on compound class since typically resins/aromatics are smaller than asphaltenes which are in turn smaller than preasphaltenes. In addition to this generalization, a distinction within a compound class was made according to the number of unit sheets in a molecule. Since there are four types of intersheet linkages to consider and from two to four unit sheet compounds in the resin/aromatics class this contributes another 12 unique molecular attributes. Similarly there are 20 unique types of intersheet linkages from the asphaltene fraction and 28 unique types of intersheet linkages from the preasphaltene fractions.

In addition to the ring structures and intersheet linkages present initially, the reaction causes new types of structures to be formed. Some of these structures are actually not new structures, but are considered separately in order to preserve the initial conditional probability. For instance, consider the removal of an ether oxygen from between two aromatic unit sheets of an asphaltene molecule. Instead of trying to recalculate the number of unit sheets distribution for the asphaltene fraction, a new intersheet link with no bond is considered. This means that when a molecule is constructed after reaction has occurred, it is possible to build a molecule consisting of several distinct fragments. Each of these fragments is then considered to be a molecule and classified either as resid $\left(850^{\circ} \mathrm{F}+\right)$ or not resid.

This type of accounting leads to several new attributes. These new attributes include biphenyl bridge rings, methyl bridge rings, no bridge rings from heteroatoms and from internal naphthenics, and no bridge links. A biphenyl bridge ring is a ring structure from which a heteroatom has been removed. A methyl bridge ring is a ring structure with an internal naphthenic from which a methyl group has been removed. The bridge ring structures can react as do the initial intersheet links to form no-bond rings. Similarly reacted intersheet linkages are considered to be no-bond links. These structures add an additional 69 unique structural species needed for the reaction model.

The reaction of sidechains and removal of heteroatoms also produce a few other species. Reaction of alkyl sidechains at the ring will leave sidechains of zero length (rather ' than recalculating the distribution of number of sidechains). Since naphthenics, aromatics/resins, asphaltenes, and preasphaltenes all have sidechain structures which can react, this leads to four more unique species. Similarly, heteroatom removal of oxygen, sulfur and nitrogen will lead to the formation of water, hydrogen disulfide, and ammonia, respectively, for three more unique species. 
By identifying these structural attributes, the number of species which need to be tracked in a reaction model has been reduced from several thousand to only 292. A model this size is easily solvable with only a minimal amount of memory. As with the petroleum resid attribute reaction model, the solution for such a model only requires approximately one CPU minute.

Reactions: In the previous section, the reactive attributes of the molecules were identified. However, a reaction model which considers all interconversions between these attributes can still be quite large. Therefore, a few more simplifying assumptions which are designed to take advantage of the statistical nature of the representation are presented here.

In principle, a paraffin can react anywhere in the chain. However, the paraffin distribution is at no point measured, and all paraffins are lighter than $850^{\circ} \mathrm{F}$, so that they are considered to be converted resid regardless of size. In order to minimize the number of possible reactions, all paraffins were considered to be reactive only in the middle of the chain. Since a boiling distribution of the products is not measured, but only the conversion to non-resid material, this approximation will at most only minimally affect the reaction model.

As with paraffins, alkyl sidechains can react anywhere along the chain. However, reaction at the ring, alpha to the ring, and beta to the ring are affected by the electronic structure of the ring. Therefore, these three reaction types are considered for each type of alkyl sidechain. Sidechain reactions beyond the third carbon should all be chemically similar, so that no differentiation is necessary. In order to simplify the reaction network, all of these reactions are lumped into cracking at the middle of the sidechain, or at the third bond from the ring structure, depending on the length of the sidechain. This approximation should affect the reaction very minimally since most of the sidechains have only one or two carbons, and since the reactions alpha and beta to the ring are favored.

The definition of the heteroatom attributes in the previous section, already greatly simplify the network. Therefore, no further approximation were necessary for reactions other than those of the paraffins and alkyl sidechains. The entire network consists of 389 possible reactions for the 292 reactive species.

Concentrations: In addition to knowing what attributes will be used in modeling the hydroconversion of coal resid, it is necessary to calculate the concentration of these attributes. since only pseudo first order rate constants are used in this reaction model, only the relative concentration of species need to be calculated. The conversion of the pdf's to these relative concentrations is straightforward.

The concentration of the paraffins is the easiest of the concentrations needed for the reaction model. The saturates mole fraction is known directly from the analytical data, and $10 \%$ of this saturates fraction is assumed to be paraffinic. The pdf for paraffin length gives the relative fraction of paraffins from 
length 20 to 30 . Knowing the paraffin mole fraction and the relative fractions of different paraffin lengths, the concentration of paraffins of length $i$ can be calculated from Eq. 6.

(concentration of paraffins of length $i$ ) $=$

(paraffin mole fraction) $X($ probability of length $i)$

Eq. 6

The concentrations of alkyl sidechains are also quite straightforward, although slightly more complex than for the paraffins. For each of the compound classes, the concentration of alkyl sidechains of length $j$ can be determined from the following equation:

$$
\begin{array}{ll}
(\text { concentration of alkyl sidechains of length } j)= & \\
(\text { compound class mole fraction }) X & \text { Eq. } 7 \\
(\text { average number of sidechains }) X(\text { probability of length } j) &
\end{array}
$$

For naphthenic the average number of sidechains can be obtained directly from the number of sidechains distributions using the following equation:

$$
\begin{aligned}
& \text { (average number of sidechains per molecule })= \\
& \sum(\text { number of sidechains }) X(\text { probability of number of sidechains })^{\text {Eq. } 8}
\end{aligned}
$$

The average number of sidechains per molecule for the resins, asphaltenes, and preasphaltenes are slightly more complex since there may be several unit sheets per molecule. Eq. 9 shows the calculation protocol for the average number of sidechains per molecule for these fractions. 


$$
\begin{aligned}
& \text { (average number of sidechains per molecule })= \\
& \sum(\text { number of sidechains on a unit sheet }) X \\
& (\text { average number of unit sheets }) X \\
& \text { (probability of number of sidechains) }
\end{aligned}
$$

Eq. 9

The average number of unit sheets for a molecule can be calculated by equation 10:

$$
\begin{array}{ll}
\text { (average number of unit sheets })= & \\
\sum(\text { number of unit sheets }) X & \text { Eq. } 10 \\
(\text { probability of number of unit sheets }) &
\end{array}
$$

The concentrations of heteroatomic cores, heteroatoms intersheet linkages and aromatic cores with internal naphthenics can also be easily calculated in an similar manner. These concentrations give the initial conditions for the reaction model which will allow for a solution of the reaction network with appropriate rate constants.

Rate Constants: In order to solve any reaction model, it is necessary to have values for the rate constants. However, the measurement of rate constants can be difficult, especially since the molecules present in a coal resid are not readily available for reaction studies. On the other hand, the removal of ring oxygen from one species to the next should proceed via similar routes, and thus have similar rate constants.

Trauth used the idea of reaction families for Monte carlo modeling of resid pyrolysis (23). By relating the rate constants of all alkyl aromatic sidechains to a model compound, it is possible to represent the pyrolysis of petroleum resid with only a few rate constants. Nigam developed quantitative structure reactivity relationships (QSRR's) to mathematically define rate constants referenced to a model compound (25). Campbell extended this idea to a deterministic attribute reaction model for resid pyrolysis with no loss of accuracy (24).

A similar approach has been developed for the hydroprocessing modeling of coal resid. The reaction families identified were: naphthenic sidechain cracking, aromatic sidechain cracking, paraffin cracking, ring oxygen removal, ring sulfur removal, ring nitrogen removal, internal naphthenics cracking, ether oxygen 
removal, sulfur bridge removal, methylene bridge removal, and biphenyl bridge removal. For this study, however, no model compound studies were available for the development of structurereactivity relationships. For this reason, the rate constants had to be optimized directly from the product data. The functional forms of the QSRR's are listed in Table 19 and the optimized parameter values are listed in Table 20 .

Regeneration of the Attribute PDF's: The attribute PDF's can be easily regenerated. In each case, the total concentration of an attribute type (e.g. asphaltene alkyl sidechains) can be calculated by summing the concentrations from the reaction model. The probability of that an asphaltene alkyl sidechain has a particular value is calculated by simply dividing the concentration of alkyl sidechains with that value by the total asphaltene alkyl sidechain calculation.

For this model, the attributes were considered in such a way that only pdf's were directly affected. This means that only the attributes involved in the reaction model need to have regenerated pdf's. For instance, the removal of ether bridges does not affect the number of unit sheets distributions. Instead, a new possibility that no bridge will connect the unit sheets of a molecule is considered. This means that when a set of molecules is regenerated, an aromatic/resin, asphaltene, or preasphaltene molecule can actually consist of several distinct fragments. Alternatively, the number of unit sheets pdf could be shifted, although this would require more difficult statistical calculations.

Product Construction and Boiling Point correlation: Once the pdf's have been regenerated, a sample set of molecules can be generated using the construction algorithm discussed earlier. Since a representative set of molecules can be generated, it is possible to compare elemental compositions, proton distribution, compound class ratios, and boiling point distributions with experimental data. For this case, however, only the conversion of resid was calculated and used for the optimization of rate constants.

Since the conversion of resid is based on the amount of low boiling materials produced $\left(<850^{\circ} \mathrm{F}\right)$, it is important to have a boiling point correlation which can accurately predict the boiling point of the product molecules. Unfortunately, there are very few literature values available for heavy molecules typical of coal liquids which boil in this range. Trauth developed a boiling point correlation for hydrocarbons for petroleum resid molecules which correlated number of aromatic rings, number of naphthenic rings, and number of sidechain carbons to the boiling point of a compound (23). That work also included corrections for sulfur species.

Using the correlations developed by Trauth as a basis, a correlation for coal resid molecules was developed. Essentially the same as Trauth's hydrocarbon correlation, corrections for nitrogen rings, oxygen rings, phenolic oxygen, and intersheet 
links were included. The equations for these correlations are shown in Table 21 and the prediction of model compounds is shown in Table 22. For the most part the correlation can predict the experimentally determined boiling points of the model compounds to within $10^{\circ} \mathrm{C}$.

Note that the correlations developed for typical coal resid molecules do not take into account the affects of structural isomers. For the most part such differences can be considered as negligible; however, small structural differences not typically accounted for in the construction algorithm can make large differences in the boiling point of a species. For instance, there is nearly a $20^{\circ} \mathrm{C}$ difference in boiling point between 2-ethyl pyridine and 4-ethyl pyridine. Such differences are not accounted for in the construction algorithm because of the extra memory and running time such detailed accounting schemes would require.

Model predictions and Discussion The model predictions for conversion are shown in Table 23. The conversion of five of the resids studied were within one experimental standard deviation (4 wt. $\%)$, and the predicted conversion of four other resids were within two experimental standard deviations. However, the predicted conversion of six resids were off by more than two experimental standard deviations, indicating some lack of fit for the model. Resids $B, D, E, H$, and $I$ were used for the optimization of rate constants.

There are a variety of reasons for the lack of highly accurate predictions. However, two reasons seem most likely: the inability to determine oxygen concentration with high precision and the large amount of light boiling material constructed, especially for resids $\mathrm{N}$ and $\mathrm{O}$.

Figure 42 shows the difference between the predicted and the experimental conversion versus the experimentally determined oxygen content. There appears to be a definite trend for higher conversion predictions with increased oxygen content. The four resids with the highest oxygen content all were overpredicted by more than an experimental standard deviation. Furthermore, four of the six resids with the lowest oxygen contents were underpredicted by more than experimental precision.

Similarly, Figure 43 shows the difference between the predicted and the experimental conversion versus the amount of low boiling materials $\left(<850^{\circ} \mathrm{F}\right)$. In this case, the 6 resids with the highest amount of initial low boilers constructed were overpredicted, while most of the resids for which the conversion was underpredicted contained only a small amount of low boiling molecules initially.

When considering both Figures 42 and 43 together, all of the resids for which conversion is overpredicted had either a high amount of oxygen or a high concentration of low boiling materials from the construction routine. In fact the four resids with the highest oxygen content and the four resids with the highest amount of low boilers were the eight resids for which conversion was 
overpredicted.

The fact that high oxygen contents correlate with the overprediction of conversion makes sense considering that oxygen removal is a primary path for conversion to lighter materials. Since the measurement of oxygen content is reproducible only to within 1.5 wt. \% of the total feed, large variations in apparent conversions are expected. Furthermore, since a very precise independent measurement is made for the phenolic oxygen content, nearly all of the error in the measurement of oxygen content is in the ether and ring oxygen structures which are the structures involved in oxygen removal reactions.

The presence of large amounts of low boiling molecules also causes the overprediction of resid hydroconversion. However, the analytical data in many cases requires that a large number of species must boil below $850 \%$. For instance, many of the saturate fractions for the resids investigated had an average molecular weight of 300 amu or less. The boiling point correlations developed for the coal resid molecules, however, make the possibility of building a molecule of molecular weight 300 and a boiling point greater than $850^{\circ} \mathrm{F}$ nearly impossible. Therefore, the analytical measurements of molecular weight indicate that nearly half of the saturates fractions for some of the resids must boil below $850^{\circ} \mathrm{F}$. Similarly, many of the aromatics fractions also must contain a large number of species boiling below $850^{\circ} \mathrm{F}$.

The measurement of molecular weights by vapor pressure osmometry is generally accurate to within 5\% of the average molecular weight. However, the difference between 300 and 315 could have a profound difference in the amount of low boiling molecules constructed. The fact that an experimentally determined molecular weight may be too low causes a few difficulties. First, it allows for the construction of a large amount of material which boils below $850^{\circ} \mathrm{F}$. This can be further complicated by the construction of a large number of molecules which boil just above $850^{\circ} \mathrm{F}$. If such molecules undergo any reaction, it is likely they will be converted to low boiling molecules.

Although there is some error associated with the determination of molecular weight, a simulated distillation performed on several of the saturates and aromatics fractions also indicated the presence of a large amount of light boiling materials. The simulated distillation indicated as much as 40 wt. $\%$ of these fractions boiled below $850^{\circ} \mathrm{F}$, or as little as 5 wt. $\%$. of course, the simulated distillation is calibrated with normal paraffins, so the results must be considered with caution.

The preparation of the resid sample was done under vacuum so that the boiling point cut off should be $850^{\circ} \mathrm{F}$. However, since the distillation can not be done at atmospheric conditions since thermal degradation is likely to set in for many of the molecules present, an extrapolation to atmospheric conditions is necessary. Therefore, these results should also be considered with caution. In addition to these many experimental considerations, considerably more uncertainty in boiling point can be introduced by the boiling point correlations discussed in the previous section. As noted there, for the most part the model compounds 
were predicted to within $10^{\circ} \mathrm{C}$. However, certain structural isomers had even greater uncertainty which could not be accounted for using the present construction algorithm. Furthermore, the correlations were optimized for molecules which generally were much smaller than the molecules typical of a coal resid since such molecules are not readily isolated and characterized.

Whether there is a significant portion of light boiling material in some of these resids, or if the analytical data is in error, such errors may cause difficulty in accurately predicting conversion. Such errors can be further compounded by boiling point correlation which are being used beyond the range of molecules used to develop the correlations.

Since it was hypothesized that the uncertainty in the oxygen content and the amount of low boiling molecules present greatly affected the conversion prediction, a correlation to account for these factors was developed. The difference between the predicted and experimentally determined conversions was correlated to the oxygen content and the initial content of low boiling molecules. For both of these properties, a quadratic correlation was developed using linear least squares regression. The correlation equation where conversion is in wt. \% is shown in Eq. 11 .

$$
\begin{aligned}
\text { Conversion } & =\text { Conversion }+2.08+3.84 *(0 \text { wt. } \%) & \\
& -1.20 *(0 \text { wt. } \%)^{2} & \\
& +0.829 *(\text { wt. } \% \text { low boilers }) & \\
& -0.168 * \text { (wt. \% low boilers) } & \text { Eq. } 11
\end{aligned}
$$

The predictions from the model with the correlation are shown in Table 24. Now, all conversion prediction are within two experimental standard deviations. Furthermore, all but four of the resids are predicted to within one experimental standard deviation.

\section{Acknowledgements}

The support of various portions of this work by the Department of Energy and CONSOL Inc. under subcontract DE-AC2294 PC9305 is acknowledged. The guidance and assistance of $\mathrm{Dr}$ S.D.Brandes, R.A. Winschel and Dr F.P.Burke in providing samples, analytical data and other assistance were also major factors in the progress of this project.

\section{References}

1) Grint A, Jackson,W.R., Larkins,F.P., Louey,M.B., Marshall,M, Trewhella, M.J. and Watkins, I.D. Fuel 73, 381 (1994)

2) Whitehurst, D.D., Mitchell, T.O., Farcasiu, M. "Coal Iiquefaction, the Chemistry and Technology of Thermal Processes" Academic Press: New York 1980 
3) Huang, He, Calkins, William H, and Klein, Michael $T$ "A Novel Laboratory Scale Short Contact Time Batch Reactor system for Studying Fuel Processes. 1.Apparatus and Preliminary Experiments" Energy and Euels 1994, 8, $1304-1309$

4) Huang, He, Fake, Dean M., Calkins, William H. and

Klein, Michael T. "A Novel Laboratory Scale Reactor system for Studying Fuel Processes from the Initial Stages. 2. Detailed Energy and Momentum Balances" Energy and Fuels, 1994, 8. 1310 1315

5) H.Huang, Keyu Wang, M.T.Klein and W.H.Calkins "A Novel Method for the Determination of the Boiling Range of Liquid Fuels by Thermogravimetric Analysis" ACS Fuel Chem Div. Preprints 40 (3) 485-491.

6) ASTM Standard Annual Book of ASTM Standards; American Society of Testing and Materials: Philadelphia, PA 1983 Vol.05.03, pp 442-455

7) ibid Vol $05.02 \mathrm{pp} 791-799$

8) Schweighardt, F.K., et al., Heteroatom Species in Coal Liquefaction Products, in Organic Chemistry of Coal, J.W. Larsen, Editor. 1978, American Chemical Society: Washington, D. C. p. 240257.

9) Kelemen, S.R., et al., Quantification of Nitrogen Forms in Argonne Premium Coals. Preprints, ACS Division of Fuel Chemistry, 1993. $38(2)=\mathrm{p} .384-392$.

10) Farcasiu, M., Fractionation and Structural Characterization of . Coal Liquids. Fuel, 1977. 56(1): p. 9-14.

11) Anderson, L.L., et al., Characteristics of Coal-Derived Liquids from Different. Processes: Relationships to Coal Structure, in New Approaches in Coal.Chemistry, B.D. Blaustein, B.C. Bockrath, and S. Friedman, Editors. 1981, American Chemical Society: Washington, D. C. p. 223-242.

12) Shultz, H.D. and J.E. Graham, Characterization of Coal Asphaltenes, in Coal Liquefaction Products, H.D. Shultz, Editor. 1983, John Wiley \& Sons: New York. p. 168-185.

13) Snape, C.E., W.R. Ladner, and K.D. Bartle, structural Characterization of Coal Extracts by NMR, in Coal Liquefaction Products, H.D. Shultz, Editor. 1983, John Wiley \& Sons: Washington, D. C. p. 70-84.

14) Neurock, M., et al., Monte Carlo Simulation of Complex Reaction Systems: Molecular Structure and Reactivity in Modelling Heavy Oils. Chemical Engineering Science, 1990.45(8): p. 20832088 . 
15) Trauth, D.M., et aI., Representation of the Molecular Structure of Petroleum Resid through Characterization and Monte Carlo Modeling. Energy and Fuels, 1994. 8 (3): p. 576-580.

16) Flory, P.J., Molecular Size Distribution in Linear Condensation Polymers. J. Am. Chem. Soc., 1936. 58: p. 1877.

17) Libanati, C., Monte Carlo Simulation of Complex Reactive. Macromolecular Systems, in Chemical Engineering. 1992, University of Delaware.

18) Whitson, C.H., Characterizing Hydrocarbon Plus Fractions. Soc. Pet. Eng. J., 1983: p. 683 .

19) Shibata, S.K., S.I. Sandler, and R.A. Behrens, Phase Equilibrium Calculations for Continuous and Semicontinuous Mixtures. Chemical Engineering Science, 1987. 42 (8): p. 1977-1988.

20) Pederson, D.S., A.L. Blilie, and K.K. Mesingset, PVT Calculations of Petroleum Reservoir Fluids Using Measured and Estimated Compositional Data for the Plus Fraction. Ind. Eng. Chem Res., 1992. 31: p. 1378.

21) Boduszynski, M.M., Composition of Heavy Petroleums. 1. Molecular Weight, Hydrogen Deficiency, and Heteroatom Concentration as a Function of Atmospheric Equivalent Boiling Point up to $1400^{\circ} \mathrm{F}\left(760^{\circ} \mathrm{C}\right)$. Energy and Fuels, 1987. 1: p. 2-11.

22) Darivakis, G.S., W.A. Peters, and J.B. Howard, Rationalization for the Molecular Weight Distribution of Coal Pyrolysis Liquids. AIChE J., 1990. $36(8)$ : p. 1189.

23) Trauth, D.M., Structure of Complex Mixtures through Characterization, Reaction, and Modeling, in Chemical Engineering. 1993, University of Delaware.

24) Campbell, D.M. and M.T. Klein, Reducing CPU Demand in the Molecular Modeling of Resid Upgrading. AIChE Preprints, 1995 (Houston).

25) Nigam, A. and M.T. Klein, A Mechanism-Oriented Lumping Strategy for Heavy Hydrocarbon Pyrolysis: Imposition of Quantitative Structure-Reactivity Relationships for Pure Components. Industrial and Engineering Chemistry pResearch, 1993. 32 : p. 1297-1303. 
Table I Selected properties of the resids

\begin{tabular}{|c|c|c|c|c|c|c|c|c|c|}
\hline Resid & Feed coal & Number & Stream* & Fa & VM wt\% & FCwt\% & Ash wt\% & Tpeak 0C & $\begin{array}{l}\text { Peak Height, wt\%/min. } \\
\text { (daf) }\end{array}$ \\
\hline $\begin{array}{l}\text { Resid L } \\
\text { Resid K } \\
\text { Resid H } \\
\text { Resid F } \\
\text { Resid E } \\
\text { Resid G } \\
\text { Resid I } \\
\text { Resid M } \\
\text { Resid D } \\
\text { Resid J } \\
\text { Resid B } \\
\text { Resid C } \\
\text { Resid A } \\
\text { Resid N } \\
\text { Resid O }\end{array}$ & \begin{tabular}{|} 
Wyodak-Anderson \\
Black Thunder \\
Wyodak-Anderson \\
Black Thunder \\
Wyodak-Anderson \\
Black Thunder . \\
Wyodak-Anderson \\
Black Thunder \\
Wyodak-Anderson \\
Black Thunder \\
Wyodak-Anderson \\
Black Thunder \\
Illinois \# 6 Burning \\
Star \# 2 \\
Illinois \# 6 Burning \\
Star \# 2 \\
Illinois \# 6 Burning \\
Star \# 3 \\
Pittsburgh Ireland \\
Pittsburgh Ireland \\
Pittsburgh Ireland \\
Wyodak-Anderson \\
Black Thunder. \\
Wyodak-Anderson \\
Black Thunder \\
Wyodak-Anderson \\
Black Thunder
\end{tabular} & $\begin{array}{l}\text { W4 } \\
\text { W5 } \\
\text { W6 } \\
\text { W10 } \\
\text { W1I } \\
\text { W12 } \\
\text { W7 } \\
\text { W8 } \\
\text { W9 } \\
\text { WI } \\
\text { W2 } \\
\text { W3 } \\
\text { W } \\
\text { HRI } \\
\text { HRI }\end{array}$ & 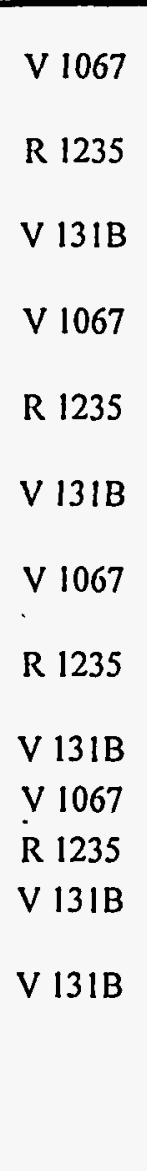 & $\begin{array}{r}24.6 \\
33.3 \\
24.3 \\
26 \\
25.9 \\
30.4 \\
29.4 \\
29.2 \\
31.6 \\
33.3 \\
31.5 \\
38.9 \\
20.6 \\
18.8\end{array}$ & $\begin{array}{c}53.6 \\
57.1 \\
55.2 \\
53.4 \\
55.7 \\
61.5 \\
59.9 \\
70.9 \\
57.6 \\
61.1 \\
61 \\
51.8 \\
90.6 \\
89.1\end{array}$ & $\begin{array}{c}46.4 \\
42.9 \\
44.8 \\
46.6 \\
44.3 \\
38.5 \\
40.3 \\
29.1 \\
42.4 \\
38.9 \\
39 \\
48.2 \\
6 \\
8.2\end{array}$ & $\begin{array}{c}17.2 \\
15.2 \\
17.5 \\
15.6 \\
15.9 \\
15.9 \\
13.7 \\
9.9 \\
10.2 \\
8.7 \\
8.5 \\
17 \\
0.4 \\
2.8\end{array}$ & $\begin{array}{l}464.8 \\
475.3 \\
461.5 \\
454.4 \\
462.2 \\
480.1 \\
481.8 \\
490.5 \\
490.1 \\
493.6 \\
490.2 \\
472.1 \\
451.5 \\
449.2\end{array}$ & 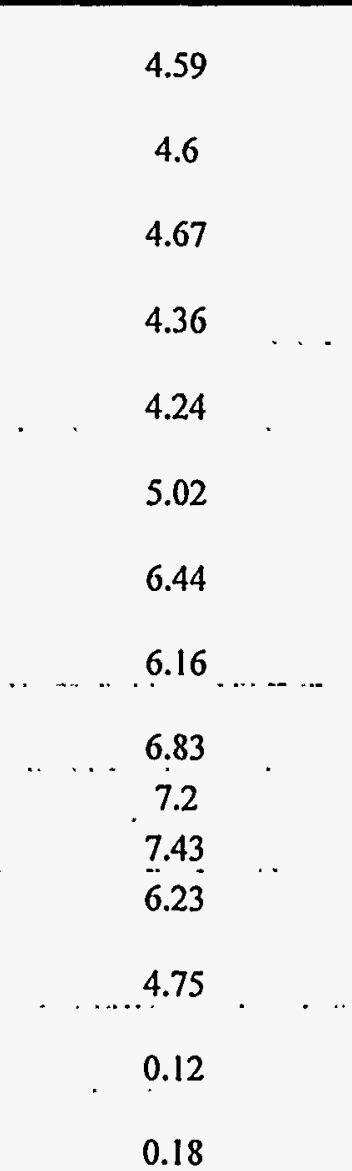 \\
\hline
\end{tabular}

V $1067=$ Interstage stream

R $1235=2$ nd stage product stream

$\mathrm{V} 131 \mathrm{~B}=$ Recycle stream

$\mathrm{W}=$ Wilsonville

$\mathrm{HRI}=$. Hydrocarbon Research Institute

Tpeak and Peak Height $=$ Peak temperature and Peak value of derivative curve of TGA 


\begin{tabular}{|c|r|r|r|r|r|}
\hline & Resid A & Resid B & Resid C & Resid D & Resid E \\
\hline $\begin{array}{c}\text { hydrogen } \\
\text { wt\% }\end{array}$ & 5.61 & 6.18 & 6.50 & 6.57 & 6.59 \\
\hline carbon wt\% & 88.30 & 90.00 & 90.92 & 88.39 & 85.34 \\
\hline sulfur wt\% & 1.74 & 1.50 & 1.24 & 1.05 & 1.74 \\
\hline $\begin{array}{c}\text { nitrogen } \\
\text { wt\% }\end{array}$ & 1.19 & 1.15 & 1.04 & 1.05 & 0.99 \\
\hline oxygen wt\% & 3.16 & 1.18 & 0.30 & 2.94 & 5.34 \\
\hline $\begin{array}{c}\text { phenolic OH } \\
\text { wt\% }\end{array}$ & 0.80 & 0.92 & 0.69 & 0.78 & 0.82 \\
\hline & & & & & \\
\hline $\begin{array}{c}\text { hydrogen } \\
\text { wt\% }\end{array}$ & 6.75 & 6.77 & 6.35 & 6.53 & 6.38 \\
\hline carbon wt\% & 86.03 & 85.84 & 87.43 & 88.14 & 90.10 \\
\hline sulfur wt\% & 1.94 & 1.73 & 1.53 & 1.54 & 1.49 \\
\hline $\begin{array}{c}\text { nitrogen } \\
\text { wt\% }\end{array}$ & 0.93 & 0.93 & 1.10 & 1.11 & 1.05 \\
\hline oxygen wt\% & 4.35 & 4.73 & 3.59 & 2.68 & 0.98 \\
\hline $\begin{array}{c}\text { phenolic OH } \\
\text { wt\% }\end{array}$ & 1.25 & 0.85 & 0.69 & 0.92 & 0.70 \\
\hline & & & & & \\
\hline & Resid K & Resid L & Resid M & Resid N & Resid O \\
\hline $\begin{array}{c}\text { hydrogen } \\
\text { wt\% }\end{array}$ & 5.89 & 6.25 & 6.59 & 8.55 & 8.36 \\
\hline carbon wt\% & 86.61 & 86.77 & 87.44 & 90.34 & 89.06 \\
\hline sulfur wt\% & 1.82 & 1.95 & 1.57 & 0.34 & 0.21 \\
\hline $\begin{array}{c}\text { nitrogen } \\
\text { wt\% }\end{array}$ & 1.09 & 1.10 & 1.19 & 0.66 & 0.31 \\
\hline oxygen wt\% & 4.59 & 3.93 & 3.21 & 0.10 & 2.05 \\
\hline $\begin{array}{c}\text { phenolic OH } \\
\text { wt\% }\end{array}$ & 0.95 & 0.69 & 0.88 & 0.50 & 0.22 \\
\hline
\end{tabular}

Table 2: Experimentally determined elemental weight percent of 15 coal resids. 


\begin{tabular}{|l|r|r|r|r|r|}
\hline & Resid A & Resid B & Resid C & Resid D & Resid E \\
\hline $\begin{array}{l}\text { Molecular Weight * } \\
\text { wt\% }\end{array}$ & 488 & 543 & 474 & 394 & 612 \\
\hline SARA wt\% & & & & & \\
\hline saturates wt\% & 2.2 & 2.3 & 2.7 & 6.3 & 6.9 \\
\hline resins wt\% & 49.6 & 49.1 & 59.5 & 56.0 & 49.4 \\
\hline asphaltenes wt\% & 41.0 & 33.5 & 27.7 & 28.8 & 32.8 \\
\hline preasphaltenes wt\% & 7.2 & 15.1 & 10.1 & 8.9 & 10.9 \\
\hline & & & & & \\
\hline $\begin{array}{l}\text { Molecular Weight * } \\
\text { wt\% }\end{array}$ & 453 & 543 & 515 & 478 & 521 \\
\hline SARA wt\% & & & & & \\
\hline saturates wt\% & 10.9 & 9.0 & 6.3 & 3.6 & 7.8 \\
\hline resins wt\% & 49.1 & 47.8 & 51.7 & 57.9 & 42.8 \\
\hline asphaltenes wt\% & 30.7 & 34.5 & 33.3 & 28.2 & 38.6 \\
\hline preasphaltenes wt\% & 9.3 & 8.7 & 8.7 & 10.3 & 10.8 \\
\hline & & & & & \\
\hline & Resid K & Resid L & Resid M & Resid N & Resid O \\
\hline Molecular Weight * \\
wt\%
\end{tabular}

Table 3: Experimentally determined molecular weights and compound class mole fractions of 15 coal resids.

* Molecular Weight determined by vapor phase asmomitry. 


\begin{tabular}{|c|c|c|c|c|c|}
\hline \multirow{2}{*}{$\begin{array}{r}\text { uncondensed arom } \\
\text { wt } \%\end{array}$} & Resid A & Resid B & Resid C & $\begin{array}{l}\text { Resid D } \\
\text { [1] }\end{array}$ & Resid E \\
\hline & 7.6 & 2.6 & 5.4 & 3.8 & 3.7 \\
\hline $\begin{array}{c}\text { condensed arom } \\
\text { wt } \%\end{array}$ & 31.3 & 30.7 & 26.1 & 25.4 & 22.3 \\
\hline alkyl alpha wt\% & 9.5 & 10.2 & 9.4 & 9.6 & 9.3 \\
\hline cyclic alpha wt\% & 18.8 & 20.9 & 18.9 & 19.7 & 19.2 \\
\hline alkyl beta wt\% & 11.9 & 13.4 & 14.6 & 16.8 & $\overline{20.9}$ \\
\hline cyclic beta wt\% & 12.9 & 13.8 & 14.8 & 15.3 & 14.6 \\
\hline gamma wt\% & 8.1 & 8.4 & 10.8 & 9.3 & 10.0 \\
\hline & & & & & \\
\hline & Resid F & Resid G & Resid $\mathrm{H}$ & Resid I & Resid J \\
\hline $\begin{array}{r}\text { uncondensed arom } \\
\text { wt\% }\end{array}$ & 3.9 & 3.7 & 3.8 & 4.5 & 3.8 \\
\hline $\begin{array}{c}\text { condensed arom } \\
\text { wt } \%\end{array}$ & 20.4 & 22.2 & 29.5 & 25.9 & 27 \\
\hline alkyl alpha wt\% & 9.0 & 9.4 & 4.5 & 9.6 & 9.6 \\
\hline cyclic alpha wt\% & 18.6 & 18.1 & 21.5 & 19.9 & 21.2 \\
\hline alkyl beta wt\% & 21.9 & 21.3 & 17.0 & 16.0 & 13.4 \\
\hline cyclic beta wt\% & 15.3 & 15.2 & 14.3 & 14.7 & 15.5 \\
\hline gamma wt\% & 10.8 & 10.1 & 9.3 & 9.3 & 8.7 \\
\hline & & & & & \\
\hline & Resid K & Resid L & Resid M & Resid N & Resid $\mathbf{O}$ \\
\hline $\begin{array}{r}\text { uncondensed } \\
\text { wt } \%\end{array}$ & 4.3 & 6.8 & 4.9 & 5.9 & 4.3 \\
\hline $\begin{array}{c}\text { condensed arom } \\
\text { wt } \%\end{array}$ & 20.3 & 27.2 & 24.5 & 14.7 & 14.5 \\
\hline alkyl alpha wt\% & 9.4 & 8.8 & 9.6 & 9.6 & 8.0 \\
\hline cyclic alpha wt\% & 17.2 & 18.3 & 21.1 & 16.3 & 14.5 \\
\hline alkyl beta wt\% & 21.2 & 16.6 & 15.6 & 24.2 & 30.0 \\
\hline cyclic beta wt\% & 15.3 & 13.6 & 15.2 & 16.1 & 15.1 \\
\hline gamma wt\% & 12.3 & 8.7 & 9.2 & 13.1 & 13.6 \\
\hline
\end{tabular}

Table 4: Experimentally determined proton distribution of 15 coal resids. 
Table 5 Conversion of thermal hydroprocessing of resid

\begin{tabular}{|c|c|c|c|c|c|c|c|c|}
\hline \multicolumn{3}{|c|}{ Resid } & \multicolumn{2}{|c|}{ Solid Residue } & \multicolumn{3}{|c|}{ Liquid Residue } & Conversion to $850 \mathrm{~F}-\mathrm{wt} \%$ \\
\hline Sampl & Name & Ash wt\% & Ash wt\% & TSF wt\% & Tetralin & RSF & $850 \mathrm{~F}+$ & \\
\hline Resid A & W258V-131B & 17.0 & 50.1 & 79.7 & 88.2 & 11.8 & 9.6 & 15.0 \\
\hline Resid B & W259R-1235 & 8.7 & 33.5 & 81.0 & 88.0 & 12.0 & 9.6 & 15.9 \\
\hline Resid C & $\mathrm{W} 259 \mathrm{~V}-131 \mathrm{~B}$ & 8.5 & 35.0 & 82.7 & 86.2 & 13.8 & 10.8 & 17.7 \\
\hline Resid D & W261V-131B & 9.9 & 45.8 & 87.1 & 87.9 & 12.1 & 9.7 & 17.1 \\
\hline Resid E & W262R-1235 & 15.6 & 43.5 & 76.0 & 88.4 & 11.6 & 8.6 & 19.6 \\
\hline Resid F & $\mathrm{W} 262 \mathrm{~V}-1067$ & 17.5 & 47.8 & 76.9 & 87.4 & 12.6 & 9.7 & 17.7 \\
\hline Resid G & $\mathrm{W} 262 \mathrm{~V}-131 \mathrm{~B}$ & 15.9 & 46.5 & 78.3 & 88.7 & ii.3 & 8.7 & 18.2 \\
\hline Resid H & $\mathrm{W} 260 \mathrm{~V}-131 \mathrm{~B}$ & 15.2 & 46.6 & 79.5 & 87.7 & 12.3 & 9.0 & 21.3 \\
\hline Resid I & W261V-1067 & 15.9 & 50.8 & 81.8 & 88.9 & ii.1 & 8.5 & 19.4 \\
\hline Resid j & W259V-1067 & 10.2 & 38.7 & 82.0 & 86.4 & 13.6 & 11.5 & 12.9 \\
\hline Resid K & W260R-1235 & 17.2 & 49.0 & $78 . \overline{4}$ & 86.9 & 13.1 & $\ddot{9} .8$ & 19.7 \\
\hline Resid L & $\mathrm{W} 260 \mathrm{~V}-1067$ & 19.1 & 51.3 & 77.6 & 89.2 & 10.8 & 8.3 & 17.8 \\
\hline Resid M & W261R-1235 & 13.7 & 45.6 & $81 . \mathrm{i}$ & 90.1 & 9.9 & 7.9 & 16.0 \\
\hline Resid N & HTI POC-01, O-43 & $0 . \dot{4}$ & 33.0 & 99.2 & 80.6 & 19.4 & 14.1 & 27.0 \\
\hline Resid O & HTI POC-02, O-43 & 4.i & 38.0 & 93.1 & .70 .6 & 29.4 & 22.4 & $\ldots$ \\
\hline \multicolumn{9}{|c|}{ Thermal: $420 \mathrm{C} ; 30 \mathrm{~min} ; 1500$ psig Hz } \\
\hline \multicolumn{9}{|c|}{ Catalytic: $420 \mathrm{C} ; 30 \mathrm{~min} ; 1500 \mathrm{psig} \mathrm{H} 2 ; 3 \mathrm{wt} \% \mathrm{Mo}$} \\
\hline \multicolumn{9}{|c|}{ Control: $25 \mathrm{C} ; 10 \mathrm{~min}$; $1500 \mathrm{psig} \mathrm{H} 2$} \\
\hline \multicolumn{9}{|c|}{ TSF: Tetralin Soluble Fraction of resid, wt\% (daf basis) } \\
\hline \multicolumn{9}{|c|}{ RSF: Resid Soluble Fraction in tetralin, wt\% } \\
\hline $850 \mathrm{~F}+$ : frac & tion of boiling above & $850 \mathrm{~F}$ & & & & & & \\
\hline
\end{tabular}


Table 6 Conversion of catalytic hydroprocessing of resid

\begin{tabular}{|c|c|c|c|c|c|c|c|c|}
\hline \multicolumn{3}{|c|}{ Resid } & \multicolumn{2}{|c|}{ Solid Residue } & \multicolumn{3}{|c|}{ Liquid Residue } & \multirow[t]{2}{*}{ Conversion wt\% } \\
\hline Sampl & Name & Ash wt\% & Ash wt\% & SF wt\% & Tetralin & |RSF in Tetralin & $850 \mathrm{~F}+$ & \\
\hline Resid A & W258V-131B & 17.0 & 51.5 & 80.7 & 82.5 & 17.5 & 9.9 & 35.0 \\
\hline Resid B & W259R-1235 & 8.7 & 40.0 & 85.6 & 79.8 & 20.2 & 11.2 & 38.1 \\
\hline Resid C & W259V-131B & 8.5 & 41.4 & 86.8 & 81.4 & 18.6 & 11.5 & 33.1 \\
\hline Resid D & W261V-131B & 9.9 & 54.9 & 91.0 & 77.9 & 22.1 & 14.1 & 32.9 \\
\hline Resid E & W262R-1235 & 15.6 & 44.2 & 76.6 & 80.6 & 19.4 & 11.3 & 32.1 \\
\hline Resid F & W262V-1067 & 17.5 & 49.4 & 78.3 & 79.6 & 20.4 & 10.7 & 37.4 \\
\hline Resid G & W262V-131B & 15.9 & 48.3 & 79.8 & 79.2 & 20.8 & 11.5 & 35.8 \\
\hline Resid H & W260V-131B & 15.2 & 50.9 & 82.7 & 75.6 & 24.4 & 11.3 & 44.6 \\
\hline Resid I & W261V-1067 & 15.9 & 56.6 & 85.5 & 76.2 & 23.8 & ii. 9 & 42.7 \\
\hline Resid J & W259V-1067 & 10.2 & 43.8 & 85.4 & 76.5 & 23.5 & 11.9 & 42.1 \\
\hline Resid K & W260R-1235 & 17.2 & 52.1 & 80.8 & 78.1 & 21.9 & 12.4 & 35.2 \\
\hline Resid L & W260V-1067 & 19.1 & 53.5 & $79 . \dot{5}$ & 79.1 & 20.9 & ii.7 & 35.0 \\
\hline Resid M & W261R-1235 & 13.7 & 53.7 & 86.3 & 80.2 & 19.8 & 11.7 & 35.3 \\
\hline Resid N & HTI POC-01, O-43 & 0.4 & 36.4 & 99.3. & 67.9 & 32.1 & 16.7 & 47.6 \\
\hline Resid O & HTI POC-02, O-43 & 4.1 & 48.3 & 95.4 & 70.2 & $\ldots . \quad 29.8$ & 19.1 & $\ldots \ldots \ldots$ \\
\hline \multicolumn{9}{|c|}{ Thermal: $420{ }^{\circ} \mathrm{C} ; 30 \mathrm{~min} ; 1500$ psig $\mathrm{H}_{2}$} \\
\hline \multicolumn{9}{|c|}{ Catalytic: $420{ }^{\circ} \mathrm{C} ; 30 \mathrm{~min} ; 1500 \mathrm{psig} \mathrm{H}_{2} ; 3 \mathrm{wt} \% \mathrm{Mo}$} \\
\hline \multicolumn{9}{|c|}{ Control: $25^{\circ} \mathrm{C} ; 10 \mathrm{~min} ; 1500 \mathrm{psig} \mathrm{H}_{2}$} \\
\hline \multicolumn{9}{|c|}{ TSF: Tetralin Soluble Fraction, wt\% (daf basis) } \\
\hline \multicolumn{8}{|c|}{ RSF: Resid Soluble Fraction in tetralin, wt\% } & \\
\hline
\end{tabular}




\section{Table 7 Elemental Analysis of Solid Resid Residues}

\begin{tabular}{|c|c|c|c|c|}
\hline $\begin{array}{l}\text { Sample } \\
\text { Sample No. }\end{array}$ & $\begin{array}{l}\text { Original } \\
\text { Clol-0 }\end{array}$ & $\begin{array}{l}\text { Cold Tetralin Washing } \\
\qquad \mathrm{Cl}_{61-1}\end{array}$ & $\begin{array}{l}\text { Tetralin Reflux } \\
\text { C161-2 }\end{array}$ & $\begin{array}{l}\text { Hydroprocessing } \\
\text { C161-3 }\end{array}$ \\
\hline \multicolumn{5}{|c|}{ Ullimale, day wt\% } \\
\hline $\begin{array}{l}\mathrm{C} \\
\mathrm{H}\end{array}$ & 82.16 & 65.01 & 52.87 & 44.34 \\
\hline $\begin{array}{l}\mathrm{H} \\
\mathrm{N}\end{array}$ & 5.93 & 3.21 & 1.83 & 1.56 \\
\hline$N$ & 0.90 & 1.21 & 1.01 & 0.69 \\
\hline$S$ (total) & 1.13 & 2.67 & 3.78 & 5.81 \\
\hline Ash & 8.57 & 24.53 & 37.94 & 46.87 \\
\hline O (by diff) & 1.31 & 3.37 & 2.57 & 0.82 \\
\hline H/C (alomic) & 0.87 & 0.59 & 0.42 & 0.42 \\
\hline
\end{tabular}




\begin{tabular}{|c|c|c|}
\hline Distribution & Name & Used to construct fractions: \\
\hline Paraffin Length & npdis & Paraffins \\
\hline \# of Naphthenic Rings & nrdis & Naphthenics \\
\hline Naphthenic \# of Sidechains & nscdis & Naphthenics \\
\hline Length of Naphthenic Sidechains & nsldis & Naphthenics \\
\hline Resin \# of Unit Sheets & rdpdis & Aromatics/Resins \\
\hline Resin \# of Aromatic Rings & rardis & Aromatics/Resins \\
\hline Resin \# of Naphthenic Rings & rnrdis & Aromatics/Resins \\
\hline Resin \# of Sidechains & rscdis & Aromatics/Resins \\
\hline Resin Sidechain Length & rsldis & Aromatics/Resins \\
\hline Asphaltene \# of Unit Sheets & adpdis & Asphaltenes \\
\hline Asphaltene \# of Aromatic Rings & aardis & Asphaltenes \\
\hline Asphaltene \# of Naphthenic Rings & anrdis & Asphaltenes \\
\hline Asphaltene \# of Sidechains & ascdis & Asphaltenes \\
\hline Asphaltene Sidechain Length & asldis & Asphaltenes \\
\hline Preasphaltene \# of Unit Sheets & pdpdis & Preasphaltenes \\
\hline Preasphaltene \# of Aromatic Rings & aardis & Asphaltenes \\
\hline Preasphaltene \# of Naphthenic Rings & anrdis & Asphaltenes \\
\hline Preasphaltene \# of Sidechains & ascdis & Asphaltenes \\
\hline Preasphaltene Sidechain Length & asldis & Asphaltenes \\
\hline Fraction of Aromatic Cores w/ 1Ring & flrar & Resins. Asphaltenes. Preasphaltenes \\
\hline $\begin{array}{l}\text { Fraction of Aromatic Cores w/ Internal } \\
\text { Naphthenics }\end{array}$ & frinrings & Resins, Asphaltenes, Preasphaltenes \\
\hline \# of Phenolic Oxygens per unit sheet & frphh & Resins. Asphaltenes. Preasphaltenes \\
\hline \multicolumn{3}{|l|}{ Intersheet Connections } \\
\hline Fraction of Oxygen Connections & fiso & Resins, Asphaltenes, Preasphaltenes \\
\hline Fraction of Sulfur Connections & fiss & Resins. Asphaltenes, Preasphaltenes \\
\hline Fraction of Methylene Connections & fism & Resins. Asphaltenes. Preasphaltenes \\
\hline Fraction of Biphenyl Connections & fisb & Resins. Asphaltenes, Preasphaltenes \\
\hline \multicolumn{3}{|l|}{ Heteroatomic Rings } \\
\hline Fraction of Oxygen Rings & frorings & Resins. Asphaltenes. Preasphaltenes \\
\hline Fraction of Sulfur Rings & frsrings & Resins. Asphaltenes. Preasphaltenes \\
\hline $\begin{array}{l}\text { Fraction of Nitrogen Rings } \\
\text { (5 and } 6 \text { members in a } 2 \text { to } 1 \text { ratio) }\end{array}$ & frnrings & Resins, Asphaltenes, Preasphaltenes \\
\hline Fraction of no Heteroatomic Rings & frhcrings & Resins. Asphaltenes, Preasphaltenes \\
\hline
\end{tabular}

Table 8: Molecular attributes and Eractions which they are used to construct. 


$$
\begin{gathered}
p_{i}=f\left(x_{i}, \alpha, \beta, \gamma\right) \\
x_{i}=\text { attribute }
\end{gathered}
$$

$\alpha, \beta, \gamma=$ pdf parameters

Exponential: $\quad p_{i}=\frac{e^{\left(\frac{x_{1}-\gamma}{\theta}\right)}}{\Theta}$

2 parameters $(\gamma, \Theta)$

$$
\begin{aligned}
& \gamma \leq x_{i}<\infty \\
& \Theta=\mu-\gamma \\
& \sigma=\mu-\gamma \\
& \gamma=\text { minimum }
\end{aligned}
$$

Gamma:

$$
p_{i}=\frac{\left(\left(x_{i}-\gamma\right)^{(\alpha-1)} * e^{\left(-\left(x_{i}-\gamma\right) / \theta\right)}\right)}{\left(\Gamma(\alpha) * \Theta^{\alpha}\right)}
$$

3 parameters $(\gamma, \alpha, \Theta)$

$$
\begin{aligned}
& \gamma \leq x_{i}<\infty \\
& \Theta=\sigma^{2} /(\mu-\gamma) \\
& \alpha=(\mu-3) \sigma^{2} \\
& \gamma=\text { minimum }
\end{aligned}
$$

Chi - Square:

$$
p_{i}=\frac{\left(\left(x_{i}-\gamma\right)\left(\left(\frac{r}{2}\right)-1\right) * e^{(-(x,-\gamma) / 2)}\right)}{\left(\Gamma\left(\frac{r}{2}\right) * 2^{2 / 2}\right)} ;
$$

$$
\begin{aligned}
& 2 \text { parameters }(\gamma, r) \\
& \gamma \leq x_{i}<\infty \\
& r=\mu-\gamma \\
& \sigma=\mathcal{R}\left(\mu-j \gamma^{0.5}\right. \\
& \gamma=\text { minimum }
\end{aligned}
$$

Table 9: Probability density functions used to represent structural groups.

$\mu=$ mean, $\sigma=$ standard deviation, $\Gamma=$ gamma function.

(Reproduced from Trauth, (23)) 


\begin{tabular}{|c|c|c|c|c|c|}
\hline & Resid A & Resid B & $\begin{array}{l}\text { Resid } \\
\end{array}$ & Resid D & Resid E \\
\hline $\begin{array}{l}\text { hydrogen } \\
\text { wt\% }\end{array}$ & 6.34 & 6.80 & 7.08 & 7.12 & 7.03 \\
\hline carbon wt\% & 86.75 & 88.80 & 89.56 & 87.39 & 84.94 \\
\hline sulfur wt\% & 1.68 & 1.42 & 1.19 & 1.10 & 1.72 \\
\hline $\begin{array}{c}\text { nitrogen } \\
\text { wt } \%\end{array}$ & 1.13 & 1.17 & 1.04 & 1.01 & $0 . \overline{95}$ \\
\hline oxygen wt\% & 4.09 & 1.80 & 1.14 & 3.39 & 5.36 \\
\hline $\begin{array}{c}\text { phenolic } \\
\text { wt } \%\end{array}$ & 0.80 & 0.92 & 0.69 & 0.78 & 0.82 \\
\hline & & & & & \\
\hline & Resid F & Resid G & Resid $\mathrm{H}$ & Resid I & Resid J \\
\hline $\begin{array}{c}\text { hydrogen } \\
\text { wt\% }\end{array}$ & 7.29 & 7.17 & 6.84 & 7.07 & 6.94 \\
\hline carbon wt\% & 84.89 & 85.41 & 86.73 & 87.21 & 88.60 \\
\hline sulfur wt\% & 1.97 & 1.70 & 1.49 & 1.57 & 1.46 \\
\hline $\begin{array}{c}\text { nitrogen } \\
\text { wt\% }\end{array}$ & 0.90 & 0.90 & 1.04 & 1.10 & 1.09 \\
\hline oxygen wt\% & 5.04 & 4.83 & 3.90 & 3.05 & 1.90 \\
\hline $\begin{array}{c}\text { phenolic } \mathrm{OH} \\
\text { wt\% }\end{array}$ & 1.24 & 0.85 & 0.69 & 0.91 & 0.69 \\
\hline & Resid $\mathbf{K}$ & Resid L & Resid M & Resid N| & Resid $\mathbf{O}$ \\
\hline $\begin{array}{c}\text { hydrogen } \\
\text { wt\% }\end{array}$ & 6.82 & 6.74 & 7.20 & 8.80 & 8.76 \\
\hline carbon wt\% & 84.57 & 86.31 & 86.58 & 89.31 & 88.52 \\
\hline sulfur wt\% & 1.83 & 1.96 & 1.52 & 0.39 & 0.22 \\
\hline $\begin{array}{c}\text { nitrogen } \\
\text { wt\% }\end{array}$ & 1.05 & 1.06 & 1.16 & 0.68 & 0.39 \\
\hline oxygen wt\% & 5.73 & 3.93 & 3.54 & 0.83 & 2.11 \\
\hline $\begin{array}{c}\text { phenolic } \\
\text { wt\% }\end{array}$ & 0.94 & 0.69 & 0.88 & 0.50 & 0.22 \\
\hline
\end{tabular}

Table 10: Simulated elemental composition of 15 coal resids. 


\begin{tabular}{|c|r|r|r|r|r|}
\hline & Resid A & Resid B & Resid C & Resid D & Resid E \\
\hline $\begin{array}{c}\text { Molecular Weight } \\
\text { wt\% }\end{array}$ & 540 & 602 & 526 & 455 & 678 \\
\hline SARA wt\% & & & & & \\
\hline saturates wt\% & 2.3 & 2.3 & 3.0 & 7.7 & 7.9 \\
\hline $\begin{array}{c}\text { resins wt\% } \\
\text { asphaltenes wt\% }\end{array}$ & 52.9 & 52.4 & 60.3 & 57.9 & 48.7 \\
\hline $\begin{array}{c}\text { preasphaltenes } \\
\text { wt\% }\end{array}$ & 6.2 & 31.8 & 29.3 & 27.1 & 33.1 \\
\hline & & & 7.4 & 7.3 & 10.2 \\
\hline $\begin{array}{c}\text { Molecular Weight } \\
\text { wt\% }\end{array}$ & 548 & 596 & 566 & 533 & 598 \\
\hline $\begin{array}{l}\text { SARA wt\% } \\
\text { saturates wt\% }\end{array}$ & 13.5 & 11.2 & 7.4 & 3.5 & 8.4 \\
\hline resins wt\% & 49.4 & 47.1 & 49.8 & 59.3 & 42.1 \\
\hline asphaltenes wt\% & 28.5 & 33.9 & 33.1 & 27.9 & 41.2 \\
\hline $\begin{array}{c}\text { preasphaltenes } \\
\text { wt\% }\end{array}$ & 8.7 & 7.7 & 9.6 & 10.2 & 8.3 \\
\hline & & & & & \\
\hline & Resid K & Resid L & Resid M & Resid N & Resid 0 \\
\hline $\begin{array}{c}\text { Molecular Weight } \\
\text { wt\% }\end{array}$ & 540 & 586 & 522 & 461 & 476 \\
\hline SARA wt\% & & & & & \\
\hline saturates wt\% & 8.8 & 4.1 & 12.4 & 20.9 & 31.3 \\
\hline resins wt\% & 53.9 & 58.3 & 44.8 & 74.9 & 63.8 \\
\hline asphaltenes wt\% & 23.0 & 28.2 & 32.3 & 3.9 & 4.3 \\
\hline $\begin{array}{c}\text { preasphaltenes } \\
\text { wt\% }\end{array}$ & 14.3 & 9.5 & 10.4 & 0.3 & 0.6 \\
\hline
\end{tabular}

Table 11: Simulated molecular weights and SARA mole fractions of 15 coal resids. 


\begin{tabular}{|c|c|c|c|c|c|}
\hline & Resid A & Resid B & Resid C & Resid D & Resid E \\
\hline $\begin{array}{l}\text { uncondensed arom } \\
\text { wt \% }\end{array}$ & 7.6 & 4.4 & 7.4 & 1.4 & 2.9 \\
\hline $\begin{array}{c}\text { condensed arom } \\
\text { wt \% }\end{array}$ & 35.7 & 33.8 & 30.2 & 27.9 & 24.1 \\
\hline alkyl alpha wt\% & 8.8 & 10.4 & 10.0 & 11.1 & 9.4 \\
\hline cyclic alpha wt\% & 17.1 & 19.9 & $\overline{18.0}$ & 18.5 & 16.4 \\
\hline alkyl beta wt\% & 10.8 & 11.5 & 12.7 & 15.6 & 20.9 \\
\hline cyclic beta wt\% & 12.8 & 12.4 & 13.6 & 15.1 & 16.1 \\
\hline gamma wt\% & 7.3 & 7.6 & 8.1 & 10.4 & 10.2 \\
\hline & Resid F & \begin{tabular}{|l|} 
Resid G \\
\end{tabular} & Resid $\mathrm{H}$ & Resid I & Resid J \\
\hline $\begin{array}{c}\text { uncondensed } \\
\text { wt } \%\end{array}$ & 3.8 & 4.5 & 4.6 & 4.2 & 3.4 \\
\hline $\begin{array}{c}\text { condensed arom } \\
\text { wt \% }\end{array}$ & 25.1 & 25.9 & 30.8 & 28.0 & 31.4 \\
\hline alkyl alpha wt\% & 9.5 & 8.8 & 4.7 & 10.5 & $\overline{9.8}$ \\
\hline cyclic alpha wt\% & 13.9 & 15.7 & $\overline{18.4}$ & 18.1 & 19.4 \\
\hline alkyl beta wt\% & 21.0 & 19.9 & 17.8 & 15.2 & 12.0 \\
\hline cyclic beta wt\% & 15.7 & 16.1 & $\overline{15.3}$ & 15.1 & 15.6 \\
\hline gamma wt\% & 10.9 & 10.0 & 8.4 & 9.0 & 8.4 \\
\hline & Resid $\bar{K}$ & Resid L & Resid M & Resid $\mathbf{N}$ & Resid O \\
\hline $\begin{array}{l}\text { uncondensed arom } \\
\text { wt \% }\end{array}$ & 5.4 & 7.6 & 4.5 & 5.1 & 3.2 \\
\hline $\begin{array}{c}\text { condensed arom } \\
\text { wt \% }\end{array}$ & 27.6 & 29.4 & $\overline{26.4}$ & 16.6 & 19.1 \\
\hline alkyl alpha wt\% & 8.0 & 8.4 & $\overline{9.6}$ & 9.4 & 7.2 \\
\hline cyclic alpha wt\% & 12.6 & 16.5 & 16.0 & 14.1 & 10.1 \\
\hline alkyl beta wt\% & 18.7 & 16.7 & 15.7 & $\overline{23.6}$ & 28.5 \\
\hline cyclic beta wt\% & 15.9 & 13.7 & $\overline{18.1}$ & 18.0 & 19.2 \\
\hline gamma wt\% & 11.8 & 7.6 & 9.8 & 13.2 & 12.6 \\
\hline
\end{tabular}

Table 12: Simulated proton distribution for 15 coal resids. 


\begin{tabular}{|l|r|r|r|r|r|r|}
\hline & Dist. & & & & & \\
\hline & Type & Min. & Resid A & Resid B & Resid C & Resid D \\
\hline Paraffin Length Mean & 2 & 20 & $25.0(2.0)$ & $25.0(2.0)$ & $25.0(2.0)$ & $25.0(2.0)$ \\
\hline$\#$ of Nap. Rings & 2 & 3 & $3.61(1.73)$ & $4.93(0.58)$ & $4.26(0.56)$ & $4.30(0.57)$ \\
\hline$\#$ of Sidechains & 1 & 0 & 3.02 & 3.21 & 7.73 & 3.90 \\
\hline Length of Sidechains & 1 & 1 & 2.54 & 4.51 & 2.89 & 3.47 \\
\hline & Dist. & & & & & \\
\hline & Type & Min. & Resid E & Resid F & Resid G & Resid H \\
\hline Paraffin Length Mean & 2 & 20 & $25.0(2.0)$ & $25.0(2.0)$ & $25.0(2.0)$ & $25.0(2.0)$ \\
\hline \# of Nap. Rings & 2 & 3 & $3.27(0.54)$ & $4.12(0.52)$ & $3.95(0.57)$ & $3.92(0.53)$ \\
\hline \# of Sidechains & 1 & 0 & 5.83 & 4.98 & 4.88 & 7.07 \\
\hline Length of Sidechains & 1 & 1 & 6.82 & 5.05 & 5.64 & 4.69 \\
\hline & Dist. & & & & & \\
\hline & Type & Min. & Resid I & Resid J & Resid K & Resid L \\
\hline Paraffin Length Mean & 2 & 20 & $25.0(2.0)$ & $25.0(2.0)$ & $25.0(2.0)$ & $25.0(2.0)$ \\
\hline \# of Nap. Rings & 2 & 3 & $3.59(0.68)$ & $4.19(0.54)$ & $4.87(0.52)$ & $3.82(2.56)$ \\
\hline \# of Sidechains & 1 & 9 & 1.90 & 4.83 & 4.99 & 2.11 \\
\hline Length of Sidechains & 1 & 1 & 3.31 & 4.02 & 2.43 & 4.59 \\
\hline & Dist. & & & & & \\
\hline & Type & Min. & Resid M & Resid N & Resid O & \\
\hline Paraffin Length Mean & 2 & 20 & $25.0(2.0)$ & $25.0(2.0)$ & $25.0(2.0)$ & \\
\hline \# of Nap. Rings & 2 & 3 & $3.40(0.61)$ & $3.90(0.50)$ & $3.70(0.53)$ & \\
\hline$\#$ of Sidechains & 1 & 0 & 5.57 & 5.83 & 4.70 & \\
\hline Length of Sidechains & 1 & 1 & 3.74 & 5.18 & 5.40 & \\
\hline & & & & & & \\
\hline Distribution Types: & & & & & & \\
\hline 1 = Exponential & & & & & & \\
\hline 2 = Gamma & & & & & & \\
\hline
\end{tabular}

Table 13: Probability Density Function parameters which describe the saturates fractions of 15 coal resids. 


\begin{tabular}{|c|c|c|c|c|c|c|}
\hline & Dist. & & & & & \\
\hline & Type & Min. & Resid A & Resid B & Resid C & Resid D \\
\hline \# of Unit Sheets & & & $2.82(1.24)$ & $3.65(2.76)$ & $3.33(2.09)$ & $2.20(0.50)$ \\
\hline \# of Ar. Rings & 1 & 2 & 7.47 & \begin{tabular}{|r|}
6.85 \\
\end{tabular} & 6.60 & 7.58 \\
\hline \# of Nap. Rings & 1 & 0 & 1.03 & 1.17 & 1.20 & 1.54 \\
\hline \# of Sidechains & & 9 & 1.09 & 1.26 & 0.65 & 0.87 \\
\hline Length of Sidechains & & & 3.62 & 2.79 & 2.47 & 2.39 \\
\hline & & & & & & \\
\hline & Dist. & & & & & \\
\hline & Type & Min. & Resid E & Resid F & Resid G & Resid $\mathrm{H}$ \\
\hline$\#$ of Unit Sheets & & & $2.25(3.27)$ & $2.65(2.72)$ & $2.72(2.74)$ & $3.01(3.18)$ \\
\hline$\#$ of Ar. Rings & & 2 & $\begin{array}{r}.99 \\
\end{array}$ & 5.65 & 7.36 & 7.30 \\
\hline$\#$ of Nap. Rings & & 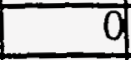 & 1.10 & 0.75 & 1.06 & 1.17 \\
\hline \# of Sidechains & & 0 & 1.70 & 1.39 & 1.63 & 0.47 \\
\hline Length of Sidechains & & 1 & 3.53 & 2.43 & 2.35 & 4.72 \\
\hline & & & & & & \\
\hline & Dist. & & & & & \\
\hline & Type & Min. & Resid I & Resid J & Resid $\mathrm{K}$ & Resid L \\
\hline$\#$ of Unit Sheets & & & $2.69(3.83)$ & $\mid 2.81(2.56)$ & $1.31(2.52)$ & $5.01(2.62)$ \\
\hline$\#$ of Ar. Rings & & & 7.67 & 7.83 & 6.08 & 7.93 \\
\hline \# of Nap. Rings & 1 & 0 & 1.22 & 1.17 & 0.92 & 1.08 \\
\hline \# of Sidechains & II & 0 & 0.60 & 0.37 & 0.80 & 0.65 \\
\hline Length of Sidechains & 1 & 1 & 3.16 & 1.67 & 4.87 & 4.14 \\
\hline & Dist. & & & & & \\
\hline & Type & Min. & Resid M & Resid N & Resid O & \\
\hline$\#$ \# of Unit Sheets & 2 & & $1.95(1.33)$ & $4.24(3.06)$ & $5.06(3.50)$ & \\
\hline$\#$ of Ar. Rings & 1 & 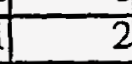 & 6.37 & 5.98 & 6.92 & \\
\hline$\#$ of Nap. Rings & & $\overline{0}$ & 1.32 & 1.09 & 0.83 & \\
\hline$\#$ of Sidechains & $\overline{1}$ & $\overline{0}$ & 0.33 & 1.62 & 1.15 & \\
\hline Length of Sidechains & & & 2.48 & 2.23 & 1.75 & \\
\hline Distribution Types: & & & & & & \\
\hline $1=$ Exponential & & & & & & \\
\hline 2 = Gamma & & & & & & \\
\hline
\end{tabular}

Table 14: Probability Density Function parameters which describe the aromatics/resins fractions of 15 coal resids. 


\begin{tabular}{|c|c|c|c|c|c|c|}
\hline & Dist. & & & & & \\
\hline & Type & Min. & Resid A & Resid B & Resid C & Resid D \\
\hline \# of Unit Sheets & 2 & 2 & $7.39(1.40)$ & $3.03(3.24)$ & $6.47(1.02)$ & $5.43(1.50)$ \\
\hline$\#$ of Ar. Rings & 1 & 2 & 6.86 & 7.89 & 6.66 & 6.43 \\
\hline \# of Nap. Rings & 1 & 9 & 0.47 & 0.77 & 0.48 & 0.50 \\
\hline$\#$ of Sidechains & 1 & a & 0.42 & 1.36 & 1.65 & 2.61 \\
\hline Length of Sidechains & 1) & 1 & 1.22 & 2.07 & 2.68 & 2.60 \\
\hline & & & & & & \\
\hline & Dist. & & & & & \\
\hline & Type & Min. & Resid E & Resid F & Resid G & Resid $\mathrm{H}$ \\
\hline$\#$ of Unit Sheets & & 2 & $7.80(2.75)$ & $6.10(2.45)$ & $7.70(2.70)$ & $6.22(3.38)$ \\
\hline \# of Ar. Rings & & 2 & 6.15 & 6.35 & 7.52 & 6.89 \\
\hline \# of Nap. Rings & & 0 & 1.20 & 1.04 & 0.87 & 0.64 \\
\hline \# of Sidechains & & a & 0.61 & 0.84 & 0.40 & 0.79 \\
\hline Length of Sidechains & & 1 & 1.25 & 2.35 & 2.89 & 4.09 \\
\hline & & & & & & \\
\hline & Dist. & & & & & \\
\hline & Type & Min. & Resid I & Resid J & Resid K & Resid L \\
\hline \# of Unit Sheets & & 2 & $5.22(3.86)$ & $5.57(1.23)$ & $7.78(2.18)$ & $6.02(1.30)$ \\
\hline$\#$ of Ar. Rings & & 2 & 7.61 & 7.73 & 7.53 & 6.89 \\
\hline \# of Nap. Rings & & $\overrightarrow{0}$ & 0.66 & 0.84 & 0.34 & 0.33 \\
\hline \# of Sidechains & & $\overline{0}$ & 2.38 & 2.21 & 0.68 & 0.86 \\
\hline Length of Sidechains & & 1 & 2.44 & 1.97 & 3.25 & 4.60 \\
\hline & & & & & & \\
\hline & Dist. & & & & & \\
\hline & Type & Min. & Resid M & Resid N & Resid O & \\
\hline \# of Unit Sheets & & & $5.72(1.12)$ & $6.76(1.98)$ & $5.53(1.37)$ & \\
\hline \# of Ar. Rings & & 2 & 6.18 & $8 \mid 5.94$ & 6.62 & \\
\hline \# of Nap. Rings & & $\overline{0}$ & 0.45 & 0.59 & 0.34 & \\
\hline$\#$ of Sidechains & & 0 & 1.80 & 1.15 & 3.21 & \\
\hline Length of Sidechains & & & 2.24 & 2.30 & 4.21 & \\
\hline Distribution Types: & & & & & & \\
\hline $1=$ Exponential & & & & & & \\
\hline $2=$ Gamma & & & & & & \\
\hline
\end{tabular}

Table 15: Probability Density Function parameters which describe the asphaltene fractions of 15 coal resias. 


\begin{tabular}{|c|c|c|c|c|c|c|}
\hline & Dist. & & & & & \\
\hline & Type & Min. & Resid A & Resid B & Resid C & Resid D \\
\hline \# of Unit Sheets & & 2 & $3.34(2.06)$ & \begin{tabular}{|l|}
$7.84(2.60)$ \\
\end{tabular} & $4.86(2.61)$ & $4.30(1.80)$ \\
\hline \# of Ar. Rings & & 2 & 8.81 & 8.43 & 7.29 & 7.75 \\
\hline \# of Nap. Rings & & 0 & 1.97 & 0.53 & 0.85 & 0.62 \\
\hline \# of Sidechains & & of & 5.14 & 1.10 & 2.65 & 3.84 \\
\hline Length of Sidechains & & & 1.48 & 2.75 & 3.66 & 2.59 \\
\hline & & & & & & \\
\hline & Dist. & & & & & \\
\hline & Type & Min. & Resid E & Resid F & Resid G & $\overline{\text { Resid H }}$ \\
\hline \# of Unit Sheets & & & $6.15(2.31)$ & $7.69(2.27)$ & $5.92(2.29)$ & $5.81(1.41)$ \\
\hline \# of Ar. Rings & II & 2 & 6.51 & \begin{tabular}{|r|}
8.23 \\
\end{tabular} & $\begin{array}{r}.9 .43 \\
\end{array}$ & 8.22 \\
\hline \# of Nap. Rings & 1 & q & 0.90 & 0.80 & 0.80 & 1.21 \\
\hline \# of Sidechains & 1 & 0 & 3.97 & 2.10 & 2.91 & 2.12 \\
\hline Length of Sidechains & & & 2.17 & 3.49 & 4.34 & 1.74 \\
\hline & & & & & & \\
\hline & Dist. & & & & & \\
\hline & Type & Min. & Resid I & Resid J & Resid K & Resid L \\
\hline$\#$ of Unit Sheets & 2 & 2 & $4.96(1.56)$ & $5.32(0.75)$ & \begin{tabular}{|l|}
$8.87(2.57)$ \\
\end{tabular} & $6.06(0.70)$ \\
\hline \# of Ar. Rings & 1 & 2 & 5.26 & 5.38 & 6.31 & 8.48 \\
\hline \# of Nap. Rings & 11 & 可 & 0.90 & 0.60 & 1.10 & 0.48 \\
\hline$\#$ of Sidechains & 1 & 9 & 3.95 & 0.79 & 2.88 & 5.40 \\
\hline Length of Sidechains & & 1 & 3.80 & 2.60 & 2.37 & 2.85 \\
\hline & & & & & & \\
\hline & Dist. & & & & & \\
\hline & Type & Min. & Resid M & Resid N & Resid O & \\
\hline \# of Unit Sheets & & 2 & $6.91(1.05)$ & $3.21(1.39)$ & $7.98(1.42)$ & \\
\hline \# of Ar. Rings & & 2 & 3.77 & 8.53 & \begin{tabular}{|l|}
8.77 \\
\end{tabular} & \\
\hline$\#$ of Nap. Rings & & 0 & 0.90 & 1.04 & 0.96 & \\
\hline \# of Sidechains & & 0 & 1.12 & 3.24 & 3.71 & \\
\hline Length of Sidechains & & & 2.36 & 3.26 & 2.53 & \\
\hline Distribution TyDes: & & & & & & \\
\hline $1=$ Exponential & & & & & & \\
\hline 2 = Gamma & & & & & & \\
\hline
\end{tabular}

Table 16: Probability Density Function parameters which describe the preasphaltene fractions of 15 coal resids. 


\begin{tabular}{|l|r|r|r|r|r|}
\hline & Resid A & Resid B & Resid C & Resid D & Resid E \\
\hline Fraction Oxygen & 0.016 & 0.042 & 0.000 & 0.017 & 0.037 \\
\hline Fraction Sulfur & 0.111 & 0.082 & 0.048 & 0.238 & 0.120 \\
\hline Fraction Methylene & 0.159 & 0.032 & 0.005 & 0.003 & 0.029 \\
\hline Fraction Biphenyl & 0.715 & 0.844 & 0.947 & 0.742 & 0.813 \\
\hline & & & & & \\
\hline & Resid F & Resid G. & Resid H & Resid I & Resid J \\
\hline Fraction Oxygen & 0.175 & 0.080 & 0.008 & 0.058 & 0.028 \\
\hline Fraction Sulfur & 0.203 & 0.183 & 0.123 & 0.015 & 0.017 \\
\hline Fraction Methylene & 0.140 & 0.198 & 0.015 & 0.004 & 0.009 \\
\hline Fraction Biphenyl & 0.482 & 0.539 & 0.854 & 0.923 & 0.946 \\
\hline & & & & & \\
\hline & & & & & \\
\hline Fraction Oxygen & 0.007 & 0.020 & 0.068 & 0.007 & 0.164 \\
\hline Fraction Sulfur & 0.017 & 0.117 & 0.005 & 0.038 & 0.034 \\
\hline Fraction Methylene & 0.064 & 0.078 & 0.143 & 0.026 & 0.122 \\
\hline Fraction Biphenyl & 0.912 & 0.785 & 0.784 & 0.929 & 0.680 \\
\hline
\end{tabular}

Table 17: Distribution of intersheet linkage types for 15 coal resids. 


\begin{tabular}{|c|c|c|c|c|c|}
\hline & Resid A|l & Resid B & Resid C II & Resid D & Resid E \\
\hline \multicolumn{6}{|l|}{ Heteroatom Cores } \\
\hline Fraction Oxygen & 0.359 & 0.025 & 0.004 & 0.436 & 0.657 \\
\hline Fraction Sulfur & 0.045 & 0.058 & 0.051 & 0.038 & 0.073 \\
\hline Fraction Nitrogen & 0.169 & 0.197 & 0.157 & 0.235 & 0.184 \\
\hline Fraction Aromatic Hydrocarbon & $0.42 \pi$ & 0.719 & 0.787 & 0.291 & 0.086 \\
\hline Fraction Internal Naphthenic & 0.820 & 0.869 & 0.683 & 0.988 & 0.944 \\
\hline Fraction of Cores with Phenolic $\mathrm{OH}$ & 0.168 & 0.216 & 0.146 & 0.255 & 0.220 \\
\hline \multirow[t]{3}{*}{$\begin{array}{l}\text { Fraction of Cores with one aromatic } \\
\text { ring }\end{array}$} & 0.455 & 0.331 & 0.533 & 0.025 & 0.252 \\
\hline & & & & & \\
\hline & Resid F[] & Resid G & Resid H & Resid I & Resid J \\
\hline \multicolumn{6}{|l|}{ Heteroatom Cores } \\
\hline Fraction Oxygen & 0.400 & 0.500 & 0.416 & 0.208 & 0.109 \\
\hline Fraction Sulfur & $0.04 \mathrm{~d}$ & 0.025 & 0.040 & 0.108 & 0.105 \\
\hline Fraction Nitrogen & 0.165 & 0.161 & 0.179 & 0.188 & 0.198 \\
\hline Fraction Aromatic Hydrocarbon & 0.391 & 0.314 & 0.365 & 0.496 & 0.588 \\
\hline Fraction Internal Naphthenic & 0.983 & 0.971 & 0.980 & 0.847 & 0.957 \\
\hline Fraction of Cores with Phenolic $\mathrm{OH}$ & 0.321 & 0.215 & 0.166 & 0.219 & 0.174 \\
\hline \multirow[t]{2}{*}{$\begin{array}{l}\text { Fraction of Cores with one aromatic } \\
\text { ring }\end{array}$} & 0.375 & 0.383 & 0.342 & 0.428 & 0.245 \\
\hline & Resid K & Resid L & |Resid M| & Resid N & Resid O \\
\hline \multicolumn{6}{|l|}{ Heteroatom Cores } \\
\hline Fraction Oxygen & 0.595 & 0.362 & 0.286 & 0.002 & 0.242 \\
\hline Fraction Sulfur & 0.119 & 0.055 & 0.111 & 0.011 & 0.002 \\
\hline Fraction Nitrogen & 0.170 & 0.160 & 0.200 & 0.127 & 0.084 \\
\hline Fraction Aromatic Hydrocarbon & 0.116 & 0.422 & 0.402 & 0.861 & 0.672 \\
\hline Fraction Internal Naphthenic & 0.952 & 0.979 & 0.959 & 0.999 & 0.937 \\
\hline Fraction of Cores with Phenolic $\mathrm{OH}$ & 0.213 & 0.146 & 0.212 & 0.130 & 0.066 \\
\hline $\begin{array}{l}\text { Fraction of Cores with one aromatic } \\
\text { ring }\end{array}$ & 0.439 & 0.459 & 0.396 & 0.680 & 0.437 \\
\hline
\end{tabular}

Table 18: Aromatic core type distribution, fraction of aromatic cores with internal naphthenic rings, fraction of aromatic cores with phenolic hydroxyls, and fraction of aromatic cores with one aromatic ring for 15 coal resids. 


\begin{tabular}{|c|c|}
\hline Reaction Family & Relationship \\
\hline Paraffin Cracking & $\mathrm{k}=(\mathrm{CNO}-1 .)^{*}(\mathrm{~b} 1 * \mathrm{CNO}-\mathrm{b} 2) * \mathrm{kpar}$ \\
\hline Naphthenic Sidechains & 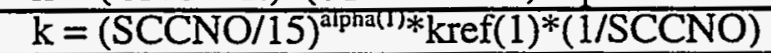 \\
\hline Aromatic Sidechains - At Ring & 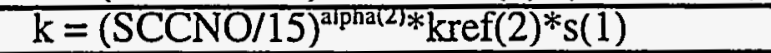 \\
\hline Aromatic Sidechains - Alpha & $\mathrm{k}=(\mathrm{SCCNO} / 15)^{\text {apphat } 2 * \mathrm{kref}(2) * \mathrm{~s}(2)}$ \\
\hline Aromatic Sidechains - Beta & $\mathrm{k}=(\mathrm{SCCNO} / 15)^{\text {alphat }(2) * \mathrm{kref}(2) * \mathrm{~s}(3)}$ \\
\hline Aromatic Sidechains - Other & $\mathrm{k}=(\mathrm{SCCNO} / 15)^{\text {alpha(2)*kref }(2)^{*} \mathrm{~s}(4)}$ \\
\hline Asphaltene Sidechains - At Ring & 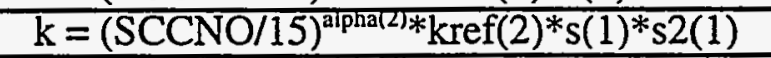 \\
\hline Asphaltene Sidechains - Alpha & $\mathrm{k}=(\mathrm{SCCNO} / 15)^{\mathrm{a} p h a(2) * \mathrm{kref}(2) * \mathrm{~s}(2) * \mathrm{~s} 2(1)}$ \\
\hline Asphaltene Sidechains - Beta & 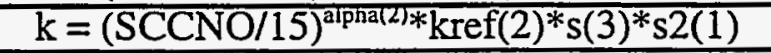 \\
\hline Asphaltene Sidechains - Other & $\mathrm{k}=(\mathrm{SCCNO} / 15)^{\text {apprat(2) }} * \mathrm{kref}(2)^{*} \mathrm{~s}(4)^{*} \mathrm{~s} 2(1)$ \\
\hline Preasphaltene Sidechains - At Ring & 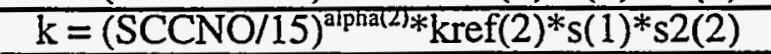 \\
\hline Preasphaltene Sidechains - Alpha & 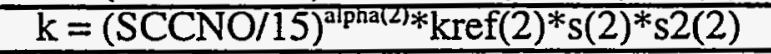 \\
\hline Preasphaltene Sidechains - Beta & 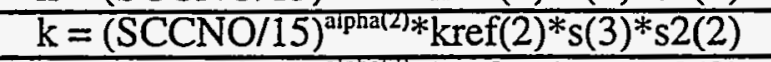 \\
\hline Preasphaltene Sidechains - Other & 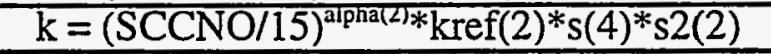 \\
\hline Intersheet Linkage - Sulfur & $\mathrm{k}=\mathrm{kref}(3)^{*}(\# \text { of Unit Sheets })^{\text {-alphas }}$ \\
\hline Intersheet Linkage - Oxygen & $\mathrm{k}=\mathrm{kref}(4) *(\# \text { of Unit Sheets })^{\text {-alphal(s) }}$ \\
\hline Intersheet Linkage - Methylene & $\mathrm{k}=\mathrm{kref}(5)^{*}(\# \text { of Unit Sheets })^{\text {-alphat( })}$ \\
\hline Intersheet Linkage - Biphenyl & $\mathrm{k}=\mathrm{kref}(6)^{*}(\# \text { of Unit Sheets })^{- \text {-apha(s) }}$ \\
\hline Thiophenic Rings & $\mathrm{k}=\mathrm{kref}(3)^{*}(\# \text { of Rings on Unit Sheet })^{-1}$ \\
\hline Furan Rings & $\mathrm{k}=\mathrm{kref}(4)^{*}(\# \text { of Rings on Unit Sheet })^{-2}$ \\
\hline 5-member Nitrogen Rings & $\mathrm{k}=\mathrm{kref}(7)^{*}(\# \text { of Rings on Unit Sheet })^{-\mathrm{al}}$ \\
\hline Internal Naphthenics & $\mathrm{k}=\mathrm{kref}(5)^{*}(\# \text { of Rings on Unit Sheet })^{\text {-aphate }}$ \\
\hline
\end{tabular}

Table 19: Reaction families and structure-reactivity relationships. 


\begin{tabular}{|c|c|c|}
\hline Parameter & Definition & $\begin{array}{l}\text { Optimized } \\
\text { Value }\end{array}$ \\
\hline b1 & First coefficient for paraffin reactivity relationship & 1.6299 \\
\hline b2 & $\begin{array}{l}\text { Second coefficient for paraffin reactivity } \\
\text { relationship }\end{array}$ & 2.5700 \\
\hline kpar & Base paraffin rate constant & $10^{-5.0305}$ \\
\hline kref(1) & $\begin{array}{l}\text { Base rate constant for sidechain cracking of } \\
\text { naphthenic compound }\end{array}$ & $10^{-2.0915}$ \\
\hline kref(2) & $\begin{array}{l}\text { Base rate constant for sidechain cracking of } \\
\text { aromatic compounds }\end{array}$ & $10^{-2.1950}$ \\
\hline kref(3) & Base rate constant for sulfur removal & $10^{-5.3960}$ \\
\hline kref(4) & Base rate constant for oxygen removal & $10^{-3 . .3+11}$ \\
\hline kref(5) & Base rate constant for methylene bridge removal & $10^{-4.0504}$ \\
\hline kref(6) & Base rate constant for biphenyl bridge removal & $10^{-1,9.9345}$ \\
\hline kref(7) & Base rate constant for nitrogen removal & $10^{-5.1619}$ \\
\hline$s(1)$ & Selectivity for reaction at aromaticring & 0.040337 \\
\hline$s(2)$ & Selectivity for reaction alpha to aromatic ring & 0.51872 \\
\hline$s(3)$ & Selectivity for reaction beta to aromatic ring & 0.29064 \\
\hline$s(4)$ & Selectivity for reaction at other position & 0.28160 \\
\hline s2(1) & Steric adjustment for asphaltene compounds & 0.68830 \\
\hline s2(2) & Steric adjustment for preasphaltene compounds & 0.47376 \\
\hline alpha(1) & $\begin{array}{l}\text { Exponent for naphthenic alkyl sidechain reactivity } \\
\text { relationship }\end{array}$ & 0.85151 \\
\hline alpha(2) & $\begin{array}{l}\text { Exponent for aromatic alkyl sidechain reactivitiy } \\
\text { relationship }\end{array}$ & 0.08291 \\
\hline alpha(3) & $\begin{array}{l}\text { Exponent for intersheet linkage reactivity } \\
\text { relationships }\end{array}$ & 0.070674 \\
\hline alpha(4) & Exponent for ring structure reactivity relationships & 0.040337 \\
\hline
\end{tabular}

Table 20: Parameter definitions and optimized values. 
Base Correlation

boiling point $=($ \# Arom. Rings/Tot. Rings $) *(-74.241+165 . *$ (Tot. Rings $\left.)-9.225 *(\text { Tot. Rings })^{2}\right)$ +(\# Naph. Rings/Tot. Rings)*(71.948+411.08* $\log 10($ Tot. Rings))

Correction for Sidechains and Phenolic Oxygens

(Phenolic Oxygens count as $2.845 \mathrm{CH}_{2}$ groups)

1 Ring Compounds

If there are more than 5 sidechain (SC) carbons then correction $=-175.63+399.29 * \log 10$ (\# of SC Carbons)

If there are 5 or fewer SC carbons then correction = (\# Naph. Rings $) *(-13.33+35.11 *$ (\# of SC Carbons $)-1.67 *$ \# of SC Carbons $\left.)^{2}\right)$ $\left.+(\text { \# Arom. Rings)*(4.8611+26.25*(\# of SC Carbons) }-0.42 * \text { (\# of SC Carbons) })^{2}\right)$

Multiring Compounds

If there are more than $4 \mathrm{SC}$ carbons then correction $=(\text { Total Rings) })^{0.25 *}(-78.82+250.83 * \log 10$ (\# of SC Carbons) $)$

If there are 4 or fewer SC carbons then

For Two-ring compounds correction = (\# Naph. Rings/Tot. Rings)*(-10.14+28.69*(\# SC Carbons) $-2.08 *\left({\left.\text { \# SC Carbons })^{2}\right)}^{2}\right.$ +(\# Arom Rings/Tot. Rings)*(14.58+11.47*(\# SC Carbons)+0.69*(\# SC Carbons) $\left.)^{2}\right)$

For Three-ring compounds correction $=($ \# Naph. Rings/Tot. Rings $\left.) *(-0.69+17.64 * \text { (\# SC Carbons) }-0.69 * \text { (\# SC Carbons })^{2}\right)$ +(\# Arom Rings/Tot. Rings)*(9.03+7.31*(\# SC Carbons)+0.97*(\# SC Carbons) $\left.)^{2}\right)$

For structures with more than three total rings correction = (\# Naph. Rings/Tot. Rings)*(-8.19+22.81*(\# SC Carbons)-1.53*(\# SC Carbons) $\left.)^{2}\right)$ +(\# Arom Rings/Tot. Rings)*(9.03+7.31*(\# SC Carbons)+0.97*(\# SC Carbons) $\left.)^{2}\right)$

\section{Correction for Nitrogen Rings}

For Three or fewer total rings correction $=($ \# Nitrogen Rings $) *(57.032-15.74 *$ (Total Rings $))$

For structures with more than three total rings

correction $=($ \# Nitrogen Rings $) *(9.812)$

Correction for Oxygen Rings

correction $=(\#$ Oxygen Rings $) *(-49.35)$

Correction for Multiple Core Structures

For Three or fewer total rings

correction $=(\text { \# Intersheet Links })^{*}(97.47-31.67 *$ (Total Rings $\left.)\right)$

For structures with more than three total rings

correction $=$ (\# Nitrogen Rings)*(2.46)

Table 21: Boiling point correlation for coal resid compounds. 


\begin{tabular}{|c|c|c|c|}
\hline & $\operatorname{Exp} . \overline{\mathrm{BP}}\left({ }^{\circ} \mathrm{C}\right)$ & Pred. $\mathrm{BP}{ }^{\circ} \mathrm{C}$ & Difference \\
\hline benzene & 80 & 82 & 2 \\
\hline naphthalene & 218 & 219 & 1 \\
\hline anthracene & 340 & 338 & -2 \\
\hline phenanthrene & 336 & 338 & 2 \\
\hline chrysene & 448 & 438 & -10 \\
\hline tetraphene & 438 & 438 & 0 \\
\hline triphenylene & 438 & 438 & 0 \\
\hline $1,2,3,4$ dibenzanthracene & 518 & 520 & 2 \\
\hline thiophene & 84 & 82 & -2 \\
\hline benzothiophene & 221 & 219 & -2 \\
\hline dibenzothiophene & 332 & 338 & 6 \\
\hline furan & 31 & 32 & 1 \\
\hline benzofuran & 174 & 169 & -5 \\
\hline dibenzofuran & 285 & 288 & 3 \\
\hline pyridine & 115 & 123 & 8 \\
\hline pyrrole & 130 & 123 & -7 \\
\hline quinoline & 237 & 244 & 7 \\
\hline indole & 253 & 244 & -9 \\
\hline 5,6 benzoquinoline & 349 & 348 & -1 \\
\hline 7,8 benzoquinoline & 338 & 348 & 10 \\
\hline pheananthridine & 349 & 348 & -1 \\
\hline carbazole & 355 & 348 & -7 \\
\hline biphenyl & 255 & 253 & -2 \\
\hline diphenyl ether & 259 & 253 & -6 \\
\hline 1 phenyl naphthalene & 324 & 340 & 16 \\
\hline 9 phenyl anthracene & 417 & 409 & -8 \\
\hline 2 methyl thiophene & 113 & 112 & -1 \\
\hline 3 methyl thiophene & 114 & 112 & -2 \\
\hline toluene & 110 & 112 & 2 \\
\hline 2,5 dimethyl thiophene & 134 & 137 & 3 \\
\hline
\end{tabular}

Table 22a: Experimentally determined and correlation predictions of boiling point. 


\begin{tabular}{|l|r|r|r|}
\hline & Exp. BP $\left({ }^{\circ} \mathrm{C}\right)$ & Pred. BP ${ }^{\circ} \mathrm{C}$ & Difference \\
\hline 1 methyl naphthalene & 241 & 246 & 5 \\
\hline 2 methyl naphthalene & 241 & 246 & 5 \\
\hline 1,3 dimethyl naphthalene & 263 & 259 & -4 \\
\hline $2,3,5$ trimethyl naphthalene & 285 & 274 & -11 \\
\hline ethyl benzene & 136 & 137 & 1 \\
\hline 4,4 dimethyl biphenyl & 295 & 293 & -2 \\
\hline ethyl furan & 92 & 88 & -4 \\
\hline 2 ethyl pyridine & 149 & 178 & 29 \\
\hline 4 ethyl pyridine & 168 & 178 & 10 \\
\hline 2 ethyl thiophene & 133 & 137 & 4 \\
\hline o-ethyl toluene & 164 & 161 & -3 \\
\hline p-ethyl toluene & 162 & 161 & -1 \\
\hline propyl benzene & 158 & 161 & 3 \\
\hline n-butyl benzene & 183 & 185 & 2 \\
\hline 2 methyl furan & 64 & 63 & -1 \\
\hline 2,5 dimethyl furan & 93 & 88 & -5 \\
\hline 3 methyl indole & 266 & 271 & 5 \\
\hline 4 methyl indole & 267 & 271 & 4 \\
\hline 7 methyl indole & 266 & 271 & 5 \\
\hline 2 methyl pyridine (picoline) & 128 & 153 & 25 \\
\hline 3 picoline & 144 & 153 & 9 \\
\hline 4 picoline & 145 & 153 & 8 \\
\hline quinaldine & 248 & 271 & 23 \\
\hline 4 -tert-butylpyridine & 196 & 226 & 30 \\
\hline phenol & 182 & 158 & -24 \\
\hline 1 -naphthol & 279 & 272 & -7 \\
\hline 2-naphthol & 285 & 272 & -13 \\
\hline 0 -cresol & 191 & 181 & -10 \\
\hline p-cresol & 203 & 181 & -22 \\
\hline m-cresol & 203 & 181 & -22 \\
\hline
\end{tabular}

Table 22b: Experimentally determined and correlation predictions of boiling point. 


\begin{tabular}{|c|c|c|c|}
\hline & Exp. BP $\left({ }^{\circ} \mathrm{C}\right)$ & Pred. $\mathrm{BP}{ }^{\circ} \mathrm{C}$ & Difference \\
\hline 2.3 dimethyl phenol & 217 & 204 & -13 \\
\hline 2,5 dimethyl phenol & 212 & 204 & -8 \\
\hline 2,6 dimethyl phenol & 203 & 204 & 1 \\
\hline 3.4 dimethyl phenol & 227 & 204 & -23 \\
\hline 2 ethyl phenol & 196 & 204 & 8 \\
\hline 4 ethyl phenol & 218 & 204 & -14 \\
\hline $2,3,5$ trimethyl phenol & 230 & 225 & -5 \\
\hline 2-n-propyl phenol & 225 & 225 & 0 \\
\hline 3-hydroxy-2-methyl pyridine & 169 & 222 & 53 \\
\hline 5-hydroxy-2-methyl pyridine & 169 & 222 & 53. \\
\hline 2-hydroxy-4-methyl pyridine & 186 & 222 & 36 \\
\hline 4 phenyl toluene & 267 & 280 & 13 \\
\hline 4-benzyl pyridine & 287 & 279 & -8 \\
\hline 3-benzyl pyridine & 287 & 279 & -8 \\
\hline 2-benzyl pyridine & 276 & 279 & 3 \\
\hline 4 phenyl pyridine & 274 & 279 & 5 \\
\hline 3 phenyl pyridine & 270 & 279 & 9 \\
\hline 2 phenyl pyridine & 269 & 279 & 10 \\
\hline 2,4 dipyridil & 281 & 304 & 23 \\
\hline 2,2 dipyridil & 273 & 304 & 31 \\
\hline 4,4 dipyridil & 305 & 304 & -1 \\
\hline 4-phenyl toluene & 267 & 280 & 13 \\
\hline 4 phenyl phenol & 321 & 306 & -15 \\
\hline 2 phenyl phenol & 282 & 306 & 24 \\
\hline biphenol & 315 & 356 & 41 \\
\hline $1,2,3,4$ tetrahyrocarbazole & 328 & 338 & 10 \\
\hline tetralin & 207 & 219 & 12 \\
\hline cyclohexane & 78 & 72 & -6 \\
\hline n-butyl cyclohexane & 179 & 172 & -7 \\
\hline decalin & 187 & 196 & 9 \\
\hline perhydrofluorene & 253 & 268 & 15 \\
\hline
\end{tabular}

Table 22c: Experimentally determined and correlation predictions of boiling point. 


\begin{tabular}{|l|r|r|r|}
\hline Resid & Experimental & Predicted & Difference \\
\hline $\mathbf{A}$ & 35.0 & 33.5 & -1.5 \\
\hline $\mathbf{B}$ & 38.1 & 34.1 & -4.0 \\
\hline $\mathbf{C}$ & 33.1 & 31.4 & -1.7 \\
\hline $\mathbf{D}$ & 32.9 & 44.8 & 11.9 \\
\hline $\mathbf{E}$ & 32.1 & 39.5 & 7.4 \\
\hline $\mathbf{F}$ & 37.4 & 45.8 & 8.4 \\
\hline $\mathbf{G}$ & 35.8 & 43.6 & 7.8 \\
\hline $\mathbf{H}$ & 44.6 & 34.6 & -10.0 \\
\hline $\mathbf{I}$ & 42.7 & 36.3 & -6.4 \\
\hline $\mathbf{J}$ & 42.1 & 33.3 & -8.8 \\
\hline $\mathbf{K}$ & 35.2 & 40.0 & 4.8 \\
\hline $\mathbf{L}$ & 35.0 & 35.6 & 0.6 \\
\hline $\mathbf{M}$ & 35.3 & 37.4 & 2.1 \\
\hline $\mathbf{N}$ & 47.6 & 64.6 & 17.0 \\
\hline $\mathbf{O}$ & 34.3 & 64.2 & 29.9 \\
\hline
\end{tabular}

Table 23: Experimentally determined and model predictions of coal resid conversion. 


\begin{tabular}{|l|r|r|r|}
\hline Resid & Experimental & Predicted & Difference \\
\hline A & 35.0 & 37.3 & 2.3 \\
\hline B & 38.1 & 40.2 & 2.1 \\
\hline $\mathbf{C}$ & 33.1 & 34.4 & 1.3 \\
\hline $\mathrm{D}$ & 32.9 & 39.5 & 6.6 \\
\hline $\mathrm{E}$ & 32.1 & 33.1 & 1.0 \\
\hline $\mathrm{F}$ & 37.4 & 39.8 & 2.4 \\
\hline $\mathbf{G}$ & 35.8 & 38.9 & 3.1 \\
\hline $\mathrm{H}$ & 44.6 & 36.8 & -7.8 \\
\hline $\mathrm{I}$ & 42.7 & 40.4 & -2.3 \\
\hline $\mathrm{J}$ & 42.1 & 36.6 & -5.5 \\
\hline $\mathrm{K}$ & 35.2 & 29.2 & -6.0 \\
\hline $\mathrm{L}$ & 35.0 & 36.9 & 1.9 \\
\hline $\mathbf{M}$ & 35.3 & 35.3 & 0.0 \\
\hline $\mathbf{N}$ & 47.6 & 48.7 & 1.1 \\
\hline $\mathbf{O}$ & 34.3 & 32.8 & -1.5 \\
\hline
\end{tabular}

Table 24: Experimental and correlated predictions of coal resid conversion. 


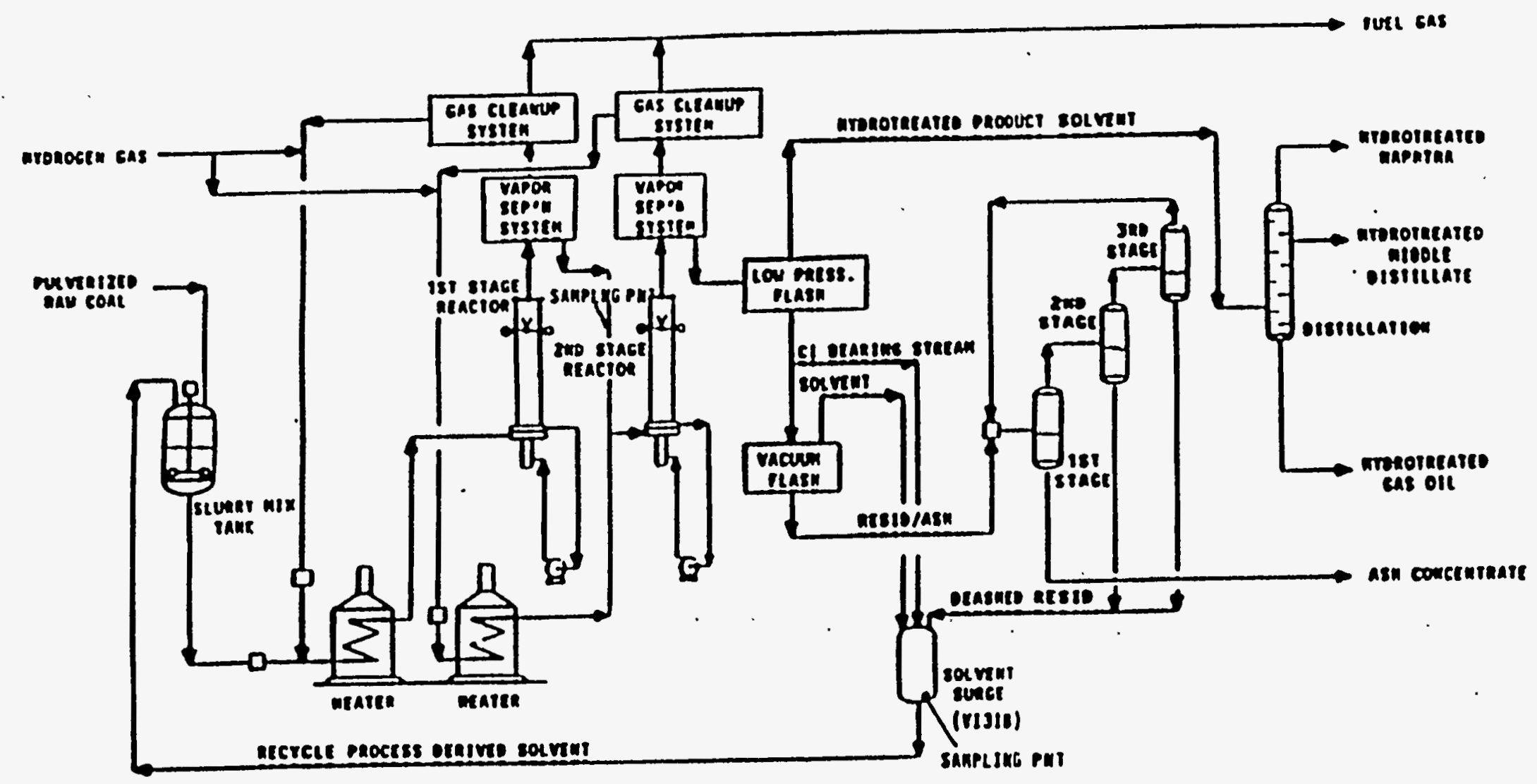

Figure 1

Generalized Flow Sheet of Closed-Coupled Integrated Two-Stage Liquefaction System (Wilsonville Facility) 


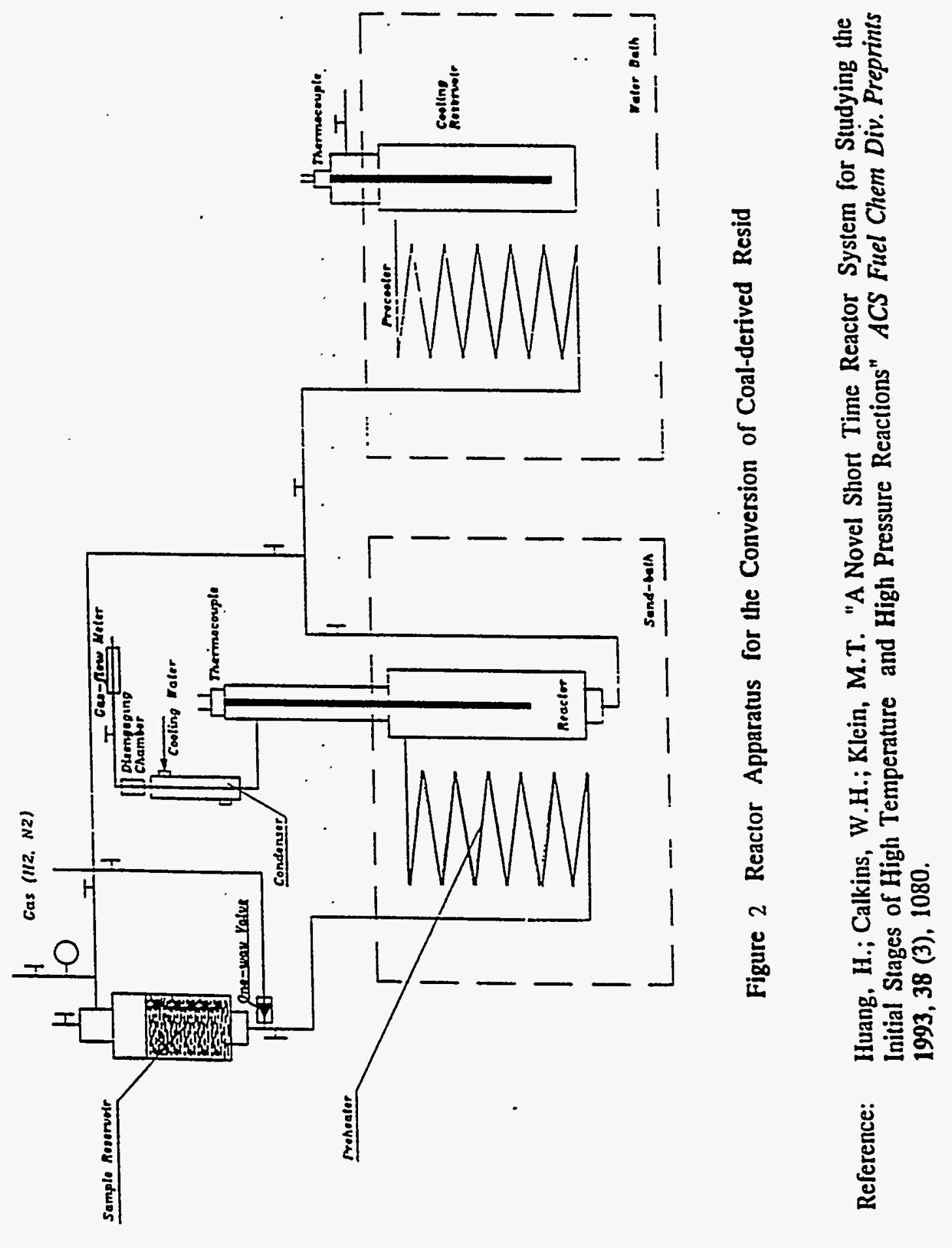


Figure 3

A Typical Temperature-Time Profile of the SCTBR Reactor

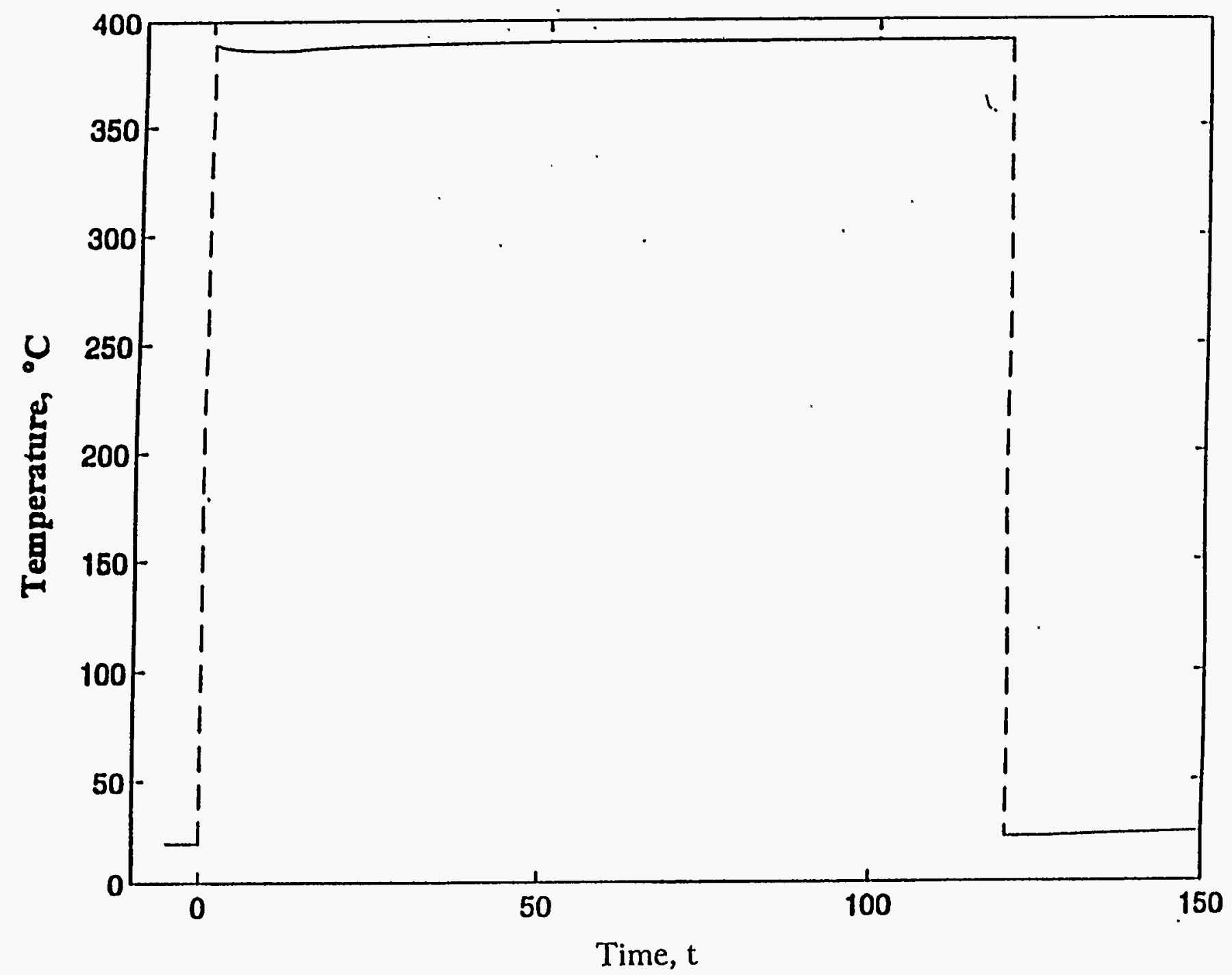




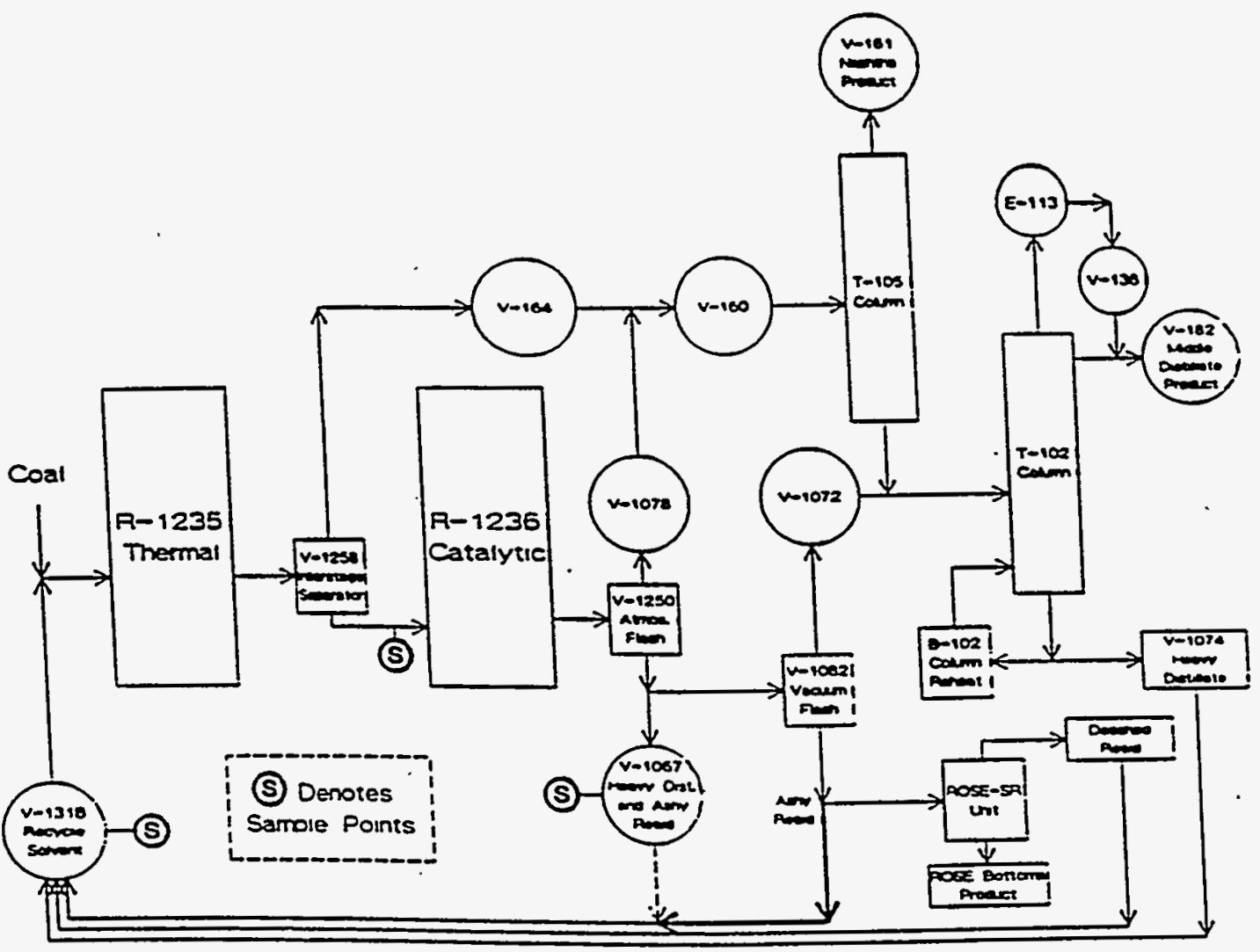

Figure 4 Partial CC-ITSL Process Diagram for Hilsonville Run 261, Showing Major Distillate Streams. 


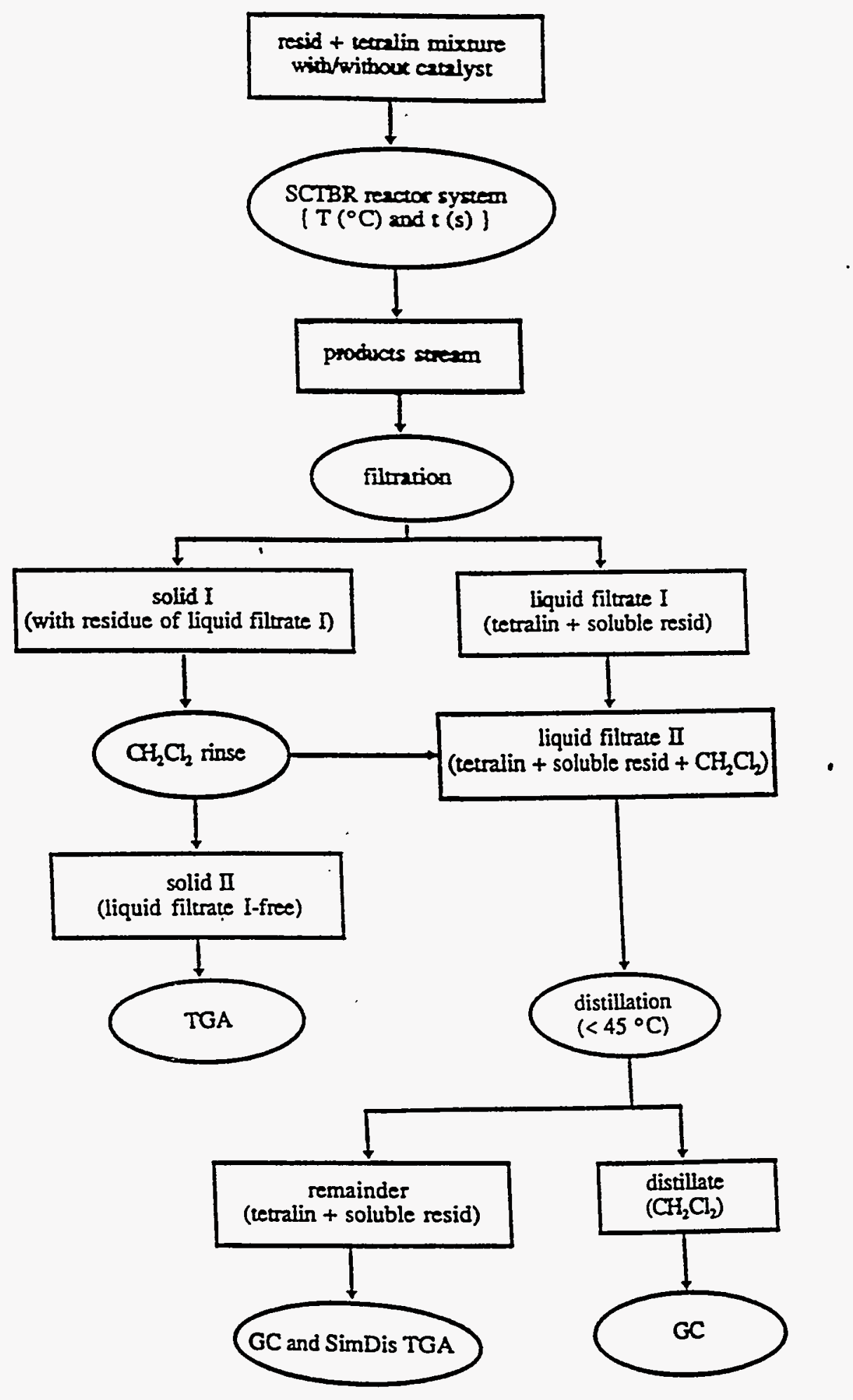

Figure 5 Scheme of the resction product workip procedure 


\section{Figure 6 Estimation of Experimental Error}

$$
\text { Conversion }=\left(1-\frac{A s h_{0}}{A s h}\right) \cdot \frac{1}{1-A s h_{0}} \cdot\left(1-\frac{850^{\circ} F^{+}}{R S F_{\text {liquid }}}\right)
$$

$\mathrm{Ash}_{0}$ determined by TGA: \pm 0.005 ( $3 \%$ relative); Ash determined by TGA: $\pm 0,005$ ( $1 \%$ relative); $850{ }^{\circ} \mathrm{F}^{+}$determined by SimDis TGA: $\pm 0,005$ ( $5 \%$ relative); $\mathrm{RSF}_{\text {liquid }}$ determined by GC: \pm 0.02 (12\% relative); Conversion: \pm 0.04 ( $12 \%$ relative). 


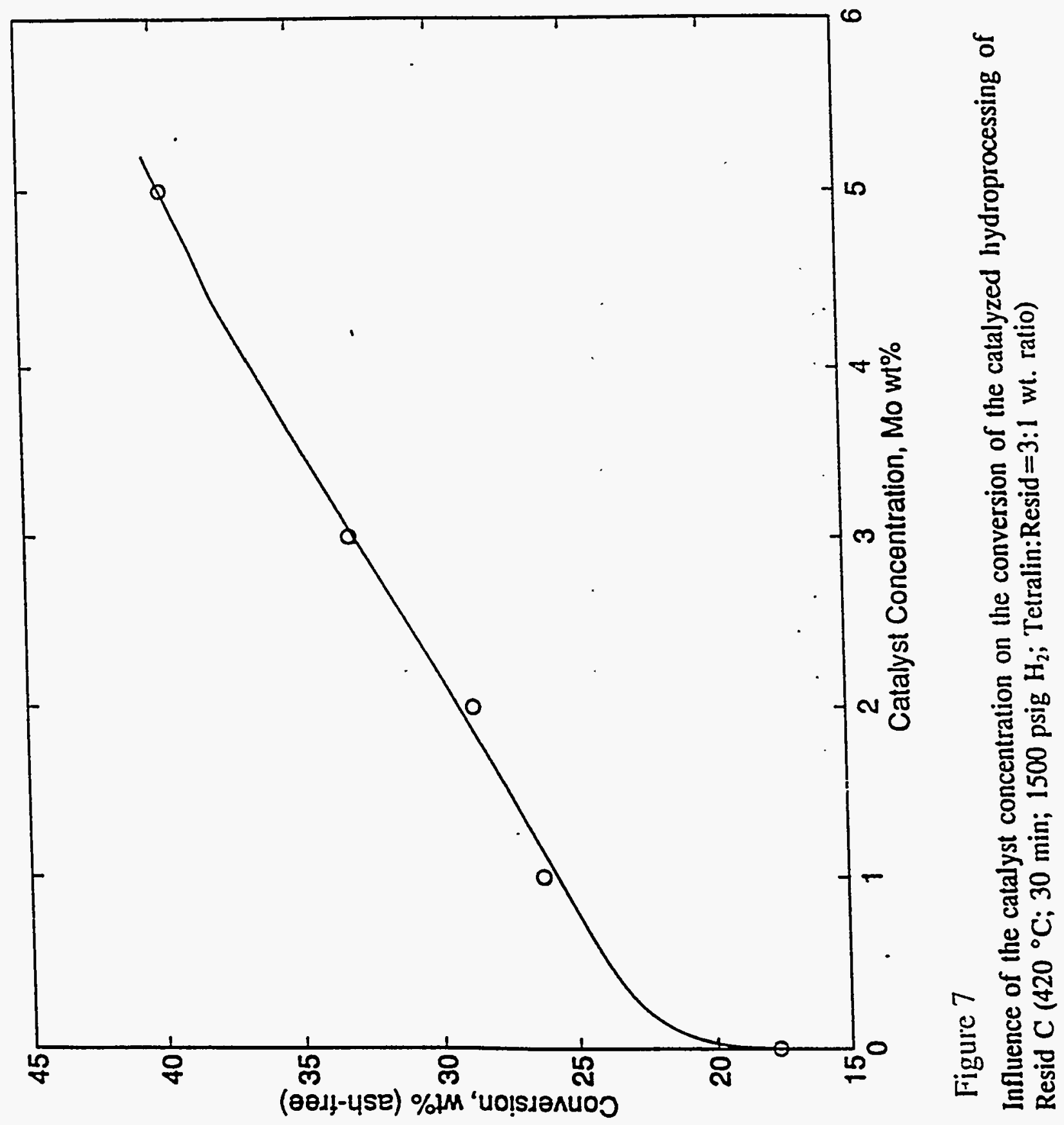




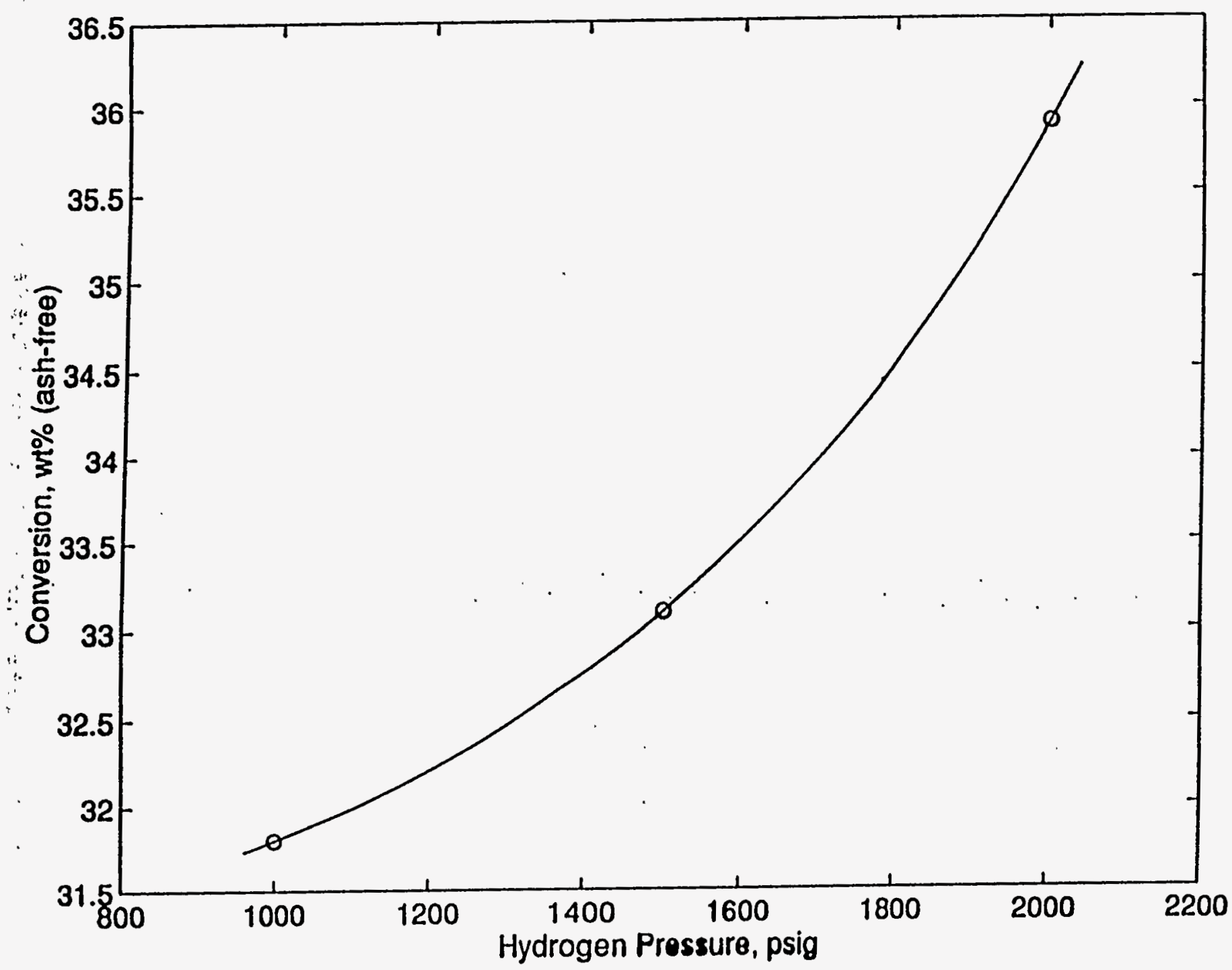

Figure 8

Influence of the hydrogen pressure on the conversion of the catalyzed hydroprocessing of Resid $\mathrm{C}\left(420^{\circ} \mathrm{C} ; 30 \mathrm{~min} ; 3 \mathrm{wt} \% \mathrm{Mo}\right.$; Tetralin: Resid $=3: 1$ wt. ratio) 


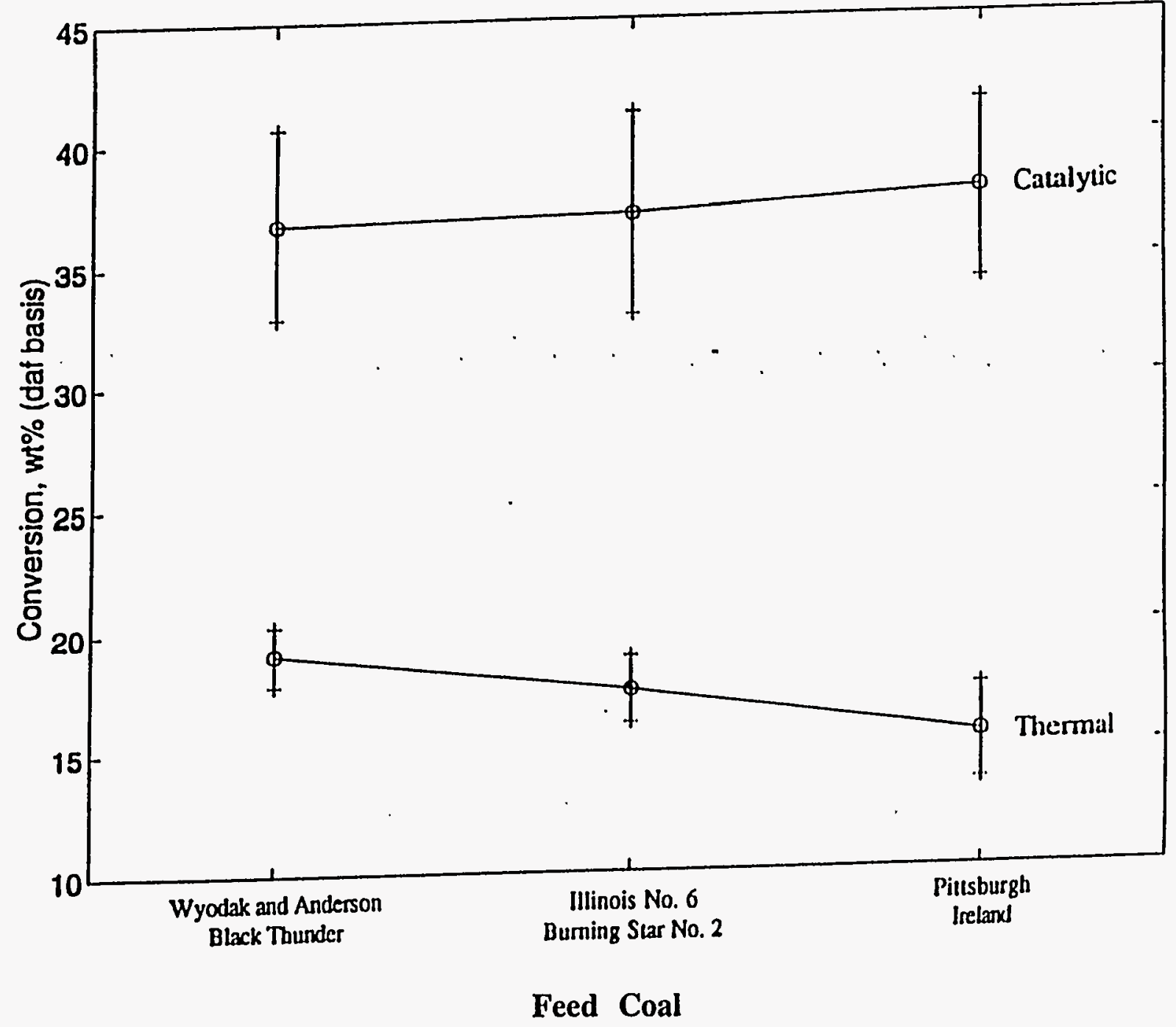

Figure 9 Thermal and catalyzed hydroprocessing conversions of the resids vs feed coal type (Samples taken for all locations) 


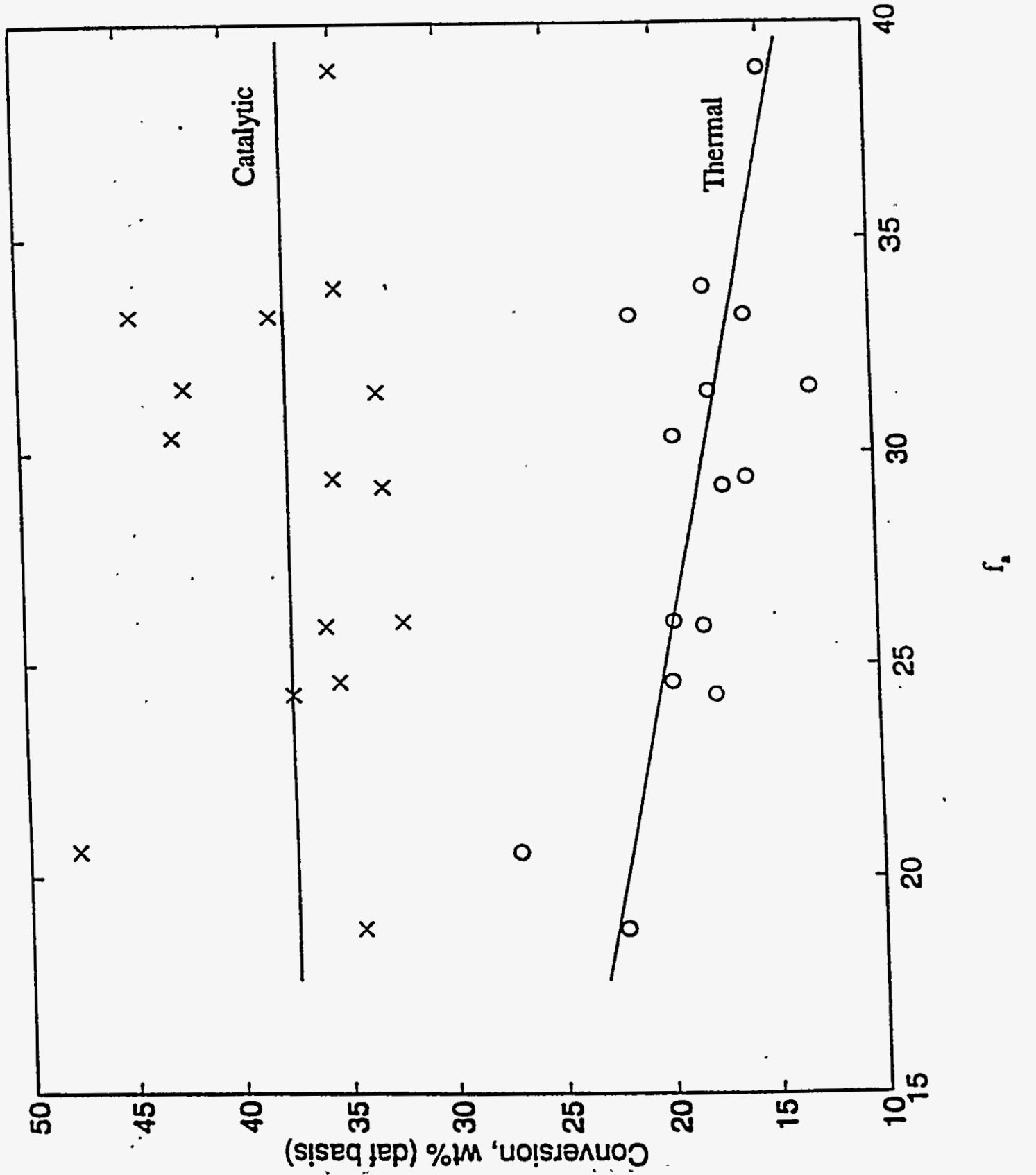

글 
Figure 13

\section{Kinetics of Catalyzed Hydroprocessing of Resid}

First-order Assumption:

$$
\begin{aligned}
& \frac{d X}{d t}=k \cdot(1-X) \\
& \ln (1-X)=-k \cdot t
\end{aligned}
$$

Second-order Assumption:

$$
\begin{aligned}
& \frac{d X}{d t}=k \cdot(1-X)^{2} \\
& \frac{X}{1-X}=k \cdot t
\end{aligned}
$$




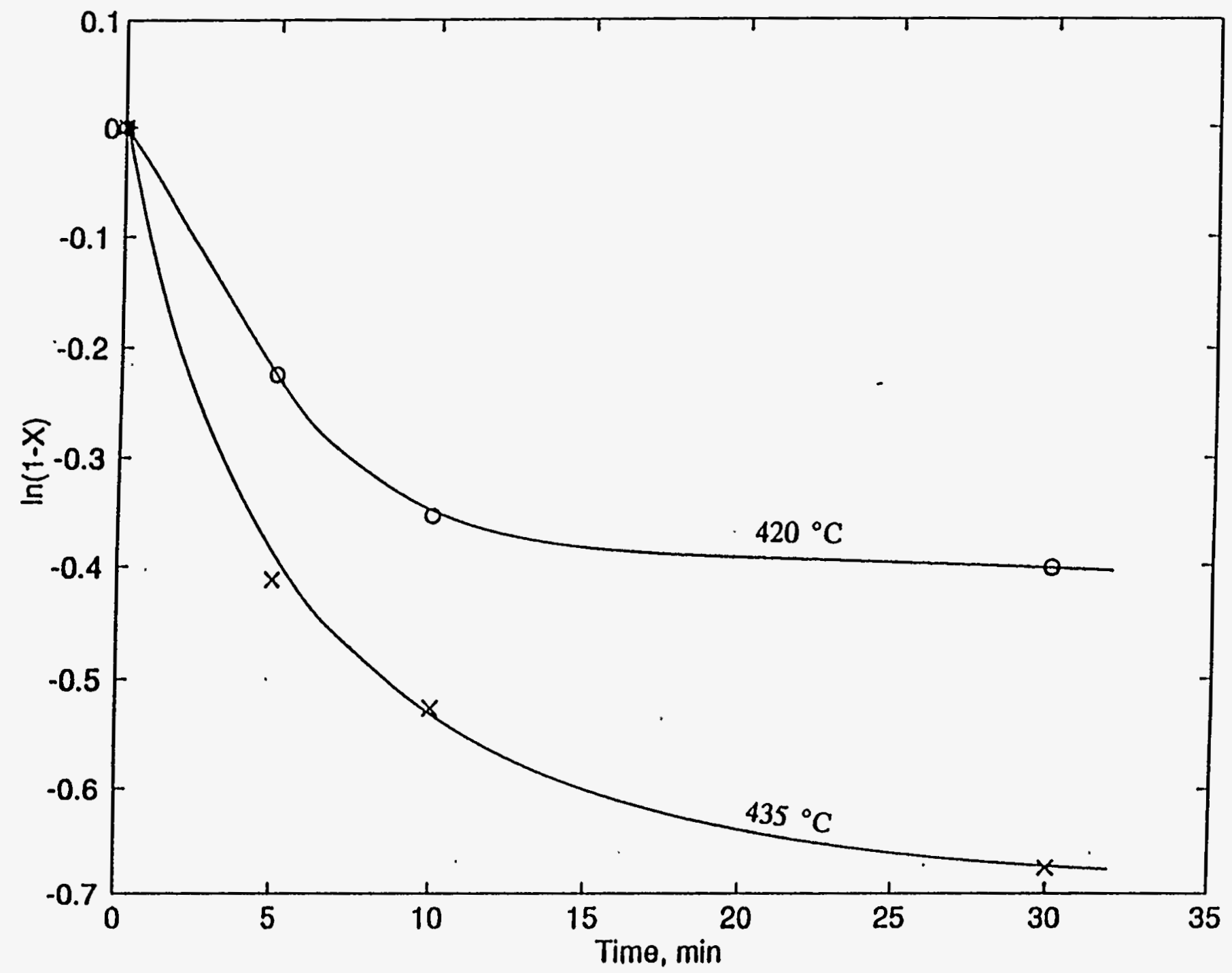

Figure 14

Relative reaction rate constant vs time for the catalyzed hydroprocessing conversion of Resid $\mathrm{C}$ using the first-order assumption (1500 psig $\mathrm{H}_{2} ; 3$ wt\% Mo; Tetralin:Resid=3:1 wt. ratio) 


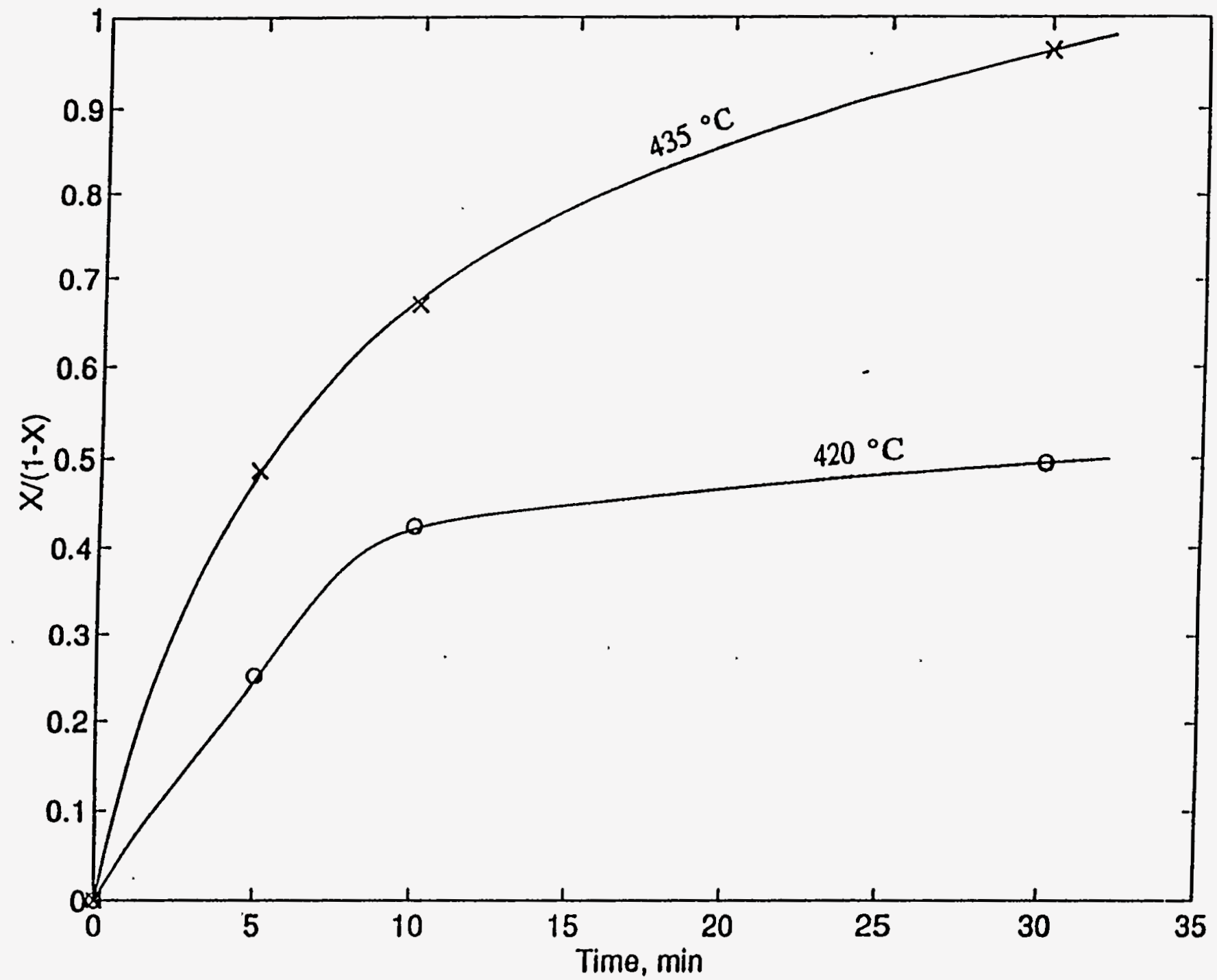

Figure 15

Relative reaction rate constant vs time for the catalyzed hydroprocessing conversion of Resid $\mathrm{C}$ using the second-order assumption (1500 psig $\mathrm{H}_{2} ; 3 \mathrm{wt} \% \mathrm{Mo}$; Tetralin:Resid=3:1 wt. ratio) 


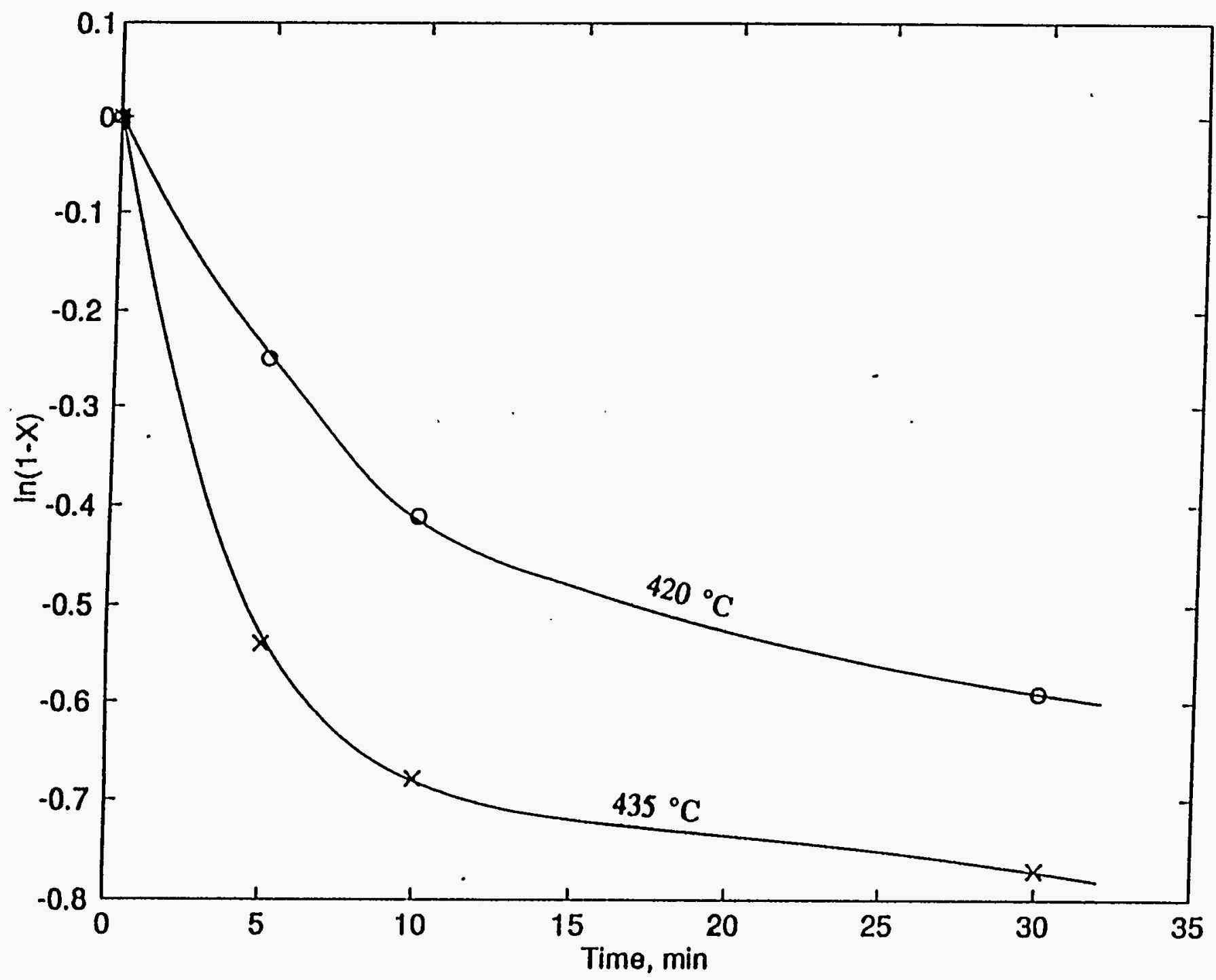

Figure 16

Relative reaction rate constant vs time for the catalyzed hydroprocessing conversion of Resid $\mathbf{H}$ using the first-order assumption (1500 psig. $\mathrm{H}_{2} ; 3 \mathrm{wt} \% \mathrm{Mo}$; Tetralin:Resid=3:1 wt. ratio) 


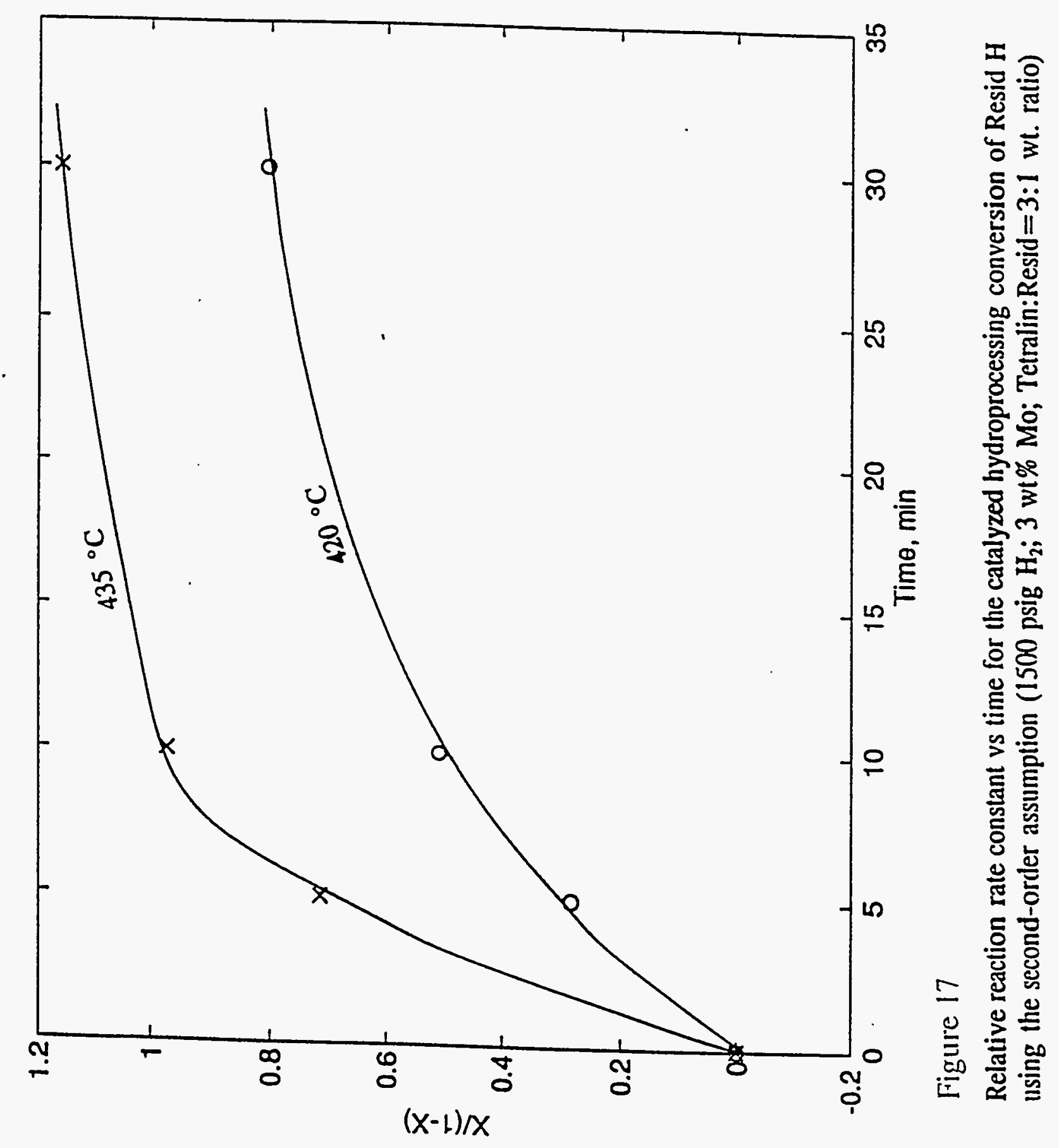




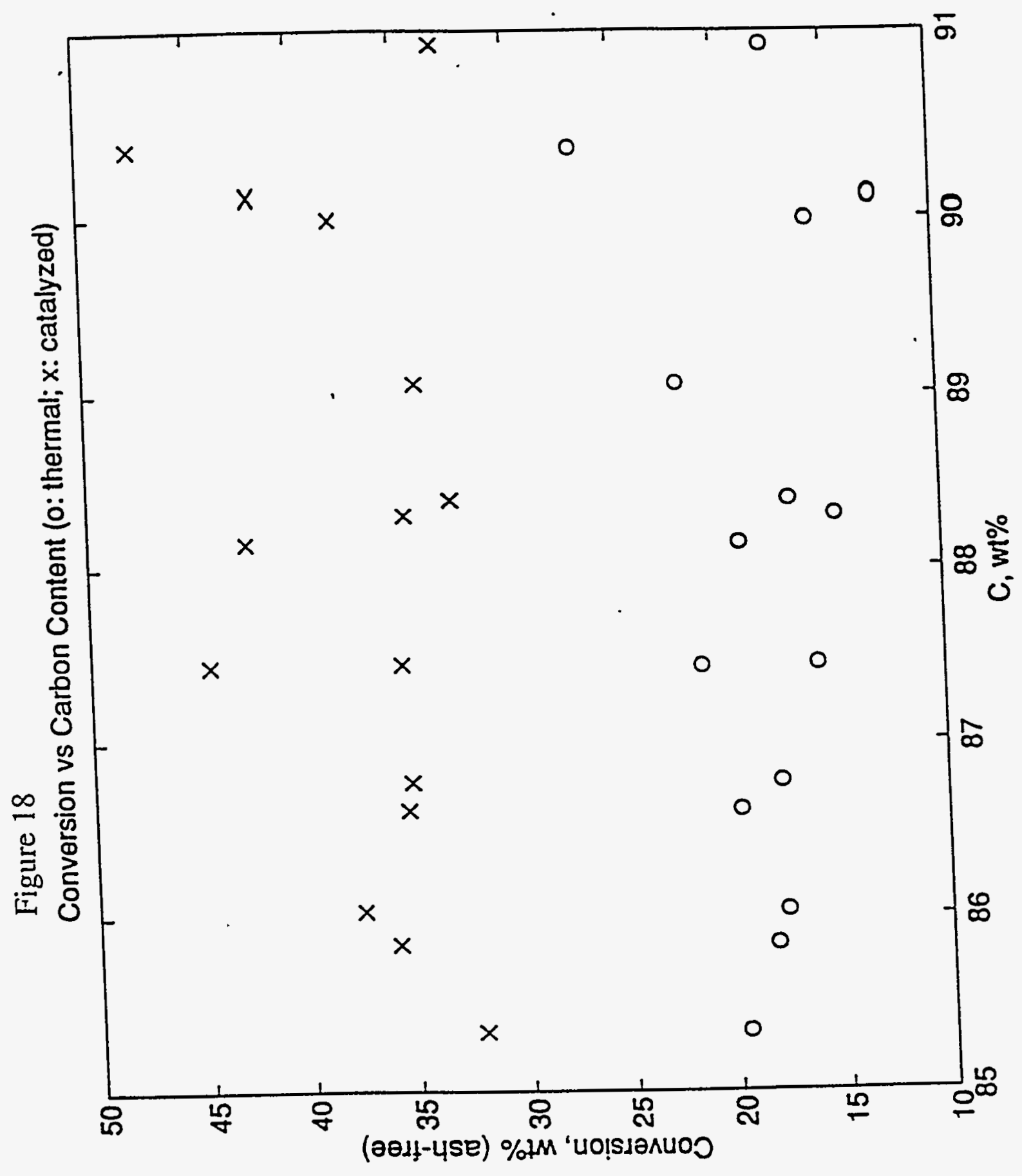




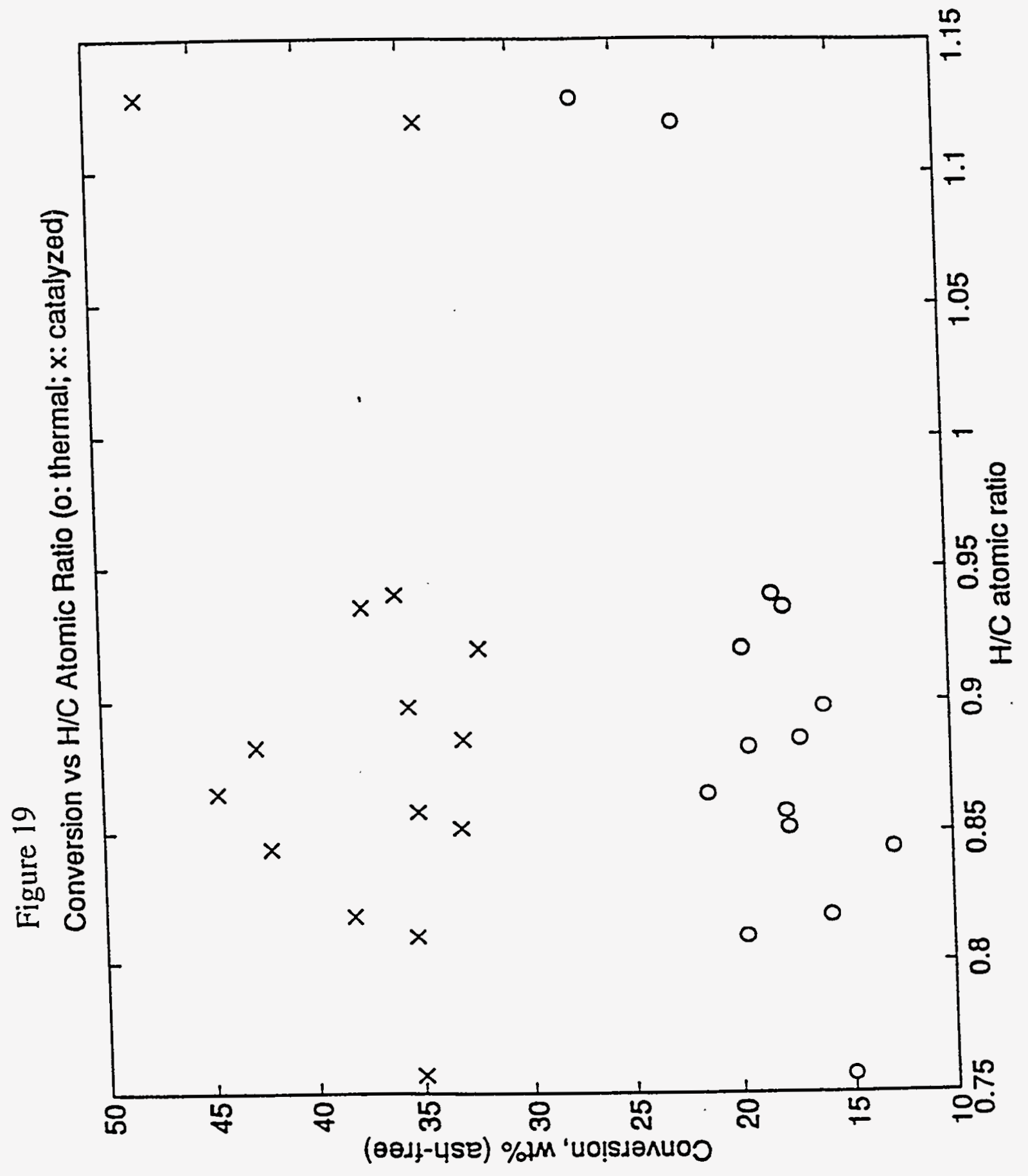




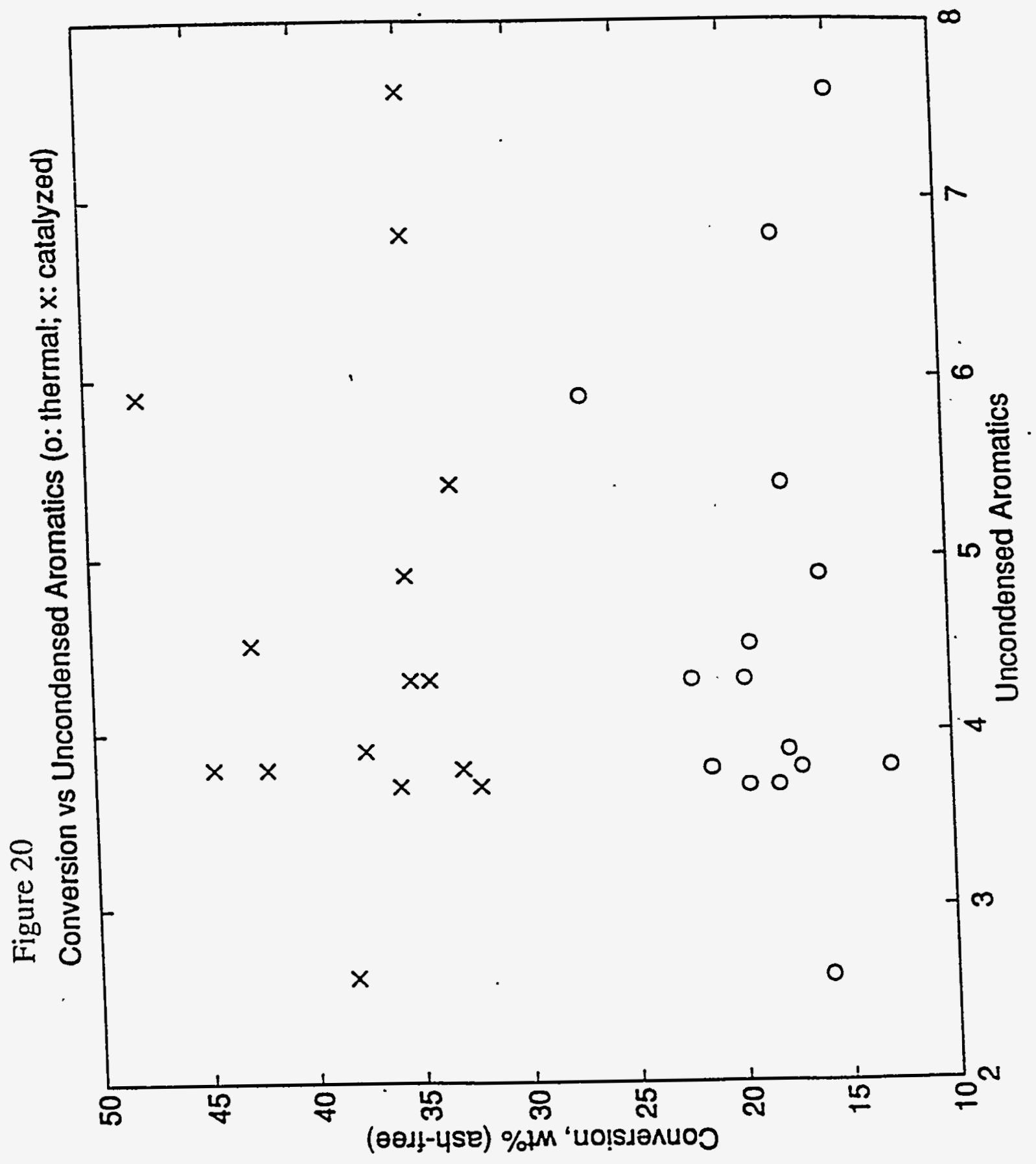




\section{Exponential Distribution}
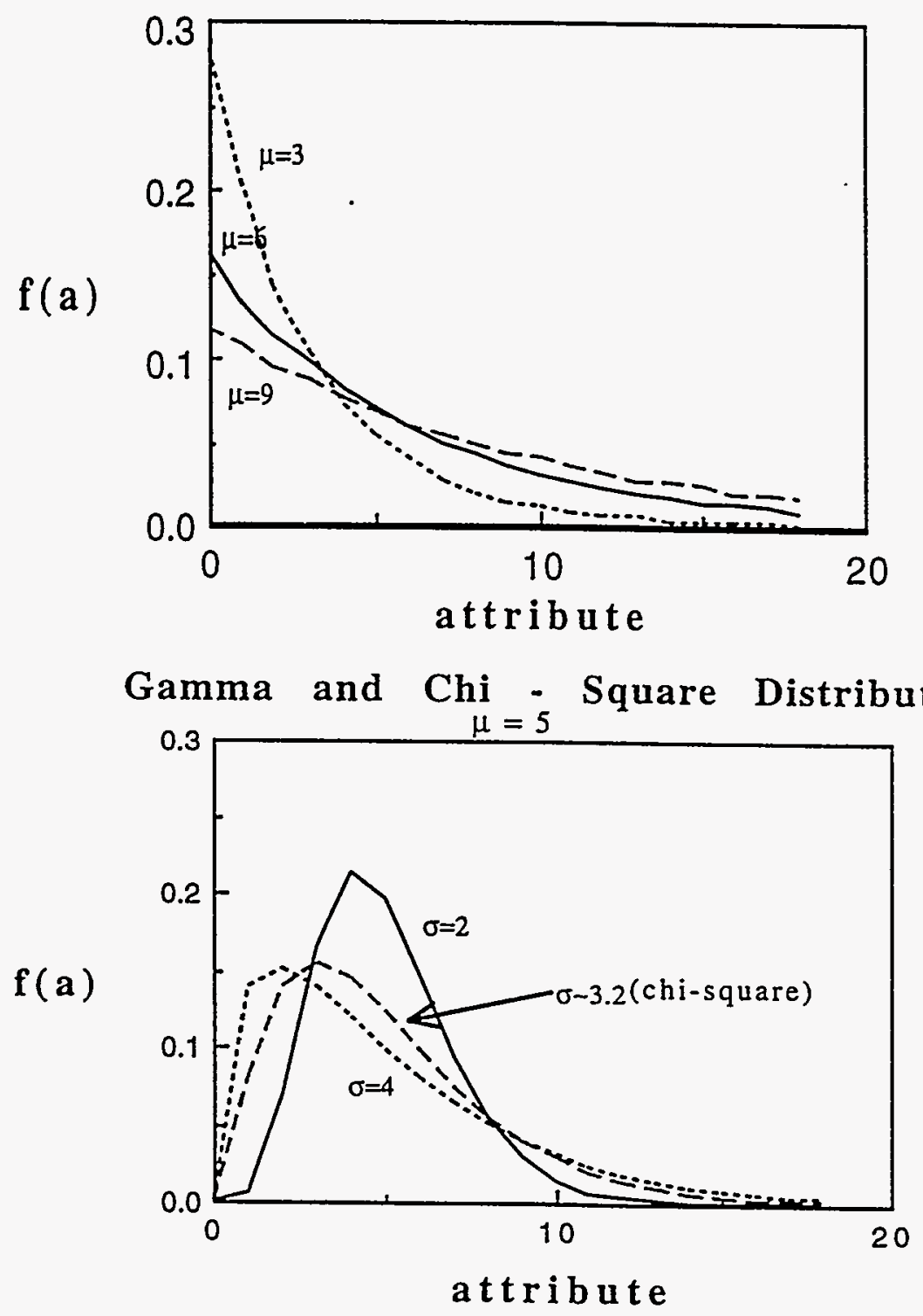

Figure 21: Two probability density functions. (Reproduced from Trauth, (23)) 


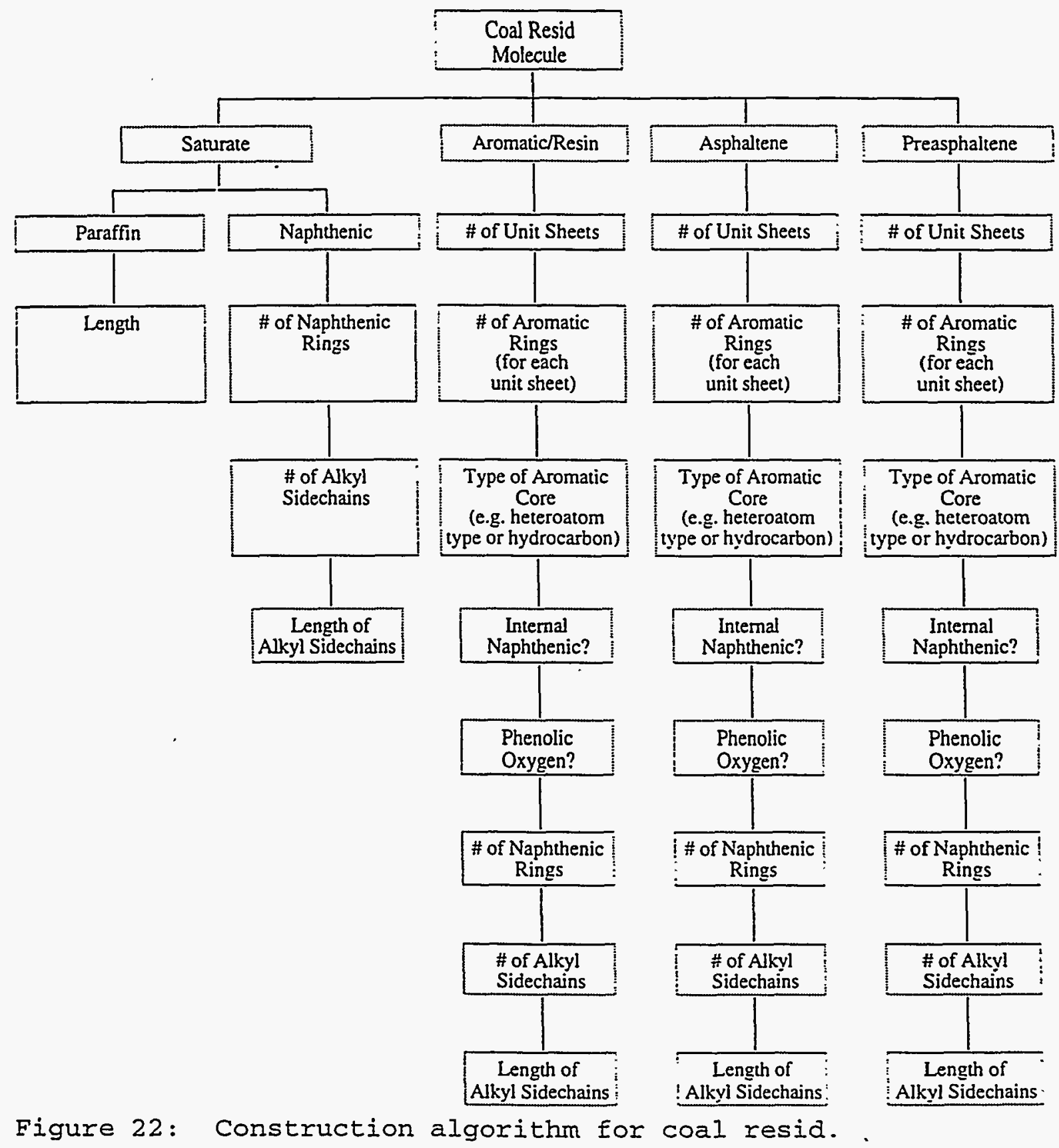



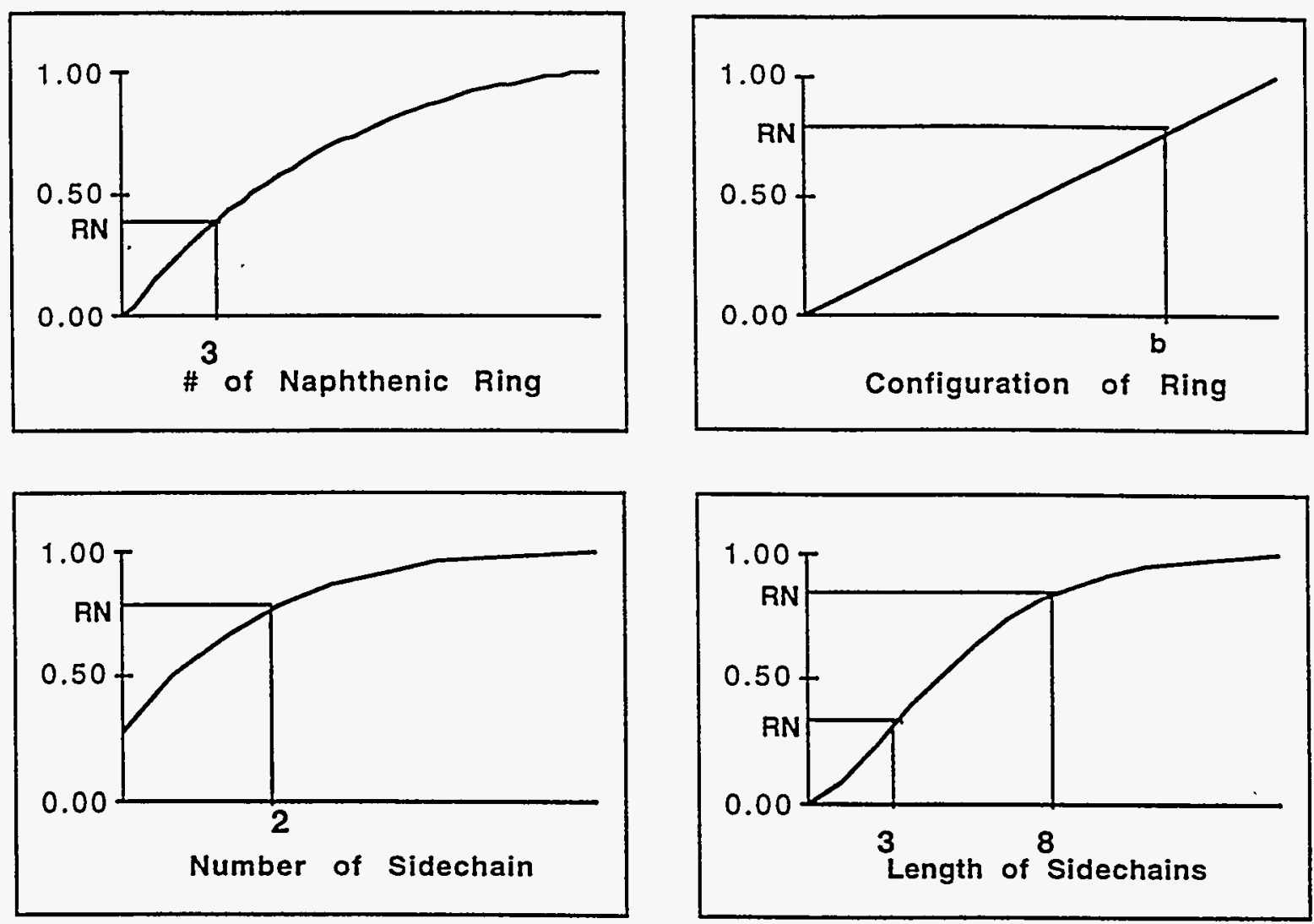

Figure 23: Stochastic construction of a naphthenic molecule. 


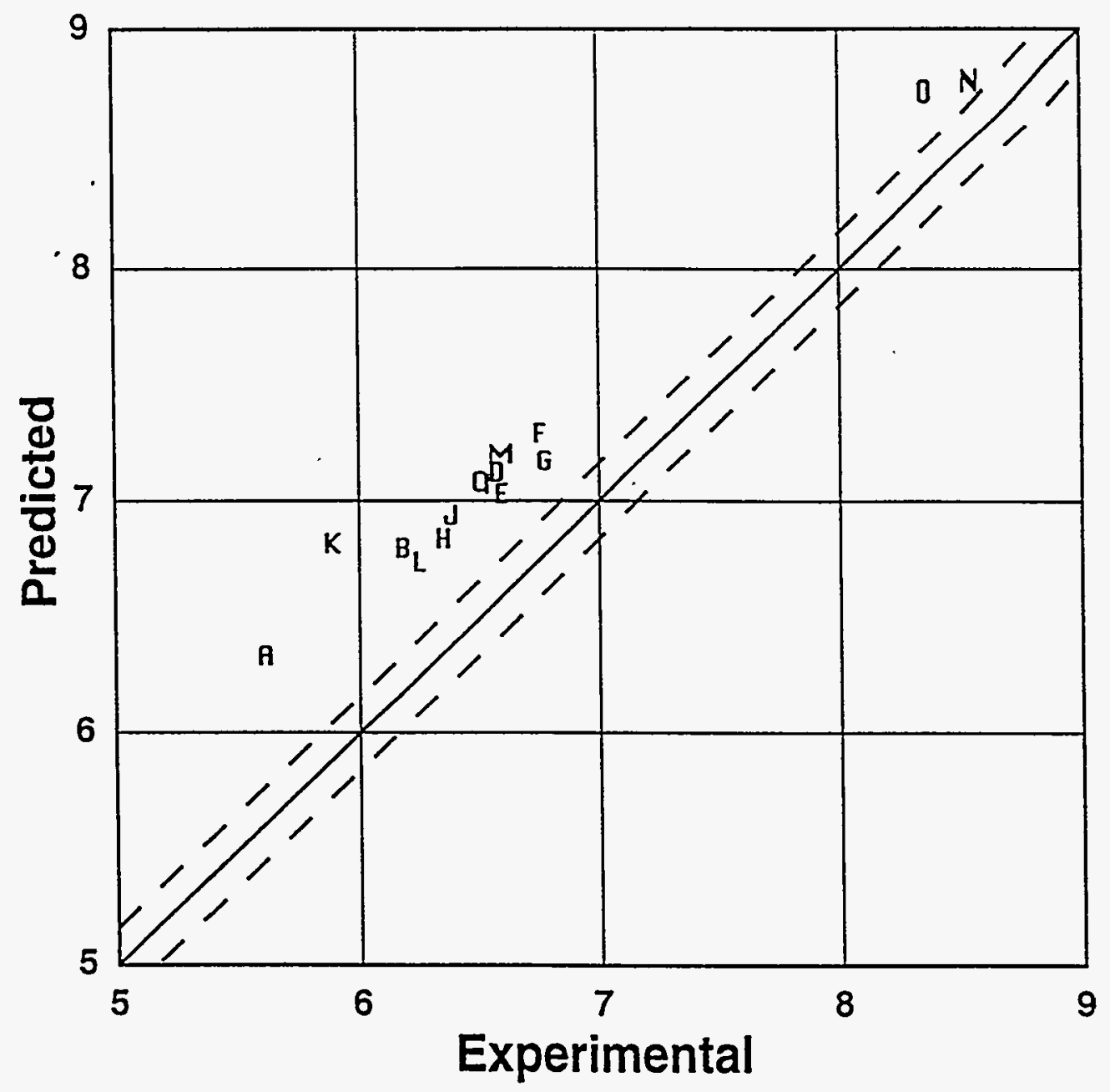

Figure 24: Predicted versus experimental hydrogen weight percent. 


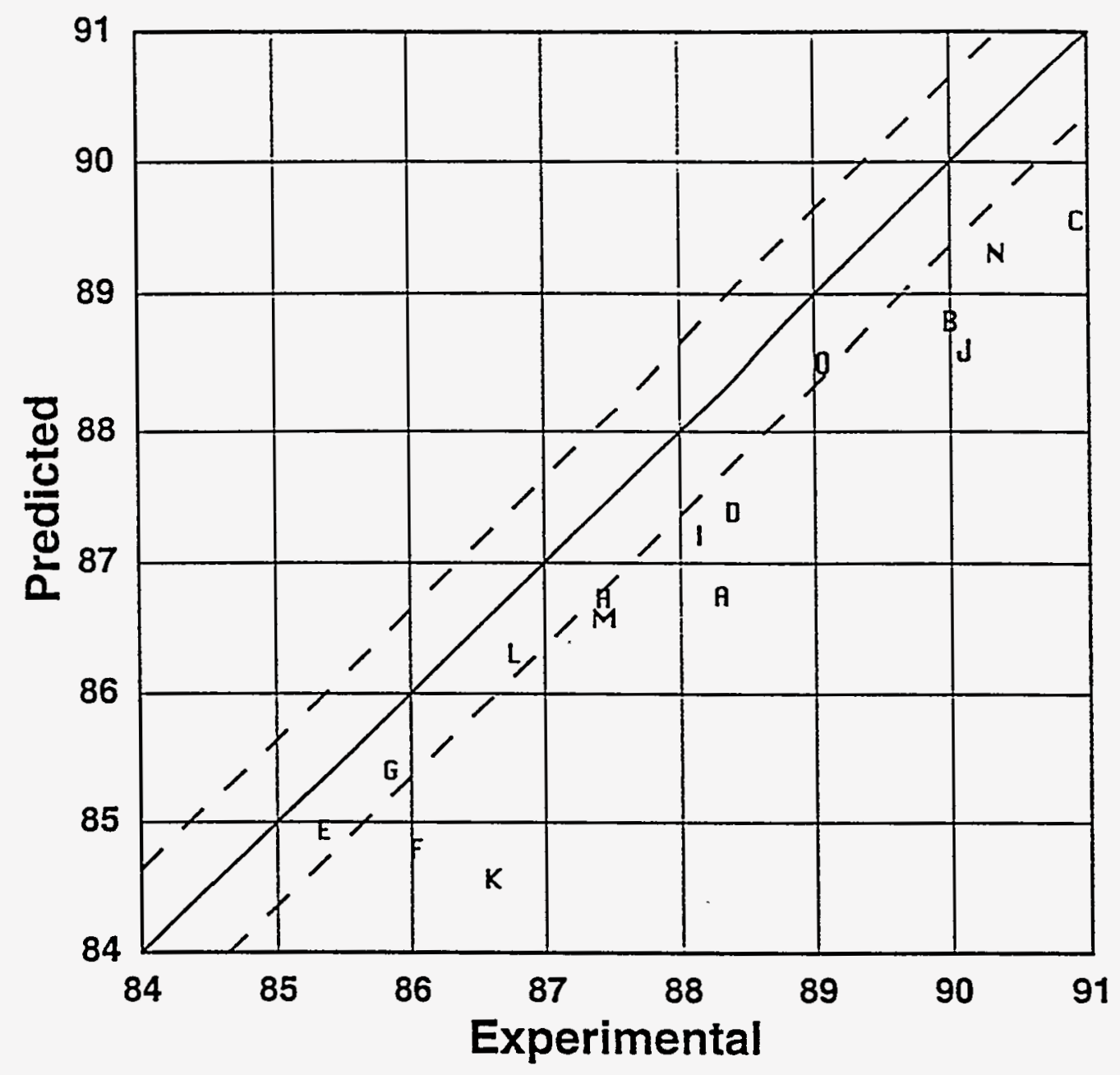

Figure 25: Predicted versus experiment carbon weight percent. 


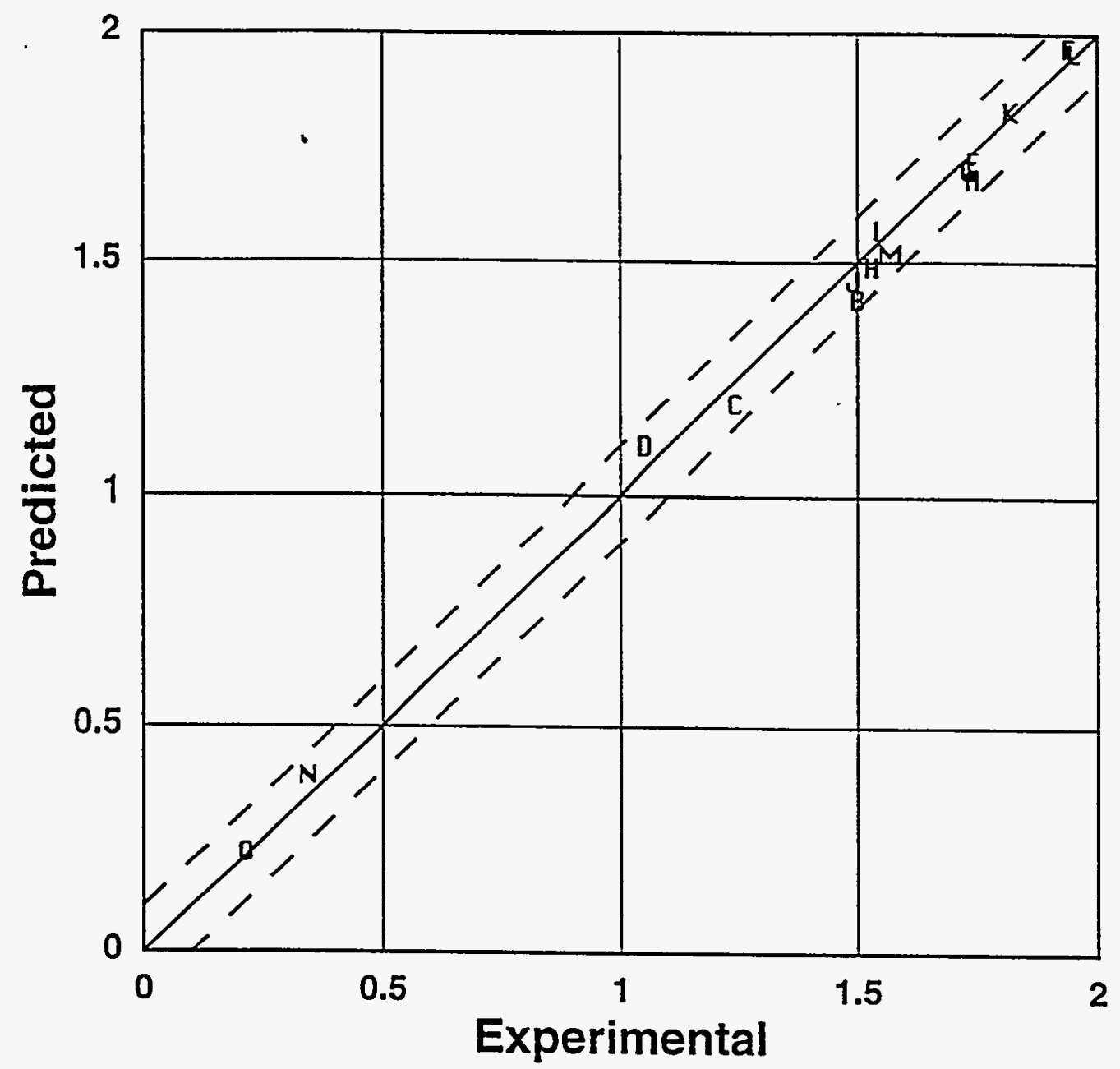

Figure 26: Predicted versus experimental sulfur weight percent. 


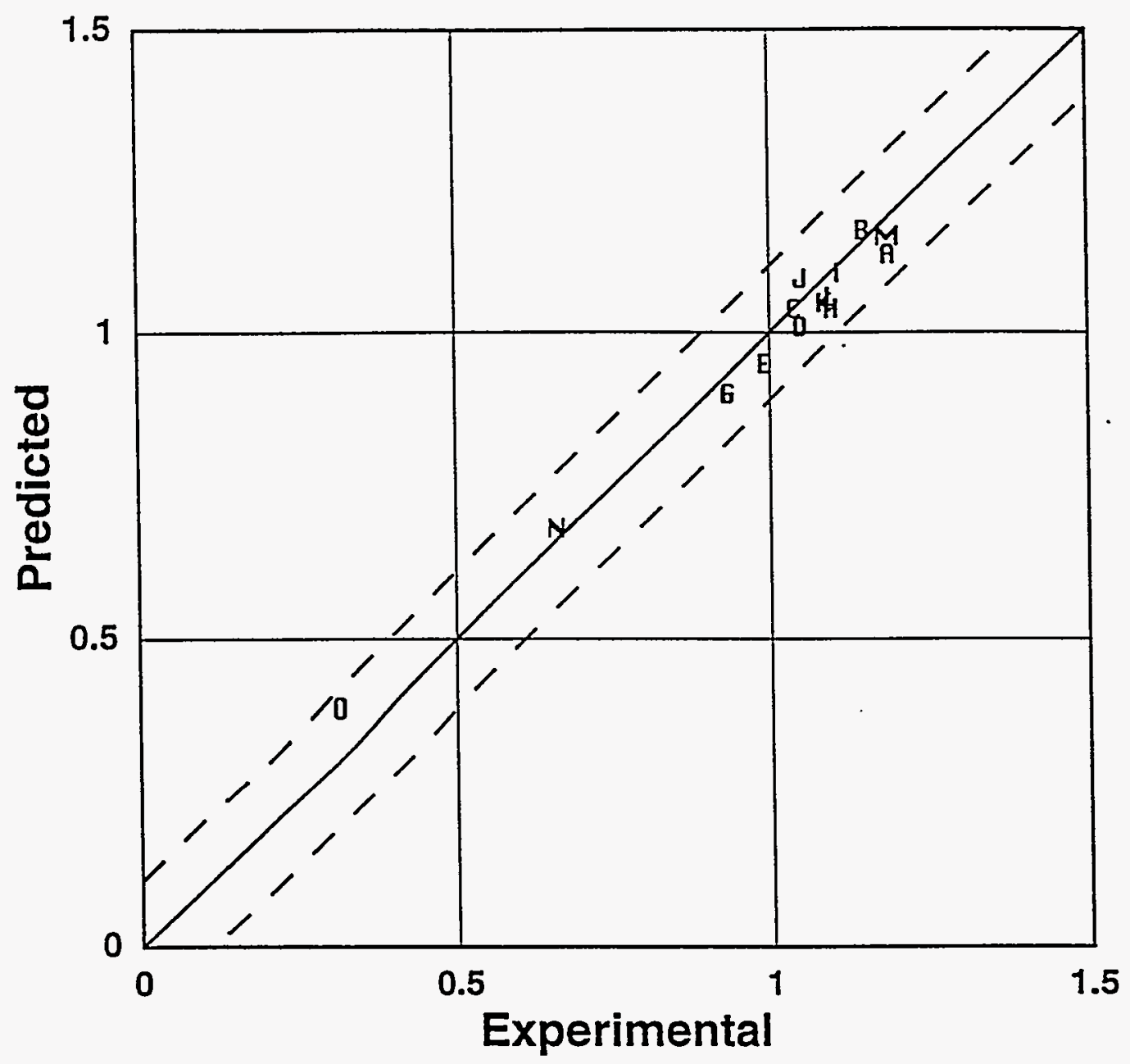

Figure 27: Predicted versus experimental nitrogen weight percent. 


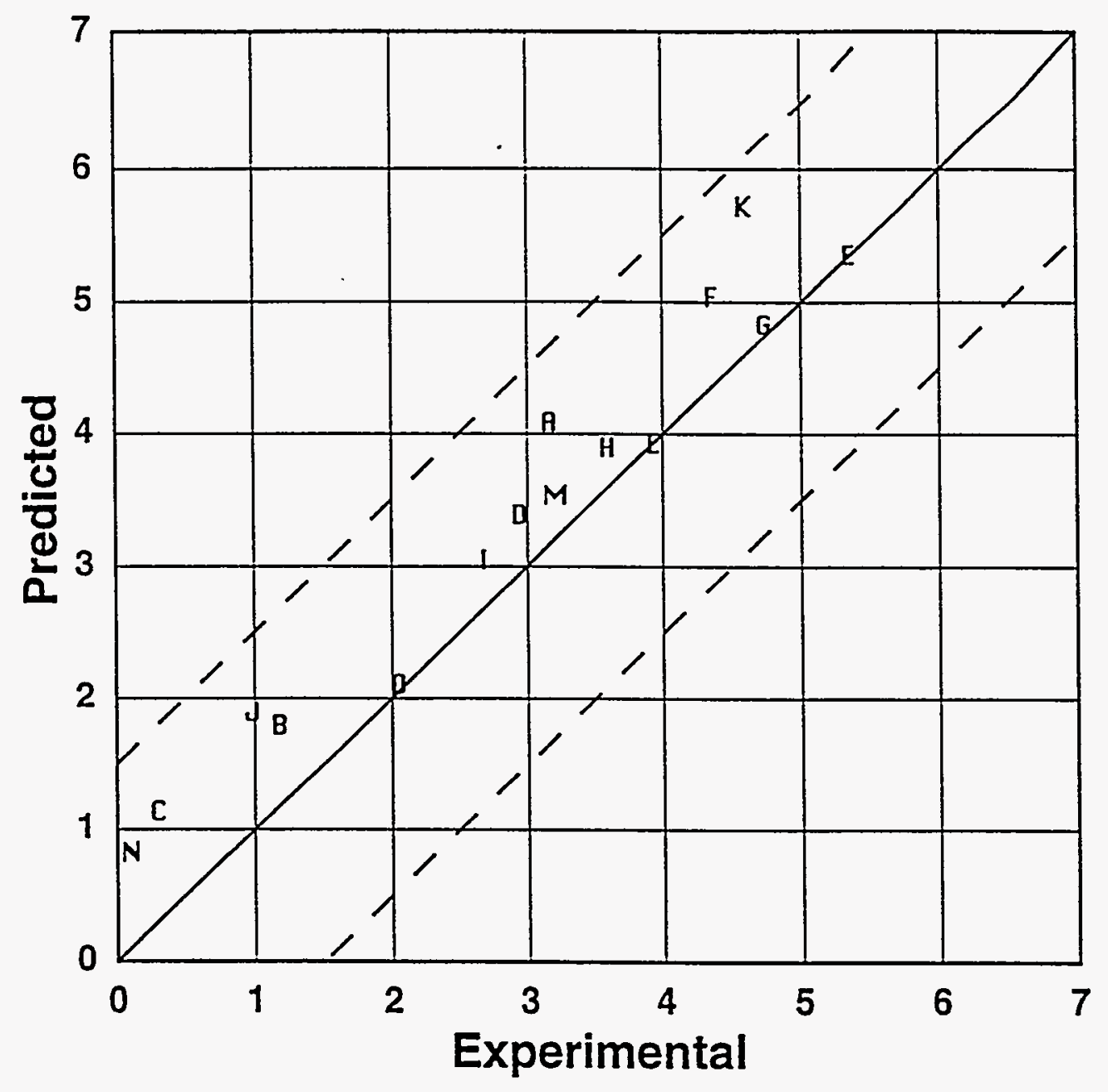

Figure 28: Predicted versus experimental oxygen weight percent. 


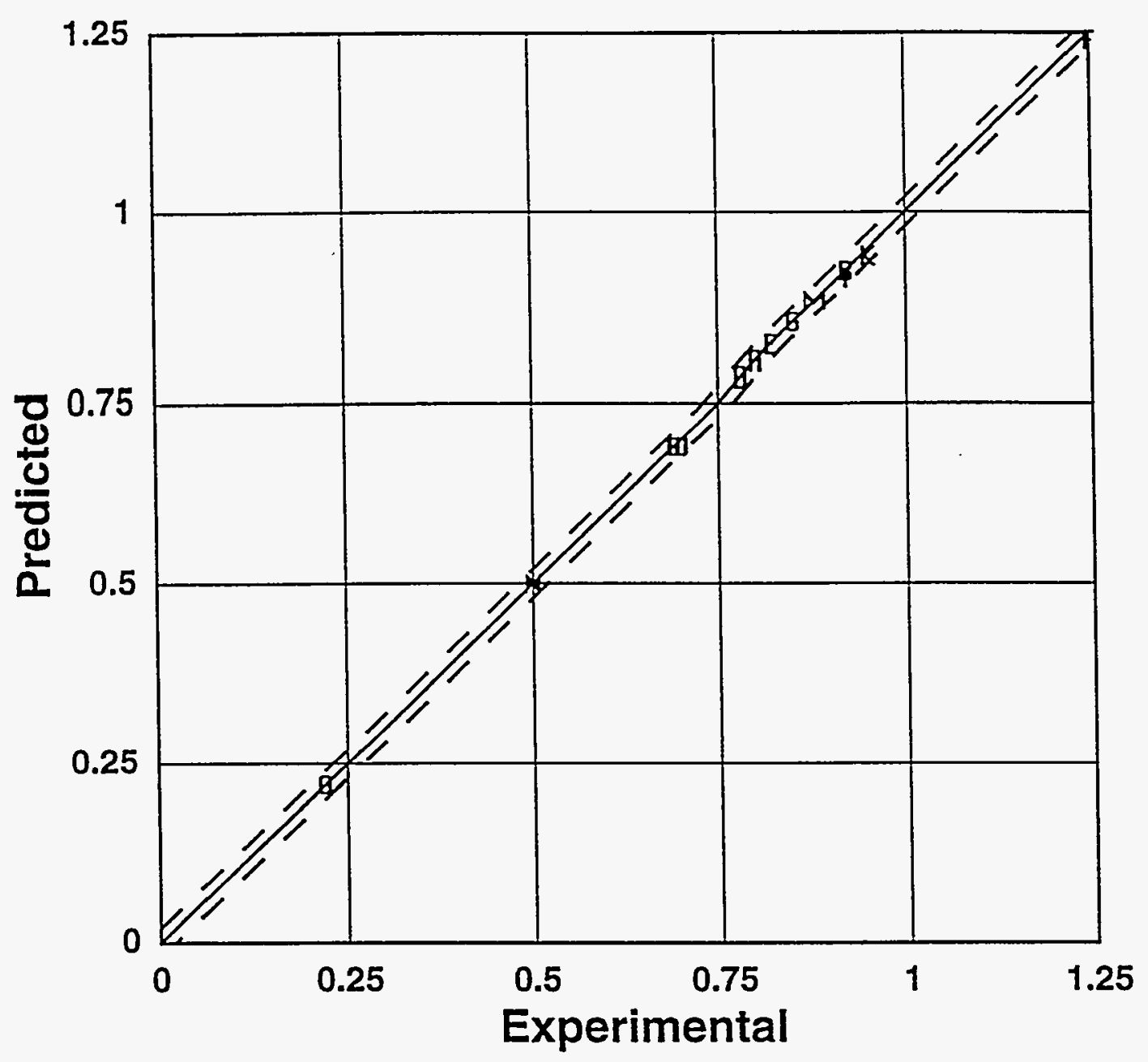

Figure 29: Predicted versus experimental phenolic oxygen (meq/g). 


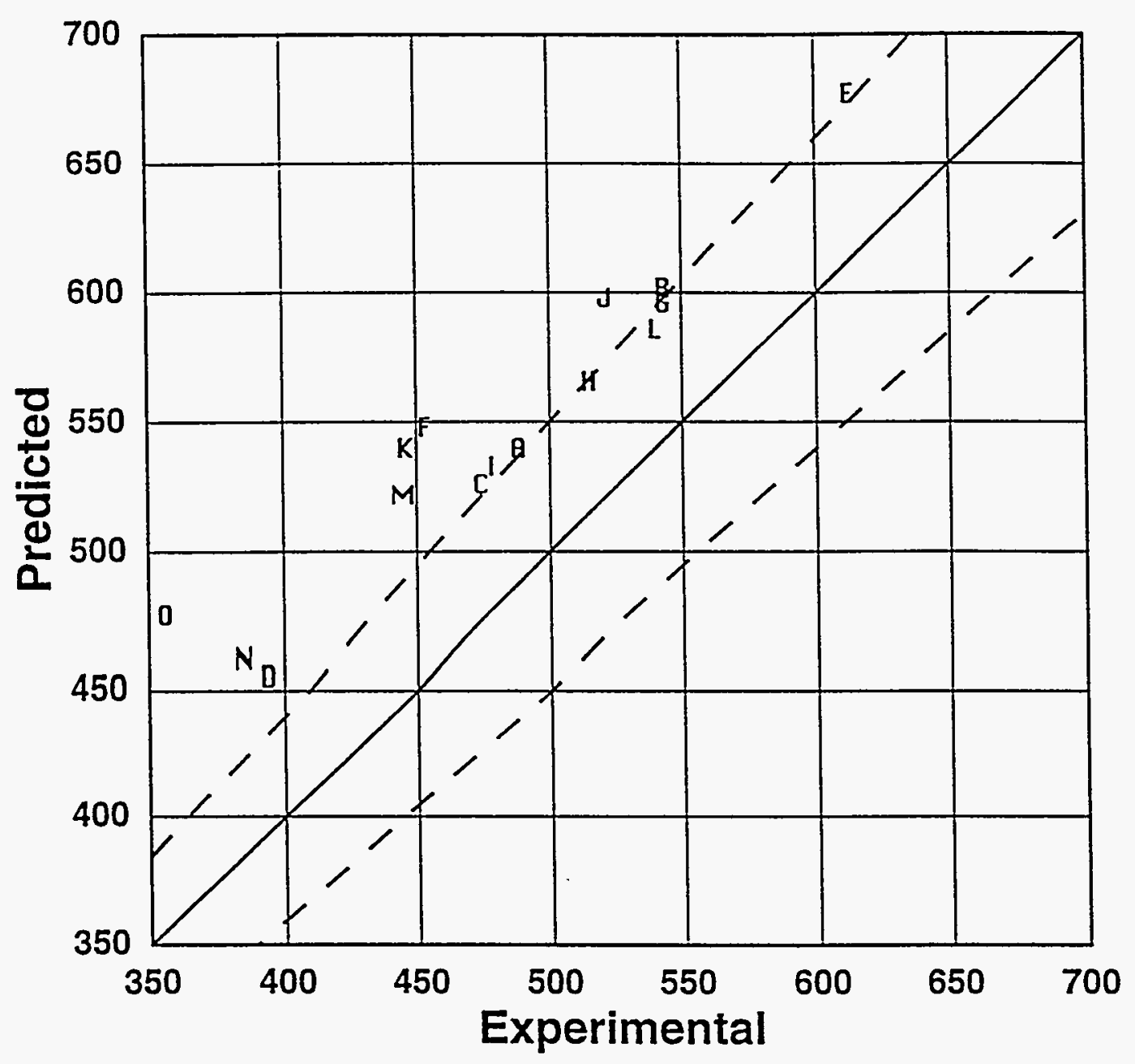

Figure 30: Predicted versus experimental molecular weight ( $\mathrm{g}$ ). 


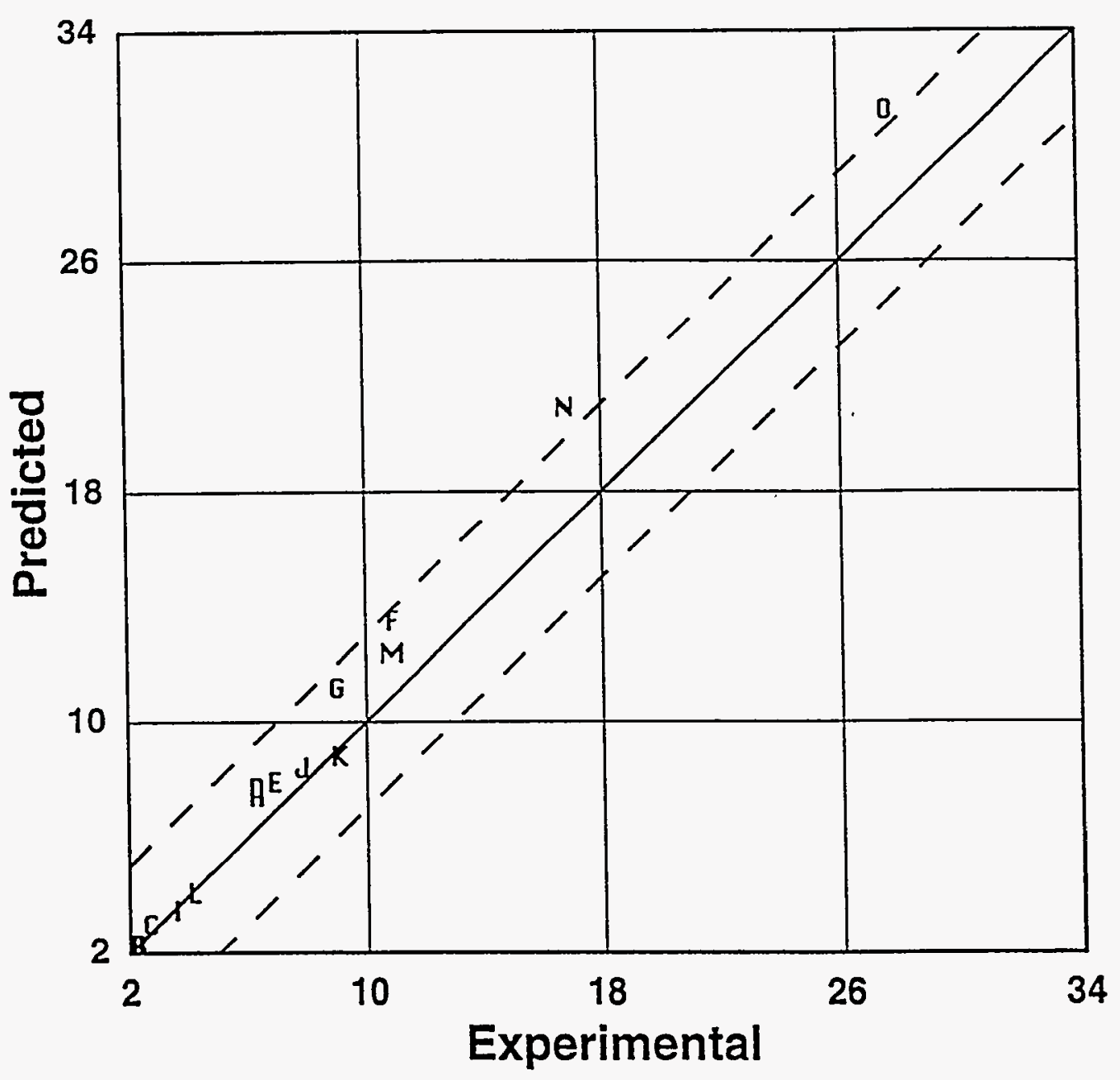

Figure 31: Predicted versus experimental saturates weight percent. 


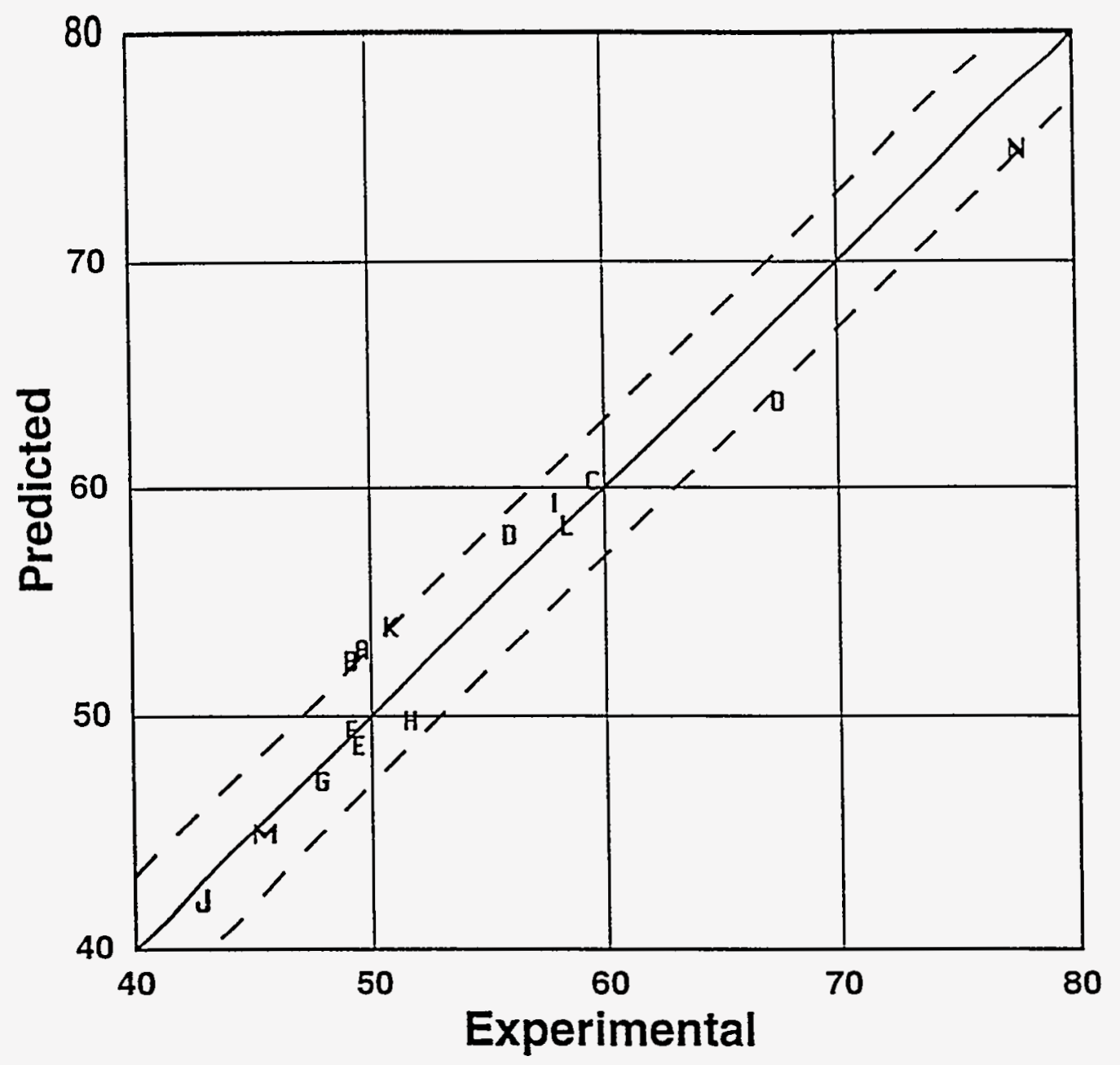

Figure 32: Predicted versus experimental resins/aromatics weight percent. 


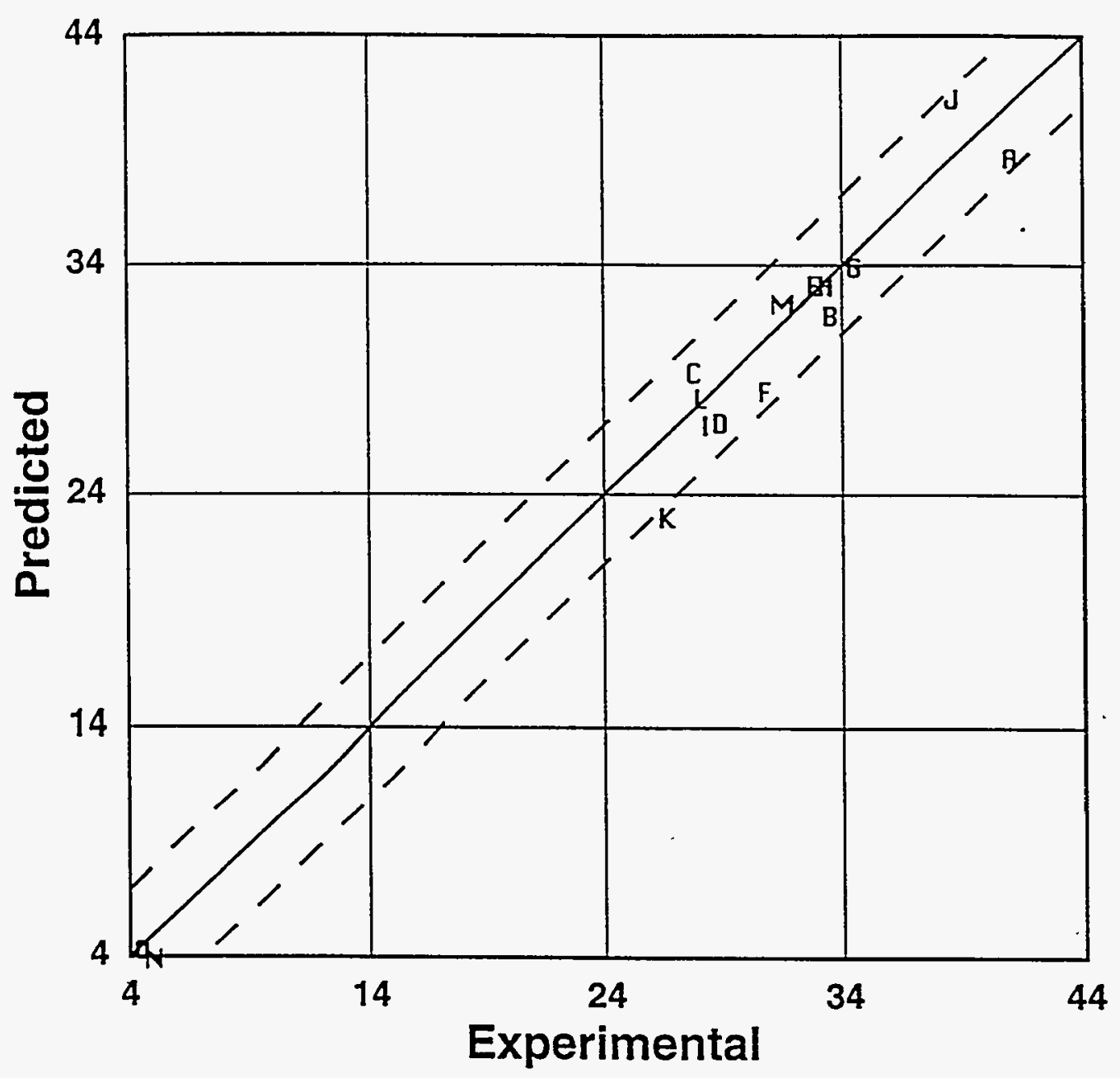

Figure 33: Predicted versus experimental asphaltene weight percent. 


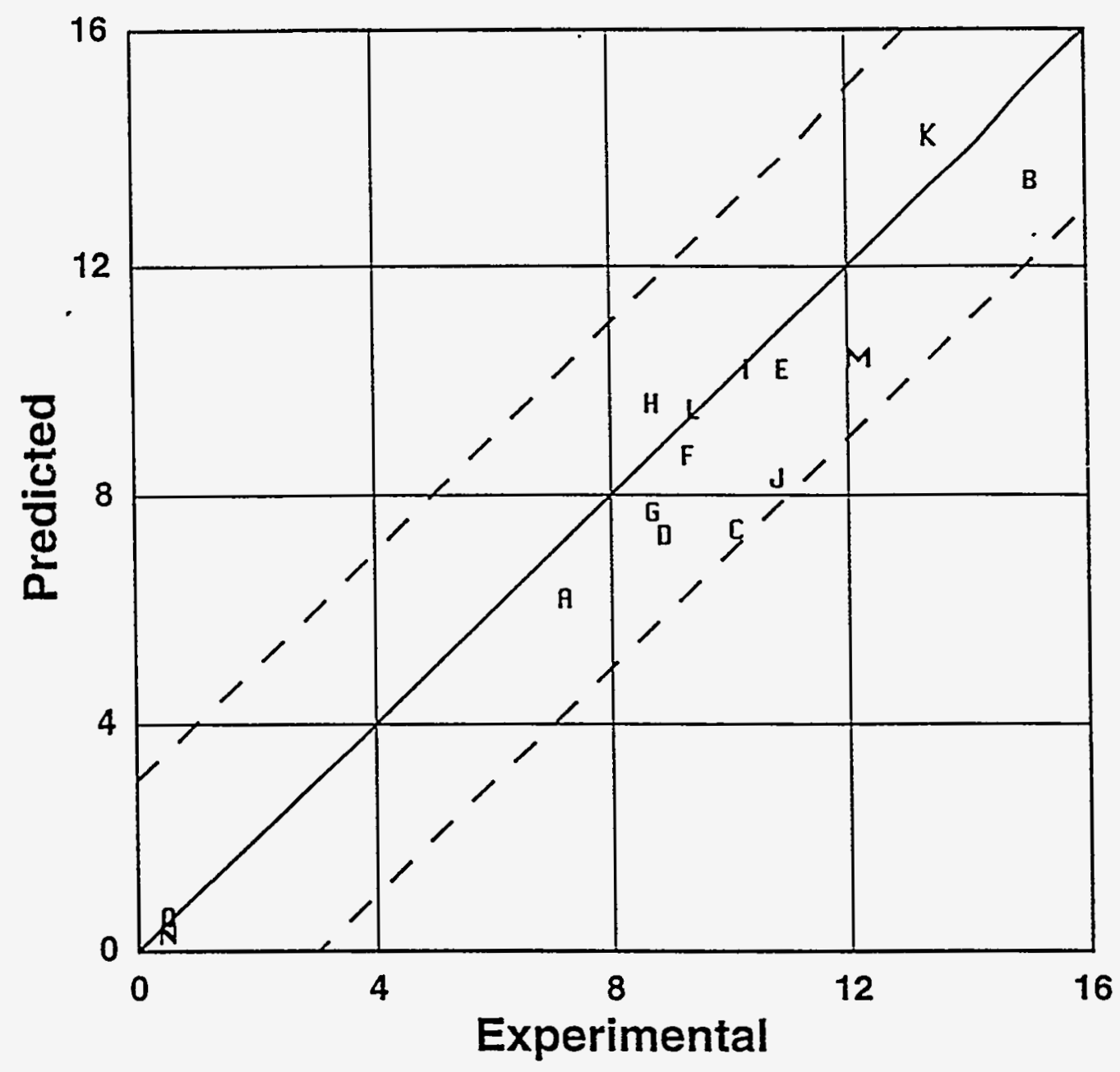

Figure 34: Predicted versus experimental preasphaltene weight percent. 


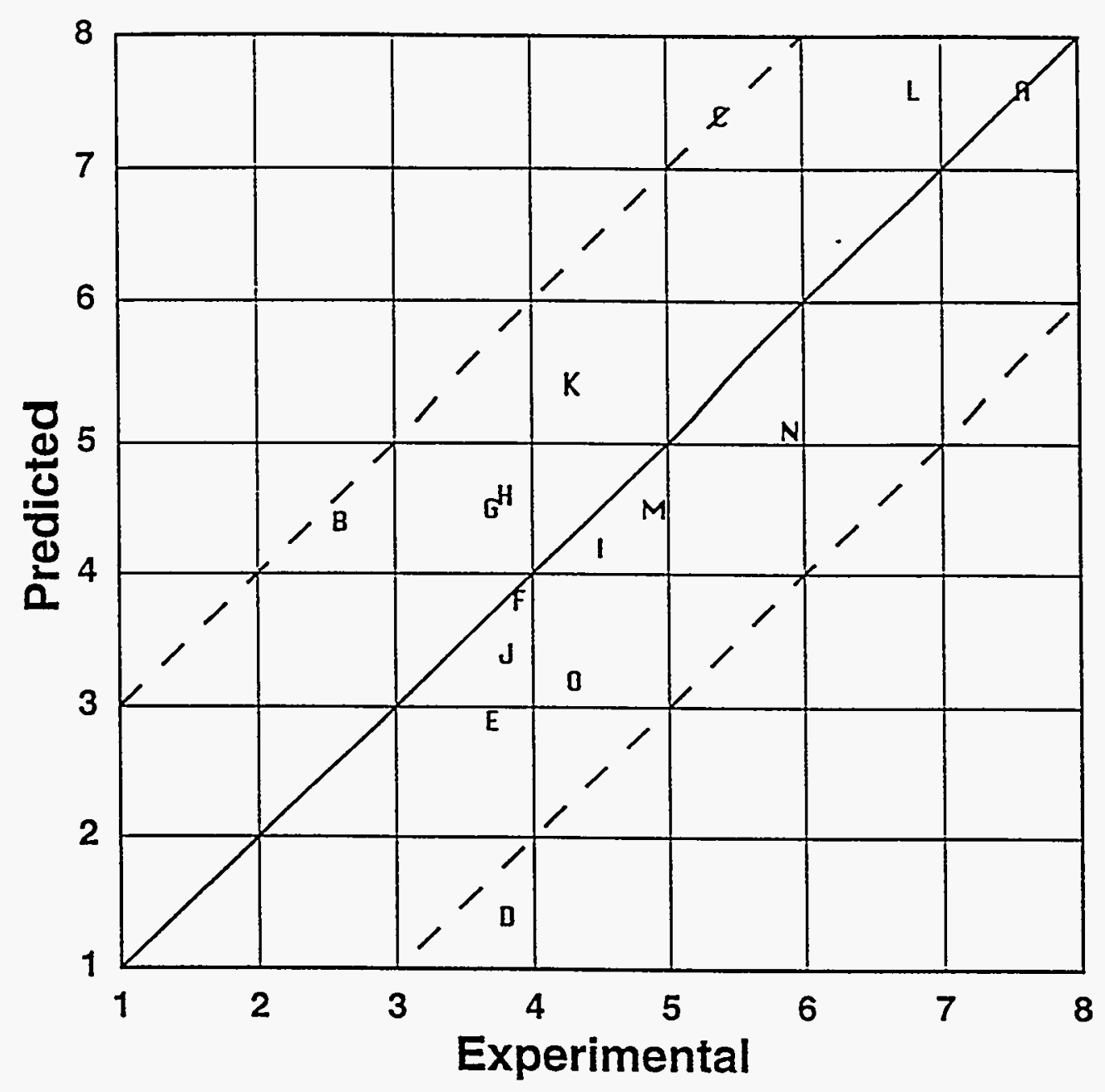

Figure 35: Predicted versus experimental aromatic hydrogen percent. 


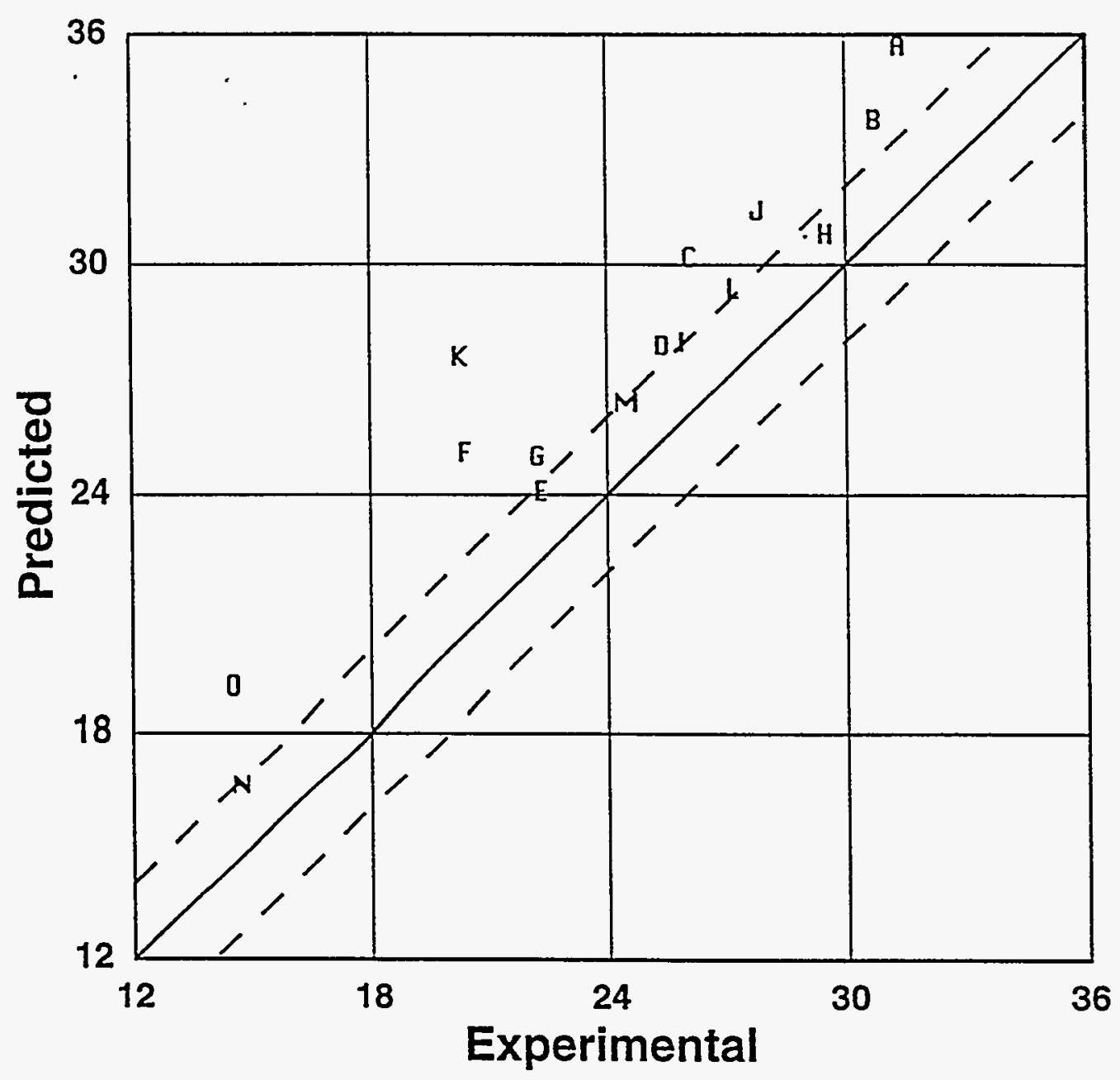

Figure 36: Predicted versus experimental condensed aromatic hydrogen percent. 


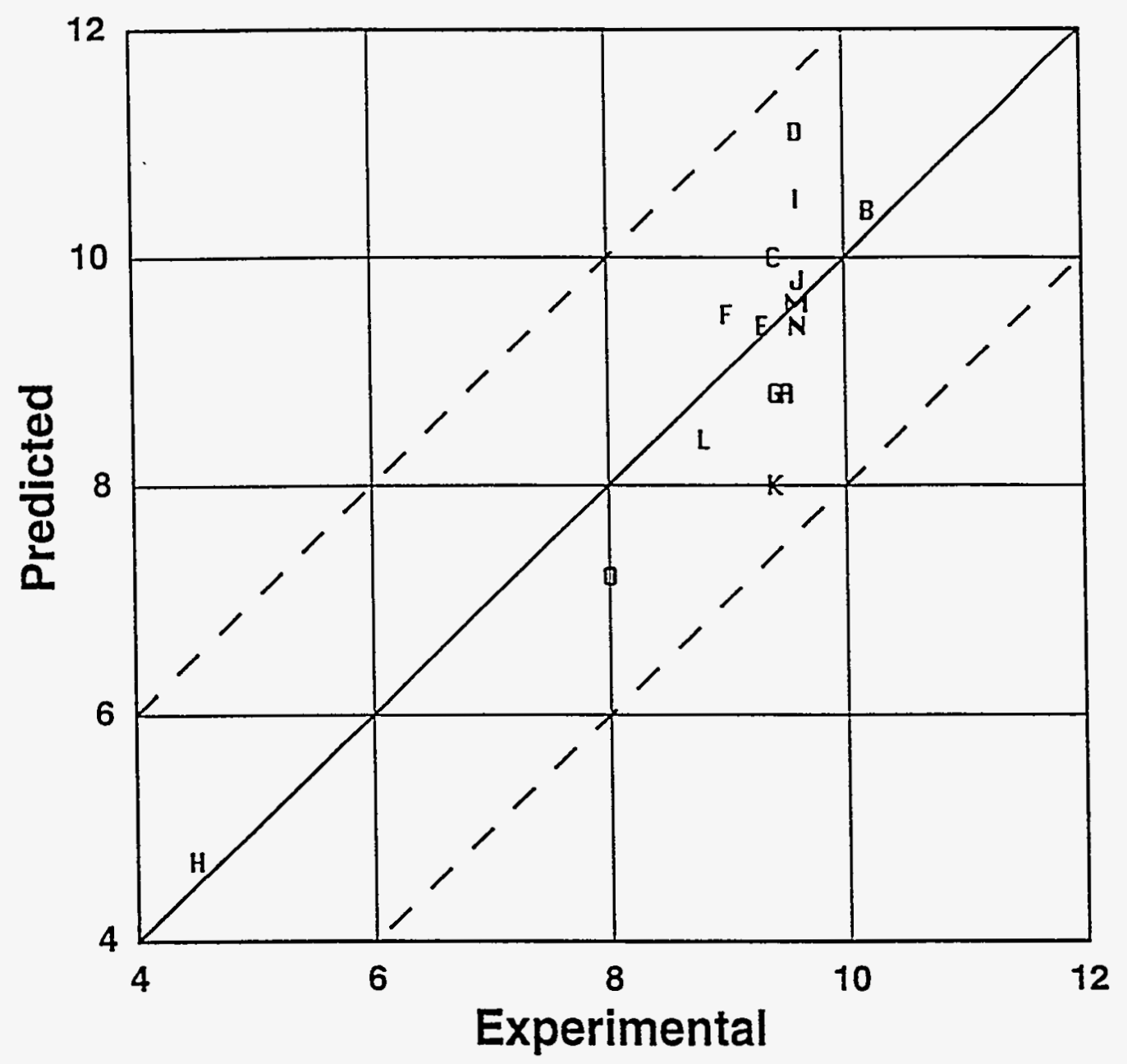

Figure 37: Predicted versus experimental alkyl alpha hydrogen percent. 


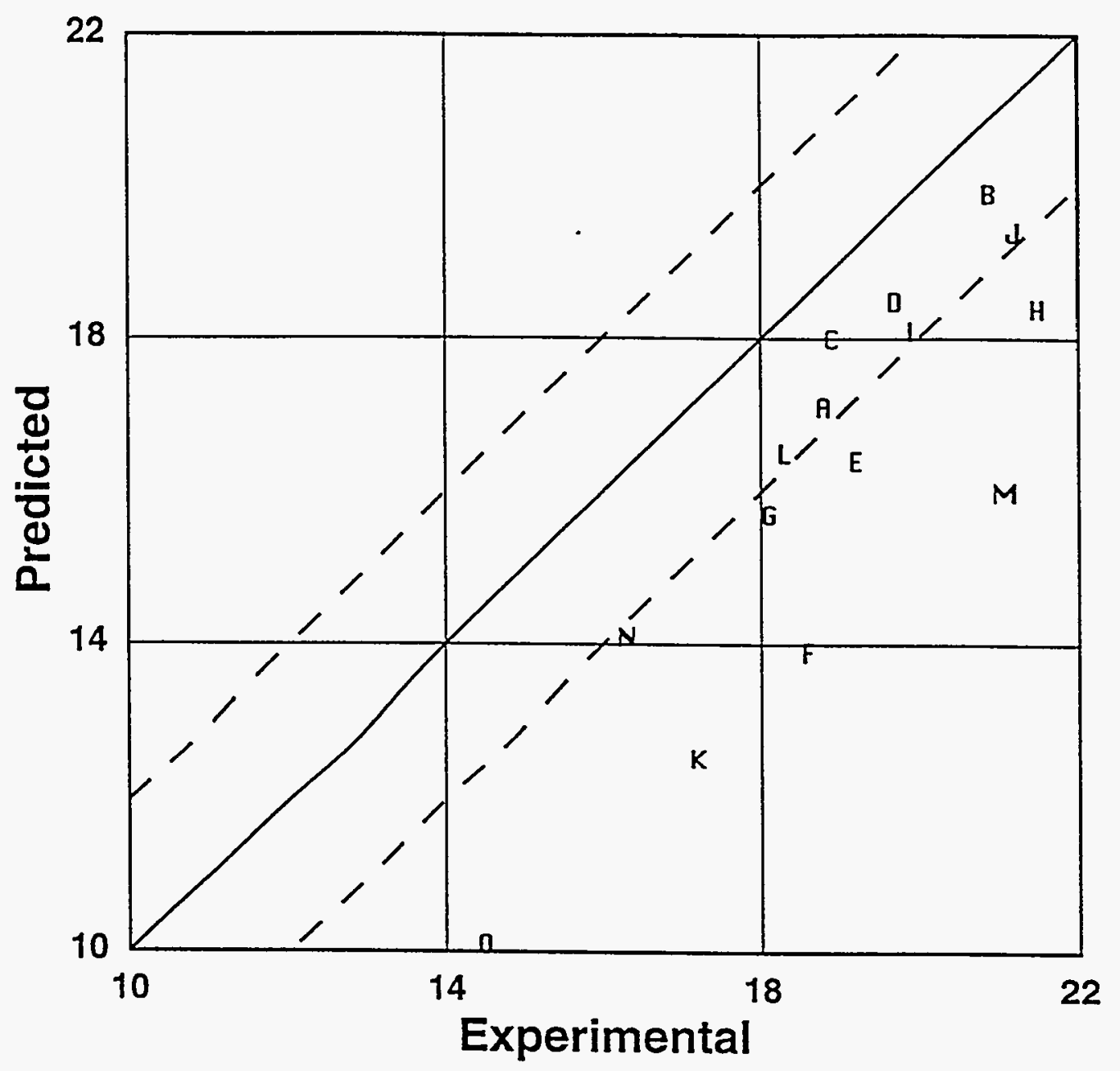

Figure 38: Predicted versus experimental cyclic alpha hydrogen percent. 


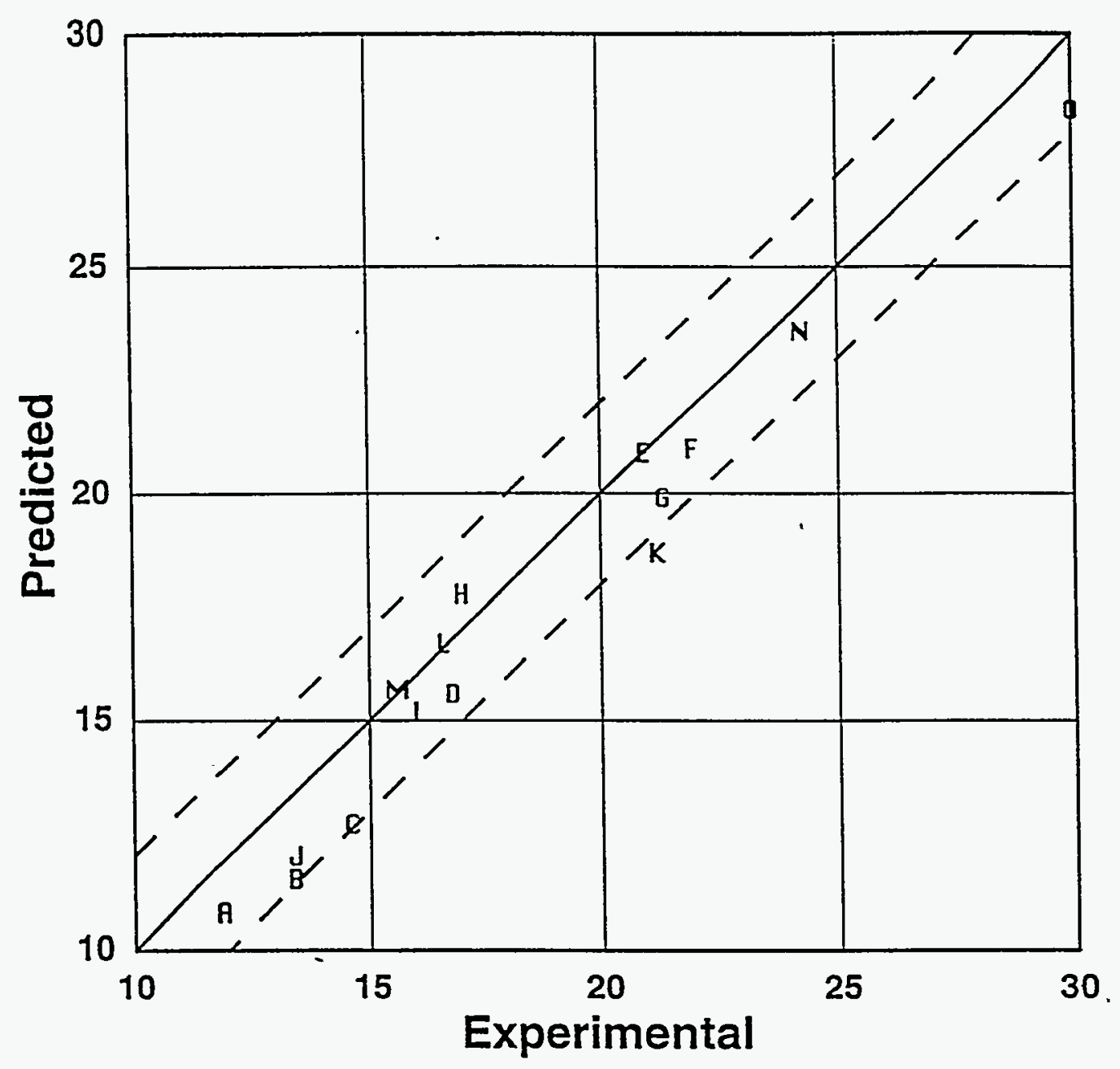

Figure 39: Predicted versus experimental alkyl beta hydrogen percent. 


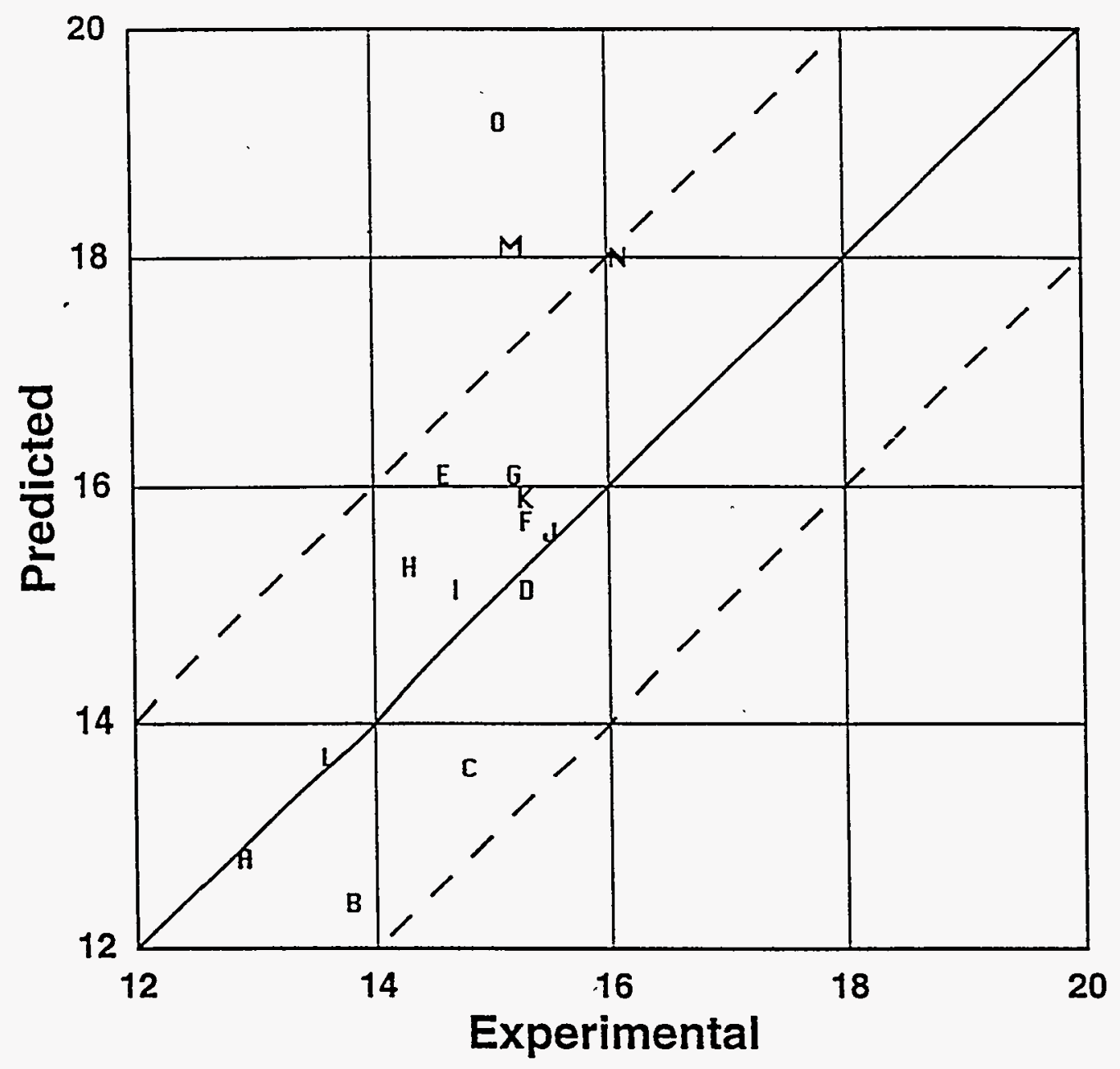

Figure 40: Predicted versus experimental cyclic beta hydrogen percent. 


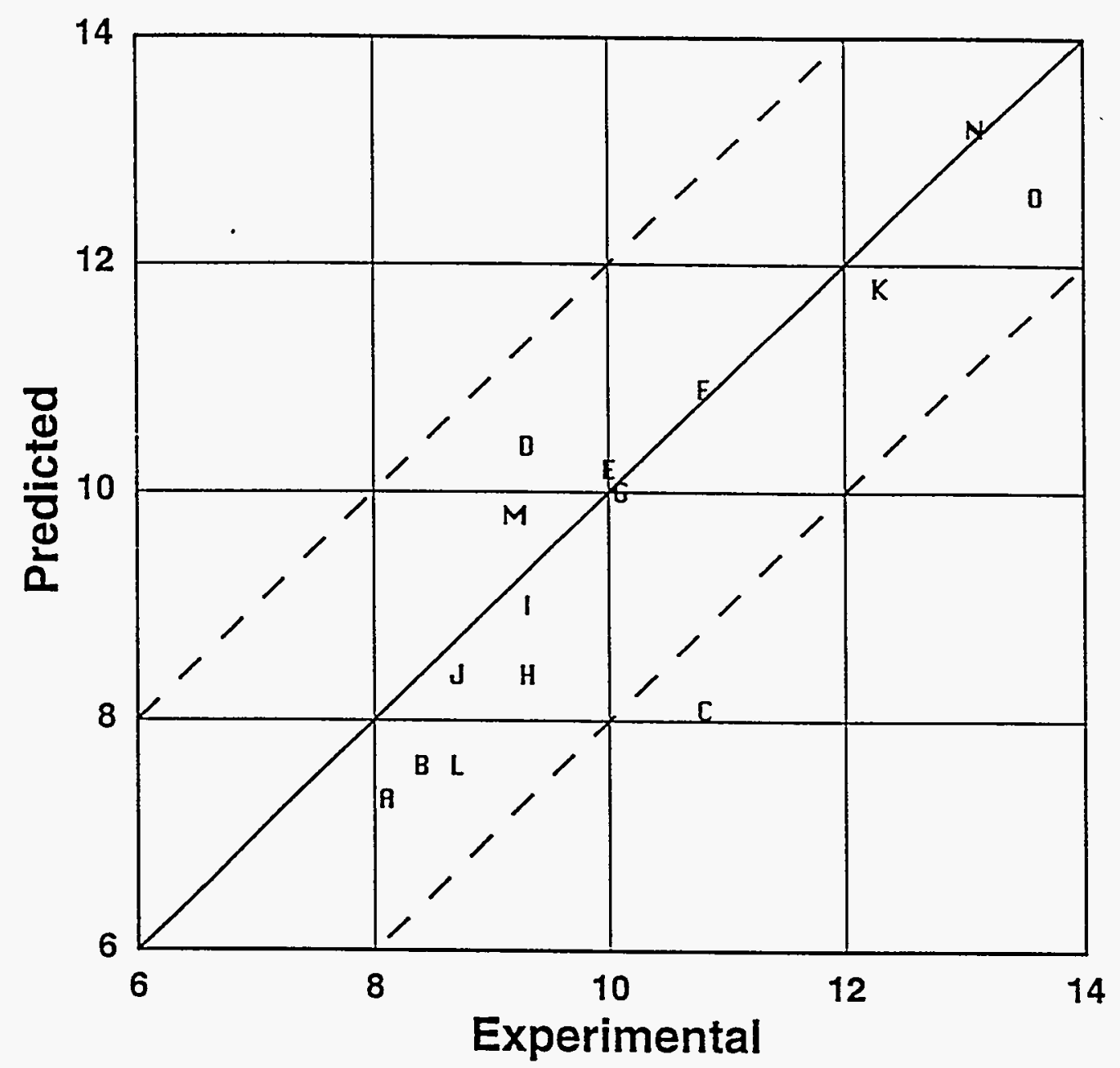

Figure 41: Predicted versus experimental gamma hydrogen percent. 


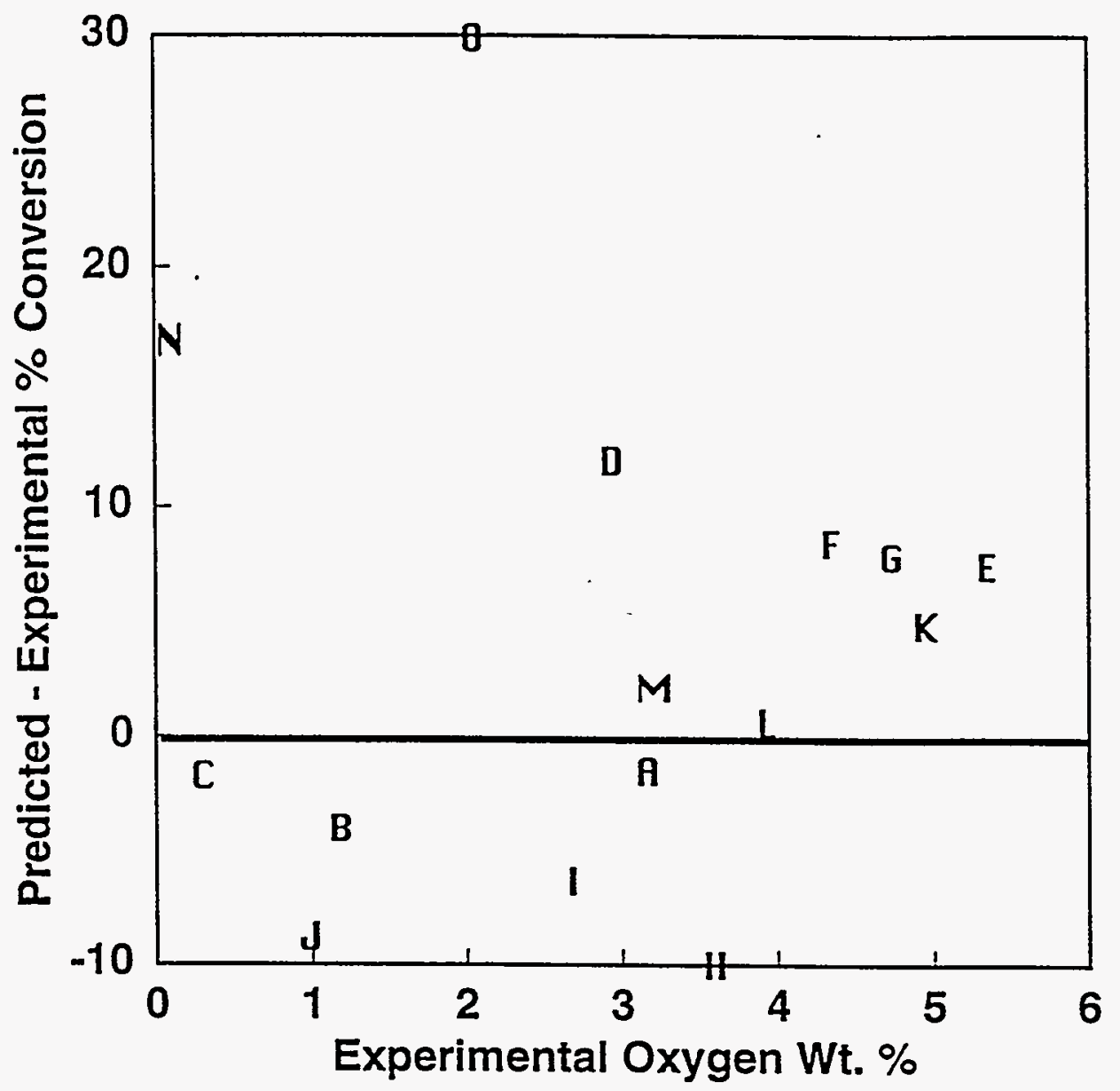

Figure 42: Predicted - Experimental \& Conversion versus oxygen Wt. \% . 


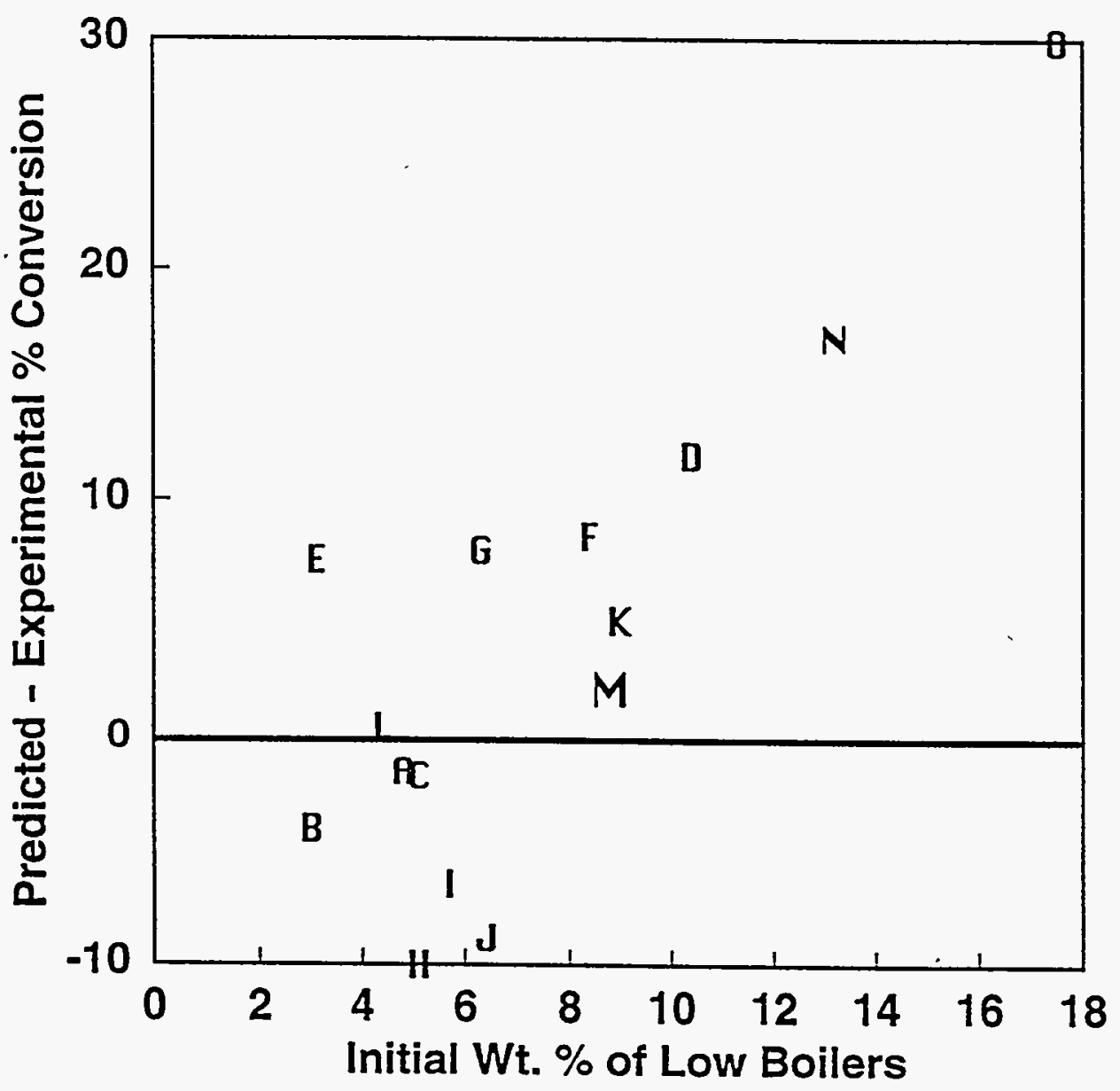

Figure 43: Predicted - Experimental conversion versus initial wt. \& of low boiling material. 


\title{
A NOVEL METHOD FOR THE DETERMINATION OF THE BOILING RANGE OF LIQUID FUELS BY THERMOGRAVIMETRIC ANALYSIS
}

\author{
He Huang, Keyu Wang, Shaojie Wang, M.T. Klein, and W.H. Calkins* \\ Center for Catalytic Science and Technology, Department of Chemical Engineering \\ University of Delaware, Newark, Delaware 19716
}

Key words: boiling range, liquid fuels. SimDis TGA

\section{INTRODUCTION}

The most widely used separation technique in the petroleum industry as well as in much of the chemical industry is distillation. This is particularly true of all liquid fuel production processes, including coal-derived liquid fuels, and shale oil as well as petroleum. To design and operate a suitable distillation column system requires a knowledge of the boiling point distribution of the materials to be separated. In recognition of this need, the ASTM developed the classical distillation procedures of ASTM D86, D216, D447, D850, and D1078. Since these methods required a relatively large sample and are not particularly precise, the widely used simulated distillation analysis based on gas chromatography (ASTM D3710-83) was introduced. This method requires only a small sample size and is reasonably rapid. However, it is limited to materials boiling below about $350^{\circ} \mathrm{C}$. Above that temperature the column packing becomes unstable and the materials being analyzed tend to crack. Also the results measured by the SimDis GC method are determined by the interactions between the tested sample and the selected column packing. Therefore the GC method is not fundamentally a determination of the boiling range of the sample mixture but rather a measure of the range of interactions of the sample with the packing.

To avoid the limitation in the higher boiling range of the tested material in the SimDis GC method, Schwartz et al developed a capillary supercritical fluid chromatography (SFC) method (1). When the SFC is properly calibrated, it has been shown to be a suitable simulated distillation method, even for materials having atmospheric equivalent boiling points as high as $760^{\circ} \mathrm{C}$ or $1400^{\circ} \mathrm{F}$. However this does not eliminate the problem of interactions of the sample with the packing material.

In their work, Schwartz et al also used both atmospheric "flow"thermogravimetric analysis (FTGA) and vacuum thermogravimetric analysis (VTGA) methods to distinguish between evaporation and thermal decomposition. They have observed a bimodal distribution of DTG (the rate of weight loss) on Arabian heavy atmospheric residue in both FTGA and VTGA runs. The first peak in the VTGA (about $0.2-0.5$ torr) profile is shifted towards lower temperature as compared with the FTGA profile since the sample vaporization was enhanced by a reduced pressure. However; the reduced pressure had no effect on the position of the second peak in the VTGA curve since the thermal decomposition or pyrolysis rate was not significantly affected by the reduced pressure. Therefore, the low temperature peak in each DTG curve is interpreted as the sample vaporization profile and the high temperanure peak as the thermal decomposition or pyrolysis reactions.

In the investigation of the hydrocracking of high boiling coal derived vacuum resids, it became important to measure the degree to which the resids had been broken down to lower boiling products. This plus the importance of a simple, rapid, and accurate analytical distillation technique mentioned above motivated the development of an analytical TGA method for boiling range measurement, i.e. atmospheric equivalent boiling point (AEBP) curve, of a variety of samples. While supercritical chromatography was an alternative, the use of thermogravimetric analysis to determine the AEBP curve was an attractive approach. Such a SimDis TGA method would not be affected by interactions with column packing and not limited by sample boiling point range. Development of this novel SimDis TGA method and the preliminary results on a variety of samples are presented in this paper.

\section{EXPERIMENTAL}

TGA Apparatus. A horizontal thermogravimetric analyzer (TGA), TA Instruments model 51 (New Castle, Delaware), was used. In this particular instrument, dual thermocouples were used for the system temperature control. One is a furnace thermocouple and the other is a sample thermocouple, which is located very close to the test sample. The sample thermocouple is always used for the temperature measurements. Only the furnace thermocouple is used for control in the ramp method (constant heating rate). However, either the furnace thermocouple or the sample thermocouple can be used for isothermal control, depending on the purpose. If the "Isothermal" mode is selected, the 
furnace thermocouple is used. On the other hand, if the "Isotrack" mode is selected, the sample thermocouple is used. The isotrack mode gives much better temperature control, for example. \pm 0.01 to $\pm 0.05^{\circ} \mathrm{C}$ for the range of 60 to $280^{\circ} \mathrm{C}$,compared to the Isothermal mode.

Nitrogen was used as an inert carrier gas at $100 \mathrm{ml} / \mathrm{min}$ volumetric flow rate. Vacuum TGA (VTGA) was carried out by attachment of the thermogravimetric analyzer to a vacuum pump. A vacuum gauge from $0-760 \mathrm{mmHg}(0-1 \mathrm{~atm}$.) range was used to monitor the pressure. After a sample was loaded onto the sample pan, the vacuum metering valve (shown in Figure 1) was gradually opened, and the pressure was adjusted to a predetermined value (down to $30 \mathrm{mmHg}$ or $0.0395 \mathrm{~atm}$ ). By this control and use of a ballast tank (buffer), the pressure (or vacuum) of the TGA chamber was found to be very stable during the VTGA analysis.

TGA Sample Pan. The SimDis TGA method requires a change in the conventional TGA sample pan because the rate of weight loss in the open pan system is controlled not only by the vapor pressure of the test sample but also by mass transfer. The TGA sample characteristics in the pan as well as the diffusion out constantly change with the sample amount as the TG analysis proceeds. For those reasons, a new sample pan configuration with a small aperture at the top, as shown in Figure 2, was devised. The objective of this change is to make the rate of the weight loss from the sample pan primarily deternined by the partial pressure of the sample molecules. This partial pressure has been shown from thermodynamic considerations and experimentation to be essentially equal to the vapor pressure of the sample. Three cylindrical quartz TGA sample pans with different sizes of circular aperture at the top were fabricated. The diameters of the apertures were 0.615 , 0.974 , and $1.538 \mathrm{~mm}$. In each TGA test, about $80 \mathrm{mg}$ of liquid sample was injected into the sample pan by a syringe before the TG analysis.

SimDis TGAMethods. Analytical variables, such as carrier gas flow rate, pressure, and temperature or heating rate, were held constant during a TG analysis. Two methods, i.e., a ramp method and an isotrack method, have been used in the SimDis TGA technique. In the ramp method, a constant heating rate was used and the rate of the weight loss determined versus temperature. In the isotrack method, the temperature of the sample is very rapidly heated to a predetermined temperature within 2 minutes, and precisely controlled at this preset temperature within 0.01 to $0.05^{\circ} \mathrm{C}$ after 5 minutes. The weight change and the DTG (the differential of the weight loss curve) decay are determined as a function of time.

Materials Studied. A light paraffinic vacuum distillate from Amoco and a converted resid liquid were used to test the SimDis TGA technique.

SimDis TGA Calibration. A SimDis TGA system can be calibrated by either a synthetic mixture which contains compounds of known boiling range or a 'standard' mixture for which distillation curves are available. In either case, the calibration sample should be similar to the sample for which the boiling range is to be determined. For the synthetic mixture, the paraffins, especially n-alkanes, provide a wide range of boiling components for calibration purposes. For the 'standard' mixture, any petroleum sample with known boiling range distribution could be selected. Some variation between samples of the same boiling point but different chemical structure are to be expected due to variation in molecular characteristics (such as molecular weight and shape) and heats and entropies of vaporization of the samples.

n-Alkane standards, C-10 to C-32, were purchased from Aldrich Chemical Co (Milwaukee, NJ). The SimDIS TGA was calibrated with a synthetic mixture of these nalkane standards shown in Table 1.

SimDis TGA Data Processing. The smoothed and noise-free DTG curves were acquired by an 11 point smoothing technique (2).

\section{RESULTS AND DISCUSSION}

Strategies for Selection of the Optimum Method for Determining Boiling Point Range of an Unknown Sample. The analytical variables of the SimDis TGA technique include: 1). time-temperanure profile: ramp method or isotrack method; 2). pressure: atmospheric pressure or under vacuum (down to $0.03 \mathrm{~atm}$.); 3). size of the aperture at the top of the pan; and 4). carrier gas type and flow rate. 
For a pure compound, SimDis TGA can be run using either the ramp or isotrack method. For an unknown mixture, the ramp method provides information concerning the vaporization range of the sample. If run under at least two pressures (vacuum), it can distinguish quantitatively between the material boiling so high that pyrolysis will occur and that fraction volatilizing under distillation conditions.

To accurately obtain the boiling range curve for a mixture, the isotrack method is the preferred technique. This method translates the decay of the rate of weight loss into the boiling point distribution. Therefore, the optimum conditions to run a simulated distillation by TGA are those conditions which give the highest sensitivity and stable decay curve. To accomplish this, the optimum conditions for a SimDis TGA run is dependent on the boiling range of the test sample. For example, for light samples, it is better to run the SimDis TGA at a low isotrack temperature, small hole size of pan, and atmospheric pressure. For very high boiling mixtures. SimDis TGA should be run at a higher isotrack temperature, larger hole size of pan, and high vacuum (for example, $30 \mathrm{mmHg}$ ). For a mixture containing a very broad boiling range, the test can be run at either more than one temperature or more than one pressure (vacuum) or both to detect the very volatile fraction as well as the higher boiling components.

The recommended general steps to run an unknown sample using the SimDis TGA technique are:

1). ramp at 1 to $5^{\circ} \mathrm{C} / \mathrm{min}$ to $600^{\circ} \mathrm{C}$ at $1 \mathrm{~atm}$ and/or under vacuum (down to ca. 0.03 atm.) at $100 \mathrm{~cm}^{3} / \mathrm{min} \mathrm{N}_{2}$. Oxygen is then introduced to bum off the combustible material remaining (if any). In this run, IBP (Initial Boiling Point), FBP (Final Boiling Point) and/or PT (Pyrolysis Temperature), the boiling range and volatile fraction, and ash fraction (if any) are determined.

2). based on the results obtained from Step 1, select the optimum conditions of aperture size of pan, isotrack temperature, pressure, etc. to run a SimDis TGA.

SimDis TGA by the Ramp Method. Typical DTG curves from SimDis TGA runs using the ramp method at two pressures on a light paraffinic vacuum distillate from Amoco are shown in Figure 3. The rate-of-weight-loss curves show a distinct shift to lower temperatures as the pressure is reduced. No pyrolysis is evident in this determination since the DTG curve is entirely shifted under vacuum. The volatilization range for this sample at atmospheric pressure is between about $200^{\circ} \mathrm{C}$ and $470^{\circ} \mathrm{C}$. Under the vacuum of 0.238 atm., it is shifted to between about $180^{\circ} \mathrm{C}$ and $420^{\circ} \mathrm{C}$. The volatilization ranges are somewhat lower than the actual boiling range because of the nitrogen gas sweep and controlled diffusion.

SimDis TGA Calibration. Temperature-time plot for a calibration run using a synthetic mixture of hydrocarbons of $C_{10}$ to $C_{32}$ is shown in Figure 4. The predetermined isotrack temperature was $280^{\circ} \mathrm{C}$. The DTG decay curve for this calibration is shown in Figure 5. Although the temperature of the sample reached the predetermined temperature of $280^{\circ} \mathrm{C}$ within 2 minutes, the loss of the light fractions in the synthetic mixture, such as $C_{10}$ and $C_{15}$, occurred before the temperanre became stable. In other words, the iight fractions in the synthetic mixture of $C_{10}$ and $C_{15}$ were evolved from the sample pan within this initial 2-5 minutes. This is clearly illustrated in Figures 6 and 7, the plot of wi\% of sample in the pan vs. temperature and wt\% of sample in the pan vs. DTG decay, respectively. From the concentrations of the $\mathrm{C}_{10}-\mathrm{C}_{32}$ components in the synthetic mixture given in Table 1 , we can find the rates of weight loss at which the components were evolved from the pan. The plot which describes a linear relationship of $\log$ (rate of weight loss) vs $1 / T_{b}\left(T_{b}\right.$, the boiling point of $\left.C_{20}-C_{32}\right)$ is shown in Figure 8, in accordance with the ClausiusClapeyron equation. This shows that the DTG decay determined by TGA technique is . indeed measuring the vapor pressure and therefore boiling range.

SimDis TGA Test. For a mixrure containing a wide range of boiling materials, such as the light paraffinic vacuum distillate from Amoco, the DTG decay determined under the same conditions of running the calibration mixture can be translated into a boiling range distribution using the equation of

$$
T_{b}=\frac{B}{\ln (r)-A}
$$

where $r$ is the decay rate of the test sample and $A$ and $B$ are parameters determined by calibration (for this case, $A=-21.06$ and $B=12778$ ). 
Temperature-time plot for the test sample of the light paraffinic vacurum distillate is similar to that as shown in Figure 4. The DTG decay curve is shown in Figure 9. Although the temperature of the sample reached the predetermined temperature of $280^{\circ} \mathrm{C}$ within 2 minutes, the 10 wt\% of light fractions in the vacuum distillate were lost before the temperature became stable, i.e., the $10 \mathrm{wt} \%$ of light fractions in the vacuum distillate were evolved from the pan within this initial 2-5 minutes. This is clearly illustrated in Figure 10, the plot of wt\% of sample in the pan vs. temperature. The simulated distillation curve for this vacuum distillate is shown in Figure 11.

A simulated distillation run by the isotrack method has been made on a sample of Wilsonville \# 258 resid converted using sulfided molybdenum naphthenate at $403^{\circ} \mathrm{C}$ for 60 minutes. The boiling range curve derived from the DTG decay of this sample is shown in Figure 12. The fraction of material in which the product boiled below $850^{\circ} \mathrm{F}$ (the cut-off point for resid) was $93.8 \mathrm{wt} \%$ (including tetralin fraction).

Advantages of the SimDis TGA Method. The most significant advantages to using the TGA technique for simulated distillation are:

1). SimDis TGA is run at much lower temperature than other techniques, especially if combined with vacuum.

2). there is no limitation to the sample type. The sample can be very light or very heavy. Even a sample with a very wide range of boiling materials can be tested by this technique.

3). Highly reproducible results can be obtained. The experimental cycle for one run can : be 1 to $12 \mathrm{hrs}$, depending on sample and purpose. No cleaning is required as would be necessary in a distillation column.

4). Very small amounts of sample $(30-80 \mathrm{mg}$ ) are required for each SimDis TGA run;

5). The SimDis TGA method measures the true boiling characteristics of the sample and is not affected by interactions between the test sample and packing, as is the case with the chromatographic methods.

\section{SUMMARY AND CONCLUSIONS}

1. Two analytical methods (a ramp and an isotrack method) have been developed for determining the boiling range of an unknown sample based on the use of thermogravimetric analysis.

2. These methods require the use of a special cylindrical sample pan with a small bole in the top to control the rate of weight loss' (diffusion of the sample vapors exiting the pan). Under these conditions, the diffusion rate is proportional to the vapor pressure of the sample at the particular temperature of the analysis.

3. For screening an unknown sample, the "ramp method" is used in which the temperature of the sample is increased at a predetermined rate while holding the purge gas flow rate constant. The temperature range of volatilization is measured. If high boiling material is present which involves pyrolysis of the sample rather than only volatilization, a similar "ramp method" is run under vacuum. This indicates which portion of the sample is volatilized and what portion is pyrolyzed under the conditions of the test.

4. For more precise determination of the boiling range of a sample, the isotrack method is used. In this method, the sample is rapidly heated to a predetermined temperature and then held constant while the rate of weight loss (DTG) is measured. When the system is properly calibrated with a known sample, the rate of weight loss (DTG decay) can be translated by a computer program into an actual boiling range.

\section{ACKNOWLEDGEMENTS}

The support of this work by the subcontract from CONSOL under DOE Contract DE-AC22-94PC93054 and by the Deparment of Energy under DE22-93PC93205 is acknowledged. Helpful discussions with F.P.Burke, R.A. Winschel, and S.D. Brandes are gratefully acknowledged. Additional funds for purchase of thermal analysis equipment was provided by the University of Delaware.

\section{REFERENCES}

1. Schwartz, H.E.; Brownlee, R.G.; Bodusczynski, M.; Su, F. Anal. Chem. 1987, 59, 1393.

2. Wang, Keyu; Huang, H.; Wang, S.;Klein, M.T.;Calkins, W.H." "A Novel Smoothing Technique for Thermogravimetric Analysis Data", to be submitted to Anal. Chem. 


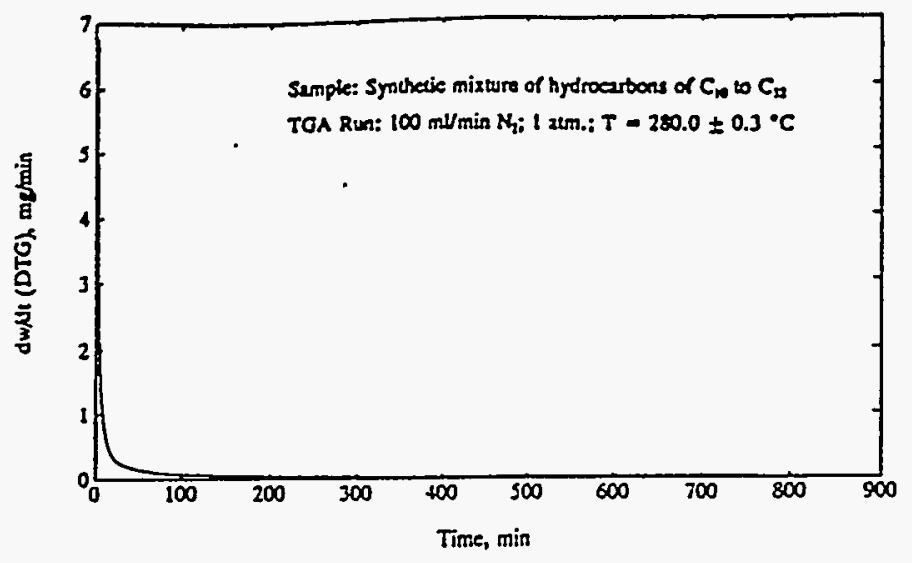

Figure 5 DTG decay curve for the calibration run

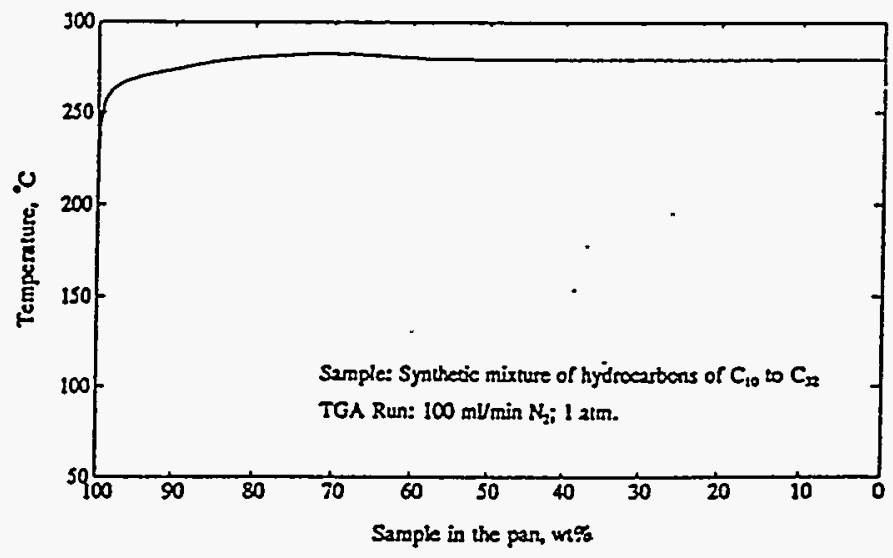

Figure 6 Plot of wr\% sample in the pan vs. temperature for the calibration run

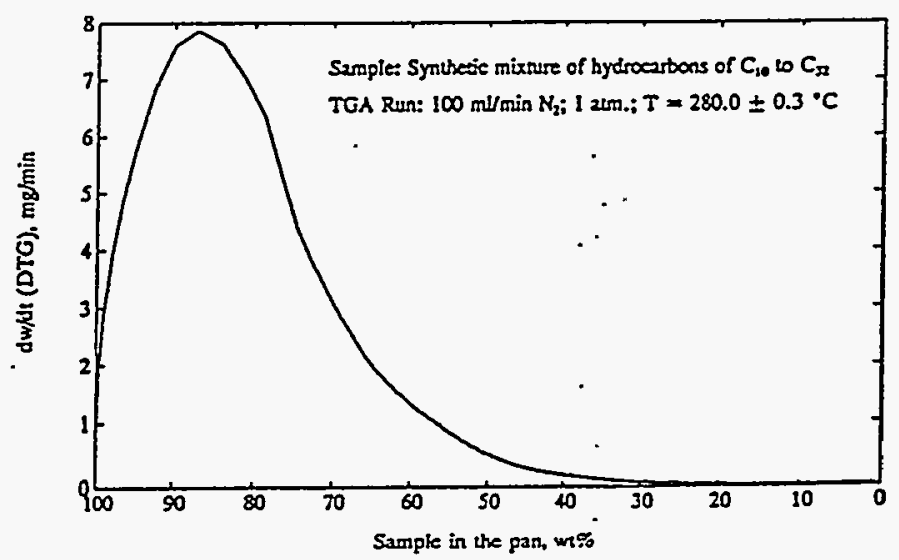

Figure 7 Plot of wt: sample in the pan vs.DTG decay for the calibration run

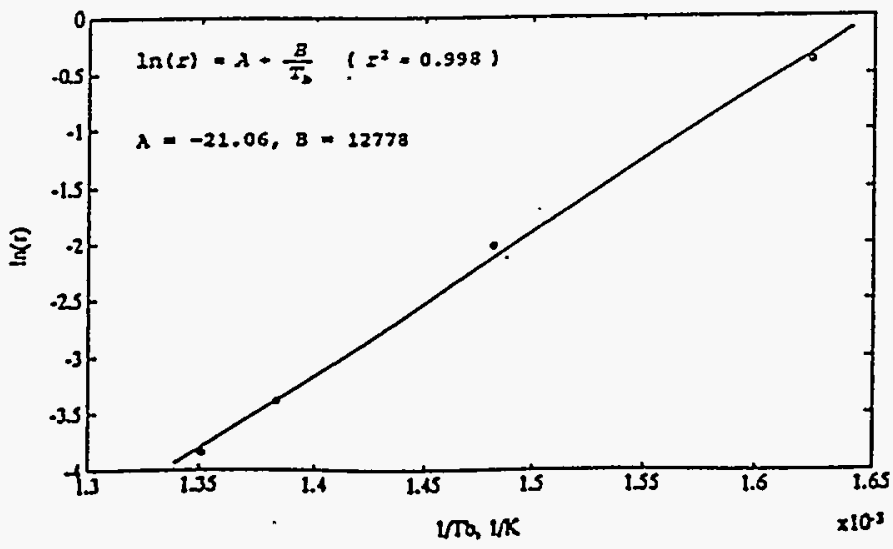

Figure $8 \ln (r)$ vs. $1 / T_{b}$ (r: rate of weight loss; $T_{3}$ : boiling point of $C_{\infty} \cdot C_{x}$ ) 
Table 1 Concentrations and properties of the $C_{10}-C_{32}$ components in the synthetic mixture

\begin{tabular}{clrrrrrr}
\hline No. of Curbon & Newe & MW & b.p., ${ }^{\circ} \mathrm{C}$ & m.p. ${ }^{\circ} \mathrm{C}$ & W. \& & C, wt\% \\
& & & & & & \\
10 & Decene & 142.28 & 174.1 & -29.7 & 1.2298 & $18.26 \%$ \\
15 & Pentadecene & 212.41 & 270.6 & 10.0 & 1.2068 & $17.92 \%$ \\
20 & Eicosene & 282.54 & 343.0 & 36.8 & 1.1238 & $16.69 \%$ \\
25 & Pentecosene & 352.67 & 401.9 & 55.0 & 1.0716 & $15.91 \%$ \\
30 & Triacontane & 422.80 & 449.7 & 65.8 & 1.0402 & $15.45 \%$ \\
32 & Dotriacontane & 450.85 & 467.0 & 69.7 & 1.0618 & $15.77 \%$ \\
\hline
\end{tabular}

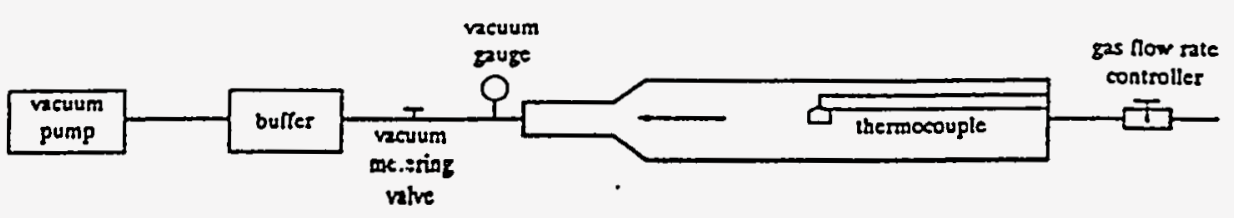

Figure 1 Instrumentation of yacuum thermogravimetric analyzer (VTGA)

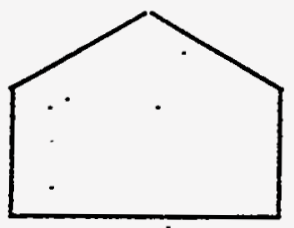

Figure 2 A SimDis TGA sample pan

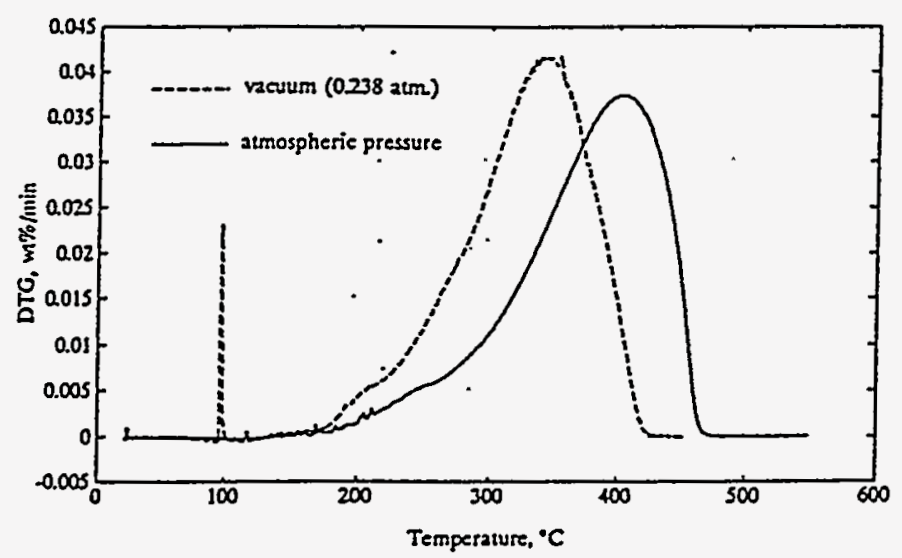

Figure 3 DTG curves from SimDis TGA runs using the ramp method at two pressures on a light paraffinic vacuum distillate from Amoco

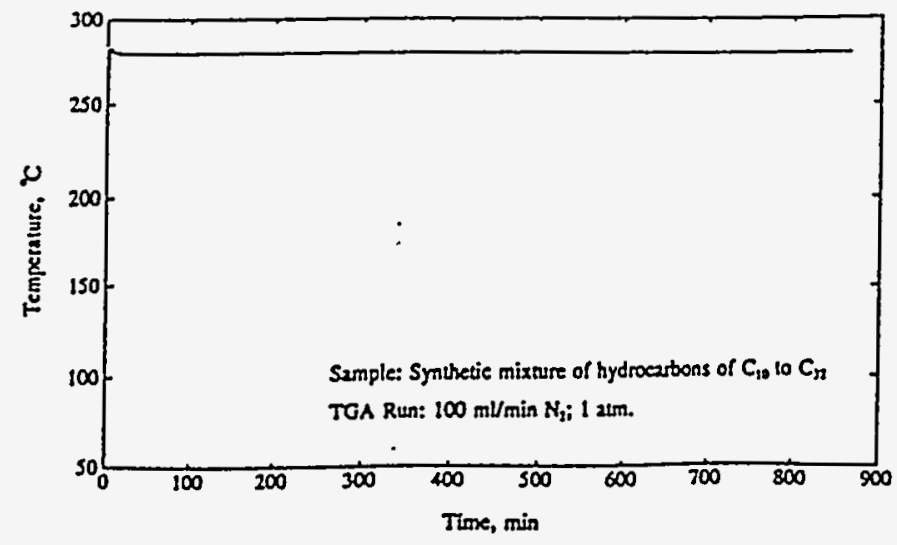

Figure 4 Temperarure-time plot for the calibration sample of 2 synthetic mixture of n-alkanes 


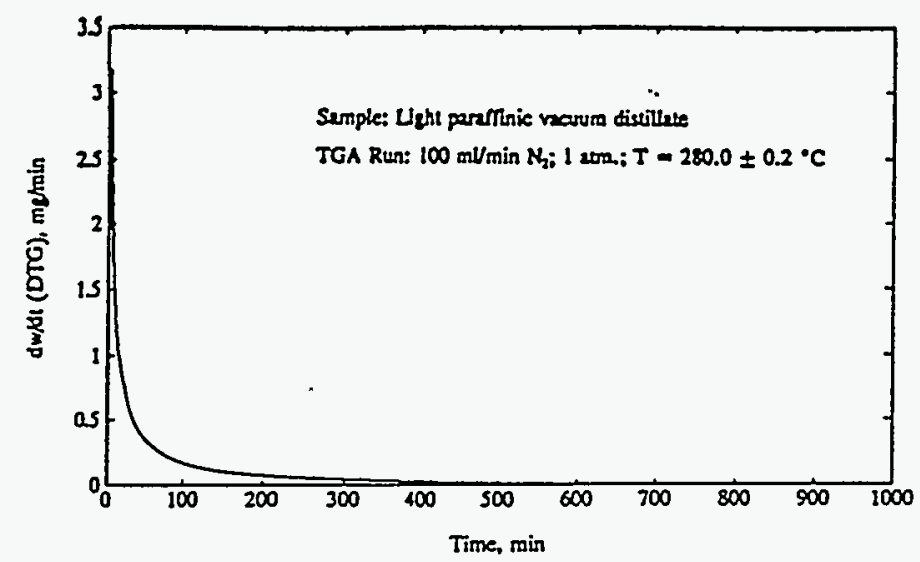

Figure 9 DTG decay curve for the light paraffinic vacuum distillate

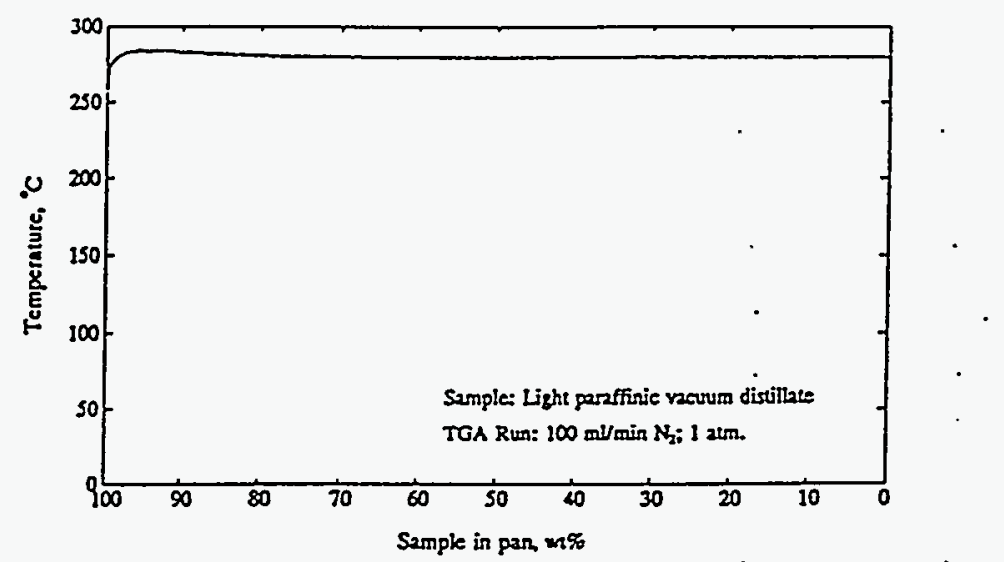

Figure 10 Plot of wt\% sample in the pan vs. temperanure for the light parafinic vacuum distillate

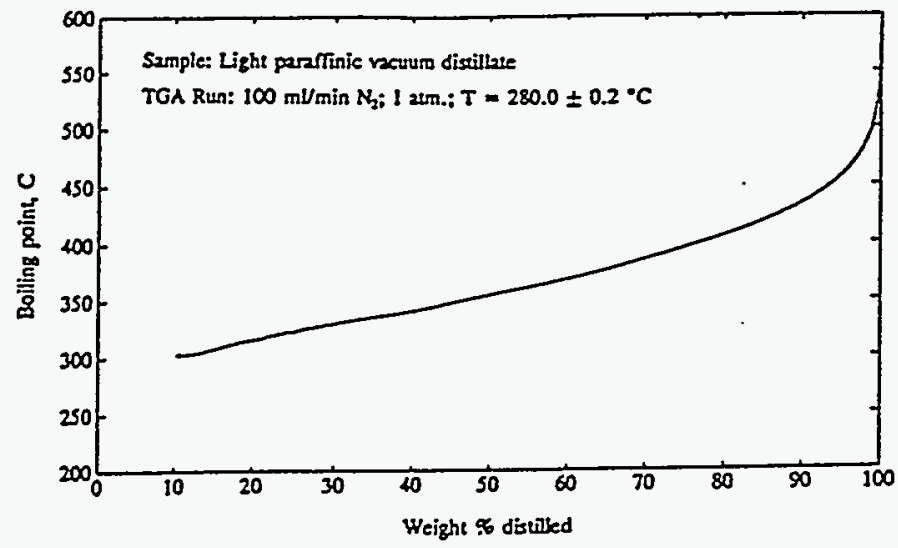

Figure 11 Simulated distillation curve (AEBP) for the light parafinic vacuum distillate

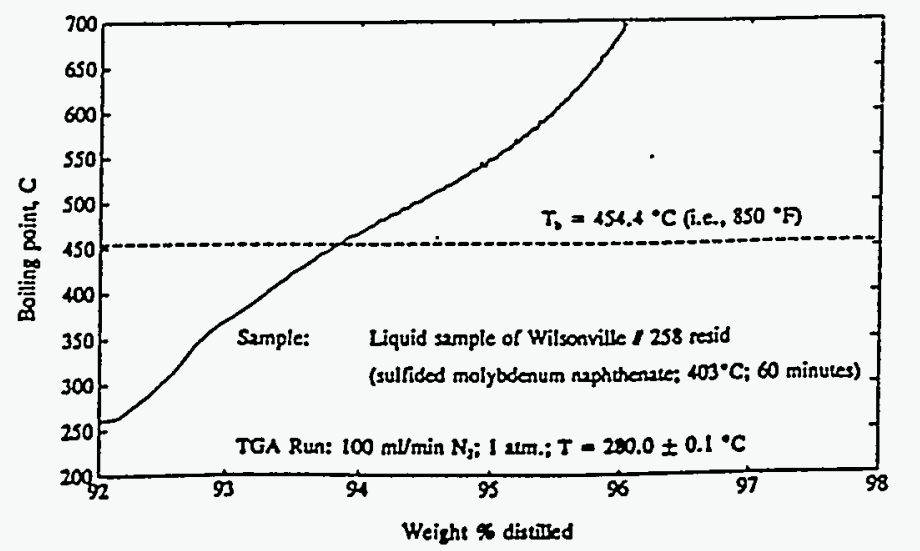

Figure 12 Simulated distillation curve (AEBP) for the liquid sample of a resid conversion run under 1500 psig $\mathrm{H}_{2}$ 
Appendix II Summary of All Consol Runs

\begin{tabular}{|c|c|}
\hline Sample $\|$ & Resid(R) \\
\hline $\mathrm{COOI}$ & A \\
\hline $\mathrm{COO} 2$ & A \\
\hline $\mathrm{C} 003$ & A \\
\hline $\mathrm{COOH}$ & A \\
\hline $\mathrm{C} 005$ & A \\
\hline $\mathrm{C} 006$ & A \\
\hline $\mathrm{C} 007$ & $A$ \\
\hline $\mathrm{C} 008$ & A \\
\hline $\mathrm{C}(009$ & $A$ \\
\hline $\mathrm{CO} 2$ & A \\
\hline $\mathrm{C} 013$ & A \\
\hline $\mathrm{C} 014$ & A \\
\hline $\mathrm{C} 015$ & A \\
\hline $\mathrm{C} 016$ & A \\
\hline $\mathrm{C} 017$ & $A$ \\
\hline $\mathrm{C} 018$ & $\Lambda$ \\
\hline $\mathrm{CO} 19$ & A \\
\hline $\mathrm{C} 020$ & A \\
\hline $\mathrm{C} 021$ & $A$ \\
\hline $\mathrm{C} 022$ & A \\
\hline $\mathrm{C} 023$ & $A$ \\
\hline $\mathrm{C} 024$ & A \\
\hline $\mathrm{C} 025$ & A \\
\hline $\mathrm{C} 026$ & A \\
\hline $\mathrm{C} 027$ & $A$ \\
\hline C028 & $\Lambda$ \\
\hline $\mathrm{C} 029$ & $A$ \\
\hline $\mathrm{C} 030$ & A \\
\hline $\mathrm{C} 031$ & $A$ \\
\hline $\mathrm{C} 032$ & $A$ \\
\hline $\mathrm{C} 033$ & $A$ \\
\hline $\mathrm{C} 034$ & A \\
\hline $\mathrm{C} 035$ & A \\
\hline $\mathrm{C} 036$ & A \\
\hline $\mathrm{C} 037$ & $A$ \\
\hline$C 038$ & $A$ \\
\hline$C 0.39$ & $\Lambda$ \\
\hline
\end{tabular}

$$
\text { lieed cioal }
$$

A. Conditions of Corisol Runs

Wyodak-Anderson Black Thunder Wyodak-Anderson Black Thunder Wyodak-Anderson Black Thunder Wyodak-Anderson Black Thunder Wyodak-Anderson Black Thunder Wyodak-Anderson Black Thunder Wyodak-Anderson Black Thunder Wyodak-Anderson Black Thunder Wyodak-Anderson Black Thunder Wyodak-Anderson Black Thunder Wyodak-Anderson Black Thunder Wyodak-Anderson Black Thunder Wyodak-Anderson Black Thunder Wyodak-Anderson Black Thunder Wyodak-Anderson Black Thunder Wyodak-Anderson Black Thunder Wyodak-Anderson Black Thunder Wyodak-Anderson Black Thunder Wyodak-Anderson Black Thunder Wyodak-Anderson Black Thunder Wyodak-Anderson IBlack Thunder Wyodak-Anderson Black Thunder Wyodak-Anderson Black Thunder Wyodak-Anderson Black Thunder Wyodak-Anderson Black Thunder Wyodak-Anderson Black 'Thunder Wyodak-Anderson Black Thunder Wyodak-Anderson Black Thunder Wyodak-Anderson Black Thunder Wyodak-Anderson Black Thunder Wyodak-Anderson Black Thunder Wyodak-Anderson Black Thunder Wyodak-Anderson Black Thunder Wyodak-Anderson Black Thunder Wyodak-Anderson Black Thunder Wyodali-Anderson Black Thunder Wyodial-Anderson I3linck Thunder

$\begin{array}{ccc}T(c) & 1(\text { min) } & \text { (illily } \\ 19 & 15 & \\ 414 & 15 & \\ 408 & 15 & \\ 410 & 7 & \\ 409 & 15 & \\ 411 & 15 & \\ 408 & 15 & \\ 406 & 15 & M N(0.9 \%) \\ 408 & 15 & M N(0.9 \%) \\ 400 & 15 & M N(0.9 \%) \\ 400 & 15 & M N(0.9 \%) \\ 392 & 15 & M N(0.9 \%) \\ 403 & 15 & M N(0.9 \%) \\ 406 & 15 & M N(0.9 \%) \\ 409 & 0.06 & M N(0.9 \%) \\ 408 & 1 & M N(0.9 \% ;) \\ 412 & 3 & M N(0.9 \%) \\ 410 & 5 & M N(0.9 \%) \\ 411 & 10 & M N(0.9 \%) \\ 408 & 30 & M N(0.9 \%) \\ 422 & 40 & M N(0.9 \% ;) \\ 408 & 60 & M N(0.9 \%) \\ 419 & 0.06 & \text { shell } \\ 420 & 1 & \text { shell } \\ 410 & 3 & \text { shell } \\ 409 & 5 & \text { shell } \\ 410 & 10 & \text { shell } \\ 400 & 15 & \text { shell } \\ 405 & 15 & \text { shell } \\ 405 & 15 & \text { shell } \\ 412 & 60 & \text { shell } \\ 405 & 30 & \text { shell } \\ 20 & & \\ 21 & & \\ 20 & & \text { shell } \\ 27 & 15 & \\ 27 & 15 & \text { shell }\end{array}$

Sull:

P(psie) Cies

$1500 \quad N 2$

Solvent(1) R.r Ratio

rimalin $1: 3$

1500 112 Tetralin $1: 3$

$1500 \quad$ N2 Tetralin $1: 3$

$1500 \quad$ N2 Tetralin $1: 3$

$1500 \quad 112$ Tetralin $1: 3$

1500 N2 Tetralin $1: 3$

$\begin{array}{llll}1500 & N 2 & \text { Tetralin } & 1: 3 \\ 1500 & 112 & \text { Tetralin } & 1: 3\end{array}$

$1500 \quad$ N2 Tetralin $1: 3$

1500 N2 Tetralin $1: 3$

$1500 \quad$ N2 $\quad$ Tetralin $\quad 1: 5$

$1500 \quad 112$ Tetralin 1:3

$1500 \quad$ N2 Tetralin $\quad 1: 3$

$1500 \quad 112$ Tetralin $1: 3$

1500) 112 Tetralin $1: 3$

1500 H2 Tetralin 1:3

$1500 \quad 112$ Tetralin $1: 3$

$\begin{array}{llll}1500 \quad 112 & \text { Tetralin } 1: 3\end{array}$

$1500 \quad 112$ Tetralin $1: 3$

$1500 \quad 112$ Tetralin $1: 3$

$1500 \quad 112 \quad$ Tetralin $1: 3$

$1500 \quad 112$ Tetralin 1:2

$1500 \quad 112 \quad$ Tetralin 1:2

$1500 \quad 112$ Tetralin 1:2

$1500 \quad 112 \quad$ Tetralin $1: 2$

$1500 \quad 112$ Tetralin $1: 4$

$1500 \quad 112$ Tetralin $1: 2$

$1500 \quad 112$ Tetralin $1: 3$

$1500 \quad$ H2 Tetralin 1:4

$1500 \quad$ H12 Tetralin 1:4

$1500 \quad 112 \quad$ Tetralin $\quad 1: 4$

Tetralin $\quad 1: 3$

TIII: $\quad 1: 3$

Tetralin 1:3

$1500 \quad$ III Tetralin $1: 3$

$1500 \quad 112 \quad$ Tetralin $\quad 1: 3$ 


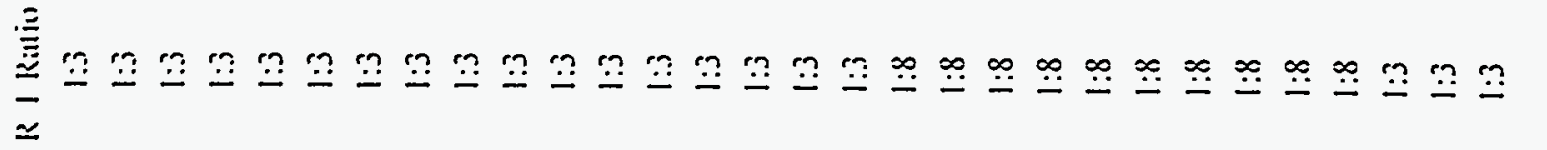

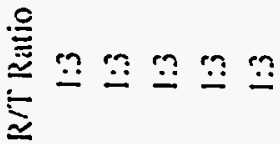

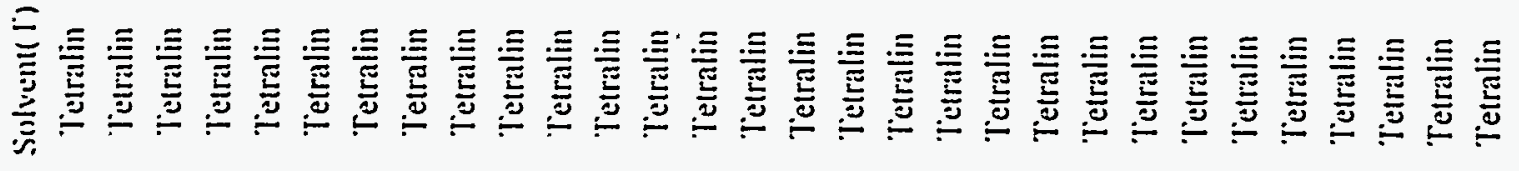

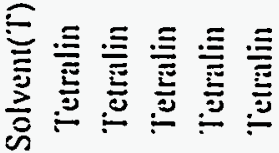

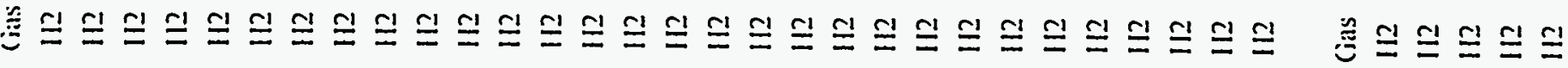

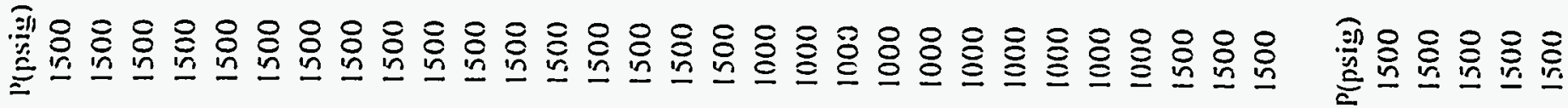

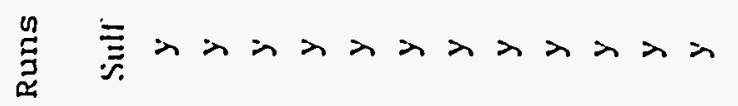

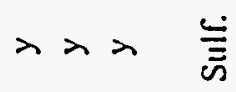

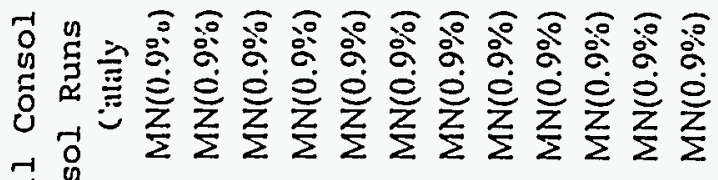

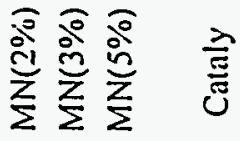

ने.

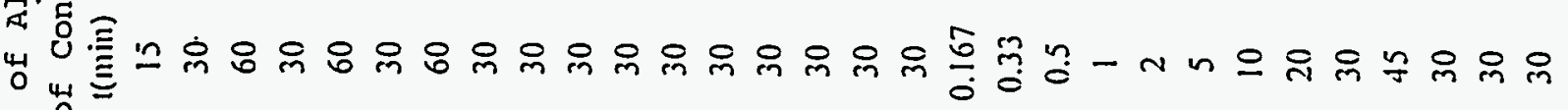

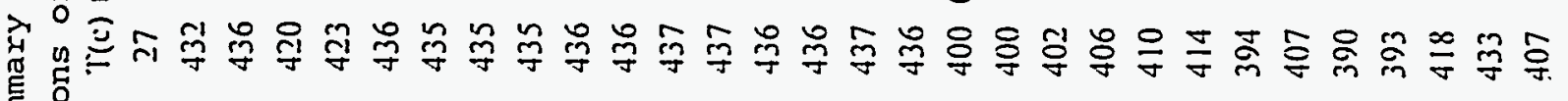

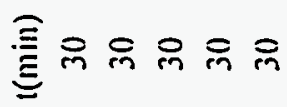

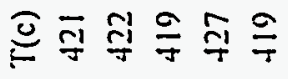
हs

$\rightarrow$

秀

总总总

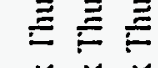

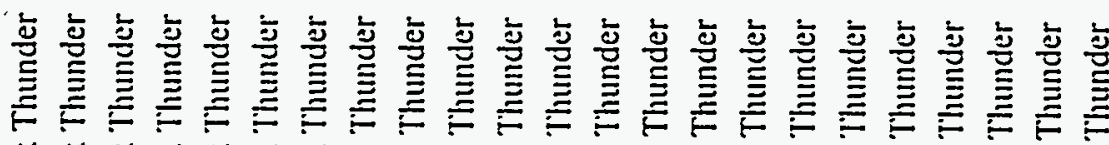

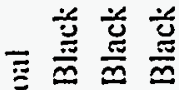

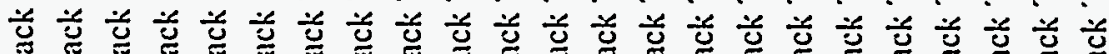

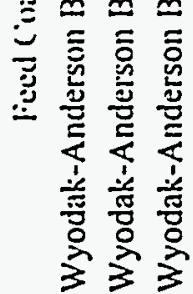

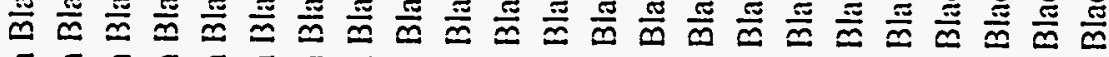

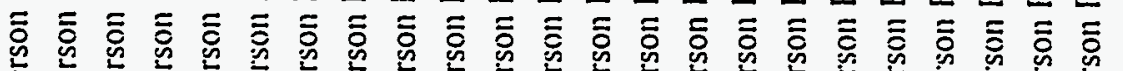

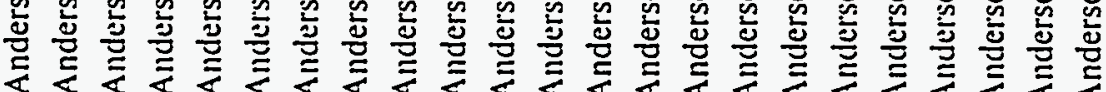

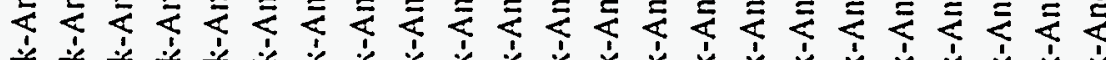

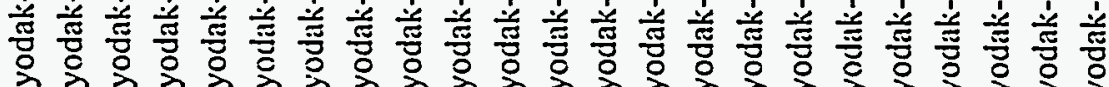

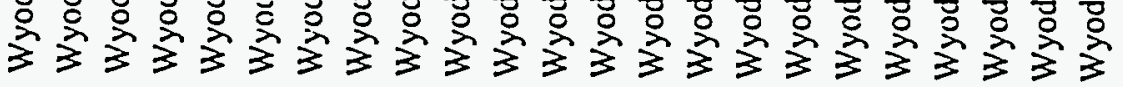

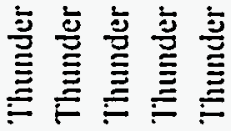

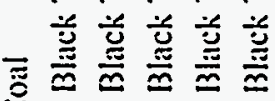

U $\overline{\bar{z}} \overline{\bar{c}} \overline{\bar{c}} \overline{\bar{c}}$

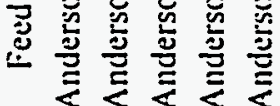

广र

咅咅咅咅蓄

乡乡引

鵶

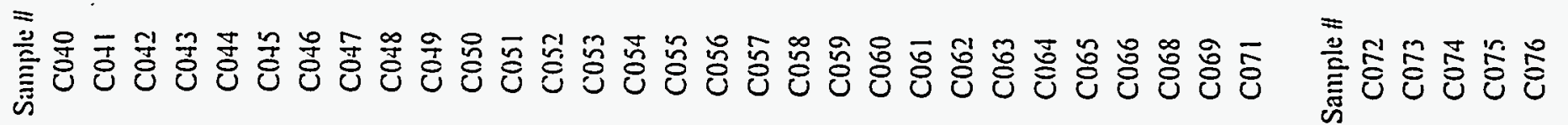




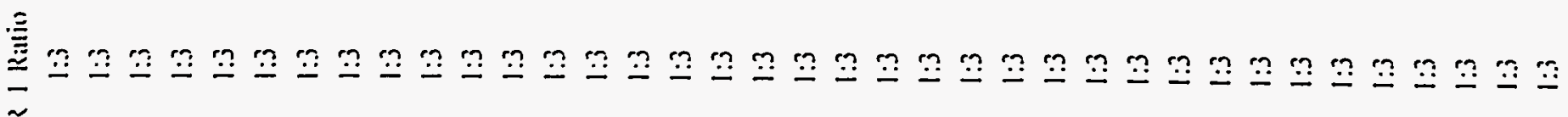

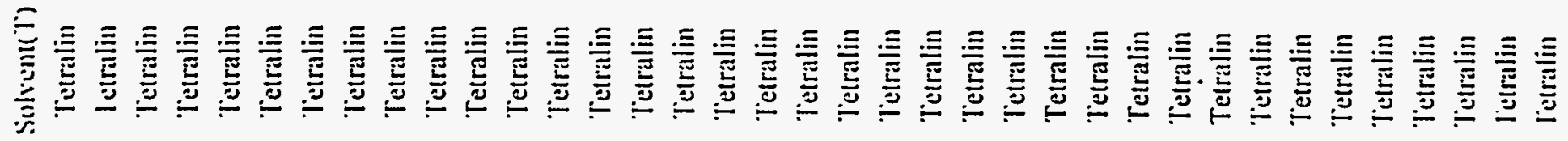

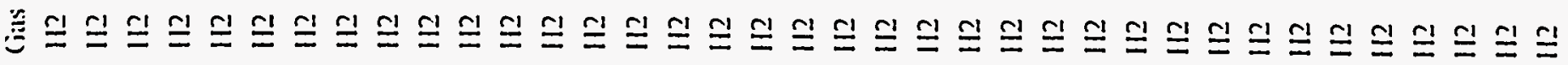

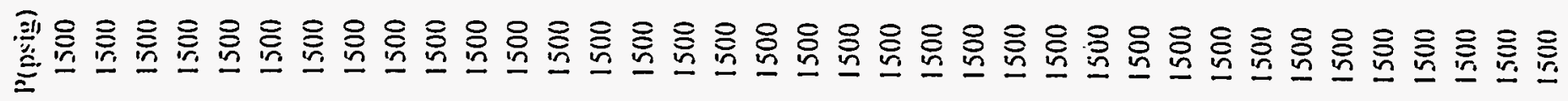

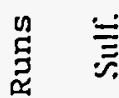

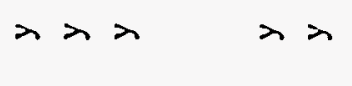

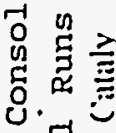
U.

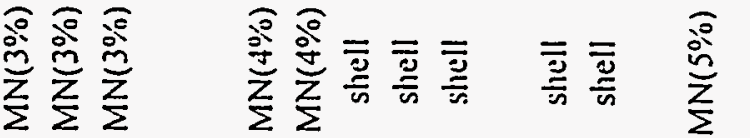
高高离

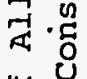

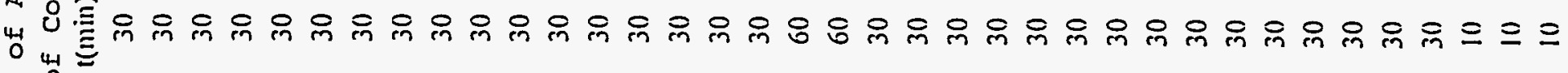

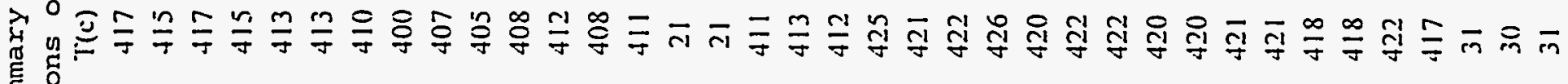
点
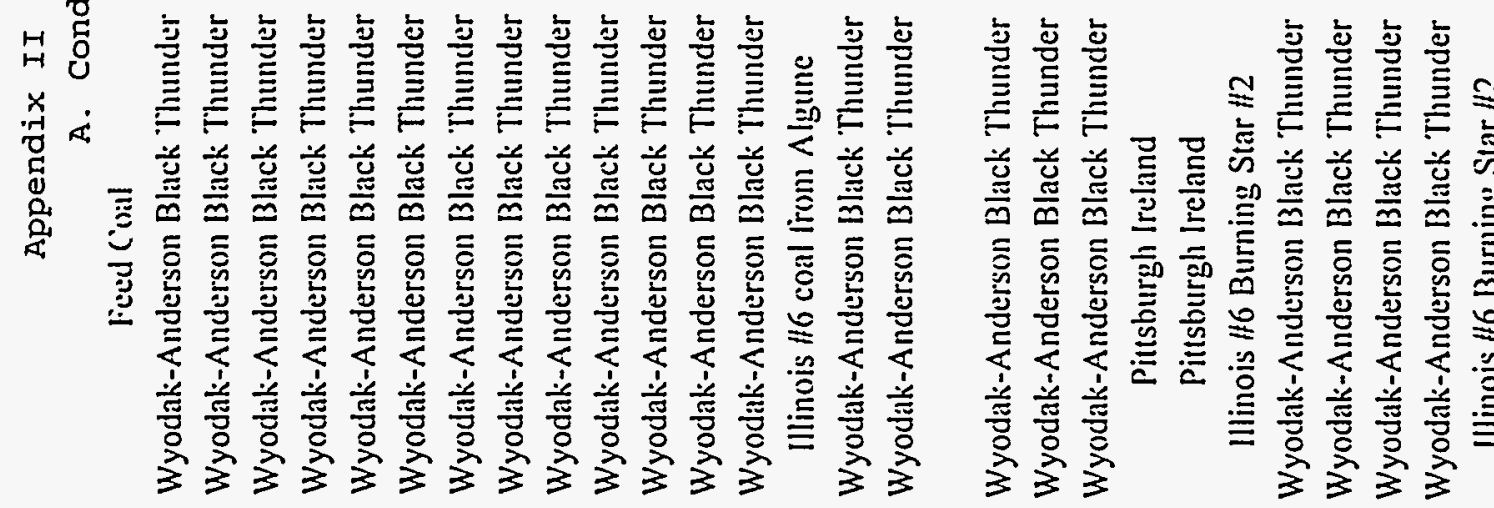

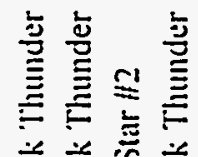

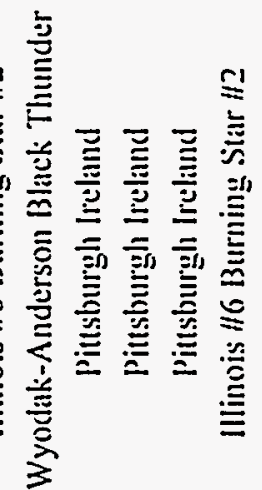

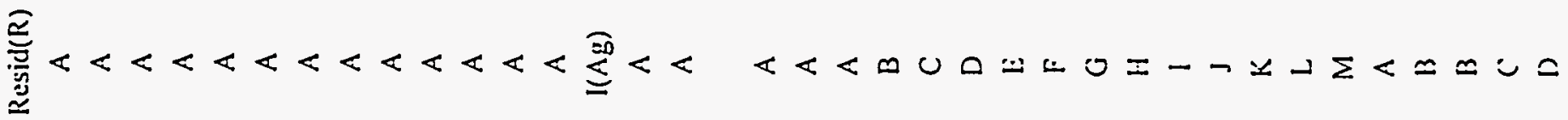

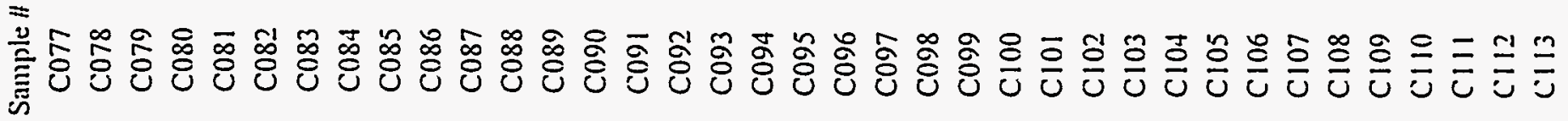




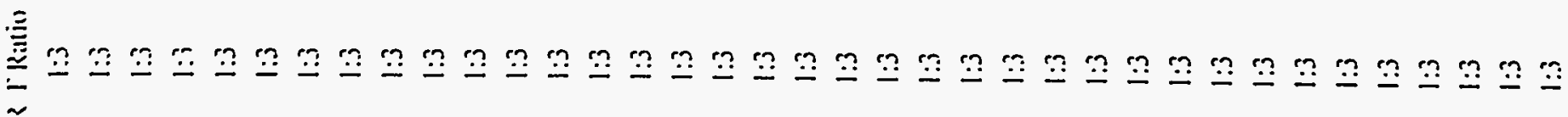

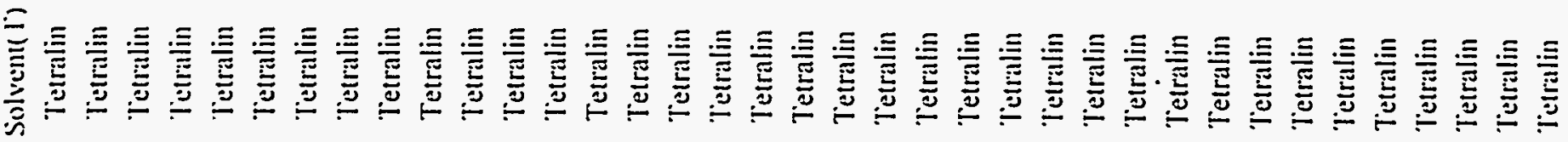

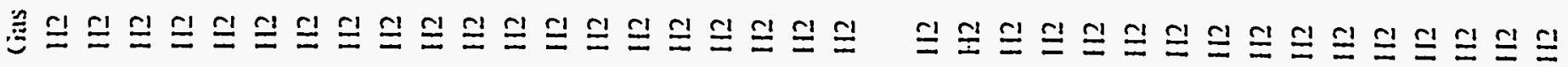

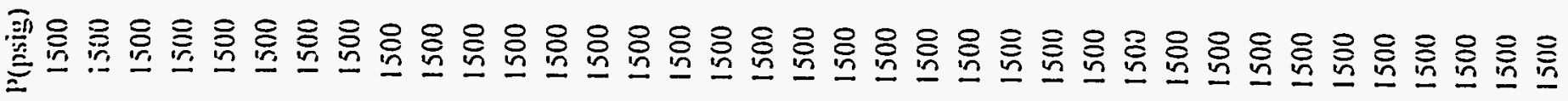

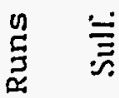

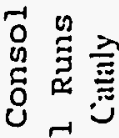

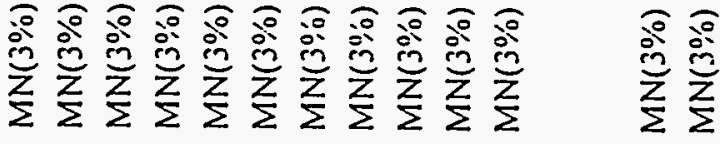

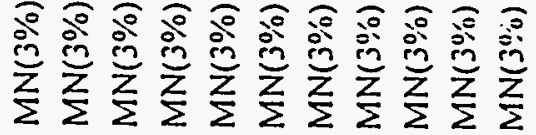

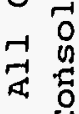

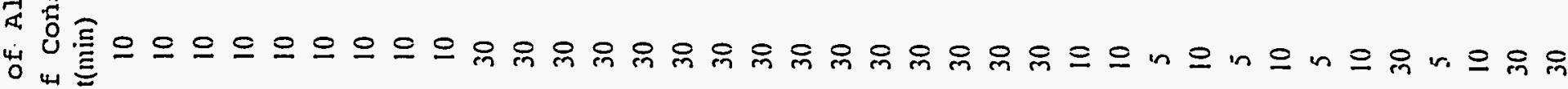

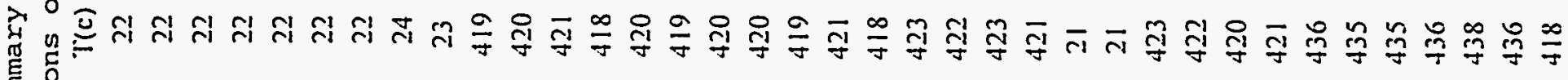
क
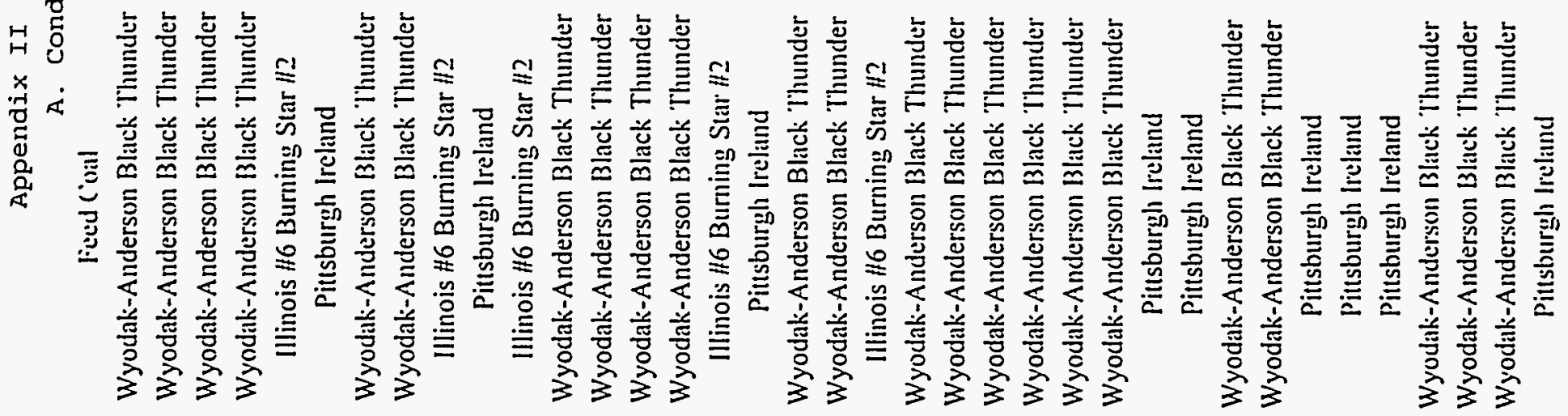

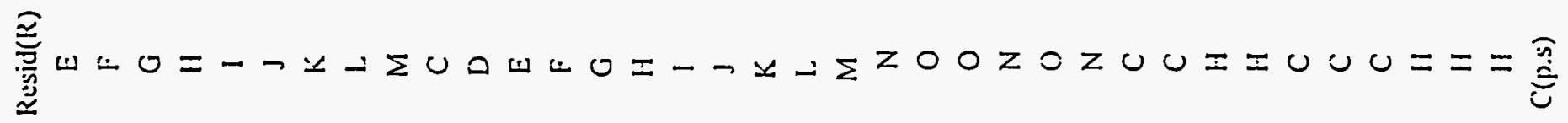

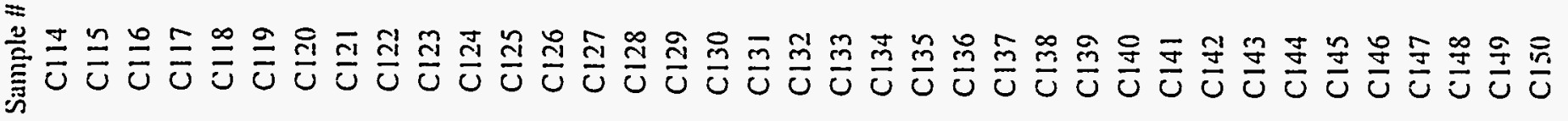




$\begin{array}{cc}\text { Sample \# } & \text { Resid(R) } \\ \text { C151 } & C(p . l) \\ C 152 & C(p . l) \\ C 153 & C(p . l) \\ C 154 & C \\ C 155 & C \\ C 156 & C \\ C 157 & C \\ C 158 & C \\ C 159 & C \\ C 160 & C \\ C 161 & \text { Processed C } \\ C 162 & I \\ C 163 & A \\ C 164 & D \\ C 165 & G \\ C 166 & A(p . s) \\ C 167 & D(p . s) \\ C 168 & G(p . s) \\ C 169 & I(A m)+C \\ C 170 & I(A m)+H \\ C 171 & I(A m) 1 C \\ C 172 & I 1\end{array}$

Note: Resid number
Appendix II Summary of All Consol Runs

A. Conditions of Corisol Runs

$$
\text { Feed Coal }
$$

Pittsburgh Ireland

Pittsburgh Ireland

Pittsburgh Ireland

Pittsburgh Ireland

Pittsburgh Ireland

Pittsburgh Ireland

Pittsburgh Ireland

Pittsburgh Ireland

Pittsburgh Ireland

Pittsburgh Ireland

Pittsburgh Ireland

Illinois 16 Burning Star 12

Wyodak-Anderson Black Thunder

Illinois " 6 Burning Star "I2

Wyodak-Anderson Black Thunder

$\begin{array}{cc}T(c) & t(m i n) \\ 421 & 30 \\ 419 & 30 \\ 421 & 30 \\ 20 & 30 \\ 423 & 30 \\ 421 & 30 \\ 422 & 30 \\ 420 & 30 \\ 419 & 30 \\ 20 & \\ 418 & 30 \\ 20 & \end{array}$

20

20

20

$423 \quad 30$

$422 \quad 30$

$422 \quad 30$

$414 \quad 30$

$418 \quad 30$

$418 \quad 60$

Wyodak-Anderson Black Thunder

$\begin{array}{cccc}\text { Cataly } & \text { Sulf. } & P(p s i g) & \text { Cals } \\ & & 1500 & 112 \\ M N(30 \%) & y & 1500 & 112 \\ \text { shell } & & 1500 & 112\end{array}$

$M N(1 \%)$ y $\quad 1500 \quad 112$

$M N(3 \%)$ y $1000 \quad 112$

$\operatorname{MN}(3 \%)$ y $2000 \quad$ II2

$M N(2 \%)$ y $1500 \quad 112$

$\operatorname{MN}(5 \%) \quad y \quad 1500 \quad 112$

$M N(300) \quad y \quad 1500 \quad 112$

Tetralin

Tetralin

Tetralin

Tetralin

Tetralin

Tetralin

Tetralin

Tetralin

Tetralin

Tetralin

Touralin

Tetralin

Tetralin 1:3

$\mathrm{MN}(3 \% 0) \quad y \quad 1500 \quad 112 \quad$ Tetralin

$M N(3 \%) \quad y \quad 1500$

MN(3\%) y 1500

MN(3\%) y 1500

$\mathrm{MN}(3 \%) \quad$ y 1500

$\operatorname{MN}(3 \%$ y $\quad 1500$

Tetralin

Resid name

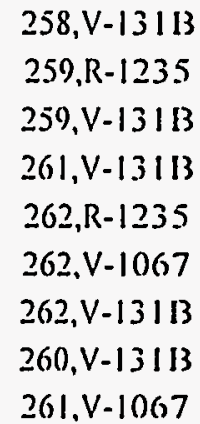




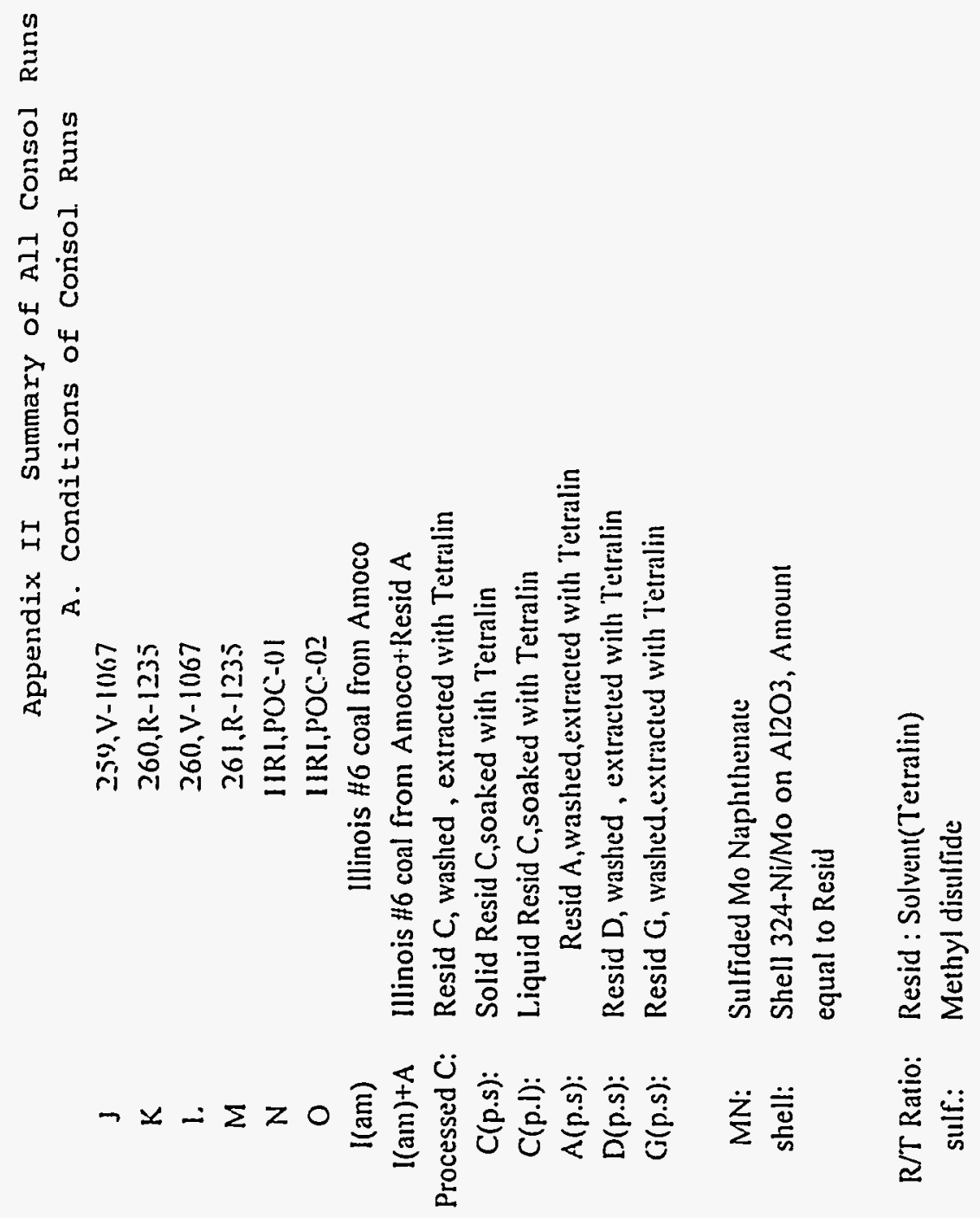




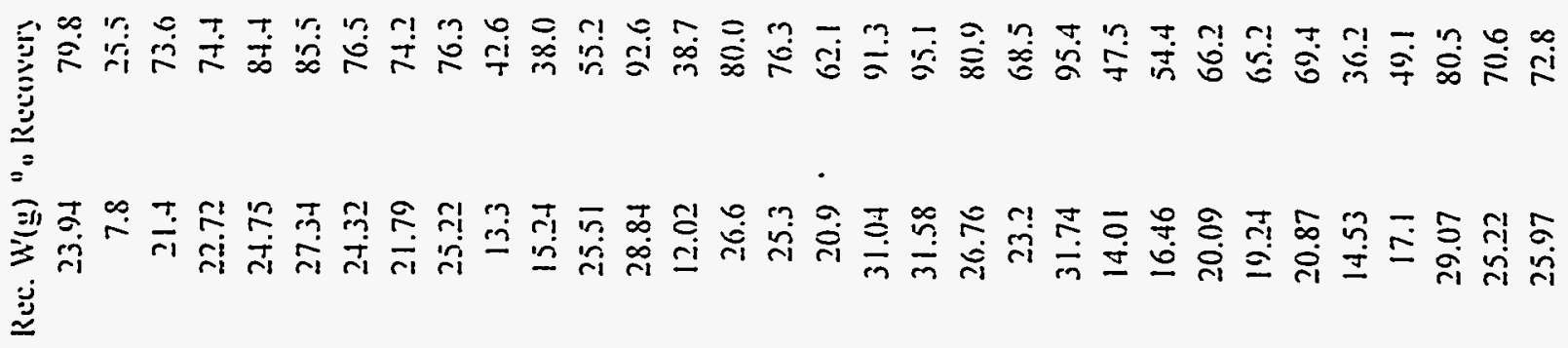

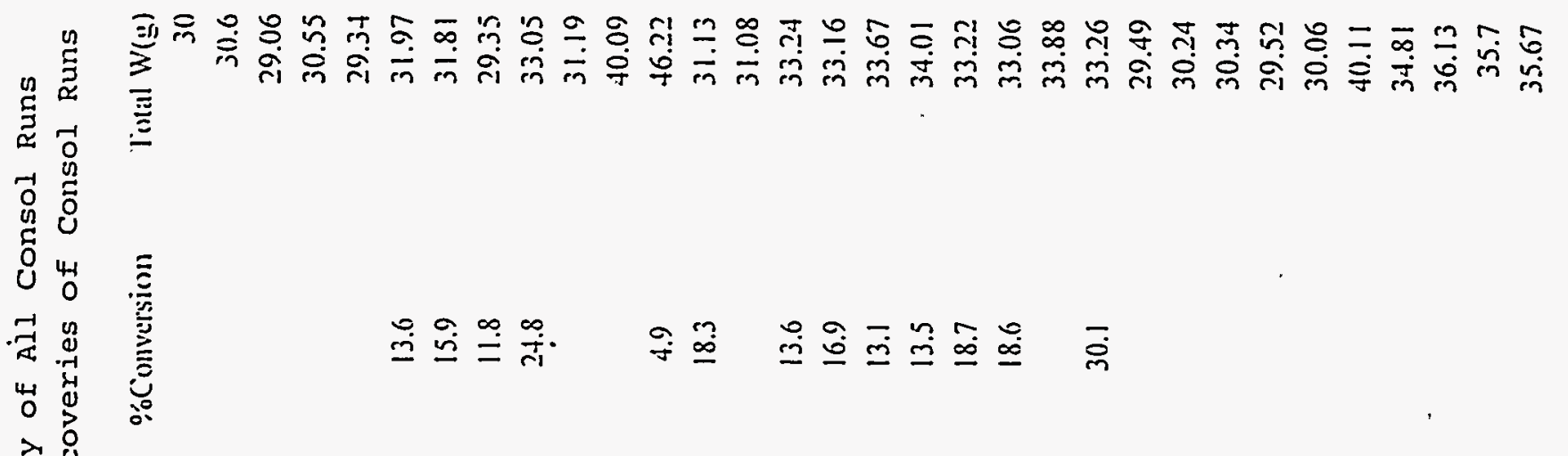

>े

胥

总

H

$\rightarrow$

ס

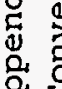

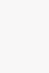

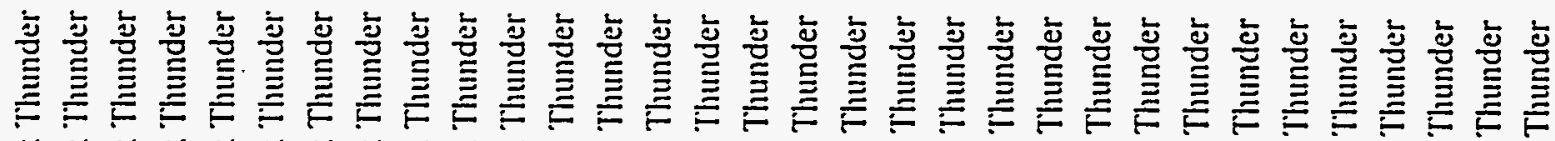

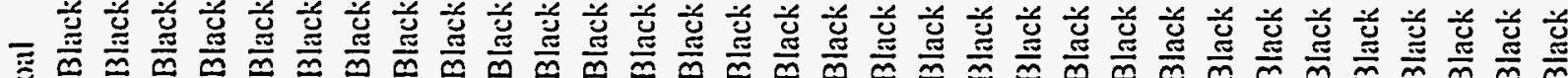
-

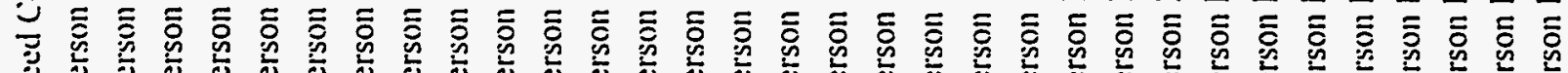

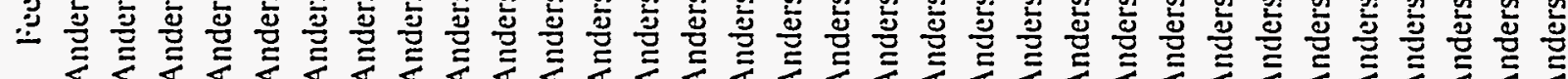

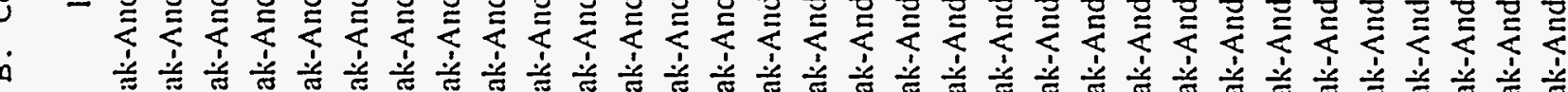

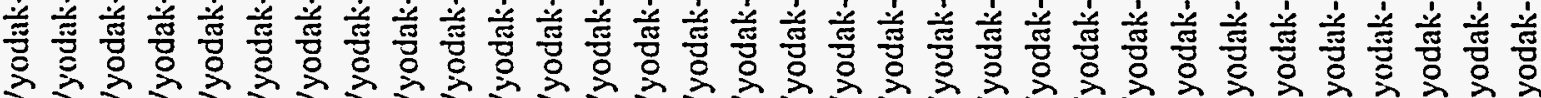
之乡

$\sqrt{n_{3}}<<<<<<<<<<<<<<<<<<<<<<<<<<<<<<<<$

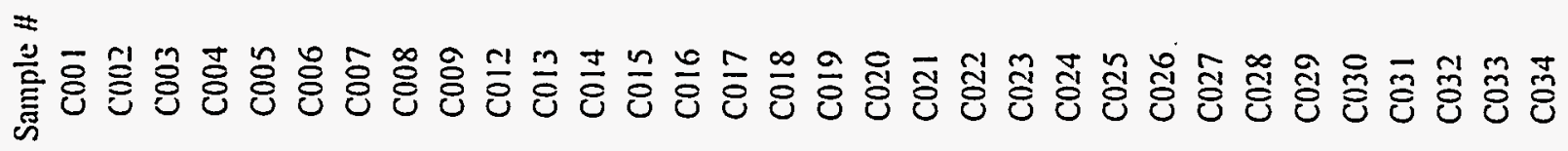



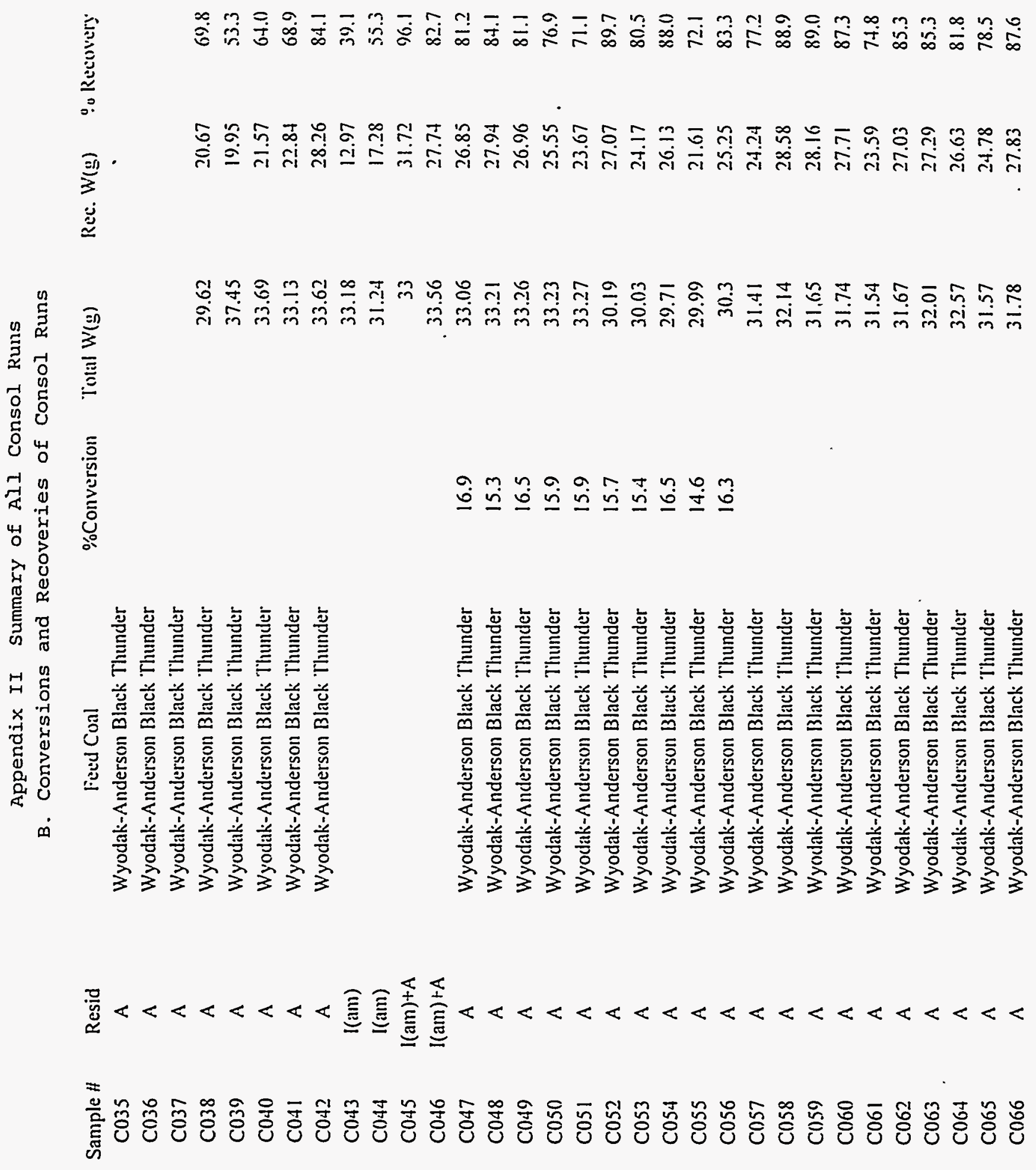

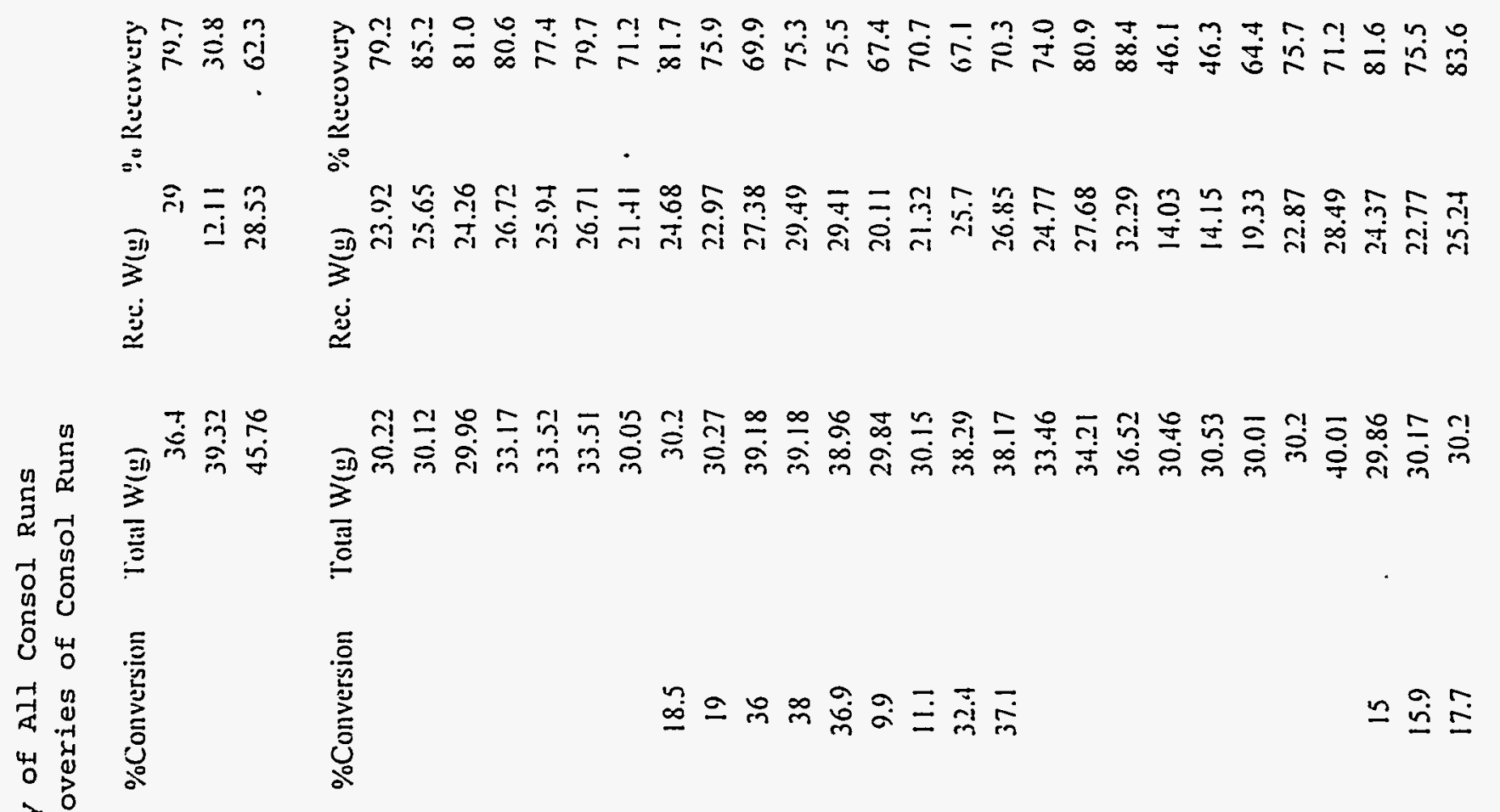

究

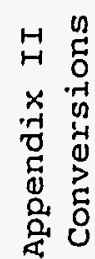
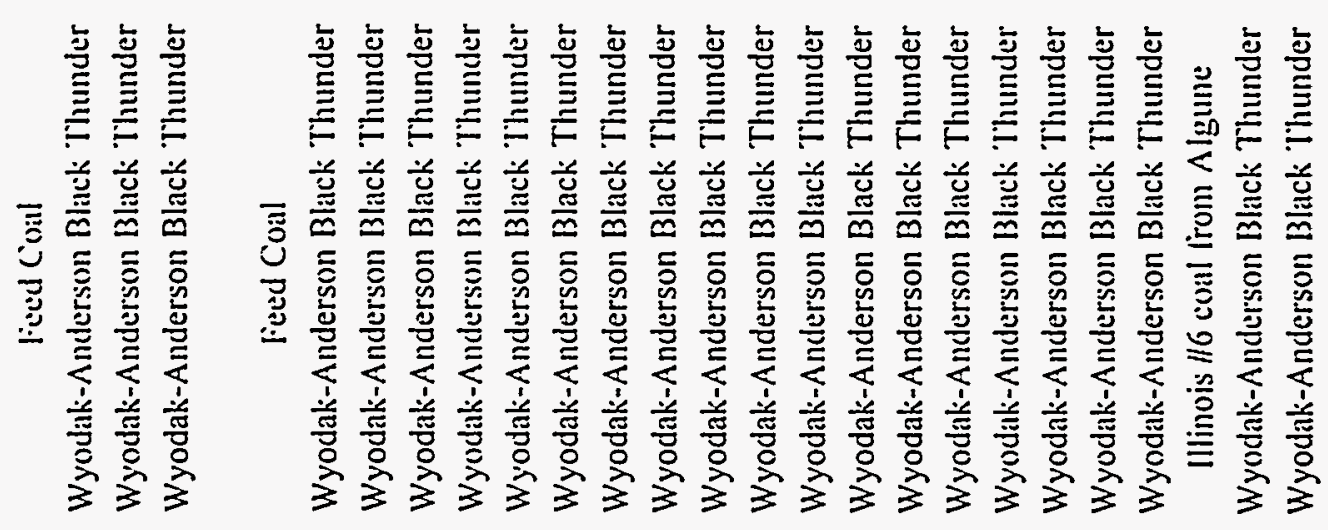

离总总

兽总总总

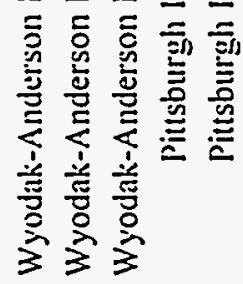

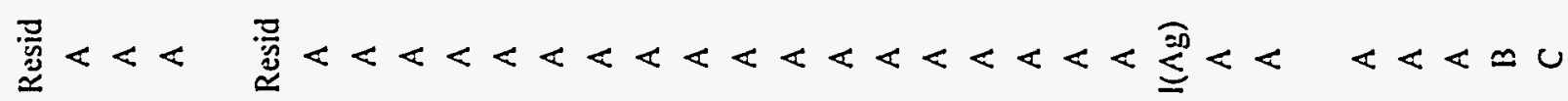

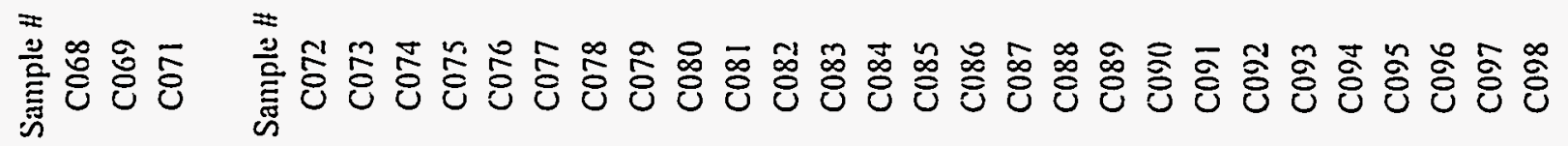


Appendix II Summary of All Consol Runs

B. Conversions and Recoveries of Consol Runs

\begin{tabular}{|c|c|}
\hline & \\
\hline C099 & D \\
\hline $\mathrm{Cl} 100$ & $E$ \\
\hline $\mathrm{ClOl}$ & $F$ \\
\hline $\mathrm{ClO} 2$ & $G$ \\
\hline $\mathrm{ClO3}$ & $H$ \\
\hline $\mathrm{ClO4}$ & 1 \\
\hline $\mathrm{C} 105$ & $\mathrm{~J}$ \\
\hline $\mathrm{Cl06}$ & $k$ \\
\hline $\mathrm{C} 107$ & L. \\
\hline $\mathrm{C} 108$ & $M$ \\
\hline $\mathrm{Cl09}$ & $A$ \\
\hline $\mathrm{C} 110$ & B \\
\hline $\mathrm{C} \| 1$ & B \\
\hline $\mathrm{Cl1} 2$ & $C$ \\
\hline $\mathrm{Cl13}$ & D \\
\hline $\mathrm{Cl} / 4$ & E \\
\hline $\mathrm{C} 115$ & $F$ \\
\hline $\mathrm{Cl16}$ & $G$ \\
\hline $\mathrm{Cl} 17$ & $H$ \\
\hline $\mathrm{C} 118$ & 1 \\
\hline $\mathrm{C} 119$ & $\mathrm{~J}$ \\
\hline $\mathrm{C} 120$ & $\mathrm{~K}$ \\
\hline $\mathrm{C} 121$ & L. \\
\hline$C 122$ & $M$ \\
\hline$C 123$ & $\mathrm{C}$ \\
\hline $\mathrm{Cl} 24$ & $D$ \\
\hline $\mathrm{C} 125$ & $\mathrm{E}$ \\
\hline $\mathrm{Cl} 26$ & $F$ \\
\hline $\mathrm{C} 127$ & $G$ \\
\hline $\mathrm{C} 128$ & $H$ \\
\hline $\mathrm{Cl} 29$ & 1 \\
\hline C130 &. \\
\hline
\end{tabular}

Fecd C'oal

Illinois 16 Burning Star \#2

Wyodak-Anderson Black Thunder

Wyodak-Anderson Black Thunder

Wyodak-Anderson Black Thunder

Wyodak-Anderson Black Thunder

Illinois 16 Burning Star H2

Pittsburgh Ireland

Wyodak-Anderson Black Thunder

Wyodak-Anderson Black Thunder

Illinois 16 Burning Star H2

Wyodah-Anderson Black Thunder

Pittsburgh Ireland

Pittsburgh Ireland

Pittsburgh Ireland

Illinois $\# 6$ Burning Star \#2

Wyodak-Anderson Black Thunder

Wyodak-Anderson Black Thunder

Wyodak-Anderson Black Thunder

Wyodak-Anderson Black Thunder

Illinois \#6 Burning Star \#2

Pittsburgh Ireland

Wyodak-Anderson Black Thunder

Wyodak-Anderson Black Thunder

Illinois 116 Burning Star $1 / 2$

$$
\text { Pittsburgh Ireland }
$$

Illinois 16 Burning Star 12

Wyodak-Anderson Black Thunder

Wyodak-Anderson Black Thunder

Wyodak-Anderson Black Thunder

Wyodak-Anderson Black Thunder

Illinois 16 Burning Star \#2

Pilısburgh lreland
\%Conversion Tutal W(g)

$\begin{array}{ll}17.1 & 30.23 \\ 19.6 & 30.37\end{array}$

$17.7 \quad 30.22$

$18.2 \quad 30.16$

$21.3 \quad 30.27$

$19.4 \quad 29.99$

$12.9 \quad 30.32$

$19.7 \quad 30.28$

$17.8 \quad 29.86$

$16 \quad 30.38$

35

38.1

34.43

34.8

30.05

30.13

30.27

30.21

29.9

30.11

29.92

30.05

30.02

30.02

29.96

30.48

34.34

34.53

34.32

34.31

34.24

34.44

34.41

32.51
Rec. $W(\underline{0})$ o. Recovery

$\begin{array}{ll}24.1 & 79.7 \\ 22.6 & 74.4\end{array}$

$23.1 \cdot 76.4$

$24.15 \quad 80.1$

$24.64 \quad 81.4$

$23.33 \quad 77.8$

$24 \quad 79.2$

$2+.53 \quad 81.0$

$24.01 \quad 80.4$

$24.26 \quad 79.9$

$26.82 \cdot 77.9$

$26.02 \quad 74.8$

$11.28 \quad 37.5$

$17.2 \quad 57.1$

$13.45 \quad 44.4$

$16.45 \quad 54.5$

$15.29 \quad 51.1$

$14.42 \quad 47.9$

$16.52 \quad 55.2$

$15.49 \quad .51 .5$

$13.98 \quad 46.6$

$17.33 \quad 57.7$

$16.47 \quad 55.0$

$16.46 \quad 54.0$

$28.5 \quad 83.0$

$25.94 \quad 75.1$

$20.7 \quad 60.3$

$27.44 \quad 80.0$

$27.18 \quad 79.4$

$26.72 \quad 77.6$

$27.39 \quad 79.6$

$26.53 \quad 81.6$ 


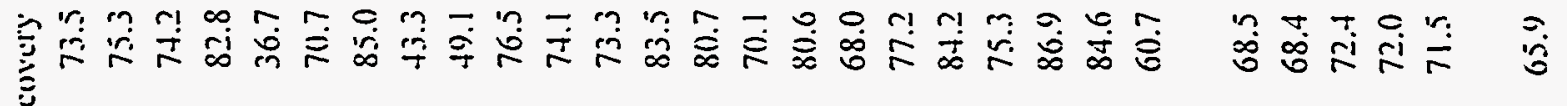

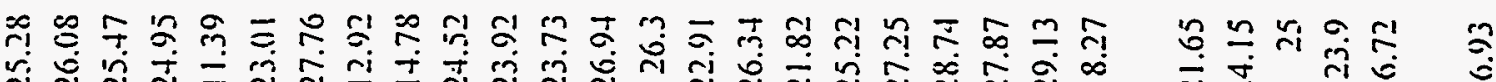

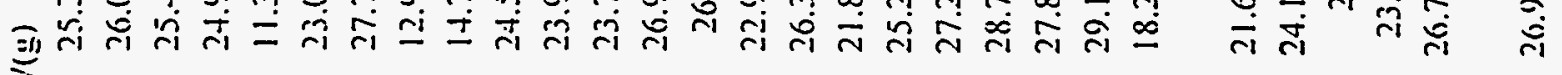
$\stackrel{3}{\check{\nu}}$

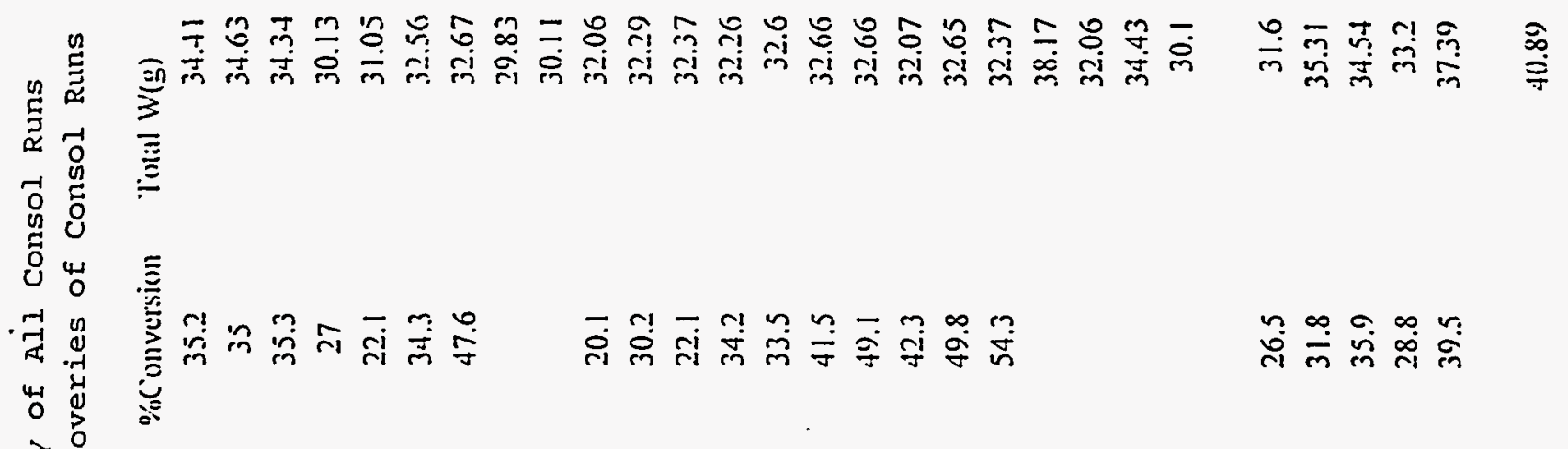

范

政

$\Rightarrow$

范

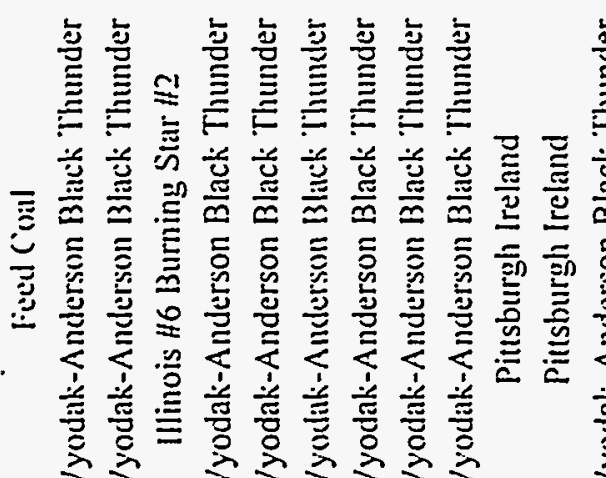

竧总

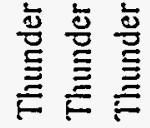

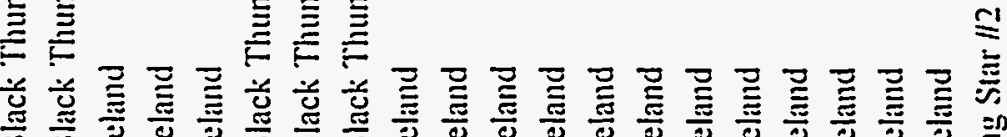

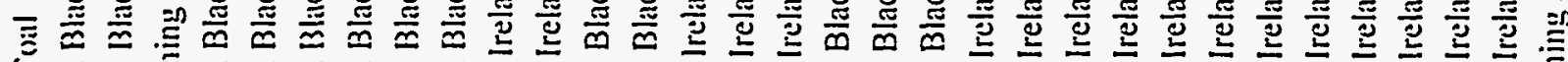

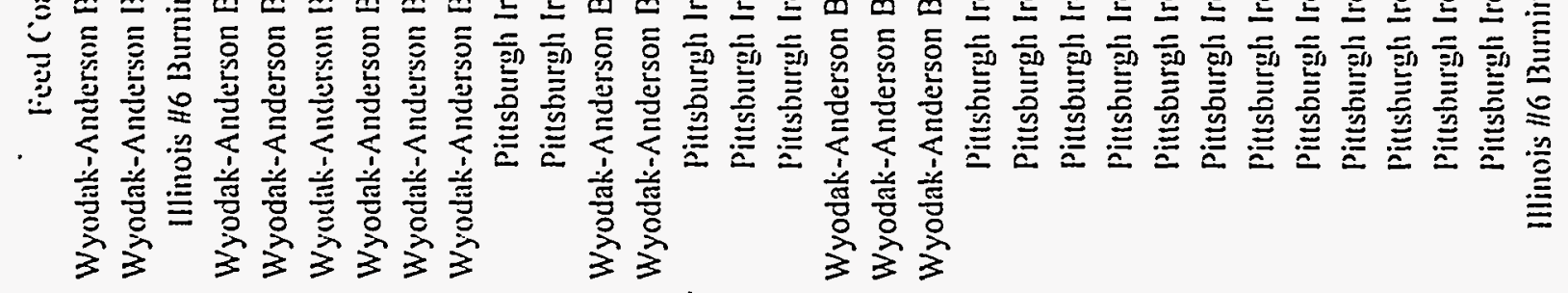

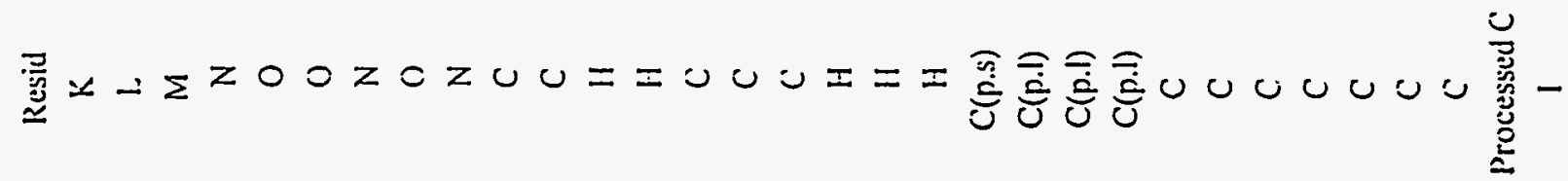

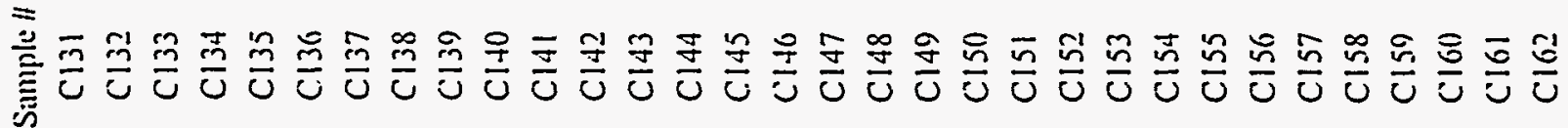



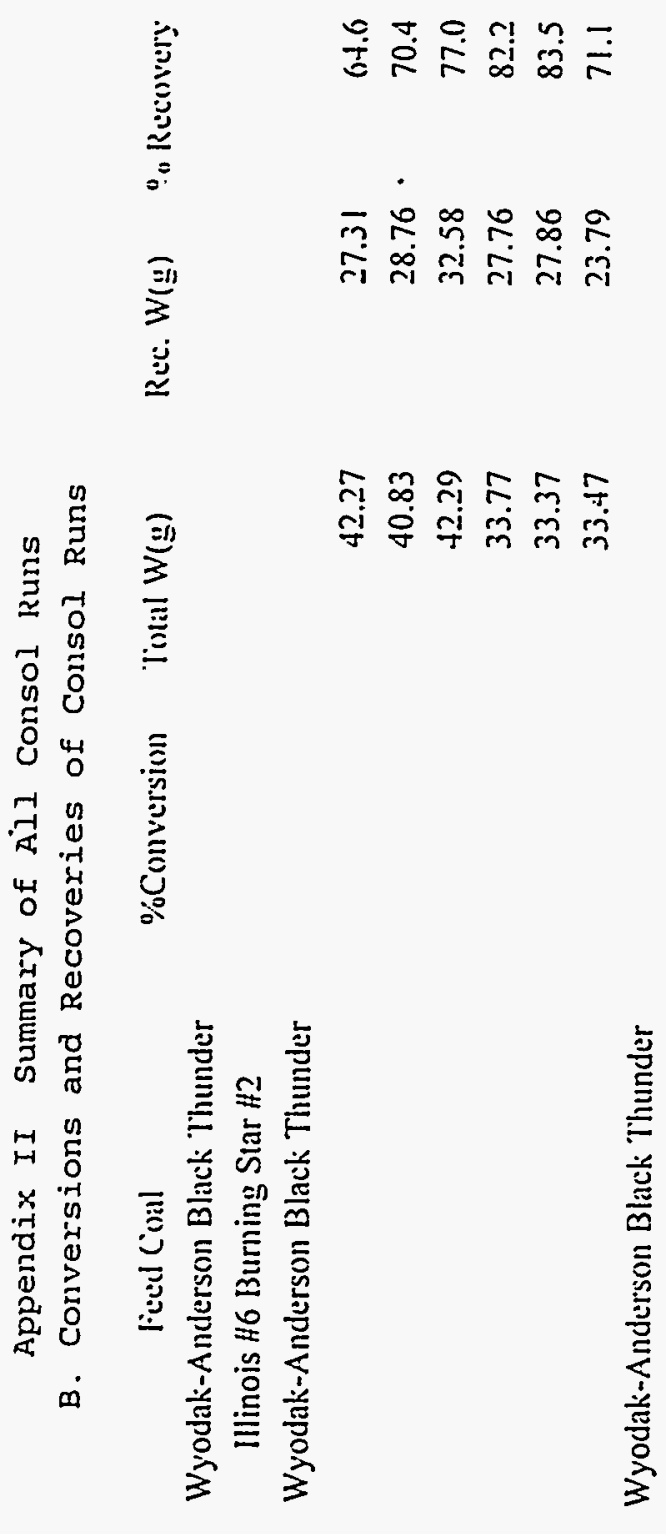

胥

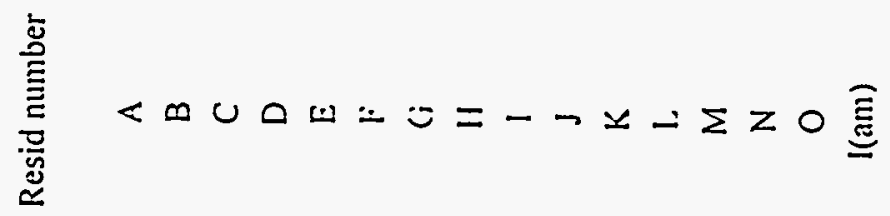

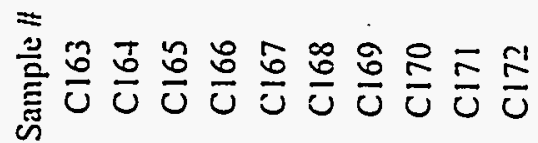

iั 
Appendix II Summary of All Consol Runs

B. Conversions and Recoveries of Consol Runs

I(am) +A Illinois 116 coil from Amoco I Resid A

Processed C: Resid C, washed, extracted by Tetralin

C(p.s): Solid Resid C, soaked by Tetralin

C(p.l): $\quad$ Liquid Resid C,soaked by Tetralin

A(p.s): $\quad$ Resid A, washed,extracted by Tetralin

$D(p . s)$ : Resid $D$, washed, extracted by Tetralin

$G(p . s)$ : Resid G, washed,extracted by Tetralin

$\%$ Conversion: \% converted to bp (8.50" $\mathrm{F})$ 


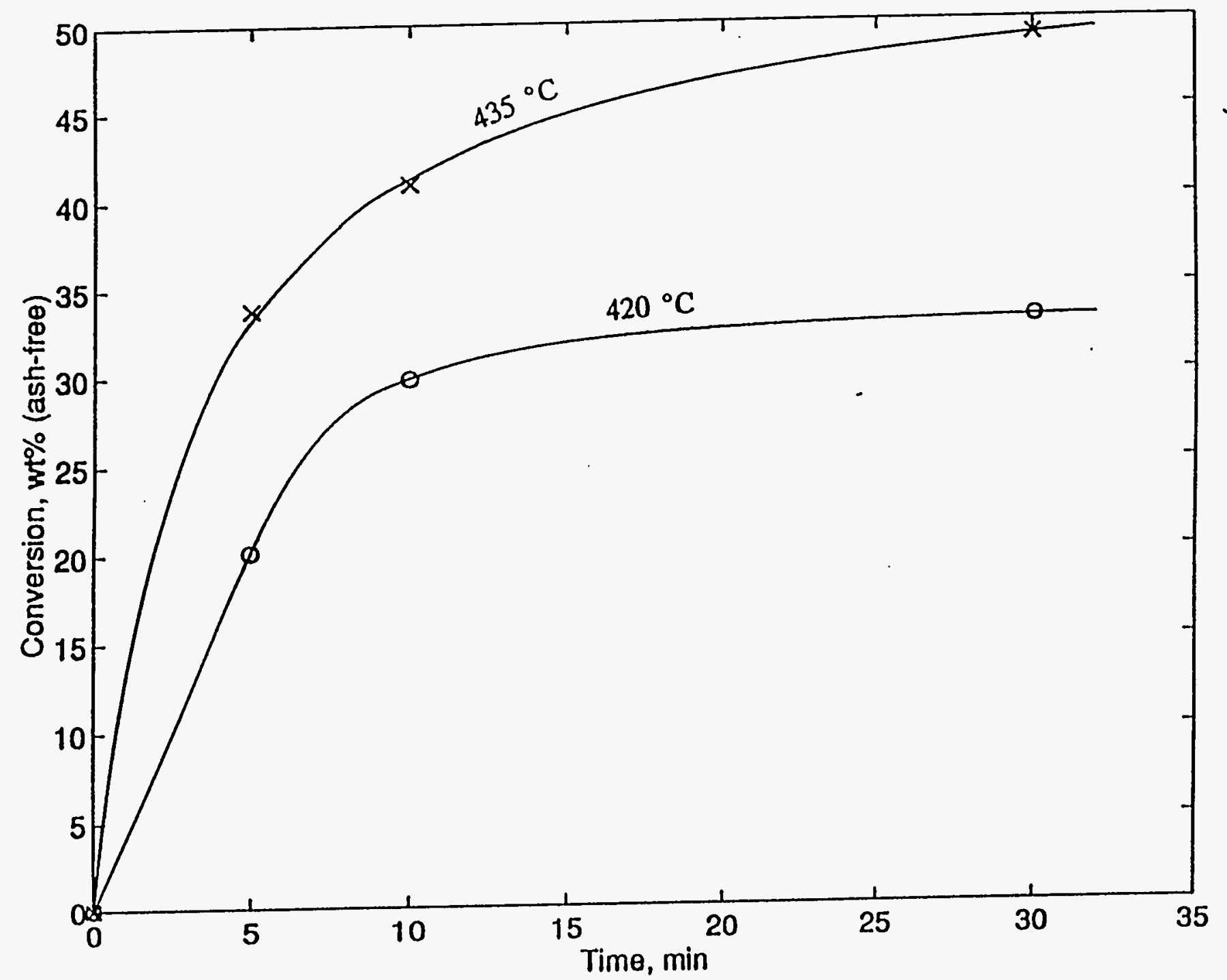

Figure II

Conversion vs time for the catalyzed hydroprocessing of Resid C (1500 psig $\mathrm{H}_{2} ; 3$ wt\% Mo; Tetralin:Resid=3:1 wt. ratio) 


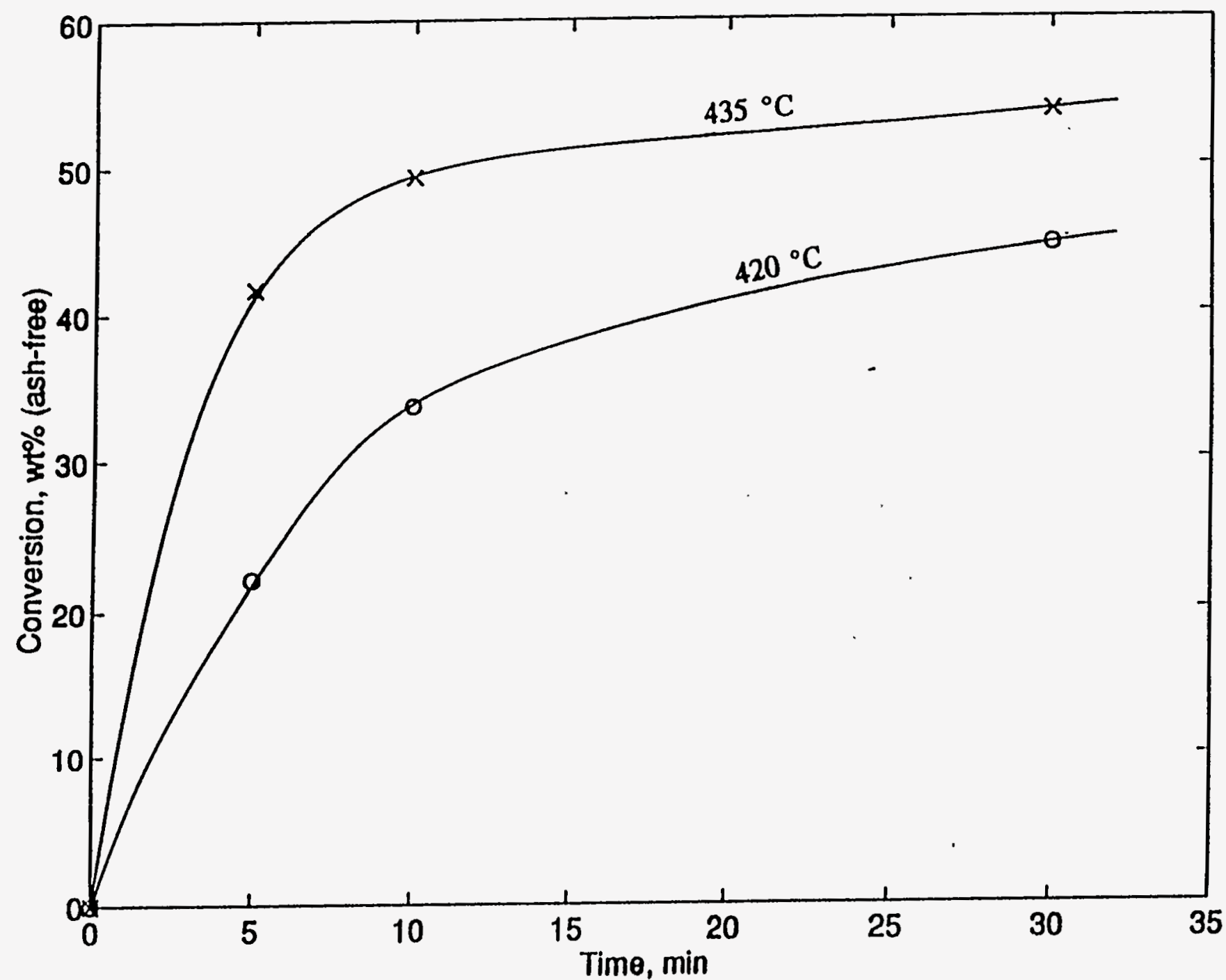

Figure 12

Conversion vs time for the catalyzed hydroprocessing of Resid $\mathrm{H}$ (1500 psig $\mathrm{H}_{2} ; 3$ wt\% Mo; Tetralin:Resid =3:1 wt. ratio) 


\title{
Appendix 1
}

\section{User's Manual for the Structure and Reaction Models for Coal Resid}

\author{
By \\ Darin Campbell \\ University of Delaware \\ Department of Chemical Engineering \\ Center for Catalytic Science and Technology \\ Newark, DE 19716
}




\section{Introduction}

A model for the structure of coal resid and a model for the catalytic hydroprocessing of coal resid have been developed. Each of these models is written in FORTRAN (with one short subroutine in $C$ which seeds the random number generator to the clock of the computer). Furthermore, each of these models can be run either in the optimization mode or the once-through mode.

The optimization and once-through modes for each of these models are very similar, differing in only two or three subroutines and containing common variables. The reaction model and structure models are closely connected and contain many subroutines of the same name. However. due to the differences in structure of the reaction products, the differences in the subroutines of the two model types are significant so that interchange of these subroutines between the structure and reaction models is generally not possible.

Each model requires only one input file. The input file for the reaction model is similar to that for the structure model, with a couple of extra lines needed for information unique to the reaction model. All input files are interchangeable between the optimization modes and the once-through modes:

In the following sections, the input file is described line by line for the structure and reaction subroutines. Furthermore. a list of the subroutines and brief description of each subroutine for both models is presented. 


\section{Structure Model - Optimization}

The structure model is used to optimize the structural attribute pdf parameters used to describe the molecules of a coal resid. A list of the subroutines along with a description is supplied below:

sa.f This is a simulated global annealing program developed by Bill Goffe. A description of the variables unique to this program are provided within the code.This is the main subroutine used to optimize the structural attribute pdf's for a coal resid. It is necessary to specify the initial guesses of the pdf parameters in the code starting at line 76 of sa.f:

$x(1)$ : nrmean - mean for number of naphthenic rings distribution for the naphthenics fraction

$x(2)$ : nrstdev - standard deviation for number of naphthenic rings distribution for the naphthenics fraction

$x(3)$ : nscmean - mean for number of sidechains distribution for the naphthenics fraction

$x(4)$ : nslmean - mean for length of sidechains distribution for the naphthenics fraction

$x(5)$ : rdpmean - mean for degree of polymerization distribution for the aromatics/resin fraction

$x(6)$ : rarmear - mean for the number of aromatic rings distribution for the aromatics/resin fraction

$x(7)$ : mrmean - mean for the number of naphthenic rings distribution for the aromatics/resin fraction

$x(8)$ : rscmean - mean for the number of sidechains distribution for the aromatics/resin fraction

$x(9)$ : rslmean - mean for the length of sidechains distribution for the aromatics/resin fraction

$x(10)$ : adpmean - mean for degree of polymerization distribution for the asphaltenes fraction

$x(11)$ : aarmean - mean for the number of aromatic rings distribution for the asphaltene fraction

$x(12)$ : anrmean - mean for the number of naphthenic rings distribution for the asphaltene fraction

$x(13)$ : ascmean - mean for the number of sidechains distribution for the asphaltene fraction

$x(14)$ : aslmean - mean for the length of sidechains distribution for the asphaltene fraction

$x(15)$ : pdpmean - mean for degree of polymerization distribution for the preasphaltenes fraction

$x(16)$ : parmean - mean for the number of aromatic rings distribution for the preasphaltene fraction

$x(17)$ : pnrmean - mean for the number of naphthenic rings distribution for the preasphaltene fraction

$x(18)$ : pscmean - mean for the number of sidechains distribution for the preasphaltene fraction

$x(19)$ : pslmean - mean for the length of sidechains distribution for the preasphaltene fraction

$x(20)$ : fiso - fraction of oxygen intersheet linkages

$x(21)$ : fiss - fraction of sulfur intersheet linkages

$x(22)$ : fism - fraction of methylene intersheet linkages 
$x$ (23): fisb - fraction of biphenyl intersheet linkages

$x(24)$ : frorings - fraction of aromatic cores with oxygen rings

$x(25)$ : frsrings - fraction of aromatic cores with sulfur rings

$x(26)$ : frnrings - fraction of aromatic cores with nitrogen rings

$x(27)$ : frhcrings - fraction of aromatic cores with no heteroatoms

$x(28)$ : frinrings - fraction of aromatic cores with an internal naphthenic ring

$x(29)$ : frphh - fraction of aromatic cores with phenolic oxygens

$x(30)$ : frlrar - fraction of aromatic.cores with one aromatic ring

$\mathrm{x}(31)$ : rdpstdev - standard deviation for the degree of polymerization distribution for the aromatics/resin fraction

$x(32)$ : adpstdev - standard deviation for the degree of polymerization distribution for the asphaltene fraction

$x(33)$ : pdpstdev - standard deviation for the degree of polymerization distribution for the preasphaltene fraction 
In addition to specifying the initial guesses for the $x$ array, it is necessary to specify values for the upper bounds (UB array) and lower bounds (LB array). Each $x$ value must fall between the corresponding $L B$ and UB values.

readinit.f This program reads in the initial values of a coal resid from the distrh.inp file.

fcn.i $\quad$ This subroutine is attached to the optfeed.f subroutine for the optimization program. It is used to pass the current pdf parameters to the structure building program.

optfeed.f This subroutine is the main structure subroutine. From this subroutine, other subroutines are called to calculate the numerical values for the pdf's, build a representative molecular representation. The analytical properties are then computed and compared to the experimentally determined values.

distr.f This subroutine is used to calculate the probabilities for each attribute value. The gamma and exponential distributions are continuous. so this routine also is used to discretize and truncate the distributions.

maxrings.f This subroutine is used to truncate and renormalize the number of ring distributions so that no ring structure is too large.

maxus.f This subroutine is used to truncate and renormalize the degree of polymerization distributions so that no molecules are built that are too large.

construct.f This subroutine is used to construct the representative molecules one at a time. The type of molecule is first determined by drawing a random number and matching it to the experimentally determined compound class molar distribution. Once the molecule type is determined, the appropriate subroutine is called to construct the molecule. This subroutine is also used to store the individual properties so that later bulk property values may be calculated.

lookup.f This subroutine is used to draw a random number and compare it to the appropriate cumulative distribution. Starting with the first possible value, the random number is compared to the cumulative probability for each attribute value. If the random number is less than the probability of a particular attribute value, that value is selected and returned.

naphus.f This subroutine is used to build a naphthenic molecule. The number of naphthenic rings are first specified. The number, length, and placement of the sidechains are then determined.

aromus.f This subroutine is used to build an aromatic core (one aromatic core for each unit sheet) for an aromatic/resin molecule. The number of aromatic rings is specified first, and then it is determined if the aromatic has a heteroatom ring and what type. For an aromatic core with three or more rings, it is also determined whether the core has an internal naphthenic rings. Once the core has been specified, it is determined whether a core has a phenolic hydroxyl group. Finally, the number, length and placement of the alkyl sidechains are determined. 
asphus.f This subroutine is used to build an aromatic core (one aromatic core for each unit sheet) for an asphaltene molecule. The number of aromatic rings is specified first, and then it is determined if the aromatic has a heteroatom ring and what type. For an aromatic core with three or more rings, it is also determined whether the core has an internal naphthenic rings. Once the core has been specified. it is determined whether a core has a phenolic hydroxyl group. Finally, the number, length and placement of the alkyl sidechains are determined.

preasphus.f This subroutine is used to build an aromatic core (one aromatic core for each unit sheet) for an preasphaltene molecule. The number of aromatic rings is specified first, and then it is determined if the aromatic has a heteroatom ring and what type. For an aromatic core with three or more rings, it is also determined whetiner the core has an internal naphthenic rings. Once the core has been specified, it is determined whether a core has a phenolic hydroxyl group. Finally, the number, length and placement of the alkyl sidechains are determined.

islink.f This subroutine is used to determine whether a molecule with an intersheet link is connected by an acid-base interaction between a phenolic hydroxyl and a ring nitrogen. If not, a subroutine which determines the covalent link type is called.

covalent.f This subroutine determines the covalent bond type for an intersheet linkage. A covalent intersheet linkage may be a sulfur, an oxygen, a methylene, or a biphenyl bridge.

time.c This subroutine is used to seed the random number generator to the clock. 
The only input file needed to run this program is distrh.inp. Following is a line by line description of the file:

LINE 1: This line is used as a header for the file.

Input File for Coal Resid Heavy Oil Monte Carlo Simulation

LINE 2: This line is used to identify the feedstock being run or optimized.

FEEDSTOCK = CONSOL Run \# 15 (HTI POC-02.0-43)

LINE 3: This line is used as a spacer.

LINE4: This line is used to start the attribute distribution parameter input.

STRUCTURAL ATTRIBUTE INPUT

LINE 5: This line is used to explain what values correspond to which distribution type.

(type: $1=$ exponential, 2 =gamma.3=chi-square)

LINE 6: This line is used as a header for the distribution parameters.

ATTRIBUTE type min. mean std. dev.

LINE 7: This line is used to input the type, minimum, mean, and standard deviation for the paraffin distribution. Note that the paraffin distribution is not optimized since the fraction of paraffins for any given feed is quite small and therefore has only a very slight effect on the objective funciton.

$\begin{array}{lllll}\text { 'n-paraffin_Number of Carbons' } \quad 2 & 20 & 25.0 & 2.0\end{array}$

LINE 8: This line is used to input the type, minimum. mean. and standard deviation for the number of naphthenics ring distribution for the naphthenics fraction.

$\begin{array}{lllll}\text { 'Naphthenic_Ring_Distribution' } \quad 2 & 3 & 3.70 & 0.53\end{array}$

LINE 9: This line is used to input the type, minimum, mean, and standard deviation for the number of sidechains distribution for the naphthenics fraction.

$\begin{array}{lllll}\text { 'Naphthenic_number_of_sidechains' } \quad 1 & 0 & 4.70 & 1.74\end{array}$

LINE 10: This line is used to input the type, minimum, mean, and standard deviation for the length of sidechains distribution for the naphthenics fraction.

'Naphthenic_alkyl_chain_length' $\quad \begin{array}{llll}1 & 1 & 5.40 & 8.84\end{array}$

LINE 11: This line is used to input the type, minimum, mean, and standard deviation for the degree of polymerization for the aromatics/resins fraction.

'Resin_degree_of_polym.' $\quad 2 \quad 1 \quad 5.06 \quad 3.50$ 
LINE 12: This line is used to input the type, minimum. mean. and standard deviation for the number of aromatic rings distribution for the aromatics/resins fraction.

'Resin_number_of_aromatic_rings' $\quad 1 \quad 2 \quad 6.92 \quad 8.84$

LINE 13: This line is used to input the type, minimum, mean. and standard deviation for the number of naphthenic rings distribution for the aromatics/resins fraction.

'Resin_number_of_naphthenic_rings' $\quad \begin{array}{llll} & 0 & 0.83 & 8.84\end{array}$

LINE 14: This line is used to input the type, minimum. mean. and standard deviation for the number of alkyl sidechains distribution for the aromatics/resins fraction.

$\begin{array}{lllll}\text { 'Resin_number_of_sidechains' } & 1 & 0 & 1.15 & 1.74\end{array}$

LINE 15: This line is used to input the type, minimum, mean, and standard deviation for the length of alkyl sidechains distribution for the aromatics/resins fraction.

$\begin{array}{lllll}\text { 'Resin_alkyl_chain_length' } \quad & 1 & 1 & 1.75 & 8.84\end{array}$

LINE 16: This line is used to input the type, minimum, mean, and standard deviation for the degree of polymerization for the asphaltenes fraction.

'Asphaltene_degree_of_polym.' $\quad 2 \quad 2 \quad 5.53 \quad 1.37$

LINE 17: This line is used to input the type, minimum, mean, and standard deviation for the number of aromatic rings distribution for the asphaltenes fraction.

'Asphaltene_\#_of_aromatic_rings' $\quad \begin{array}{llll}1 & 2 & 6.62 & 8.84\end{array}$

LINE 18: This line is used to input the type, minimum, mean, and standard deviation for the number of naphthenic rings distribution for the asphaltenes fraction.

'Asphaltene_\#_of_naphthenic_rings' $\quad 1 \quad 0 \quad 0.34 \quad 8.84$

LINE 19: This line is used to input the type, minimum. mean. and standard deviation for the number of alkyl sidechains distribution for the asphaltenes fraction.

'Asphaltene_\#_of_sidechains' $\quad \begin{array}{llll} & 0 & 3.21 & 1.74\end{array}$

LINE 20: This line is used to input the type, minimum, mean, and standard deviation for the length of alkyl sidechains distribution for the asphaltenes fraction.

'Asphaltene_alkyl_chain_length' $\quad \begin{array}{llll}1 & 1 & 4.21 & 8.84\end{array}$

LINE 21: This line is used to input the type, minimum, mean, and standard deviation for the degree of polymerization for the preasphaltenes fraction.

$\begin{array}{lllll}\text { 'Preasphaltene_degree_of_polym.' } & 2 & 2 & 7.98 & 1.42\end{array}$ 
LINE 22: This line is used to input the type, minimum. mean, and standard deviation for the number of aromatic rings distribution for the preasphaltenes fraction.

'Preasphaltene_\#_of_aromatic_rings' $1 \quad 2 \quad 8.77 \quad 8.84$

LINE 23: This line is used to input the type, minimum, mean, and standard deviation for the number of naphthenic rings distribution for the preasphaltenes fraction.

'Preasphaltene_\#_of_naphthenic_rings' $1100.96 \quad 8.84$

LINE 24: This line is used to input the type, minimum, mean, and standard deviation for the number of alkyl sidechains distribution for the preasphaltenes fraction.

$\begin{array}{lllll}\text { 'Preasphaltene_\#_of_sidechains' } & 1 & 0 & 3.71 & 1.74\end{array}$

LINE 25: This line is used to input the type, minimum, mean, and standard deviation for the length of alkyl sidechains distribution for the preasphaltenes fraction.

$\begin{array}{lllll}\text { 'Preusphaltene_alkyl_chain_length' } & 1 & 1 & 2.53 & 8.84\end{array}$

LINE 26: This line is used as a spacer.

LINE 27: This line is used as a header for the SARA fractions section.

SARA FRACTIONS mol wt (cumulative)

LINE 28: This line is used to input the experimentally determined mole and weight fractions (cumulative) of the paraffins.

'Paraffins' $\quad 0.032 \quad 0.028$

LINE 29: This line is used to input the experimentally determined mole and weight fractions (cumulative) of the naphthenics.

'Naphthenics' $0.324 \quad 0.276$

LINE 30: This line is used to input the experimentally determined mole and weight fractions (cumulative) of the aromatics/resins.

'Resins' $\quad 0.977 \quad 0.950$

LINE 31: This line is used to input the experimentally determined mole and weight fractions (cumulative) of the asphaltenes.

'Asphaltenes' $0.998 \quad 0.995$

LINE 32: This line is used to input the experimentally determined mole and weight fractions (cumulative) of the preasphaltenes. -

'Preasph' $\quad 1.0 \quad 1.0$ 
LINE 33: This line is used as a spacer.

LINE 34: This line is used to input the experimentally determined molecular weight.

'MW' 355.7

LINE 35: This line is used to input the experimentally determined weight fraction of carbon.

'wt frac C' 0.8906

LINE 36: This line is used to input the experimentally determined weight fraction of hydrogen.

'wt frac $\mathrm{H}^{\prime} \quad 0.0836$

LINE 37: This line is used to input the experimentally determined weight fraction of nitrogen.

'wt frac $N^{\prime} \quad 0.0031$

LINE 38: This line is used to input the experimentally determined weight fraction of sulfur.

'wt frac S' 0.0021

LINE 39: This line is used to input the experimentally determined weight fraction of oxygen.

'wt frac O' 0.0205

LINE 40: This line is used as a spacer.

LINE 41: This line is used to input the experimentally determined fraction of condensed aromatic protons.

'fr Harom con' 0.145

LINE 42: This line is used to input the experimentally determined fraction of monoaromatic protons.

'fr Harom un' 0.043

LINE 43: This line is used to input the experimentally determined fraction of cyclic alpha protons.

'fr HCalpha' 0.145 
LINE 44: This line is used to input the experimentally determined fraction of alkyl alpha protons.

'fr HAalpha' 0.080

LINE 45: This line is used to input the experimentally determined fraction of cyclic beta protons.

'fr HCbeta' 0.151

LINE 46: This line is used to input the experimentally determined fraction of alkyl beta protons.

'fr HAbeta' $\quad 0.300$

LINE 47: This line is used to input the experimentally determined fraction of gamma protons.

'fr Hgamma' 0.136

LINE 48: This line is used to input the concentration (meq/g) of phenolic hydroxyls.

'Phenolic $\mathrm{OH}^{\prime} \quad 0.22$

LINE 49: This line is used as a spacer.

LINE 50: This line is used to input the fraction of oxygen intersheet linkages.

'fiso' $\quad 0.164$

LINE 51: This line is used to input the fraction of sulfur intersheet linkages.

'fiss' $\quad 0.034$

LINE 52: This line is used to input the fraction of methylene intersheet linkages.

'fism' $\quad 0.122$

LINE 53: This line is used to input the fraction of biphenyl intersheet linkages.

'fisb' $\quad 0.680$

LINE 54: This line is used to input the fraction of aromatic cores containing one oxygen ring.

'frorings' $\quad 0.242$

LINE 55: This line is used to input the fraction of aromatic cores containing one sulfur ring.

'frsrings' $\quad 0.002$ 
LINE 56: This line is used to input the fraction of aromatic cores containing one nitrogen ring.

'frnings' $\quad 0.084$

LINE 57: This line is used to input the fraction of aromatic cores containing no heteroatomic rings.

'frhcrings' $\quad 0.672$

LINE 58: This line is used to input the fraction of aromatic cores containing one internal naphthenic ring.

'frinrings' $\quad 0.937$

LINE 59: This line is used to input the fraction of aromatic cores containing one phenolic hydroxyl.

'frphh' $\quad 0.066$

LINE 60: This line is used to input the fraction of aromatic cores with exactly one aromatic ring.

'flrar' $\quad 0.437$

LINE 61: This line is used to specify the fraction of saturatures which are paraffins (currently not used - automatically set to 0.1 in the main program).

'fparf' $\quad 0.1$ 
A sample input file for each of the fifteen coal resids used in the development of this model has been supplied. Note that for any new feeds, or any new data for the current feeds, the values should be placed in the same field as the template files.

It is also important to note that the values for standard deviation in lines 7 to 25 matter only when the distribution type is 2 (gamma). The exponential distribution is defined only by a minimum and a mean.

The input values for the mean and standard deviations for those parameters that are being optimized (lines 8 to 25) and the values for lines 50 to 61 are not important for the optimization program since they are set directly in sa.f. Each of these values should be set to the optimized value from the optimization routine for the once-through program.

The output from the optimization also may give values that are significantly different for lines 50 to 57 . This is because lines fiso, fiss, fism, and fisb must add to one and so must frorings, frsrings, frnrings, and frhcrings. The values reported in each of the sample files have been normalized to one. However, the output values may not be normalized to one. This is not critical, however, since the values are normalized to one during the course of the program. 


\section{Structure Model - Once Through}

The once-through structure model is very similar to the optimization model. Only a couple of subroutines are different:

croptout.f This subroutine is the driver program for the once-through version of the structure model. This subroutine is used in place of the sa.f program used for the optimization model.

runfeed.f This subroutine is the main subroutine used to call the other routines to set up the numerical probabilities of the pdf's and to construct the molecules. It then calculates the predicted properties of the representative molecular sample and calls the subroutine to print the information to the screen.

output.f This subroutine is used to output the experimentally determined and predicted properties. The contribution that each analytical property contributes to the objective function is also output.

Other than these different subroutines. and the fact that the optimized parameter values should be input to distrh.inp, this program runs exactly the same as the optmization program. 


\section{Reaction Model - Optimization}

This program is used to optimize the rate parameters for the reaction model. Five of the initial resids in this study were used to optimize the rate parameters. Following is a list of the subroutines used for this model (Note: although many of these subroutines have the same name and function as the corresponding structure model subroutines, they are not interchangeable).

sa_rxopt.f This is the simulated annealing program used to optimize the rate parameters for the reaction model. Below is a list of the parameters:

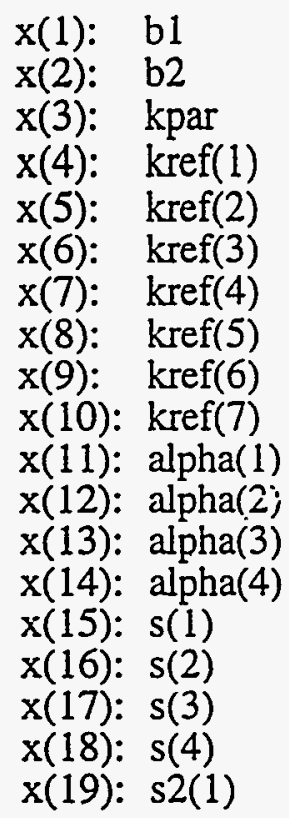

These parameters are used to calculate the rate constants according to Table 1. 
TABLE 1: Reactivity relationships for coal resid catalytic hydroprocessing model.

\begin{tabular}{|c|c|}
\hline Reaction Family & Structure Reactivity Relationship \\
\hline Paraffin Cracking & $\mathrm{k}=(\mathrm{CNO}-1 .)^{*}(\mathrm{~b} 1 * \mathrm{CNO}-\mathrm{b} 2) * \mathrm{kpar}$ \\
\hline Naphthenic Sidechains & 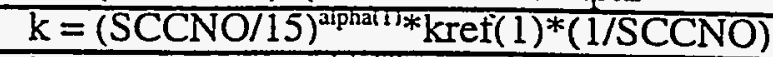 \\
\hline Aromatic Sidechains - At Ring & $\mathrm{k}=(\mathrm{SCCNO} / 15)^{\text {arphar(2) }} * \mathrm{kref}(2) * \mathrm{~s}(1)$ \\
\hline Aromatic Sidechains - Alpha & $\mathrm{k}=(\mathrm{SCCNO} / 15)^{\mathrm{alpha(2)} * \mathrm{kref}(2) * \mathrm{~s}(2)}$ \\
\hline Aromatic Sidechains - Beta & $\mathrm{k}=(\mathrm{SCCNO} / 15)^{\mathrm{alpha}(2) * \mathrm{kref}(2) * \mathrm{~s}(3)}$ \\
\hline Aromatic Sidechains - Other & 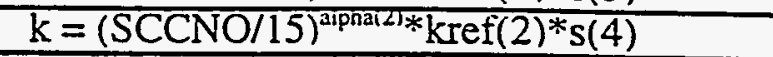 \\
\hline Asphaltene Sidechains - At Ring & $\mathrm{k}=(\mathrm{SCCNO} / 15)^{\mathrm{apna} / 2 / *} \mathrm{kref}(2)^{*} \mathrm{~s}(1)^{*} \mathrm{~s} 2(1)$ \\
\hline Asphaltene Sidechains - Alpha & 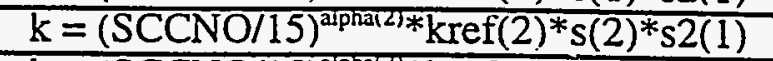 \\
\hline Asphaltene Sidechains - Beta & $\mathrm{k}=(\mathrm{SCCNO} / 15)^{\mathrm{apna}(2)} * \mathrm{kref}(2) * \mathrm{~s}(3) * \mathrm{~s} 2(1)$ \\
\hline Asphaltene Sidechains - Other & $\mathrm{k}=(\mathrm{SCCNO} / 15)^{\mathrm{apha}(2)} * \mathrm{kref}(2) * \mathrm{~s}(4) * \mathrm{~s} 2(1)$ \\
\hline Preasphaltene Sidechains - At Ring & 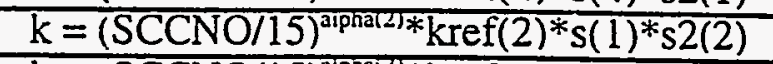 \\
\hline Preasphaltene Sidechains - Alpha & $\mathrm{k}=(\mathrm{SCCNO} / 15)^{\text {apnal } 2 / * \mathrm{kref}(2) * \mathrm{~s}(2) * \mathrm{~s} 2(2)}$ \\
\hline Preasphaltene Sidechains - Beta & $\mathrm{k}=(\mathrm{SCCNO} / 15)^{\text {alphat }} * \mathrm{kref}(2) * \mathrm{~s}(3)^{*} \mathrm{~s} 2(2)$ \\
\hline Preasphaltene Sidechains - Other & $\mathrm{k}=(\mathrm{SCCNO} / 15)^{\text {aphas }(2) * \mathrm{kref}(2) * \mathrm{~s}(4) * \mathrm{~s} 2(2)}$ \\
\hline Intersheet Linkage - Sulfur & $\mathrm{k}=\mathrm{kref}(3)^{*}\left(\#\right.$ of Unit Sheets) ${ }^{- \text {alphats }}$ \\
\hline Intersheet Linkage - Oxygen & $\mathrm{k}=\mathrm{kref}(4) *\left(\#\right.$ of Unit Sheets) ${ }^{-s i p n a t s)}$ \\
\hline Intersheet Linkage - Methylene & $\mathrm{k}=\mathrm{kref}(5)^{*}$ (\# of Unit Sheets) ${ }^{- \text {sipnats }}$ \\
\hline Intersheet Linkage - Biphenyl & $\mathrm{k}=\mathrm{kref}(6) *$ (\# of Unit Sheets) $^{- \text {alphals) }}$ \\
\hline Thiophenic Rings & $\mathrm{k}=\mathrm{kref}(3)^{*}\left(\#\right.$ of Rings on Unit Sheet) ${ }^{\text {-uphait }}$ \\
\hline Furan Rings & 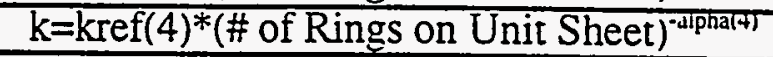 \\
\hline 5-member Nitrogen Rings & $\mathrm{k}=\mathrm{kref}(7)^{*}(\# \text { of Rings on Unit Sheet })^{\text {-ulphait }}$ \\
\hline Internal Naphthenics & $\mathrm{k}=\mathrm{kref}(5) *$ (\# of Rings on Unit Sheet) ${ }^{\text {-alphalक }}$ \\
\hline
\end{tabular}

$\mathrm{CNO}=$ carbon number for the paraffin

$\mathrm{SCCNO}=$ number of carbons in the reactive sidechain. 
readinit_rxn.f This subroutine is used to read in the analytical data and optimized pdf parameters for the five resids used in the optimization.

fcn.f This subroutine is attached to rxopt.f and is used to call the setup.f subroutine to set the analytical properties and pdf parameters correctly for each resid used in the optimization.

setup.f This subroutine set the analytical properties and pdf parameters to the values of the resid being reacted. For each step in the optimization, all five resids are reacted and the products constructed for comparison to experimentally determined conversion values.

Ixopt.f This subroutine is used to call the subroutines which set up the appropriate distributions, determine the initial concentrations, determine the rate constants, react the attributes, regenerate the pdf's, construct the molecules. It then determines the properties of the molecular representation. and calculates the conversion and compares to the experimentally determined value.

distr.f This subroutine is used to calculate the probabilities for each attribute value. The gamma and exponential distributions are continuous, so this routine also is used to discretize and truncate the distributions.

maxrings.f This subroutine is used to truncate and renormalize the number of ring distributions so that no ring structure is too large.

maxus.f This subroutine is used to truncate and renormalize the degree of polymerization distributions so that no molecules are built that are too large.

ncdist.f This subroutine is used to calculate the normalized non-cumulative distributions from the normalized cumulative distributions. These noncumulative distributions are needed to calculate the initial concentrations of the reactive attributes.

attrconc.f This subroutine is used to calculate the initial concentrations of the reactive attributes.

rates.f This subroutine is used to calculate the rate constants from the parameters supplied by the simulated annealing program.

coalattrxn.f This subroutine is used to solve the reaction network for the time specified in the input file.

pdfregen.f This subroutine is used to regenerate the probability density function from the updated concentrations from the reaction subroutine.

construct.f This subroutine is used to construct the representative molecules one at a time. The type of molecule is first determined by drawing a random number and matching it to the experimentally determined compound class molar distribution. Once the molecule type is determined. the appropriate subroutine is called to construct the moleeule. This subroutine is also used to store the individual properties so that later bulk property values may be calculated. 
lookup.f This subroutine is used to draw a random number and compare it to the appropriate cumulative distribution. Starting with the first possible value, the random number is compared to the cumulative probability for each attribute value. If the random number is less than the probability of a particular attribute value. that value is selected and returned.

naphus.f This subroutine is used to build a naphthenic molecule. The number of naphthenic rings are first specified. The number, length, and placement of the sidechains are then determined.

aromus.f This subroutine is used to build an aromatic core (one aromatic core for each unit sheet) for an aromatic/resin molecule. The number of aromatic rings is specified first. and then it is determined if the aromatic has a heteroatom ring and what type. For an aromatic core with three or more rings, it is also determined whether the core has an internal naphthenic rings. Once the core has been specified. it is determined whether a core has a phenolic hydroxyl group. Finally, the number. length and placement of the alkyl sidechains are determined.

asphus.f This subroutine is used to build an aromatic core (one aromatic core for each unit sheet) for an asphaltene molecule. The number of aromatic rings is specified first. and then it is determined if the aromatic has a heteroatom ring and what type. For an aromatic core with three or more rings, it is also determined whether the core has an internal naphthenic rings. Once the core has been specified. it is determined whether a core has a phenolic hydroxyl group. Finally, the number, length and placement of the alkyl sidechains are determined.

preasphus.f This subroutine is used to build an aromatic core (one aromatic core for each unit sheet) for an preasphaltene molecule. The number of aromatic rings is specified first, and then it is determined if the aromatic has a heteroatom ring and what type. For an aromatic core with three or more rings, it is also determined whether the core has an internal naphthenic rings. Once the core has been specified, it is determined whether a core has a phenolic hydroxyl group. Finally, the number. length and placement of the alkyl sidechains are determined.

islink.f This subroutine is used to determine whether a molecule with an intersheet link is connected by an acid-base interaction between a phenolic hydroxyl and a ring nitrogen. If not. a subroutine which determines the covalent link type is called.

covalent.f This subroutine determines the covalent bond type for an intersheet linkage. A covalent intersheet linkage may be a sulfur, an oxygen, a methylene, or a biphenyl bridge.

time.c This subroutine is used to seed the random number generator to the clock. 
The input files for the reaction model are quite similar to the input files for the structure model. In fact the first 61 lines are identical to those that would be used for the once-through structure model. The remaining lines are defined as follows:

LINE 62: This line is used as a header for the section required for the reaction model.

'Information needed for conversion calculations'

LINE 63: This line is used to input the experimentally determined fraction of THF insolubles.

'Frac THF Ins' 0.176

LINE 64: This line is used to input the experimentally determined conversion at the time specified on line 65 .

'Conv@ tl' 0.225

LINE 65: This line is used to input the reaction .

't1 (sec)' 0

LINE 66: This line is used to determine the quantity of low boilers initially constructed. This can be determined by running the once-through reaction model using a reaction time of zero seconds.

'\% Low Boilers' 5.1

As mentioned previously, five ( $B, D, E, H$, and $L$ ) of the fifteen resids used in the study were used to optimize the rate parameters. This files are coded in readinit_rxn.f. In order to change these, readinit_rxn.f would need to be modified. 


\section{Reaction Model - Once Though}

As with the structure models. the once-through reaction model is quite similar to the optimization reaction model except for a few subroutines:

crxout.f This main program replaces the sa_rxopt.f used in the optimization program.

readinit_rxn.f This subroutine is used to read in the necessary information for the reaction model. It is very similar to the subroutine used in the optimization, except that only one resid is read in rather than five. This subroutine is also used to read in the input file rates.inp which is not used in the optimization routine.

setup.f This subroutine is not used for the once-through model.

rxfeed.f This subroutine is used to replace the rxopt.f subroutine for the optimization model.

The once-through model needs one more input file not used for the optimization routine. This file. rates.inp, contains the 19 parameters specified in the program sa_rxopt.f. Each of these 19 parameters takes one line in rates.inp and the order is exactly the same as that specified for sa_rxopt.f.

In addition to the descriptions of the subroutines and input files a list of the variables used for the structure model and the reaction model is also attached. The variable types and common blocks are defined in construct.h for the structure model and in reaction.h for the reaction model. 


\section{Variables used for the structure model.}

\begin{tabular}{|c|c|}
\hline Variable & Definition \\
\hline aardis & asphaltene \# of aromatic rings cumulative distribution \\
\hline aarmean & asphaltene \# of aromatic rings distribution mean \\
\hline aarmin & minimum asphaltene \# of aromatic rings \\
\hline aarstdev & asphaltene \# of aromatic rings distribution standard deviation \\
\hline aartyp & distribution type for asphaltene \# of aromatic rings \\
\hline adpdis & asphaltene degree of polymerization cumulative distribution \\
\hline adpmean & asphaltene degree of polymerization distribution mean . \\
\hline adpmin & minimum asphaltene degree of polymerization \\
\hline adpstdev & asphaltene degree of polymerization distribution standard deviation \\
\hline adptyp & distribution type for asphaltene degree of polymerization \\
\hline aiusl & variable to keep track of the number of unit sheet being constructed \\
\hline amw & total molecular weight of the asphaltene fraction \\
\hline amwpred & predicted asphaltene weight fraction \\
\hline anrdis & asphaitene \# of naphthenic rings cumulative distribution \\
\hline anrmean & asphaltene \# of naphthenic rings distribution mean \\
\hline anrmin & minimum asphaltene \# of naphthenic rings \\
\hline anrstdev & asphaltene \# of naphthenic rings distribution standard deviation \\
\hline annip & distribution type for asphaltene \# of naphthenic rings \\
\hline ascdis & asphaltene \# of sidechains cumulative distribution \\
\hline ascmean & asphaltene \\
\hline ascmin & minimum asphaltene \# of sidechains \\
\hline ascstdev & asphaltene \# of sidechains distribution standard deviation \\
\hline asciyp & distribution type for asphaltene \# of sidechains \\
\hline asldis & asphaltene sidechain length cumulative distribution \\
\hline aslmean & asphaltene sidechain length distribution mean \\
\hline aslmin & minimum asphaltene sidechain length \\
\hline aslstdev & asphaltene sidechain length distribution standard deviation \\
\hline asltyp & distribution type for asphaltene sidechain length \\
\hline asphno & number of asphaltene molecules constructed \\
\hline btype & $\begin{array}{l}\text { bond type for intersheet links } \\
0 \text { corresponds to a covalent link } \\
1 \text { or } 2 \text { correspond to an acid base interaction }\end{array}$ \\
\hline catomtot & total number of carbon atoms \\
\hline Cno & number of carbon atoms in a molecule \\
\hline cwtexp & experimentally measured carbon weight fraction \\
\hline cwtpred & predicted carbon weight fraction \\
\hline degpol & degree of polymerization for molecule being constructed \\
\hline easph & experimentally measured asphaltene mole fraction (cumulative) \\
\hline easph_wt & experimentally measured asphaltene weight fraction (cumulative) \\
\hline flrar & fraction of aromatic cores with exactly one aromatic ring \\
\hline fisb & fraction of biphenyl intersheet linkages \\
\hline fism & fraction of methylene intersheet linkages \\
\hline fiso & fraction of oxygen intersheet linkages \\
\hline fiss & fraction of sulfur intersheet linkages \\
\hline flag & $\begin{array}{l}\text { flag used to indicate type of atom an intersheet linkage is attached to on } \\
\text { the previous unit sheet } \\
\qquad \begin{array}{l}1=\text { aromatic } \\
2=\text { naphthenic }\end{array}\end{array}$ \\
\hline frhcrings & fraction of aromatic cores containing a no heteroatoms \\
\hline frinrings & fraction of aromatic cores with an intemal naphthenic ring \\
\hline frnrings & fraction of aromatic cores containing a nitrogen ring \\
\hline frorings & fraction of aromatic cores containing an oxygen ring \\
\hline
\end{tabular}




\section{Variables used for the structure model.}

\begin{tabular}{|c|c|}
\hline frphh & fraction of aromatic cores substituted with a phenolic oxygen \\
\hline frsrings & fraction of aromatic cores containing a sulfur ring \\
\hline haaexp & experimentally measured fraction of alkyl alpha hydrogens \\
\hline haano & number of alkyl alpha hydrogen atoms in a molecule \\
\hline haapred & predicted alkvl alpha hydrogen fraction \\
\hline habexp & experimentally measured fraction of alkyl beta hydrogens \\
\hline habno & number of alkyl beta hydrogen atoms in a molecule \\
\hline habpred & predicted alkyl beta hydrogen fraction \\
\hline harexp & experimentally measured fraction of aromatic hydrogens \\
\hline harno & number of aromatic hydrogen atoms in a molecule \\
\hline harpred & predicted aromatic hydrogen fraction \\
\hline hatomtot & total number of hydrogen atoms \\
\hline hcaexp & experimentally measured fraction of cyclic alpha hydrogens \\
\hline hcano & number of cyclic alpha hydrogen atoms in a molecule \\
\hline hcapred & predicted cyclic alpha hydrogen fraction \\
\hline hcarexp & experimentally measured fraction of condensed aromatic hydrogens \\
\hline hcarno & number of condensed aromatic hydrogen atoms in a molecule \\
\hline hcarpred & predicted condensed aromatic hydrogen fraction \\
\hline hcbexp & experimentally measured fraction of cyclic beta hydrogens \\
\hline hebno & number of cyclic beta hydrogen atoms in a molecule \\
\hline hcbpred & predicted cyclic beta hydrogen fraction \\
\hline hgno & number of gamma hydrogen atoms in a molecule \\
\hline hgpred & predicted gamma hydrogen fraction \\
\hline hgpred & experimentally measured fraction of gamma hydrogens \\
\hline hno & number of hydrogen atoms in a molecule \\
\hline hwtexp & experimentally measured hydrogen weight fraction \\
\hline hwtpred & predicted hydrogen weight fraction \\
\hline iaarzz & spread of the truncated asphaltene $\#$ of aromatic rings distribution \\
\hline iadpzz & spread of the truncated asphaltene sidechain length distribution \\
\hline ianrzz & spread of the truncated asphaltene \# of naphthenic rings distribution \\
\hline iasczz & spread of the truncated asphaltene \# of sidechain distribution \\
\hline iaslzz & spread of the truncated asphaltene sidechain length distribution \\
\hline indpzz & spread of the truncated naphthenic degree of polymerization \\
\hline inpzz & spread of the truncated paraffin distribution \\
\hline inrzz & spread of the truncated naphthenic ring distribution \\
\hline insczZ & spread of the truncated \# of naphthenic sidechains distribution \\
\hline inslzz & spread of the truncated naphthenic sidechain length distribution \\
\hline iparzz & spread of the truncated preasphaltene \# of aromatic rings distribution \\
\hline ipdpzz & spread of the truncated preasphaltene sidechain length distribution \\
\hline ipnrzz & spread of the truncated preasphaltene \# of naphthenic rings distribution \\
\hline ipsczz. & spread of the truncated preasphaltene \# of sidechain distribution \\
\hline ipslzz & spread of the truncated preasphaltene sidechain length distribution \\
\hline irarzz & spread of the truncated resin \# of aromatic rings distribution \\
\hline irdpzz & spread of the truncated resin sidechain length distribution \\
\hline irnrzz & spread of the truncated resin \# of naphthenic rings distribution \\
\hline irsczz & spread of the truncated resin \# of sidechain distribution \\
\hline irslzz & spread of the truncated resin sidechain length distribution \\
\hline iseed & variable used to seed the random number generator \\
\hline isltype & $\begin{array}{l}\text { type of intersheet linkage between cores } \\
1=\text { sulfur } \\
2=\text { oxygen } \\
3=\text { methylene } \\
4=\text { biphenyl }\end{array}$ \\
\hline
\end{tabular}




\section{Variables used for the structure model.}

\begin{tabular}{|c|c|}
\hline mwexp & experimentally measured average molecular weight \\
\hline napmw & total molecular weight of the naphthenic fraction \\
\hline napno & number of naphthenic molecules constructed \\
\hline natomtot & total number of nitrogen atoms \\
\hline ncoreatom & \# of aromatic and naphthenic carbons and ring heteroatoms \\
\hline ndpdis & naphthenic degree of polymerization cumulative distribution \\
\hline ndpmean & naphthenic degree of polymerization distribution mean \\
\hline ndpmin & minimum naphthenic degree of polymerization \\
\hline ndpstdev & naphthenic degree of polymerization distribution standard deviation \\
\hline ndptyp & distribution type for napthenic degree of polymerization \\
\hline nfrac & \# of simulated distillation fractions (not used) \\
\hline nmwpred & predicted naphthenic weight fraction \\
\hline nno & number of nitrogen atoms in a molecule \\
\hline npdis & paraffin length cumulative distribution \\
\hline npmean & paraffin length distribution mean \\
\hline npmin & minimum paraffin length \\
\hline npstdev & paraffin length distribution standard deviation \\
\hline nptyp & distribution type for paraffin length \\
\hline nrdis & \# of naphthenic rings cumulative distribution \\
\hline nrmean & \# of naphthenic rings distribution mean \\
\hline nrmin & minimum \# of naphthenic rings \\
\hline nrstdev & \# of naphthenic rings distribution standard deviation \\
\hline nrtyp & distribution type for \# of naphthenic rings \\
\hline nscdis & naphthenic \# of sidechains cumulative distribution \\
\hline nscmean & naphthenic \# of sidechains distribution mean \\
\hline nscmin & minimum \# of naphthenic sidechains \\
\hline nscstdev & naphthenic \# of sidechains distribution standard deviation \\
\hline nsctyp & distribution type for naphthenic \# of sidechains \\
\hline nsldis & naphthenic sidechain length cumulative distribution \\
\hline nslmean & naphthenic sidechain length distribution mean \\
\hline nslmin & minimum naphthenic sidechain length \\
\hline nslstdev & naphthenic sidechain length distribution standard deviation \\
\hline nsltyp & distribution type for naphthenic sidechain length \\
\hline ntotmol & total number of molecules constructed \\
\hline nwtexp & experimentally measured nitrogen weight fraction \\
\hline nwtpred & predicted nitrogen weight fraction \\
\hline oatomtot & total number of oxygen atoms \\
\hline ono & number of oxygen atoms in a molecule \\
\hline owtexp & experimentally measured oxygen weight fraction \\
\hline owtpred & predicted oxygen weight fraction \\
\hline $\mathrm{pl}$ & fraction of peripheral aromatic positions \\
\hline $\mathrm{p} 2$ & fraction of peripheral cyclic alpha positions \\
\hline $\mathrm{p}^{3}$ & fraction of peripheral cyclic beta positions \\
\hline pardis & preasphaltene \# of aromatic rings cumulative distribution \\
\hline part & experimentally measured paraffin mole fraction \\
\hline parf_wt & experimentally measured paraffin weight fraction \\
\hline parmean & preasphaltene \# of aromatic rings distribution mean \\
\hline parmin & minimum preasphaltene \# of aromatic rings \\
\hline parno & number of paraffin molecules constructed \\
\hline parstdev & preasphaltene \# of aromatic rings distribution standard deviation \\
\hline partyp & distribution type for preasphaltene \# of aromatic rings \\
\hline pdpdis & preasphaltene degree of polymerization cumulative distribution \\
\hline pdpmean & preasphaltene degree of polymerization distribution mean \\
\hline
\end{tabular}




\section{Variables used for the structure model.}

\begin{tabular}{|c|c|}
\hline pdpmin & minimum preasphaltene degree of polymerization \\
\hline pdpstdev & preasphaltene degree of polymerization distribution standard deviation \\
\hline pdptyp & distribution type for preasphaltene degree of polymerization \\
\hline phono & number of phenolic oxygen atoms in a molecule \\
\hline phoxpred & predicted concentration of phenolic oxygen \\
\hline phoxpred & experimentally measured fraction of phenolic oxygen \\
\hline phoxtot & total number of phenolic oxygen atoms \\
\hline $\mathrm{pmw}$ & total molecular weight of the paraffin fraction \\
\hline pmwpred & predicted paraffin weight fraction \\
\hline pnrdis & preasphaltene \# of naphthenic rings cumulative distribution \\
\hline pnrmean & preasphaltene \# of naphthenic rings distribution mean \\
\hline pnrmin & minimum preasphaltene \# of naphthenic rings \\
\hline pnrstdev & preasphaltene \# of naphthenic rings distribution standard deviation \\
\hline pnrtyp & distribution type for preasphaltene \# of naphthenic rings \\
\hline preasph & experimentally measured preasphaltene mole fraction \\
\hline preasphno & number of preasphaltene molecules constructed \\
\hline preasph_wt & experimentally measured preasphaltene weight fraction (cumulative) \\
\hline prinw & total molecular weight of the preasphaltene fraction \\
\hline prmwpred & predicted preasphaltene weight fraction \\
\hline pscdis & preasphaltene \# of sidechains cumulative distribution \\
\hline pscmean & preasphaltene \# of sidechains distribution mean \\
\hline pscmin & minimum preasphaltene \# of sidechains \\
\hline pscstdev & preasphaltene \# of sidechains distribution standard deviation \\
\hline psctyp & distribution type for preasphaltene \# of sidechains \\
\hline psldis & preasphaltene sidechain length cumulative distribution \\
\hline pslmean & preasphaltene sidechain length distribution mean \\
\hline pslmin & minimum preasphaltene sidechain length \\
\hline pslstdev & preasphaltene sidechain length distribution standard deviation \\
\hline psltyp & distribution type for preasphaltene sidechain length \\
\hline raar & asphaltene \# of aromatic rings noncumulative distribution \\
\hline radp & asphaltene degree of polymerization noncumulative distribution \\
\hline ranr & asphaltene \# of naphthenic rings noncumulative distribution \\
\hline rardis & resin \# of aromatic rings cumulative distribution \\
\hline rarmean & resin \# of aromatic rings distribution mean \\
\hline rarmin & minimum resin \# of aromatic rings \\
\hline rarstdev & resin \# of aromatic rings distribution standard deviation \\
\hline rartyp & distribution type for resin \# of aromatic rings \\
\hline rasc & asphaltene \# of sidechains noncumulative distribution \\
\hline rasl & asphaltene sidechain length noncumulative distribution \\
\hline rdpdis & resin degree of polymerization cumulative distribution \\
\hline rdpmean & resin degree of polymerization distribution mean \\
\hline rdpmin & minimum resin degree of polymerization \\
\hline rdpstdev & resin degree of polymerization distribution standard deviation \\
\hline rdptyp & distribution type for resin degree of polymerization \\
\hline resin & experimentally measured resin mole fraction (cumulative) \\
\hline resin_wt & experimentally measured resin weight fraction (cumulative) \\
\hline resno & number of resin molecules constructed \\
\hline $\mathrm{rmw}$ & total molecular weight of the resin fraction \\
\hline Imwpred & predicted resin weight fraction \\
\hline mdp & naphthenic degree of polymerization noncumulative distribution \\
\hline $\mathrm{mp}$ & paraffin length noncumulative distribution \\
\hline mpth & experimentally measured naphthenic mole fraction (cumulative) \\
\hline mpth_wt & experimentally measured naphthenic weight fraction (cumulative) \\
\hline
\end{tabular}




\section{Variables used for the structure model.}

\begin{tabular}{|c|c|}
\hline $\mathrm{mr}$ & \# of naphthenic rings noncumulative distribution \\
\hline mrdis & resin \# of naphthenic rings cumulative distribution \\
\hline mrmean & resin \# of naphthenic rings distribution mean \\
\hline mrmin & minimum resin \# of naphthenic rings \\
\hline mrstdev & resin \# of naphthenic rings distribution standard deviation \\
\hline mrtyp & distribution type for resin \# of naphthenic rings \\
\hline msc & naphthenic \# of sidechains noncumulative distribution \\
\hline msl & naphthenic sidechain length noncumulative distribution \\
\hline Ipar & preasphaltene \# of aromatic rings noncumulative distribution \\
\hline rpdp & preasphaltene degree of polymerization noncumulative distribution \\
\hline rpnr & preasphaltene \# of naphthenic rings noncumulative distribution \\
\hline Ipsc & preasphaltene \# of sidechains noncumulative distribution \\
\hline IpsI & preasphaltene sidechain length noncumulative distribution \\
\hline Irar & resin \# of aromatic rings noncumulative distribution \\
\hline rrdp & resin degree of polymerization noncumulative distribution \\
\hline rrnr & resin \# of naphthenic rings noncumulative distribution \\
\hline rrsc & resin \# of sidechains noncumulative distribution \\
\hline rrsl & resin sidechain length noncumulative distribution \\
\hline rscdis & resin \# of sidechains cumulative distribution \\
\hline rscmean & resin \# of sidechains distribution mean \\
\hline rscmin & minimum resin $\#$ of sidechains \\
\hline rscstdev & resin \# of sidechains distribution standard deviation \\
\hline rsctyp & distribution type for resin \# of sidechains \\
\hline rsldis & resin sidechain length cumulative distribution \\
\hline rslmean & resin sidechain length distribution mean \\
\hline rslmin & minimum resin sidechain length \\
\hline rslstdev & resin sidechain length distribution standard deviation \\
\hline rsltyp & distribution type for resin sidechain length \\
\hline satomtot & total number of sulfur atoms \\
\hline sno & number of sulfur atoms in a molecule \\
\hline swtexp & experimentally measured sulfur weight fraction \\
\hline swtpred & predicted sulfur weight fraction \\
\hline tcharno & total number of condensed aromatic hydrogen atoms \\
\hline thaano & total number of alkyl alpha hydrogen atoms \\
\hline thabno & total number of alkyl beta hydrogen atoms \\
\hline thamo & total number of aromatic hydrogen atoms \\
\hline theano & total number of cyclic alpha hydrogen atoms \\
\hline thebno & total number of cyclic beta hydrogen atoms \\
\hline thgno & total number of gamma hydrogens \\
\hline totmw & total molecular weight of molecules constructed \\
\hline usmw & molecular weight of a unit sheet \\
\hline uscno & number of carbon atoms of a unit sheet \\
\hline ushno & number of hydrogen atoms of a unit sheet \\
\hline usnno & number of nitrogen atoms of a unit sheet \\
\hline usono & number of oxygen atoms of a unit sheet \\
\hline usphono & number of phenolic oxygen atoms of a unit sheet \\
\hline ussno & number of sulfur atoms of a unit sheet \\
\hline ushar & number of aromatic hydrogen atoms of a unit sheet \\
\hline ushcar & number of condensed aromatic hydrogen atoms of a unit sheet \\
\hline ushaa & number of alkyl alpha hydrogen atoms of a unit sheet \\
\hline ushca & number of cyclic alpha hydrogen atoms of a unit sheet \\
\hline ushab & number of alkyl beta hydrogen atoms of a unit sheet \\
\hline ushcb & number of cyclic beta hydrogen atoms of a unit sheet \\
\hline
\end{tabular}




\section{Variables used for the structure model.}

ushg

vpopred number of gamma hydrogen atoms of a unit sheet

predicted average molecular weight 


\section{Variables used for the reaction model.}

\begin{tabular}{|c|c|}
\hline Variable & Definition \\
\hline & for frag_arrays subscript corresponds to fragment number ( 1 to 3 ) \\
\hline & for mfrag _ arrays first subscript corresponds to unit sheet number \\
\hline & and second subscript corresonds to fragment number \\
\hline aardis & asphaltene \# of aromatic rings cumulative distribution \\
\hline aarmean & asphaltene \# of aromatic rings distribution mean \\
\hline aarmin & minimum asphaltene \# of aromatic rings \\
\hline aarstdev & asphaltene \# of aromatic rings distribution standard deviation \\
\hline aartyp & distribution type for asphaltene \# of aromatic rings \\
\hline adpdis & asphaltene degree of polymerization cumulative distribution \\
\hline adpmean & asphaltene degree of polymerization distribution mean \\
\hline adpmin & minimum asphaltene degree of polymerization \\
\hline adpstdev & asphaltene degree of polymerization distribution standard deviation \\
\hline adptyp & distribution type for asphaltene degree of polymerization \\
\hline afin & $\begin{array}{l}\text { fraction of asphaltene aromatic cores with internal naphthenics } \\
\text { (subscript denotes number of rings on aromatic core) }\end{array}$ \\
\hline afinm & $\begin{array}{l}\text { fraction of asphaltene aromatic cores with one methylene removed } \\
\text { (subscript denotes number of rings on aromatic core) }\end{array}$ \\
\hline afinn & $\begin{array}{l}\text { fraction of asphaltene aromatic cores with two methylenes removed } \\
\text { (subscript denotes number of rings on aromatic core) }\end{array}$ \\
\hline afisb & $\begin{array}{l}\text { fraction of biphenyl bridges for asphaltenes } \\
\text { (subscript denotes number of intersheet links for the molecule) }\end{array}$ \\
\hline afism & $\begin{array}{l}\text { fraction of methylene bridges for asphaltenes } \\
\text { (subscript denotes number of intersheet links for the molecule) }\end{array}$ \\
\hline afisn & $\begin{array}{l}\text { fraction of no bridges for asphaltenes } \\
\text { (subscript denotes number of intersheet links for the molecule) }\end{array}$ \\
\hline afiso & $\begin{array}{l}\text { fraction of oxygen bridges for asphaltenes } \\
\text { (subscript denotes number of intersheet links for the molecule) }\end{array}$ \\
\hline afiss & $\begin{array}{l}\text { fraction of sulfur bridges for asphaltenes } \\
\text { (subscript denotes number of intersheet links for the molecule) }\end{array}$ \\
\hline afrbr & $\begin{array}{l}\text { fraction of asphaltene aromatic cores with removed heteroatoms } \\
\text { (subscript denotes number of rings on aromatic core) }\end{array}$ \\
\hline afrher & $\begin{array}{l}\text { fraction of asphaltene aromatic cores with no heteroatoms } \\
\text { (subscript denotes number of rings on aromatic core) }\end{array}$ \\
\hline afmor & $\begin{array}{l}\text { fraction of asphaltene aromatic cores with heteroatom ring } \\
\text { (subscript denotes number of rings on aromatic core) }\end{array}$ \\
\hline afrnr & $\begin{array}{l}\text { fraction of asphaltene aromatic cores with nitrogen rings } \\
\text { (subscript denotes number of rings on aromatic core) }\end{array}$ \\
\hline afror & $\begin{array}{l}\text { fraction of asphaltene aromatic cores with oxygen rings } \\
\text { (subscript denotes number of rings on aromatic core) }\end{array}$ \\
\hline afrsr & $\begin{array}{l}\text { fraction of asphaltene aromatic cores with sulfur rings } \\
\text { (subscript denotes number of rings on aromatic core) }\end{array}$ \\
\hline aiusl & variable to keep track of the number of unit sheet being constructed \\
\hline amw & total molecular weight of the asphaltene fraction \\
\hline amwpred & predicted asphaltene weight fraction \\
\hline anrdis & asphaltene \# of naphthenic rings cumulative distribution \\
\hline anrmean & asphaltene \# of naphthenic rings distribution mean \\
\hline anrmin & minimum asphaltene \# of naphthenic rings \\
\hline anrstdev & asphaltene \# of naphthenic rings distribution standard deviation \\
\hline anrtyp & distribution type for asphaltene \# of naphthenic rings \\
\hline ascdis & asphaltene \# of sidechains cumulative distribution \\
\hline ascmean & asphaltene \# of sidechains distribution mean \\
\hline ascmin & minimum asphaltene \# of sidechains \\
\hline
\end{tabular}




\section{Variables used for the reaction model.}

\begin{tabular}{|c|c|}
\hline ascstdev & asphaltene \# of sidechains distribution standard deviation \\
\hline asctyp & distribution type for asphaltene \# of sidechains \\
\hline asldis & asphaltene sidechain length cumulative distribution \\
\hline aslmean & asphaltene sidechain length distribution mean \\
\hline aslmin & minimum asphaltene sidechain length \\
\hline aslstdev & asphaltene sidechain length distribution standard deviation \\
\hline asltyp & distribution type for asphaltene sidechain length \\
\hline asphno & number of asphaltene molecules constructed \\
\hline bnarm & molecule total number of aromatic rings \\
\hline bnisl & molecule total number of intersheet linkages \\
\hline bnnap & molecule total number of naphthenic rings \\
\hline bnrings & molecule total number of nitrogen rings \\
\hline bnscc & molecule total number of sidechain carbons \\
\hline borings & molecule total number of oxygen rings \\
\hline bpho & molecule total number of phenolic oxygens \\
\hline btype & $\begin{array}{l}\text { bond type for intersheet links } \\
0 \text { corresponds to a covalent link } \\
1 \text { or } 2 \text { correspond to an acid base interaction }\end{array}$ \\
\hline catomtot & total number of carbon atoms \\
\hline cno & number of carbon atoms in a molecule \\
\hline conv & array to store conversions for multiple resids \\
\hline convexp & experimentally determined conversion \\
\hline cwtexp & experimentally measured carbon weight fraction \\
\hline cwtpred & predicted carbon weight fraction \\
\hline degpol & degree of polymerization for molecule being constructed \\
\hline easph & experimentally measured asphaltene mole fraction (cumulative) \\
\hline easph_wt & experimentally measured asphaltene weight fraction (cumulative) \\
\hline flrar & fraction of aromatic cores with exactly one aromatic ring \\
\hline fh20 & fraction of the heteroatoms that are water molecules \\
\hline fh2s & fraction of the heteroatoms gases that are hydrogen disulfide molecules \\
\hline fisb & fraction of biphenvl intersheet linkages \\
\hline fism & fraction of methylene intersheet linkages \\
\hline fiso & fraction of oxygen intersheet linkages \\
\hline fiss & fraction of sulfur intersheet linkages \\
\hline flag & $\begin{array}{l}\text { flag used to indicate type of atom an intersheet linkage is attached to on } \\
\text { the previous unit sheet } \\
1=\text { aromatic } \\
2 \text { = naphthenic }\end{array}$ \\
\hline fnh3 & fraction of the heteroatoms that are ammonia molecules \\
\hline fnhc & fraction of paraffins which are heteroatom gases \\
\hline fragcno & carbon number of fragment \\
\hline fraghaa & number of alkyl alpha hydrogens for fragment \\
\hline fraghab & number of alkyl beta hydrogens for fragment \\
\hline fraghar & number of aromatic hydrogens for fragment \\
\hline fraghca & number of cyclic alpha hydrogens for fragment \\
\hline fraghcar & number of condensed aromatic hydrogens for fragment \\
\hline fraghcb & number of cyclic beta hydrogens for fragment \\
\hline fraghg & number of gamma hydrogens for fragment \\
\hline fraghno & hydrogen number of fragment \\
\hline fragisl & number of intersheet linkages for fragment \\
\hline fragmw & molecular weight of fragment \\
\hline fragnarm & number of aromatic rings for fragment \\
\hline fragnf3d & number of positions to which a naphthenic can be attached \\
\hline
\end{tabular}




\section{Variables used for the reaction model.}

\begin{tabular}{|c|c|}
\hline fragnt3n & number of positions naphthenic positions which would add 3 carbons \\
\hline fragnnap & number of naphthenic rings for fragment \\
\hline fragnno & nitrogen number of fragment \\
\hline fragnscc & number of sidechain carbons for fragment \\
\hline fragono & oxygen number of fragment \\
\hline fragpa & number of peripheral aromatic carbons for fragment \\
\hline fragpan & number of peripheral alpha naphthenic carbons for fragment \\
\hline fragpbn & number of peripheral beta naphthenic carbons for fragment \\
\hline fragpca & number of peripheral condensed aromatic carbons for fragment \\
\hline fragpho & phenolic oxygen number of fragment \\
\hline fragsno & sulfur number of fragment \\
\hline fragtype & $\begin{array}{l}\text { type of fragment - specifies whether fragment has heteroatom. } \\
\text { internal naphthenic. reacted moieties. or purely hydrocarbon }\end{array}$ \\
\hline frhcrings & fraction of aromatic cores containing a no heteroatoms \\
\hline frinrings & fraction of aromatic cores with an internal naphthenic ring \\
\hline frnrings & fraction of aromatic cores containing a nitrogen ring \\
\hline frorings & fraction of aromatic cores containing an oxygen ring \\
\hline frThh & fraction of aromatic cores substituted with a phenolic oxygen \\
\hline frsrings & fraction of aromatic cores containing a sulfur ring \\
\hline haaexp & experimentally measured fraction of alkyl alpha hydrogens \\
\hline haano & number of alkyl alpha hydrogen atoms in a molecule \\
\hline haapred & predicted alkyl alpha hydrogen fraction \\
\hline habexp & experimentally measured fraction of alkyl beta hydrogens \\
\hline habno & number of alkyl beta hydrogen atoms in a molecule \\
\hline habpred & predicted alkyl beta hydrogen fraction \\
\hline harexp & experimentally measured fraction of aromatic hydrogens \\
\hline harno & number of aromatic hydrogen atoms in a molecule \\
\hline harpred & predicted aromatic hydrogen fraction \\
\hline hatomtot & total number of hydrogen atoms \\
\hline hcaexp & experimentally measured fraction of cyclic alpha hydrogens \\
\hline hcano & number of cyclic alpha hydrogen atoms in a molecule \\
\hline hcapred & predicted cyclic alpha hydrogen fraction \\
\hline hcarexp & experimentally measured fraction of condensed aromatic hydrogens \\
\hline hcarno & number of condensed aromatic hydrogen atoms in a molecule \\
\hline hcarpred & predicted condensed aromatic hydrogen fraction \\
\hline hcbexp & experimentally measured fraction of cyclic beta hydrogens \\
\hline hcbno & number of cyclic beta hydrogen atoms in a molecule \\
\hline hcbpred & predicted cyclic beta hydrogen fraction \\
\hline hgno & number of gamma hydrogen atoms in a molecule \\
\hline hgpred & predicted gamma hydrogen fraction \\
\hline hgpred & experimentally measured fraction of gamma hydrogens \\
\hline hno & number of hydrogen atoms in a molecule \\
\hline hwtexp & experimentally measured hydrogen weight fraction \\
\hline hwtpred & predicted hydrogen weight fraction \\
\hline iaarzz & spread of the truncated asphaltene \# of aromatic rings distribution \\
\hline iadpzz & spread of the truncated asphaltene sidechain length distribution \\
\hline ianrzz & spread of the truncated asphaltene \# of naphthenic rings distribution \\
\hline iasczz & spread of the truncated asphaltene \# of sidechain distribution \\
\hline iaslzz & spread of the truncated asphaltene sidechain length distribution \\
\hline indpzz & spread of the truncated naphthenic degree of polymerization \\
\hline inpzz & spread of the truncated paratfin distribution \\
\hline inrzz & spread of the truncated naphthenic ring distribution \\
\hline
\end{tabular}




\section{Variables used for the reaction model.}

\begin{tabular}{|c|c|}
\hline insczz & spread of the truncated \# of naphthenic sidechains distribution \\
\hline inslzz & spread of the truncated naphthenic sidechain length distribution \\
\hline iparzz & spread of the truncated preasphaltene $\#$ of aromatic rings distribution \\
\hline ipdpzz & spread of the truncated preasphaltene sidechain length distribution \\
\hline ipnrzz & spread of the truncated preasphaltene $\#$ of naphthenic rings distribution \\
\hline ipsczz & spread of the truncated preasphaltene $\#$ of sidechain distribution \\
\hline ipslzz & spread of the truncated preasphaltene sidechain length distribution \\
\hline irarzz. & spread of the truncated resin \# of aromatic rings distribution \\
\hline irdpzz & spread of the truncated resin sidechain length distribution \\
\hline irnrzz & spread of the truncated resin \# of naphthenic rings distribution \\
\hline irsczz & spread of the truncated resin \# of sidechain distribution \\
\hline irslzz & spread of the truncated resin sidechain length distribution \\
\hline iseed & variable used to seed the random number generator \\
\hline isltype & $\begin{array}{l}\text { type of intersheet linkage between cores } \\
1=\text { sulfur } \\
2=\text { oxygen } \\
3=\text { methylene } \\
4=\text { biphenyl }\end{array}$ \\
\hline Ibinit & wt. \% of low boilers $\left(<850^{\circ} \mathrm{F}\right)$ \\
\hline mfragcno & carbon number of fragment \\
\hline mfraghaa & number of alkyl alpha hydrogens for fragment \\
\hline mfraghab & number of alkyl beta hydrogens for fragment \\
\hline mfraghar & number of aromatic hydrogens for fragment \\
\hline mfraghca & number of cyclic alpha hydrogens for fragment \\
\hline mfraghcar & number of condensed aromatic hydrogens for fragment \\
\hline mfraghcb & number of cyclic beta hydrogens for fragment \\
\hline mfraghg & number of gamma hydrogens for fragment \\
\hline mfraghno & hydrogen number of fragment \\
\hline mfragisl & number of intersheet linkages for fragment \\
\hline mfragmw & molecular weight of fragment \\
\hline mfragnarm & number of aromatic rings for fragment \\
\hline mfragnt3d & number of positions to which a naphthenic can be attached \\
\hline mfragnf3n & number of positions naphthenic positions which would add 3 carbons \\
\hline mfragnnap & number of naphthenic rings for fragment \\
\hline mfragnno & nitrogen number of fragment \\
\hline mfragnscc & number of sidechain carbons for fragment \\
\hline mfragnum & fragment number for molecule (from 1 to 24 ) \\
\hline mfragono & oxygen number of fragment \\
\hline mfragpa & number of peripheral aromatic carbons for fragment \\
\hline mfragpan & number of peripheral alpha naphthenic carbons for fragment \\
\hline mfragparts & number of fragments for unit sheet \\
\hline mfragpbn & number of peripheral beta naphthenic carbons for fragment \\
\hline mfragpca & number of peripheral condensed aromatic carbons for fragment \\
\hline mfragpho & phenolic oxygen number of fragment \\
\hline mfragsno & sulfur number of fragment \\
\hline mfragtype & $\begin{array}{l}\text { type of fragment - specifies whether fragment has heteroatom, } \\
\text { internal naphthenic, reacted moieties, or purely hydrocarbon }\end{array}$ \\
\hline mfrhcrings & fraction of aromatic cores containing a no heteroatoms \\
\hline mwexp & experimentally measured average molecular weight \\
\hline napmw & total molecular weight of the naphthenic fraction \\
\hline napno & number of naphthenic molecules constructed \\
\hline natomtot & total number of nitrogen atoms \\
\hline ncoreatom & \# of aromatic and naphthenic carbons and ring heteroatoms \\
\hline
\end{tabular}




\section{Variables used for the reaction model.}

\begin{tabular}{|c|c|}
\hline ndpdis & naphthenic degree of polymerization cumulative distribution \\
\hline ndpmean & naphthenic degree of polymerization distribution mean \\
\hline ndpmin & minimum naphthenic degree of polymerization \\
\hline ndpstdev & naphthenic degree of polymerization distribution standard deviation \\
\hline ndptyp & distribution type for napthenic degree of polymerization \\
\hline nfrac & \# of simulated distillation fractions (not used) \\
\hline nmwpred & predicted naphthenic weight fraction \\
\hline nno & number of nitrogen atoms in a molecule \\
\hline nparts & total number of fragments for molecule \\
\hline npdis & paraffin length cumulative distribution \\
\hline npmean & paraffin length distribution mean \\
\hline npmin & minimum paraffin length \\
\hline npstdev & paraffin length distribution standard deviation \\
\hline nptyp & distribution type for paraffin length \\
\hline nrdis & \# of naphthenic rings cumulative distribution \\
\hline nrmean & \# of naphthenic rings distribution mean \\
\hline nrmin & minimum \# of naphthenic rings \\
\hline nrstdev & \# of naphthenic rings distribution standard deviation \\
\hline nrtyp & distribution type for \# of naphthenic rings \\
\hline nscdis & naphthenic \# of sidechains cumulative distribution \\
\hline nscmean & naphthenic \# of sidechains distribution mean \\
\hline nscmin & minimum \# of naphthenic sidechains \\
\hline nscstdev & naphthenic \# of sidechains distribution standard deviation \\
\hline nsctyp & distribution type for naphthenic \# of sidechains \\
\hline nsldis & naphthenic sidechain length cumulative distribution \\
\hline nslmean & naphthenic sidechain length distribution mean \\
\hline nslmin & minimum naphthenic sidechain length \\
\hline nslstdev & naphthenic sidechain length distribution standard deviation \\
\hline nsltyp & distribution type for naphthenic sidechain length \\
\hline ntotmol & total number of molecules constructed \\
\hline nwtexp & experimentally measured nitrogen weight fraction \\
\hline nwtpred & predicted nitrogen weight fraction \\
\hline oatomtot & total number of oxygen atoms \\
\hline ono & number of oxygen atoms in a molecule \\
\hline owtexp & experimentally measured oxygen weight fraction \\
\hline owtpred & predicted oxygen weight fracticn \\
\hline $\mathrm{pl}$ & fraction of peripheral aromatic positions \\
\hline $\mathrm{p} 2$ & fraction of peripheral cyclic alpha positions \\
\hline p3 & fraction of peripheral cyclic beta positions \\
\hline pardis & preasphaltene \# of aromatic rings cumulative distribution \\
\hline parf & experimentally measured paraffin mole fraction \\
\hline parf_wt & experimentally measured paraffin weight fraction \\
\hline parmean & preasphaltene \# of aromatic rings distribution mean \\
\hline parmin & minimum preasphaltene \# of aromatic rings \\
\hline parno & number of paraffin molecules constructed \\
\hline parstdev & preasphaltene \# of aromatic rings distribution standard deviation \\
\hline partyp & distribution type for preasphaltene \# of aromatic rings \\
\hline pdpdis & preasphaltene degree of polymerization cumulative distribution \\
\hline pdpmean & preasphaltene degree of polymerization distribution mean \\
\hline pdpmin & minimum preasphaltene degree of polymerization \\
\hline pdpstdev & preasphaltene degree of polymerization distribution standard deviation \\
\hline pdptyp & distribution type for preasphaltene degree of polymerization \\
\hline
\end{tabular}




\section{Variables used for the reaction model.}

\begin{tabular}{|c|c|}
\hline pfin & $\begin{array}{l}\text { fraction of preasphaltene aromatic cores with intemal naphthenics } \\
\text { (subscript denotes number of rings on aromatic core) }\end{array}$ \\
\hline pfinm & $\begin{array}{l}\text { fraction of preasphaltene aromatic cores with one methylene removed } \\
\text { (subscript denotes number of rings on aromatic core) }\end{array}$ \\
\hline pfinn & $\begin{array}{l}\text { fraction of preasphaltene aromatic cores with two methylenes removed } \\
\text { (subscript denotes number of rings on aromatic core) }\end{array}$ \\
\hline pfisb & $\begin{array}{l}\text { fraction of biphenyl bridges for preasphaltenes } \\
\text { (subscript denotes number of intersheet links for the molecule) }\end{array}$ \\
\hline pfism & $\begin{array}{l}\text { fraction of methylene bridges for preasphaltenes } \\
\text { (subscript denotes number of intersheet links for the molecule) }\end{array}$ \\
\hline pfisn & $\begin{array}{l}\text { fraction of no bridges for preasphaltenes } \\
\text { (subscript denotes number of intersheet links for the molecule) }\end{array}$ \\
\hline pfiso & $\begin{array}{l}\text { fraction of oxygen bridges for preasphaltenes } \\
\text { (subscript denotes number of intersheet links for the molecule) }\end{array}$ \\
\hline pfiss & $\begin{array}{l}\text { fraction of sulfur bridges for preasphaltenes } \\
\text { (subscript denotes number of intersheet links for the molecule) }\end{array}$ \\
\hline pfrbr & $\begin{array}{l}\text { fraction of preasphaltene aromatic cores with removed heteroatoms } \\
\text { (subscript denotes number of rings on aromatic core) }\end{array}$ \\
\hline pfrher & $\begin{array}{l}\text { fraction of preasphaltene aromatic cores with no heteroatoms } \\
\text { (subscript denotes number of rings on aromatic core) }\end{array}$ \\
\hline pfrnor & $\begin{array}{l}\text { fraction of preasphaltene aromatic cores with heteroatom ring } \\
\text { (subscript denotes number of rings on aromatic core) }\end{array}$ \\
\hline pfrnr & $\begin{array}{l}\text { fraction of preasphaltene aromatic cores with nitrogen rings } \\
\text { (subscript denotes number of rings on aromatic core) }\end{array}$ \\
\hline pfror & $\begin{array}{l}\text { fraction of preasphaitene aromatic cores with oxygen rings } \\
\text { (subscript denotes number of rings on aromatic core) }\end{array}$ \\
\hline pfrsr & $\begin{array}{l}\text { fraction of preasphaltene aromatic cores with sulfur rings } \\
\text { (subscript denotes number of rings on aromatic core) }\end{array}$ \\
\hline phono & number of phenolic oxygen atoms in a molecule \\
\hline phoxpred & predicted concentration of phenolic oxygen \\
\hline phoxpred & experimentally measured fraction of phenolic oxygen \\
\hline phoxtot & total number of phenolic oxygen atoms \\
\hline pmw & total molecular weight of the paraffin fraction \\
\hline pmwpred & predicted paraffin weight fraction \\
\hline pnrdis & preasphaltene \# of naphthenic rings cumulative distribution \\
\hline pnrmean & preasphaltene \# of naphthenic rings distribution mean \\
\hline pnrmin & minimum preasphaltene \# of naphthenic rings \\
\hline pnrstdev & preasphaltene \# of naphthenic rings distribution standard deviation \\
\hline pnrtyp & distribution type for preasphaltene \# of naphthenic rings \\
\hline preasph & experimentally measured preasphaltene mole fraction \\
\hline preasphno & number of preasphaltene molecules constructed \\
\hline preasph_wt & experimentally measured preasphaltene weight fraction (cumulative) \\
\hline prmw & total molecular weight of the preasphaltene fraction \\
\hline prmwpred & predicted preasphaltene weight fraction \\
\hline pscdis & preasphaltene \# of sidechains cumulative distribution \\
\hline pscmean & preasphaltene \# of sidechains distribution mean \\
\hline pscmin & minimum preasphaltene \# of sidechains \\
\hline pscstdev & preasphaltene \# of sidechains distribution standard deviation \\
\hline psctyp & distribution type for preasphaltene \# of sidechains \\
\hline psldis & preasphaltene sidechain length cumulative distribution \\
\hline psimean & preasphaltene sidechain length distribution mean \\
\hline pslmin & minimum preasphaltene sidechain length \\
\hline pslstdev & preasphaltene sidechain length distribution standard de \\
\hline
\end{tabular}




\section{Variables used for the reaction model.}

\begin{tabular}{|c|c|}
\hline psltyp & distribution type for preasphaltene sidechain length \\
\hline ptamw & total molecular weight of the asphaltenes in the product \\
\hline pteno & total number of carbon atoms in the product \\
\hline pthaa & total number of alkyl alpha hydrogen atoms in the product \\
\hline pthab & total number of alkyl beta hydrogen atoms in the product \\
\hline pthar & total number of aromatic hydrogen atoms in the product \\
\hline pthca & total number of cyclic alpha hydrogen atoms in the product \\
\hline pthcar & total number of condensed aromatic hydrogen atoms in the product \\
\hline ptheb & total number of cyclic beta hydrogen atoms in the product \\
\hline pthg & total number of gamma hydrogen atoms in the product \\
\hline pthno & total number of hydrogen atoms in the product \\
\hline ptmol & total number of molecules in the product \\
\hline ptmw & total molecular weight of the product \\
\hline ptnmw & total molecular weight of the naphthenics in the product \\
\hline ptnno & total number of nitrogen atoms in the product \\
\hline ptono & total number of oxygen atoms in the product \\
\hline ptpho & total number of phenolic oxygen atoms in the product \\
\hline ptpmw & total molecular weight of the paraffins in the product \\
\hline prprmw & total molecular weight of the preasphaltenes in the product \\
\hline ptrmw & total molecular weight of the resins/aromatics in the product \\
\hline raar & asphaltene \# of aromatic rings noncumulative distribution \\
\hline radp & asphaltene degree of polymerization noncumulative distribution \\
\hline ranr & asphaltene \# of naphthenic rings noncumulative distribution \\
\hline rardis & resin \# of aromatic rings cumulative distribution \\
\hline rarmean & resin \# of aromatic rings distribution mean \\
\hline rarmin & minimum resin \# of aromatic rings \\
\hline rarstdev & resin \# of aromatic rings distribution standard deviation \\
\hline rartyp & distribution type for resin \# of aromatic rings \\
\hline rasc & asphaltene \# of sidechains noncumulative distribution \\
\hline rasl & asphaltene sidechain length noncumulative distribution \\
\hline rdpdis & resin degree of polymerization cumulative distribution \\
\hline rdpmean & resin degree of polymerization distribution mean \\
\hline rdpmin & minimum resin degree of polymerization \\
\hline rdpstdev & resin degree of polymerization distribution standard deviation \\
\hline rdptyp & distribution type for resin degree of polymerization \\
\hline resin & experimentally measured resin mole fraction (cumulative) \\
\hline resin_wt & experimentally measured resin weight fraction (cumulative) \\
\hline resno & number of resin molecules constructed \\
\hline ffin & $\begin{array}{l}\text { fraction of resin aromatic cores with intemal naphthenics } \\
\text { (subscript denotes number of rings on aromatic core) }\end{array}$ \\
\hline rfinm & $\begin{array}{l}\text { fraction of resin aromatic cores with one methylene removed } \\
\text { (subscript denotes number of rings on aromatic core) }\end{array}$ \\
\hline rfinn & $\begin{array}{l}\text { fraction of resin aromatic cores with two methylenes removed } \\
\text { (subscript denotes number of rings on aromatic core) }\end{array}$ \\
\hline rfisb & $\begin{array}{l}\text { fraction of biphenyl bridges for resins } \\
\text { (subscript denotes number of intersheet links for the molecule) }\end{array}$ \\
\hline rfism & $\begin{array}{l}\text { fraction of methylene bridges for resins } \\
\text { (subscript denotes number of intersheet links for the molecule) }\end{array}$ \\
\hline Ifisn & $\begin{array}{l}\text { fraction of no bridges for resins } \\
\text { (subscript denotes number of intersheet links for the molecule) }\end{array}$ \\
\hline Ifiso & $\begin{array}{l}\text { fraction of oxygen bridges for resins } \\
\text { (subscript denotes number of intersheet links for the molecule) }\end{array}$ \\
\hline
\end{tabular}




\section{Variables used for the reaction model.}

\begin{tabular}{|c|c|}
\hline rfiss & $\begin{array}{l}\text { fraction of sulfur bridges for resins } \\
\text { (subscript denotes number of intersheet links for the molecule) }\end{array}$ \\
\hline ifrbr & $\begin{array}{l}\text { fraction of resin aromatic cores with removed heteroatoms } \\
\text { (subscript denotes number of rings on aromatic core) }\end{array}$ \\
\hline Ifrher & $\begin{array}{l}\text { fraction of resin aromatic cores with no heteroatoms } \\
\text { (subscript denotes number of rings on aromatic core) }\end{array}$ \\
\hline Ifrnor & $\begin{array}{l}\text { fraction of resin aromatic cores with heteroatom ring } \\
\text { (subscript denotes number of rings on aromatic core) }\end{array}$ \\
\hline Ifrnr & $\begin{array}{l}\text { fraction of resin aromatic cores with nitrogen rings } \\
\text { (subscript denotes number of rings on aromatic core) }\end{array}$ \\
\hline Ifror & $\begin{array}{l}\text { fraction of resin aromatic cores with oxygen rings } \\
\text { (subscript denotes number of rings on aromatic core) }\end{array}$ \\
\hline rfrsr & $\begin{array}{l}\text { fraction of resin aromatic cores with sulfur rings } \\
\text { (subscript denotes number of rings on aromatic core) }\end{array}$ \\
\hline Imw & total molecular weight of the resin fraction \\
\hline Imwpred & predicted resin weight fraction \\
\hline mdp & naphthenic degree of polymerization noncumulative distribution \\
\hline $\mathrm{mp}$ & paraffin length noncumulative distribution \\
\hline Inpth & experimentally measured naphthenic mole fraction (cumulative) \\
\hline Inpth_wt & experimentally measured naphthenic weight fraction (cumulative) \\
\hline $\mathrm{mr}$ & \# of naphthenic rings noncumulative distribution \\
\hline Inrdis & resin \# of naphthenic rings cumulative distribution \\
\hline mrmean & resin \# of naphthenic rings distribution mean \\
\hline mrmin & minimum resin \# of naphthenic rings \\
\hline mrstdev & resin \# of naphthenic rings distribution standard deviation \\
\hline Inrtyp & distribution type for resin \# of naphthenic rings \\
\hline msc & naphthenic \# of sidechains noncumulative distribution \\
\hline msl & naphthenic sidechain length noncumulative distribution \\
\hline Ipar & preasphaltene \# of aromatic rings noncumulative distribution \\
\hline Ipdp & preasphaltene degree of polymerization noncumulative distribution \\
\hline Ipnr & preasphaltene \# of naphthenic rings noncumulative distribution \\
\hline rpsc & preasphaltene \# of sidechains noncumulative distribution \\
\hline Ips! & preasphaltene sidechain length noncumulative distribution \\
\hline Irar & resin \# of aromatic rings noncumulative distribution \\
\hline $\operatorname{rrdp}$ & resin degree of polymerization noncumulative distribution \\
\hline rnnr & resin $\#$ of naphthenic rings noncumulative distribution \\
\hline IISC & resin \# of sidechains noncumulative distribution \\
\hline rrs! & resin sidechain length noncumulative distribution \\
\hline rscdis & resin $\#$ of sidechains cumulative distribution \\
\hline rscmean & resin \# of sidechains distribution mean \\
\hline rscmin & minimum resin \# of sidechains \\
\hline rscstdev & resin \# of sidechains distribution standard deviation \\
\hline rsctyp & distribution type for resin \# of sidechains \\
\hline rsldis & resin sidechain length cumulative distribution \\
\hline rslmean & resin sidechain length distribution mean \\
\hline rslmin & minimum resin sidechain length \\
\hline rslstdev & resin sidechain length distribution standard deviation \\
\hline rsltyp & distribution type for resin sidechain length \\
\hline Itamw & total molecular weight of the asphaltenes in the unconverted resid \\
\hline rtcno & total number of carbon atoms in the unconverted resid \\
\hline rthaa & total number of alkyl alpha hydrogen atoms in the unconverted resid \\
\hline Ithab & total number of alkyl beta hydrogen atoms in the unconverted resid \\
\hline
\end{tabular}




\section{Variables used for the reaction model.}

\begin{tabular}{|c|c|}
\hline thar & total number of aromatic hydrogen atoms in the unconverted resid \\
\hline rthca & total number of cyclic alpha hydrogen atoms in the unconverted resid \\
\hline rthcar & $\begin{array}{l}\text { total number of condensed aromatic hydrogen atoms in the unconverted } \\
\text { resid }\end{array}$ \\
\hline ithcb & total number of cyclic beta hydrogen atoms in the unconverted resid \\
\hline Ithg & total number of gamma hydrogen atoms in the unconverted resid \\
\hline rthno & total number of hydrogen atoms in the unconverted resid \\
\hline rtime & array to store reaction times for multiple resids \\
\hline Itmol & total number of molecules in the unconverted resid \\
\hline rtmw & total molecular weight of the unconverted resid \\
\hline $\mathrm{rtnmw}$ & total molecular weight of the naphthenics in the unconverted resid \\
\hline Itnno & total number of nitrogen atoms in the unconverted resid \\
\hline Itono & total number of oxygen atoms in the unconverted resid \\
\hline rtpho & total number of phenolic oxygen atoms in the unconverted resid \\
\hline rtpmw & total molecular weight of the paraffins in the unconverted resid \\
\hline rtprmw & total molecular weight of the preasphaltenes in the unconverted resid \\
\hline rtrmw & total molecular weight of the resins/aromatics in the unconverted resid \\
\hline satomtot & total number of sulfur atoms \\
\hline ScWt I & carbon wt. \% for the first resid used in rate constant optimization \\
\hline Scwt2 & carbon wt. \% for the second resid used in rate constant optimization \\
\hline scwt3 & carbon wt. \% for the third resid used in rate constant optimization \\
\hline SCWt4 & carbon wt. $c / c$ for the fourth resid used in rate constant optimization \\
\hline Scwt5 & carbon wt. \% for the fifth resid used in rate constant optimization \\
\hline shwt l & hydrogen wt. \% for the first resid used in rate constant optimization \\
\hline shwt2 & hydrogen wt. \% for the second resid used in rate constant optimization \\
\hline shwt3 & hydrogen wt. \% for the third resid used in rate constant optimization \\
\hline shwt4 & hydrogen wt. \% for the fourth resid used in rate constant optimization \\
\hline shwt5 & hydrogen wt. \% for the fifth resid used in rate constant optimization \\
\hline sisll & intersheet link dist. for first resid used in rate constant optimization \\
\hline sisl2 & intersheet link dist. for second resid used in rate constant optimization \\
\hline sisl3 & intersheet link dist. for third resid used in rate constant optimization \\
\hline sisl4 & intersheet link dist. for fourth resid used in rate constant optimization \\
\hline sisl5 & intersheet link dist. for fifth resid used in rate constant optimization \\
\hline smean 1 & pdf means for the first resid used in rate constant optimization \\
\hline smean2 & pdf means for the second resid used in rate constant optimization \\
\hline smean3 & pdf means for the third resid used in rate constant optimization \\
\hline smean4 & pdf means for the fourth resid used in rate constant optimization \\
\hline smean5 & pdf means for the fifth resid used in rate constant optimization \\
\hline smin 1 & pdf minimimums for the first resid used in rate constant optimization \\
\hline $\operatorname{smin} 2$ & pdf minimimums for the second resid used in rate constant optimization \\
\hline $\operatorname{smin3}$ & pdf minimimums for the third resid used in rate constant optimization \\
\hline $\operatorname{smin} 4$ & pdf minimimums for the fourth resid used in rate constant optimization \\
\hline $\operatorname{smin} 5$ & pdf minimimums for the fifth resid used in rate constant optimization \\
\hline smwl & average MW for the first resid used in rate constant optimization \\
\hline smw2 & average $\mathrm{MW}$ for the second resid used in rate constant optimization \\
\hline smw3 & average MW for the third resid used in rate constant optimization \\
\hline smw4 & average MW for the fourth resid used in rate constant optimization \\
\hline smw5 & average $\mathrm{MW}$ for the fifth resid used in rate constant optimization \\
\hline snmrl & proton distribution for the first resid used in rate constant optimization \\
\hline snmr2 & proton distribution for the second resid used in rate constant optimization \\
\hline snmr3 & proton distribution for the third resid used in rate constant optimization \\
\hline snmr4 & proton distribution for the fourth resid used in rate constant optimization \\
\hline
\end{tabular}




\section{Variables used for the reaction model.}

\begin{tabular}{|c|c|}
\hline snmr5 & proton distribution for the fifth resid used in rate constant optimization \\
\hline sno & number of sulfur atoms in a molecule \\
\hline snwtl & nitrogen wt. \% for the first resid used in rate constant optimization \\
\hline snwt2 & nitrogen wt. \% for the second resid used in rate constant optimization \\
\hline snwt3 & nitrogen wt. \% for the third resid used in rate constant optimization \\
\hline snwt4 & nitrogen wt. \% for the fourth resid used in rate constant optimization \\
\hline snwt5 & nitrogen wt. \% for the fifth resid used in rate constant optimization \\
\hline sother 1 & other pdf parameters for second resid used in rate constant optimization \\
\hline sother2 & other pdf parameters for second resid used in rate constant optimization \\
\hline sother3 & other pdf parameters for third resid used in rate constant optimization \\
\hline sother4 & other pdf parameters for fourth resid used in rate constant optimization \\
\hline sother5 & other pdf parameters for fifth resid used in rate constant optimization \\
\hline Sowt I & oxygen wt. \% for the first resid used in rate constant optimization \\
\hline Sowt2 & oxygen wt. \% for the second resid used in rate constant optimization \\
\hline sowt3 & oxygen wt. \% for the third resid used in rate constant optimization \\
\hline Sowt4 & oxygen wt. \% for the fourth resid used in rate constant optimization \\
\hline sowt5 & oxygen wt. \% for the fifth resid used in rate constant optimization \\
\hline sring 1 & heteroatom ring core dist. for the first resid used in rate constant opt. \\
\hline sring2 & heteroatom ring core dist. for the second resid used in rate constant opt. \\
\hline sring 3 & heteroatom ring core dist. for the third resid used in rate constant opt. \\
\hline sring4 & heteroatom ring core dist. for the fourth resid used in rate constant opt. \\
\hline sring5 & heteroatom ring core dist. for the fifth resid used in rate constant opt. \\
\hline ssaraml & sara mole fractions for the first resid used in rate constant optimization \\
\hline ssaram2 & sara mole fractions for the second resid used in rate constant optimization \\
\hline $\operatorname{ssaram3}$ & sara mole fractions for the third resid used in rate constant optimization \\
\hline ssaram4 & sara mole fractions for the fourth resid used in rate constant optimization \\
\hline ssaram5 & sara mole fractions for the fifth resid used in rate constant optimization \\
\hline ssarawt l & sara weight fractions for the first resid used in rate constant optimization \\
\hline ssarawt2 & $\begin{array}{l}\text { sara weight fractions for the second resid used in rate constant } \\
\text { optimization }\end{array}$ \\
\hline ssarawt3 & sara weight fractions for the third resid used in rate constant optimization \\
\hline ssarawt4 & $\begin{array}{l}\text { sara weight fractions for the fourth resid used in rate constant } \\
\text { optimization }\end{array}$ \\
\hline ssarawt5 & sara weight fractions for the fifth resid used in rate constant optimization \\
\hline sstdevl & pdf standard deviations for the first resid used in rate constani opt. \\
\hline sstdev2 & pdf standard deviations for the second resid used in rate constant opt. \\
\hline sstdev $\overline{3}$ & pdf standard deviations for the third resid used in rate constant opt. \\
\hline sstdev4 & pdf standard deviations for the fourth resid used in rate constant opt. \\
\hline sstdev5 & pdf standard deviations for the fifth resid used in rate constant opt. \\
\hline sswt l & sulfur wt. \%c for the first resid used in rate constant optimization \\
\hline sswt2 & sulfur wt. \% for the second resid used in rate constant optimization \\
\hline sswt3 & sulfur wt. \% for the third resid used in rate constant optimization \\
\hline SSwt4 & sulfur wt. \% for the fourth resid used in rate constant optimization \\
\hline sswt5 & sulfur wt. \% for the fifth resid used in rate constant optimization \\
\hline styp 1 & pdf types for the first resid used in rate constant optimization \\
\hline styp2 & pdf types for the second resid used in rate constant optimization \\
\hline styp3 & pdf types for the third resid used in rate constant optimization \\
\hline styp4 & pdf types for the fourth resid used in rate constant optimization \\
\hline styp5 & pdf types for the fifth resid used in rate constant optimization \\
\hline swtexp & experimentally measured sulfur weight fraction \\
\hline swtpred & predicted sulfur weight fraction \\
\hline tcharno & total number of condensed aromatic hydrogen atoms \\
\hline thaano & total number of alkyl alpha hydrogen atoms \\
\hline
\end{tabular}




\section{Variables used for the reaction model.}

\begin{tabular}{|l|l|}
\hline thabno & total number of alkyl beta hydrogen atoms \\
\hline tharno & total number of aromatic hydrogen atoms \\
\hline thcano & total number of cyclic alpha hydrogen atoms \\
\hline thcbno & total number of cyclic beta hydrogen atoms \\
\hline thfinsol & wt. \% of resid that is insoluble in tetrahydrofuran \\
\hline thgno & total number of gamma hydrogens \\
\hline totmw & total molecular weight of molecules constructed \\
\hline trx & reaction time \\
\hline uscno & number of carbon atoms of a unit sheet \\
\hline ushaa & number of alkyl alpha hydrogen atoms of a unit sheet \\
\hline ushab & number of alkyl beta hydrogen atoms of a unit sheet \\
\hline ushar & number of aromatic hydrogen atoms of a unit sheet \\
\hline ushca & number of cyclic alpha hydrogen atoms of a unit sheet \\
\hline ushcar & number of condensed aromatic hydrogen atoms of a unit sheet \\
\hline ushcb & number of cyclic beta hydrogen atoms of a unit sheet \\
\hline ushg & number of gamma hydrogen atoms of a unit sheet \\
\hline ushno & number of hydrogen atoms of a unit sheet \\
\hline usmw & molecular weight of a unit sheet \\
\hline usnno & number of nitrogen atoms of a unit sheet \\
\hline usono & number of oxygen atoms of a unit sheet \\
\hline usphono & number of phenolic oxygen atoms of a unit sheet \\
\hline ussno & number of sulfur atoms of a unit sheet \\
\hline vpopred & predicted average molecular weight \\
\hline
\end{tabular}




\title{
Appendix 2
}

\section{Conversion of Resid Structure/Reactivity Model Software from the IBM RS-6000 to the HP-9000/735 RISC Workstation}

By

\author{
D. J. Pazuchanics and D. G. Nichols \\ CONSOL Inc. \\ Research \& Development \\ 4000 Brownsville Road \\ Library, PA 15129
}




\title{
CONVERSION OF RESID STRUCTURE / REACTIVITY MODEL SOFTWARE FROM THE IBM RS-6000 TO THE HP-9000/735 RISC WORKSTATION
}

\author{
D. J. Pazuchanics and D. G. Nichols \\ CONSOL Inc. \\ Research \& Development \\ 4000 Brownsville Road \\ Library, PA 15129
}

\section{INTRODUCTION}

The Structure and Reaction Models for Coal Resid software programs were modified to run on the HP 9000/735 workstation at CONSOL Research \& Development in Library, PA. The models originally were developed in FORTRAN and C on an IBM RS/6000 RISC workstation at the University of Delaware, under subcontract from CONSOL (DOE Contract DE-AC22-94PC93054). Specific commands for running each module on the HP-735 are discussed below. Additional information about the changes to the software made by CONSOL for testing and use on the HP-735, and a discussion of the feasibility of running this software on a PC are discussed in this memorandum.

The Structure and Reaction Models for Coal Resid software are made up of four major programs. These are:

1. Structure Optimization; consisting of 16 files with 21 subprograms.

2. Structure Once-Through; consisting of 17 files with 18 subprograms.

3. Reaction Optimization; consisting of 25 files with 55 subprograms.

4. Reaction Once-Through; consisting of 23 files with 40 subprograms.

\section{STRUCTURE OPTIMIZATION}

According to the User's Manual (See University of Delaware Final Report), "The Structure Optimization is used to optimize the structure attribute pdf parameters used to describe the coal resid molecules." The Structure Optimization program attempts to find the particular combination of values for the 33 pdf parameters that result in the minimal value of the objective function. See the User's Manual for a list of the 33 pdf parameters. By minimizing the objective function, the difference between experimental and predicted results is minimized. The pdf parameters are optimized by a "simulated annealing" algorithm. 
On the HP-735, the Structure Optimization program is located in the consol directory. The file name of the Structure Optimization executable program is sadr. See the User's Manual for the list of files that are needed to build sadr. The sadr program requires 2 sets of input values. The first input set is read from the file distrh.inp. The values used from distrh.inp are:

- The "type" parameter of the "Structural Attribute" section (lines 7 - 25, column 2)

- The SARA fractions section (lines 28 - 32, columns 2 - 3)

- The Molecular Weight/Weight Fraction section (lines 34 - 39, column 2)

- The "fr" section (lines $41-48$, column 2)

These are experimentally determined values. The other numbers in distrh.inp are ignored by sadr.

The second set of input values are the initial values and bounds of the 33 pdf parameters. The "simulated annealing" algorithm used by sadr requires an initial guess as well as upper and lower bounds for each of the pdf parameters. These values are specified in the file sadr.f (lines 76 176). When sadr.f is changed, the Structure Optimization executable program, sadr, must be rebuilt. This is done with the command:

make sadr

The sadr program is then run by typing:

sadr

The Structure Optimization program, as received from the University of Delaware, sent all output to the computer's screen. This was modified so that output goes to the file ftn08. This allows the user to initiate sadr and log off. At a later time, the user may monitor the status of the program operation. To start sadr in this way, type:

nohup sadr \& 
The sadr program will continue to run after the user logs off. The user may then log in at a later time and type:

tail -f ftn08

The level of output generated by sadr is controlled by the value of the variable IPRINT (line 73 of sadr.f). A value of 1 produces the least amount of output, while a value of 3 produces the most. The output shows the progress of sadr in finding a combination of pdf parameter values that minimizes the objective function. On the HP-735, sadr takes around $20 \mathrm{CPU}$ hours to complete. The output will show the pdf parameters as $X(1)$ through $X(33)$, and the value of the objective function.

Since both the resid structure model and the "simulated annealing" algorithm are nondeterministic, successive runs with the same input will yield different output. However, output will vary over a relatively narrow range.

In the process of running the Structure Optimization program on various resid data sets, it was found that care must be used in selecting the upper and lower bounds for each of the $33 \mathrm{pdf}$ parameters being optimized. These bounds are used to define the domain over which the pdf parameters may vary as the Structure Optimization program searches for the combination of parameter values that minimizes the objective function. Choosing bounds that are too wide can cause the Structure Optimization program to abort.

An example of this occurred during the optimization of the original " $L$ " resid data set. The pdf parameter "Mean Preasphaltene Degree of Polymerization" had a starting value of 6.06 and bounds of 3.03 and 12.12. The parameter "Standard Deviation of Preasphaltene Degree of Polymerization" had a starting value of 0.7 and bounds of 0.35 and 1.4. At one point in the optimization, these parameters had values of 10.422 and 0.57878 , respectively. This combination described an unrealistically compact distribution. Calculations involving these quantities produced a number too large to be stored. This did not directly cause the program to abort, however. The Structure Optimization program continued for a time, until eventually memory became corrupted by the overflow values. 


\section{STRUCTURE ONCE-THROUGH}

The Structure Once-Through program calculates the parametric and overall F-values of the structure model. The Structure Once-Through shares many of the same source files as the Structure Optimization. On the HP-735, the Structure Once-Through is also located in the consol directory. The file name of the Structure Once-Through executable program is croptout. See the User's Manual for the list of files that are needed to build croptout.

The croptout program requires distrh.inp as input. The results of the Structure Optimization should be entered into this file. See the User's Guide on how to transfer the results of the sadr into distrh.inp. For example, the first pdf parameter is $X(1)$ as calculated by sadr. This number is the value for NRMEAN, the mean number of naphthenic rings distribution for the naphthenics fraction. This number goes in distrh.inp in line 8 , column 4 .

Because the input file distrh.inp is read at run-time, croptout need not be rebuilt each time the input changes (unlike sadr). However, if rebuilding croptout is desired, it is done with the command:

make croptout

The croptout program is run by typing:

croptout

Output is displayed on the computer screen. To capture the output to a file, type:

croptout > croptout.out

As delivered from the University of Delaware, the output of croptout was a single value, the overall F-value. The output was expanded to include the experimental and predicted descriptive parameters, and the parametric F-values. An example of croptout output is shown in Table A. This program takes about 20 seconds on the HP-735. 
As with the Structure Optimization, the non-deterministic method used by the Structure OnceThrough to build the resid model results in somewhat different output for multiple entries of the same input. The program runs quickly enough to do "many" successive runs to get a representative range of values for a given input, if this is desired.

\section{REACTION OPTIMIZATION}

The Reaction Optimization program is used to optimize the 19 rate parameters used in the Reaction Once-Through program. See the User's Manual for a list of the 19 rate parameters. As in the Structure Optimization program, the rate parameters are optimized by a "simulated annealing" algorithm.

On the HP-735, the file name of the Reaction Optimization program is sa_rxopt. The User's Manual lists the source files needed to build sa_rxopt. Note that many of the file names are the same as those needed to build the Structure Optimization program, but are in fact different files. Therefore the Reaction Optimization files are in a different directory than the Structure Optimization/Once-Through files. On the HP-735, the Reaction Optimization files are in the rxopt directory.

For input, sa_rxopt uses five resid data files. The names of these data files are specified in readinit_rxn.f on lines 8 - 17. For example, the data files distrhB.inp, distrhD.inp, distrhE.inp, distrhH.inp, distrhL.inp could be specified.

When readini_rxn.f is changed, the Reaction Optimization executable program, sa_rxopt, must be rebuilt. This is done with the command:

make sa_rxopt

The sa_rxopt program is then run by typing:

sa_rxopt

The Reaction Optimization program as received from the University of Delaware sent all output to the computer screen. This was modified so that output goes to the file ftn08. This allows the 
user to initiate sa_rxopt and log off. At a later time, the user may monitor the progress. To start sa_rxopt in this way, type:

nohup sa_rxopt \&

The Reaction Optimization program will continue to run after the user logs off. The user may then log in at a later time and type:

tail -f ftn08

As with the Structure Optimization program, the level of output generated by sa_rxopt is controlled by the value of the variable IPRINT (line 73 of sa_rxopt.f). A value of 1 produces the least amount of output, while a value of 3 produces the most. The output will show the rate parameters as $X(1)$ through $X(19)$.

Since both the resid reaction conversion model and the "simulated annealing" optimization algorithm are non-deterministic, successive runs with the same input will yield different output. However, these output values will vary over a relatively narrow range. Multiple runs of the program can be performed, if desired, to permit the determination of a mean and standard deviation.

It was observed that the iterative optimization process, as programmed, continues the minimization activity for a very long time even though very little progress (improvement) is being achieved in the objective function. This appears to be related to two circumstances. First, for each step in the iteration, a concentration distribution for the sample is generated from the pdf relationships, the model mixture is then reacted to the desired reaction time and the pdf relationships are reconstructed; the repetition of this sequence at each iteration is very computationally intensive. Second, the objective function appears not to be very sensitive to small changes in the optimization variables over much of the feasible domain for these variables. The "simulated annealing" optimization process involves an "annealing temperature" which is gradually reduced as the optimization process continues; and, the search process will terminate when this "temperature" reaches zero. 


\section{REACTION ONCE-THROUGH}

The Reaction Once-Through program calculates the percent conversion for any selected resid sample. The rate parameters used in the Reaction Once-Through program are the results of the Reaction Optimization program. On the HP-735, the file name of the Reaction Once-Through program is crxout. See the User's Manual for the list of files that are needed to build crxout. This program shares many of the same files with the Reaction Optimization program, and could reside in the same directory. However, on the HP-735, the Reaction Once-Through files are in the coalrx directory.

The crxout program requires two files for input. The first is the file rates.inp. This file is simply the 19 rate parameters optimized by the Reaction Optimization program. The second file is distrh.inp. This file may be the same as the distrh.inp used by the Structure Once-Through program if it contains lines 62 through 66 . (The Structure Once-Through program only uses lines 1 through 61). See the User's Manual for the explanation of these parameters. In addition to these 66 lines, an additional line was added. Line 67 contains the resid's name, which will appear on the output to distinguish between different resid samples. An example of this line is:

'Resid Name' 'RESID A'

Because the input files rates.inp and distrh.inp are read at run-time, crxout need not be rebuilt each time the input changes (unlike sa_rxopt). However, if rebuilding crxout is desired, it is done with the command:

make crxout

The crxout program is run by typing:

crxout

The output is displayed on the computer screen. To capture the output to a file, type:

crxout > crxout.out 
As delivered from the University of Delaware, the output of crxout was a single value, the predicted percentage conversion. The output was expanded to include other results. An example of crxout output is shown in Table B. The Reaction Once-Through program takes about 15 seconds to run on the HP-735.

By setting the $t 1$ parameter (line 65 in distrh.inp) equal to 0 (zero) and running this program, the conversion is a measure of the computed percent of the feed resid sample which is low-boiling material.

\section{CHANGES MADE FOR HP-735 USAGE AT CONSOL}

The changes made to the code fall into 2 categories:

1. Changes to output

2. Changes to function declarations

Additional quantities are provided as output for the Structure Once-Through and Reaction OnceThrough programs. These quantities make the results more meaningful and complete. Also, for the Structure Optimization and Reaction Optimization programs, the destination device of the output was changed from the computer screen to a computer file. This allows for permanent storage of these results.

Several subroutines make use of the Unix system call drand48. This function returns pseudorandom numbers. In order for these subroutines to work correctly on the HP-735, the drand48 function and each variable receiving its value from drand48 had to be declared as double precision. For example:

double precision drand48, $z, z z$

The code from the University of Delaware did not have these declarations, and apparently did not require them. However, the declaration are necessary on the HP-735.

In addition to the software developed by the University of Delaware, the models require an implementation of the DASSL library and a "log of the gamma function". DASSL is the Differential Algebraic System Simulation Language for the solution of sets of differential algebraic equations; in this case, these are the reaction rate equations. A version of the DASSL library is included with 
the University of Delaware programs. An implementation of the "log of the gamma function" called DGAMLN was obtained from the AMOS math library at the National Institute of Standards and Technology.

In order for the four resid modules to execute properly on the HP-735, the " $-K$ " switch had to be used when building the executable files. This switch forces static storage for local variables.

\section{PORTING THE COAL RESID SOFTWARE TO A PC}

Because the Coal Resid software was written in FORTRAN and C, it potentially could be rebuilt on a PC with the use of FORTRAN and $C$ compilers. The use of $C$ is minimal, and could be eliminated. There is one Unix dependency, and that is the use of the system function drand48. If a substitute pseudo-random number generating function is used, that dependency could be eliminated.

In practice, it is unknown whether the memory requirements of these models would exceed the capabilities of a specific PC FORTRAN compiler and linker. If built, the Structure and Reaction Optimization programs could take significantly longer to execute on a PC than on the HP-735 (or other RISC workstation), possibly so long as to be impractical. Therefore, these optimization programs are not good candidates for PC execution. If built, the Structure and Reaction OnceThrough programs would probably execute in a reasonable amount of time. In general, therefore, it is not recommended that PC versions of these programs be developed. 
TABLE A2-1

EXAMPLE STRUCTURE ONCE-THROUGH OUTPUT

Experimental Computed Chi-Square

Molecular weight

355.7

465.7

9.57

Elemental

hydrogen

8.36

8.69

4.30

carbon

89.06

sulfur

0.21

nitrogen

oxygen

0.31

88.68

0.20

0.35

0.27

0.01

2.05

2.16

0.12

0.00

SARA

saturates

27.6

67.4

31.6

0.74

asphaltenes

4.5

64.2

3.7

reasphaltenes

0.5

0.5

Proton NMR

uncondensed arom

4.3

14.3

condensed arom

8.0

alkyl alpha

14.5

cyclic alpha

30.0

alkyl beta

15.1

cyclic beta

13.6

gamma

0.22

4.2

19.9

6.3

9.5

27.8

19.0

13.3

0.23

0.01

7.25

0.70

6.14

1.25

3.82

0.02

phenolic $\mathrm{OH}$

Chi-Square value (total)

34.75 
TABLE A2-2

EXAMPLE REACTION ONCE-THROUGH OUTPUT

Resid Name: RESID A

Frac THF Ins 0.176

Conv@ @ 0.35

$\mathrm{t} 1$ (sec) $\quad 1800.0$

\% Low Boilers 4.8

Original conversion $(\%)=33.7252$

Correlated conversion $(\%)=37.5632$

FEED

MW

wt frac C

wt frac $\mathrm{H}$

wt frac $\mathrm{N}$

wt frac S

wt frac $O$

fr Harom con

fr Harom un

fr HCalpha

fr HAalpha

fr HCbeta

fr HAbeta

fr Hgamma

Phenolic $\mathrm{OH}$
487.50

0.8830

0.0561

0.0119

0.0174

0.0316

0.3130

0.0760

0.1880

0.0950

0.1290

0.1190

0.0810

0.8000
PRODUCT

231.16

0.8437

0.1287

0.0016

0.0154

0.0107

0.0512

0.0157

0.0098

0.0170

0.0172

0.7540

0.1351

0.1488
RESIDUE

528.32

0.8743

0.0598

0.0128

0.0101

0.0431

0.4077

0.0796

0.1959

0.1116

0.1421

0.0115

0.0515

0.8778 